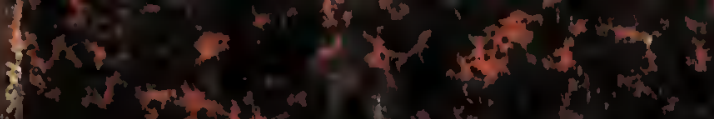

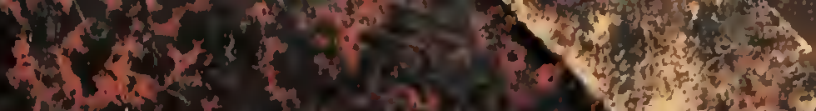

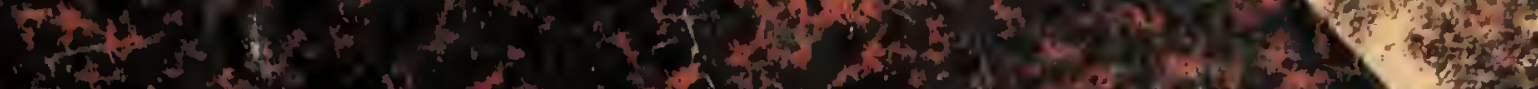
$(x+2)+2$

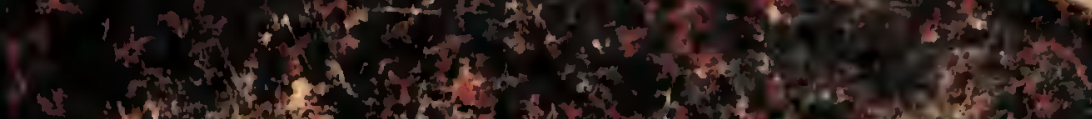

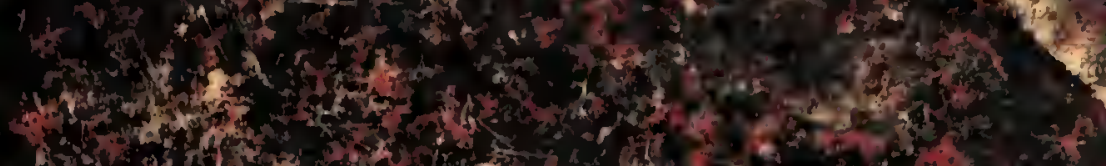

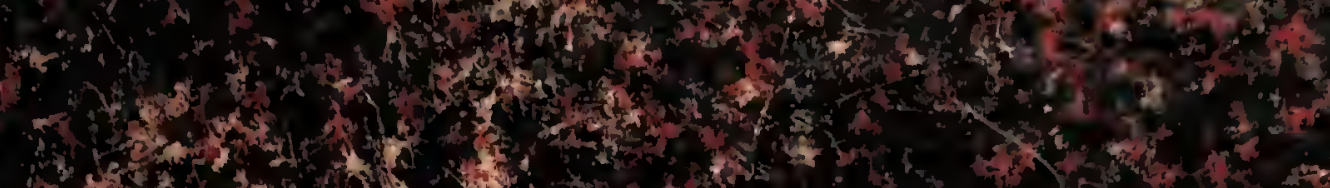

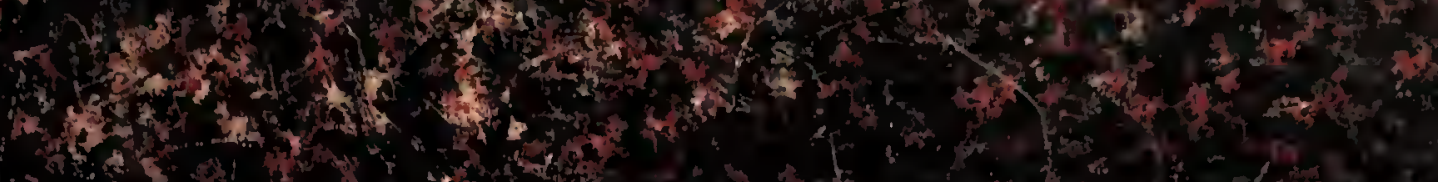

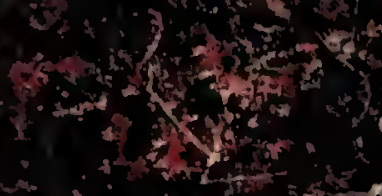
and

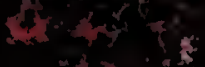

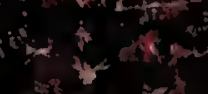

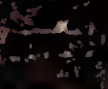

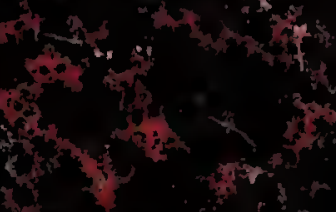

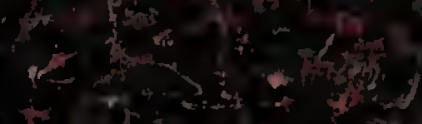

(3)

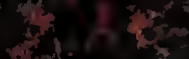

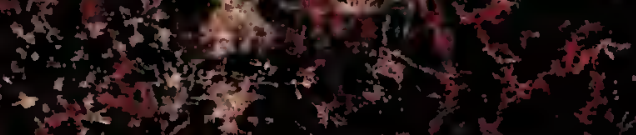

1. 320

S

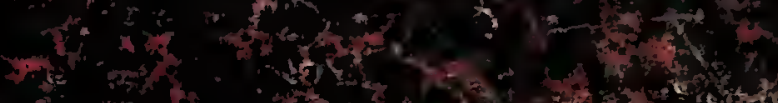

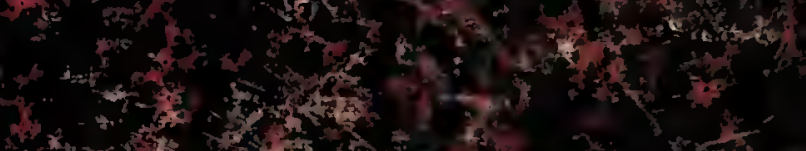

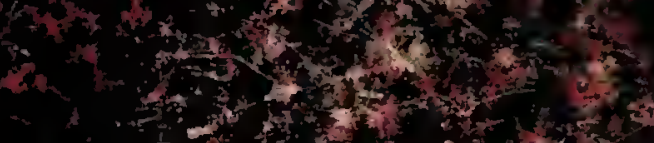

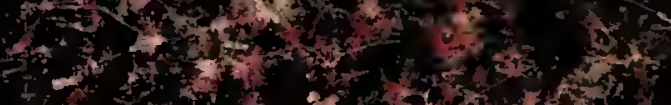

;

4

1. $3 x^{2}+1$

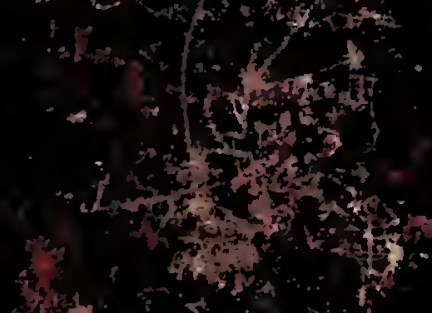

(3)

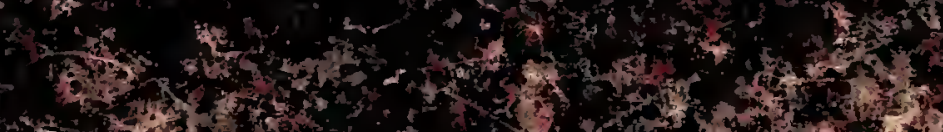

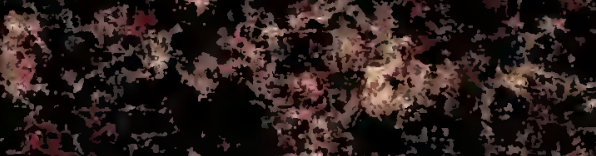
4

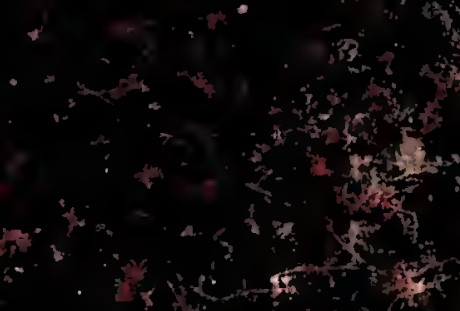
is

I.

$x_{x \rightarrow+2}+x^{2}$

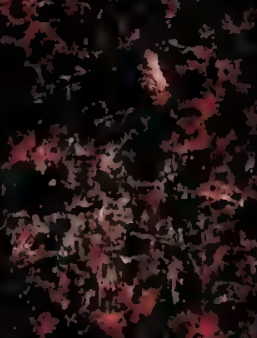

4

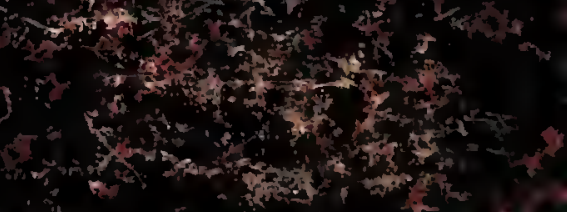


N.xus.

EX LIBRIS

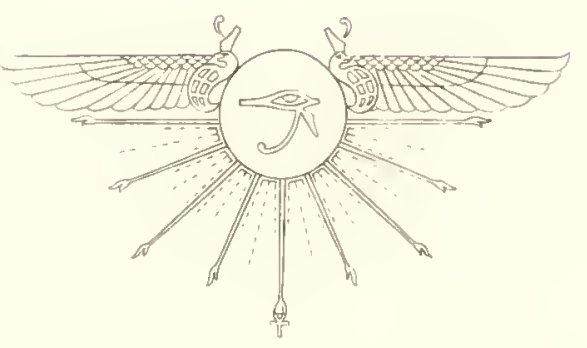

Wellcome Bureau of Scientific Research

LONDON 
Med

K5497 
Digitized by the Internet Archive in 2017 with funding from Wellcome Library

https://archive.org/details/b29336065_0002 


\section{AUSLÄNDISCHE}

\section{K ULTURPFLANZE N}

IN FARBIGEN WANDTAFELN

MIT ERLÄUTERXDEM TEXT.

ZWEITE ABTEILUNG. 



\title{
AUSL ̈̈NDISCHE
}

\section{KULTURPFLANZEN}

\section{IN FARBIGEN WANDTAFETN}

MIT ERL IUTRRNIEM TEXT,

IM AXSCHLLSS AX DIE

\section{..REPRÄSENTANTEX EINHEINISCHER PFLANZENFAMILIEN".}

$11 \mathrm{ER}$ A USGEGEBEN

$\operatorname{VON}$

\section{HER】ANN ZIPPEL,}

ordentlichem Lehrer an der Zabelschen höheren Töchterschule zu Gera.

\author{
Z E I C H N U N G E N \\ rox \\ KARL BOLLMANN ZU GERA.

\section{$\mathrm{TE} \mathrm{X} \mathrm{T.}$} \\ Zweite Abteilung.
}

Mit eiuem Altas, enthaltend 24 Tafeln mit 27 grofsen Pflanzenbildern, zahlreichen Abbildungen charakteristischer Pflanzenteile und Abbildung der Reblaus.

Dritte, vielfach verbesserte und vermehrte Inflage.

B R A U N S CH W I G,

DPLCK UND VERLAG VON FliEDLICH VIEWEG UND SOIN.

1896. 
Alle Rechtevorbelialten.

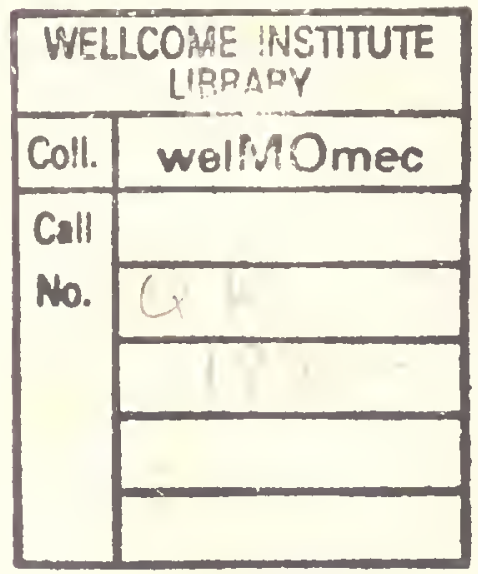




\section{IXIIALSTERZEIOINIS.}

Tafel 1. Echte Kolospahne (cocos mecifera L.) . . . . . . . . . ]

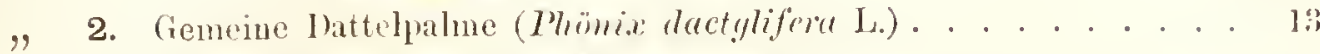

"3. Vehte ragopalme (Sugus limmlhii W. . . . . . . . . 22

"4. Drachen-liotang. Drachenhlutpalme, spanisches Rohr (C'ulumus (Men M.). . . . . . . . . . . . . . . 27

5. Grolsblätteriger Siagohaum (Cycas circinalis L. . . . . . . 31

6. Gemeines Bambusrohr (Bumbusa armmdinaced Willd.) . . . . . 57

7. Wohlriechender Schraubenbaum (I'mulams odorntissimus L. fil.) 40

8. Fig. I. Kapseltriachtige Jute (Corchores cupsuluris L.) . . . . It

Fig. II. Ramieptlanze. Chinagras (Borthmeriu tenucissimn Gaud.) 5!)

9. Fig. 1. Echte Ananas (Anamasse sativa Lind.) . . . . . . 55

Fig. II. Amerikanische Agave (Agure tmericrimu L.) . . . . . . 59

10. Verek-Gummiakazie (Acacin lereli Cinillemin et P'erott.) . . . (it

11. Binchnulsbaum (Strychnos mux iomica L.) . . . . . . . . . 71

12. (icmeiner Ölbaum (Hea enopaea L.) . . . . . . . . . . 75

13. Fig. I. Eehter Safran (Crocus sutivus L.) . . . . . . . 82

Fig. II. Gemeiner Kappernstraneh (c'apponis spimosa L.) . . . . 88

14. lichter Inotfinchtbaum (Aitocripus incisa L. fil.) . . . . . . 91

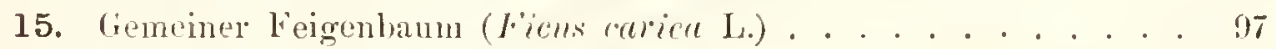

16. Litnane oder Bananenpisang (Husa stpricntum L.) . . . . . . 105

17. Der Weinstock (Titis timifro L., grofse weilse Cibebentranbe) . 11:3

18. Gemeiner Walnufsbaum (Kugluns vegin $\mathrm{I}_{\text {. }}$ ) . . . . . . . . . 136

19. Maronen-liastanie (Custunea rescu Gaert.) . . . . . . . . . . 143

20. Indigoptlan\%e (Imligofere tinctoria L.) . . . . . . . . . . . 14h

21. Kork-Eiche (Quereus sulue L.) . . . . . . . . . . . 154

22. I'feilwur\% (Marunta armdinucen I.) . . . . . . . . . . . 162

23. Angebaute lanswurzel (l)iuscorea satira 1.) . . . . . . . . 166

24. Batate, süfse Kírtoffel (Bututus inlulis Chois.). . . . . . . . 169 



\section{Tafol 1.}

\section{Figur 1. Echte Kokospalme') \\ $\left(\operatorname{Cocos}^{1}\right)$ nucifer $\left.{ }^{2}\right)$ L.).}

Die echte Kokospalme gehört zur Klasse der Einsamenlappigen (Monocotyleue oder Monocotyledones) und zur Ordnung und Familie der Palmen (Principes) ${ }^{3}$ ).

Die Ordnung nnd die Familie der Palmen (Principes) stellen den vollendetsten Typus der Monokotylen dar. Durch die Unscheinbarkeit ihrer Bliiten erinnern sie an die Binsen, durch den Habitus mancher Arten an die Gräser und durch den Bau der Bliiten und des Blïtenstandes nähern sie sich den Spadicifloren (siehe unsere „Repräsentanten einheimischer Pflanzenfamilien II. Abteilung, 1. Lieferung). Der Palmenstamm ist meist einfach, indem er nur durch die einzige Terminalknospe, mit welcher er abschliefst, sich stetig verjüngt und höher wächst und letztere zugleich die ganze einfache Krone von Blätteru, die an der Spitze des Stammes sitzen, erzeugt und verjüngt. Selten nur bilden die Palmen Sträucher, in der Regel schlanke Bäume, mit einem walzigen, astlosen Stamme, der eine endständige Blätterkrone trägt. Bei manchen Arten läuft der Stamm in der Mitte verdickt zu, bei anderen ist er rübenförmig, bei noch anderen pyramidal. Nur wenige Palmenstämme verästeln sich (Dhumpalme) und nur die Rotangstämme (siehe Drachen-Rotang, 4. Tafel) klettern. Der Palmenstamm geht nach unten nicht in eine Pfahlwurzel aus, sondern ist nur mit kräftigen Nebenwurzeln befestigt. Die Gefäfsbïndel bilden im Stamme keinen Kreis, weshalb ein eigentlicher Kambiumring fehlt. Daher nimmt der Palmenstamm im späteren Alter nicht an Dicke zu, sondern verlängert sich nur in gleicher Dicke und bilket also keine Jahresringe; sein Inneres ist vielmehr weich, markartig und nur der peripherische Teil, in welchem die aufsteigenden Gefäfsbiindel begimnen, bildet eine härtere, holzige Schicht. Die

1) Siehe „(ieschichte". - 2) Nufstragend. - ${ }^{3}$ ) Von Linné die „Fïrsten des l'flanzenreichs" (1'rineipes) genaunt.

Zipjel-Bollmann, Auslindische Kulturpilanen. II. 
:̈ulsere harte Lmhiillung des Stammes giebt einem Drucke von innen nicht nach, die nenen Gefífsbinulel driicken dic :ilteren immer rnger zansammen und schliefilich werdon dem Safte alle Wege virschlossen. Daher werlen P'ahnen selten 100 Jahre alt. Die Oherfläche des Stammes ist dnreh die I'berreste der Blattscheiden schuppig oder von den ringförnigen Battbasen bedeckt, mitunter auch stachelig. Die Blïter werden Wodel genannt und sind fächerförmig (Fücherjalmen) orler tiedrefoimig (Fiederpalmen), selten ungeteilt. Die 'T'eilung 1) entsteht whrch wirkliches Zerreilsen der ursprïnglich ganzen Fliiche; in der Kinospenlage ist die Blatthliche gefaltet, und an den Faltenlinien tritt dic Kerreilsung des Zellgewelres ein. Die sehr zahlreichen, unansehnlichen Bliiten *) stehen auf einem einfachen odler veristelten lioblben, welcher im hospenznstande von einer gemeinsamen Hiille (spatha) mmschlossen wird (Fig. 1). und sind der Anlage nach rollstïndig. werden aber durch Fehlschlagen der Staubbliitter oder Stempel finst regelmäfsig diklinisch oder polygamisch. Die Bestiubung wird durch Wind oder Insekten bewirkt. Die Glieder der sechsteiligen oder sechsblütterigen Bliitenhiille sind in zwei Kreise, Kelch und Blumenkrone, geschieden, welchen drei, sechs oder mehr, den Blumenkronbliittern eingefïgte Staubblïtter folgen, wïhrend in Mittelpunkt der Bliite bald ein aus drei Fruchtblättern entstandener, oberstïndiger, dreif̈icheriger Fruchtknoten auftritt, bald drei einfäicherige Fruchtknoten rorhanden sind. Jedes Fruchtknotenfach, resp. jeder der einfäicherigen Fruchtknoten enthïlt eine meist geradlïutige. anfrechte Samenknospe. In der Regel bildet sich nu eine Samenknospe zu Samen aus, wïhrend zwei derselben verkïnmern. Ilie drei Griffel sind rerwachsen oder etwas getrennt mid tragen eine cinfache, ungeteilte Narbe. Die Frucht, eine ein-oder dreisamige Beere oder Steinbeere, ron der Grölse der Frbse bis zum Unfang des Menschenkopfes, ist meist von dem erhärtenden Perigon nmgeben mind hat Heischiges oder faseriges Fruchttleisch and einen papierartigen oder holzigen, knochen-oder steinharten Kern. Das reichliche Endosperm les Sahens ist anfangs milchartig Hiissig, später verdichtet es sich, wird knorpelig orler hornig, trocken oder ölig, massir oder gehöht. Der schr kleine cylindrische oder kegelförunge Keimling in ciner Höhlung an der Peripherie des Eiweifskörpers wird aler noch ron einer diinnen Lage Eiweils wie mit einem Deckelchen bedeckt. Das Wurzelende kehrt der lieimling gegen die Peripherie des Samens. Bei der Keimung tritt der Kémuling hier aus lem Samen herror, inden die mutere Partie des scheilenförmigen lieimblattes sich streckt und das Wu\%elende sant der von der Keimblattseheide umhiullten Keimknospe ans dem Sanen hinansschiebt, wïhrend seine obere Partie

1) 'Thom E. Lehrluch der Botanik. - 2) Bei der Öhrahe (siehe 3. Abt.) etwa bin)(n). 
als Sangolgan in Sanneneiweils stecken hleibt, his dieses aufgesogen ist. Nun streckt sich dis lieimblatt beträichtlich albwirts und vertieft die ron iln eingeschlossone lieinkuospe simt dem Wurzelonde in dis Erdreich. Die lieimknospe lroidit dann mit ihren scheidigen rrsten libittern aus der Simenblattscheide nach oben hervor. Die kräiftige rertikal abwärts wachsende Irauptwuzel wird bahl durch Nebenwurzeln elsetzt.

Von den !ri bekimnten Arten gelören nư etwa 40 nicht den Tropen an. Auf der nördlichen Halbkngel gehen sie bis zum 44. Grad (Europa, Chanterops), anf der siidlichen in Neuhollind in wenigen Arten his zum 34. Glad, in Neuseeland bis zum 38. Grad. In dem an l'alnen armen Siidwest-A trika liegt die Grenze bei 21 rirad, in Siidwest-Amerika bei 34 Grad. Kwei Irittel der Gesamtzall aller Arten sind in der Zone rom 10. Grad nördlicher bis 10. Grad südlicher lireite dahein. Die meisten Palmen vegetieren in der Elyene bei einer mittleren Wärme ron 26 bis $290 \mathrm{C}$., doch gedeiht die Wachspalme in den Anden noch zwischen 1900 bis $2800 \mathrm{~m}$ iiber dem Meere, wo die mittlere Wïme kitum $13^{\circ} \mathrm{C}$. betrïgt und die Quecksilbersäule llachts auf $6^{\circ} \mathrm{C}$. fällt. In der vorweltlichen Vegetation werden die l'alnen rom Kolnlengebirge an bis in die 'Tertiärzeit, und zwar in letzterer am liänfigsten gefunden.

Nach Dr. Drude findet die Artenverteilung der folgenden 'Tabelle gemïls statt:

$$
\text { Westliche Erdhälfte: }
$$

Anazonenthal . 180 Artell

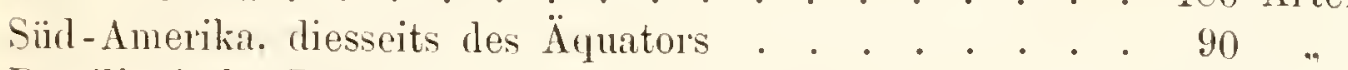

Brasilianische Region

Mexikanisclıe Region

bie tropischen Andes

Westindien.

Nördliche Panmas

Florida-Region

Pröirien

Chili

$\begin{array}{rr}90 & , \\ 80 & " \\ 70 & " \\ 40 & " \\ 6 & \cdots \\ 6 & " \\ 3 & " \\ 2 & "\end{array}$

567 Arten

Östliche Erodhälfte:

sunda-Inseln, Molukken und Nen-Guinea. 200 Arten

Das östliche Indien

Das westliche Indien

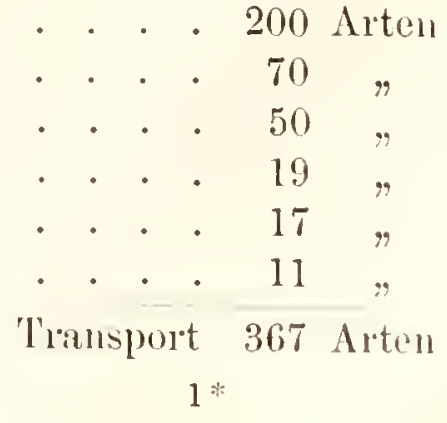

Australien, Nordkiiste .

Afrika, tropische Westkiiste

Afrikil, tropische Ostkiiste 
Siinlliches Chinal.

Maldagalscan

Australion, Ostliiisto

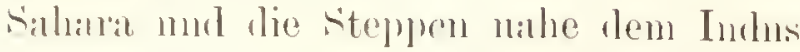

Siirl- Ifilikis

Mittrolneorlinulon

Tlanspurt 367 Arten

lis wird allgenein angenommen, dills im Laute der Jahre noch aino Menge neuer Arten rrkinnt werden wird. Man muterscheidet zur \%eit 132 Gattungen in 5 Grmppen.

I) Gattung Kokospalme (c'ocos L.). Stachellose Fiederpalmen mit glittem, geringeltem stamm, gefiederten Blätten mit linienförmigen Blïttchen. Die Bliitenkolben stehen in den Achsen der unteren Blïtter. Frïchte elliptisch orler eiförmig, mit faseriger Imhiïllung und einer Nuls (Simen), welche am Girmde drei Löcher zeigt. Asien und Amerika.

12 Artell.

Die echte Kokospalme (Cocos nucifera L.) wird 19 bis $28 \mathrm{~m}$ hoch und 30 lis $60 \mathrm{~cm}$ am Grunde im Durchmesser dick. Die Wurzel hesteht aus einem Büschel einfacher fingerdicker und dicht zusammengedrängter Fasern, welche oft aus der Erde hervorsehen. Stamm walzenrund und im Alter gebogen, wird durch die vom Abfall der BTitter gebilıleten $3 \mathrm{~cm}$ breiten Ringel unregelmïlsig eingeschnitten. Die grauliche oder bräunlich-aschgrane Oberfläche, besonders der iilteren Stïmme, ist sehr rauh und zeigt eine Menge der von der Einfïgung der Blattspiralgef:̈̈lse hervorgebrachten Narben und Knötchen. Der Stamm ist von so grofser Elasticitit, diffs selbst der stärkste Orkinl den Baum nicht umznstiirzen vermag. Hol\% blafsrötlich gell, aus einem weichen Mark (Parenchym) bestehend, das von fast cylinderförnigen, schlanken und zähen Fasern durchsetzt ist.

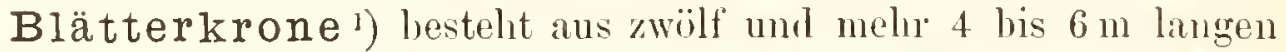
Wedehn. Sie bildet einen der schönsten und charaliteristischen Zïige tropischer Landschaftsbilder:

Blätter, 3,8 bis $5 \mathrm{ml}$ ling, leicht gekrümmt, die immeren aufrecht, die ïufseren fast horizontal ahstehend, die unteren herabgebogen. Blattstiel fast stengelunfassend, unten ohne Fiederblittclien, einwïrts gleccl einem Kanal ansgehöhlt, answïrts gewölbt, am Grunde von cincm zälien, luannen Geftecht umgeben; als Mittelrippe ist ('r an den Seiten f'ür die Firderl)littchen gefincht und unten gelblichgriin sefürbt. Fiederblättchen glatt, grasgriun, stehen in $\because$ ('m breiter Entfernung von einamler, 63 bis $89 \mathrm{~cm}$ lang und in

1) Siche , hultur und Eutwickelung"! 
der Mitte : his $5 \mathrm{em}$ hreit. fast linien-lanzettfiomig, splitzig, zuerst zusammongefaltet, otwas an einander gedriokt, spitor ansgelneitet

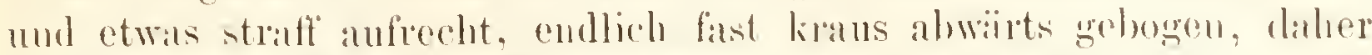
die juingeren Wedel regehnäligg goomelnot, die iilteren first kraus.

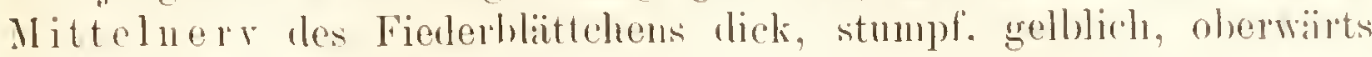
riemlich horrorrangend.

Blütenkolben (l'eil des geoiffiseten, Fig. 1) gleicht noch in semer Scheide cingeschlossen auf dem Stammo ainem emportagenden Spiefse und wird 1,56 his 1.86 m lang. Die gesch lossene Scheide ist spindeltörnug. spitrig, in der Mitte arm- his schenkoldick mul hesteht aus ciner redhol\%enden, $1 \mathrm{~cm}$ dicken Haut, welche der Jänge mach tief gefurcht ist, grünlich, aber hiev und da mit riucm hräimlich-graucn abwischlaren Fil\% bekleidet wird. Geöffnet erscheint sie schmillanzettförnig, aufsen fast olivengrïn, innen gelblich bis kistanienbraun. Kolbenstiel $25 \mathrm{~cm}$ lang und $3 \mathrm{~cm}$ dick, erst filzig. dann watt. oben, sowie am Grunde jeden Zweiges des Kolbenstiels nit Deckblättern rersehen. I)ie sehr zahloeichen (bis 30) Äste des liolbensticls entspringen von einer riemlich walzenrunden, grıbigen und eckigen Achse, 55 bis $63 \mathrm{~cm}$ lang. am (irumle gekroiummt-gedreht und zusammengedriickt, voln leicht gebogen, fast dreiseitig, von blafsgrüulicher Färbung. Die männlichen Blüten stehen an den Kolbenzweigen oben in lockeren Ähren (Fig. 2 und 3); die winzigen Deckblitter unterstiitzen die einzelnen Bliitenpare von linten. Kelch (Fig. 4) ist ans drei sehr kleinen, eiförmigen, spitzigen Bliittern in ein einziges dreiseitiges, dreifich gezähneltes zusammengewalchen, weifslich. Blumenkrone $1,5 \mathrm{~cm}$ grofs, aus drei schmal-lanzettförmigen, etwas spitrigen, blals gellrötlichen Blïttern bestehend. Staubblätter (Fig. 4, 5) etwas kleiner als die Blumenblïitter; Staubfäden solu kur, pfriemenförmig. weils; staubbeutel linienförmig. stumpf, am Grumde fast ausgerandet, weifs. Your Pistill sind num Andentungen da, die oft ganz fehlen. Die weiblichen Blüten sind am unteren 'Teil der Äste (des Kolbens) zelstrent (Fig. 2 und 3), erst eiförnig-liugclig, dann rein eiförnig. Das rreifache. häutige Deckblatt wird nach nud nach so grofs, dafs es die dick geworlene Bliite ungielt. Kelchblättchen fast kreisruud, die zarte Pliite fast ganu einschliefsend. Blumenblätter kreislıurzugespitzt, weifslich-griu. Fruchtknoten nierlergedriickt-kugelig, dicht ron einer weifsen, sehr feinen zottigen Wolle unhiillt, enthïlt eigentlich drei Fächer; zwei Fïcher simd meist ohne Samenlinospen und an der Basis zusanmengewachsen.

Steinfrucht (l丷ig. 6) 22 bis 30 cul linng und 18 l)is 25 cu in Durchmesser dick, einige Pfund schwer wiegend 1), an jeden Kiolhen

1) "Es wandelt niemand ungestraft unter I'almen", Goethr ('T'agebuch Ottiliens in den "Wahlverwandtschaften", Teil II. Kill. 2). 
10) his 30 reife, cifomign-, oder foust kugelig-, stmmpf-dreikantigr, an heiden Enden mit emen Hïcker versehen. Oberhaut diin, sehr gratt, hram, endlich stroligelb; Rinde am (irmultoil der l'nucht oft I0 ('m dick, besteht :ms Fasem, welche der Lïnge mach durch das weiche Parenchym herablanfen nnd riblhe, brann, mnd hei alten schwammiger, ghatt mol hlisser gotroffen werden. Das eigentliche Kernhaus (Fig. 7), Keruschale. Nufsschale, befindet sich im oberen Fruchtteile, ist knöchern, 5 bis $7 \mathrm{~mm}$ dick. durch die iiberall angewachsenen lindenfisern der Lïnge nach narbig. schwär\%lich-hram, eifömig, obon durch drei erhabene, an der Spitze sich zosammenneigende Leisten bezeichnet, an dem Grunde aber mit drei Ernailnungslïchern versehen, wovon zwei, welche den fehlgeschlagenen fächern entgegenstelien, mit einer dickeren, das dritte aber zum fruchttragenden Fach fiilnende, mit einer diimen Haut verschlossen vird. Innen ist die Haut blafsgelb und dunkel geadert. Kern eiformig, lobl, in der Jugend mit einer sïnerlich-süfsen Lymphe erfüllt, welche allmählich zu Eiweifs verdichtet wird, ̈̈ufserlich rötlich-braun, mit sehr zahlreichen, gehogenen Gefïfsen versehen; Eiweifs Heischig, etwas weicher als Mandehn, weils, hesteht aus mzähligen lutenförmigen Balken, die unter sich zusammenwachsen, äulserlich ritzig und etwas warzig. Keinung siehe bei Kinltur.

Vaterland: Inseln der Südsee und des ostindischen Archipels (Kokosinseln im Westen von Smmatra). Verbreitungsbezirk (meist durch die Meeresströınungen verbreitet worden): Alle Länder innerhalb der Wendekreise, Kosmopolit der Tropenländer. Wo sie die Wendekreise ïberschreitet, verliert sie an Schönheit und Ergiehigkeit (Sandwich-Inseln). Unter dem Äquator gehen diese Palmen bis 1000 his $1150 \mathrm{~m}$ Meereshöhe empor. Am schönsten gedeihen sie zwischen dem 15. Grad nördlicher und 12. Grad südlicher Breite; am reichsten tragen sie auf den Sumda-Inseln, Philippinen, Carohinen, Mariannen und Laccadiven. In Asien westlich ron Indien wachsen kenne. In Anerika stehen sie auf' der Westseite dïmn (18. Crad nörrlicher und 18. Grad südlicher Breite), auf der Ostseite ist ihre \%one gröfser (24. Grad nördlicher bis 27. Grarl sïdlicher Breite). Die liokospalme bedirf zu ihren Gedeihen der Seehrise, mit ihren Wurzehn strebt sie dem Salzwasser zn. Die Kokospalme wird in einer grolsen Anzahl rou spielarten augebaut.

Die Kultur dieser Palme wird an ansgedehntesten in Ostindien und anf Ceylou betrieben. Die Kokospahmen bleiben nufruchtbar, wenn sie nicht gepflegt werden. Daher sigen die Eingrhorenen Ceylons: .Die Kokospalmen traren nicht, wemn Du nicht muter ilnen gehst mul mit ihmen surichst." Der Hnngertod hat schon manche Sïlsee-lusel entvölkert, obschon sie nit vielen (nicht geptlegten) líokospalmen bestanden war. Liegt die Pthan\%mg nicht im Fhthereich der See, so berknf sie einer liewaissermugsanlage, in still stehenden Wasser verkriiplpelt sie. 


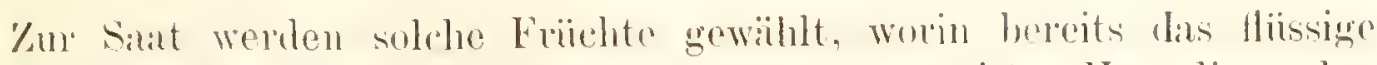
liweifs in einc fostere Substan\% iblorgegangen ist. Int diese den kein ein weng hervorgetrieben (durch das weitere blinde forh der

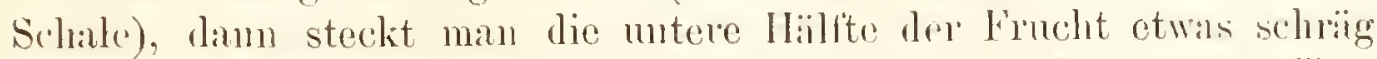
in rine im samenbeet remachte mul mit Asche mul Sal\% (gogen 'Termiten) gediungte Grube oler in grolse Bhumentöple. Bei gruter Bewïsscrung erscheint der Kem schon nach fïnf his sechs Monaten in Gestalt cines kleinen Elefantenzahnes. Der junge 'Trieh muls durch Decken und Matten, die man des Nachts wieder entfernt, vor der Sommenght geschiitzt werdeu. Er wird in kurer \%eit $60 \mathrm{~cm}$ hoch nud ist damn mit Blittern ver'sehen. Nach weiteren Monaten kömmen die jungen l'ahmen verptlanzt werden. Die IBätter fangen nach dem ersten tahre an gefiedert zu werden, d. h. sie verlieren ihre zusammenhängende Form. Am Ende des zweiten Jahres haben sie am Grunde einen Durchmesser von $8 \mathrm{~cm}$. In dritten Jahre nimmt der Fufs der Krone die Gestalt eines Hufeisens an und der Stamm heginnt sich über die Erde zu erheben. In vierten Jahre wächst er höher auf und vermehrt die /ahl seiner Blätter auf zwölf. Im fünten Jahre entwickelt er sich zu einem Baume mit 24 Blïttern. In den folgenden Jahren setat er noch weitere 12 Blätter an, damit ist seine Krone vervollständigt. Nun wendet sich das Wachstum mehr auf den Umfang der Pflanze. Der eigentliche Stamm wird gebildet, indem die alten Blätter abfallen und sich dafiir aus der Mitte der eigentlichen und einzigen Blattknospe nene entwickeln. Ein einzelnes Blatt bedarf zu seiner gehörigen Ausbildung einer Zeit von drei Monaten. Die Bliitenscheiden brechen je nach der Güte des Bodens früher (im dritten) oder später (im zehnten Jahre) unter den sieben obersten Blättern hervor, üffuen sich nach vierzehn Tagen und lassen nach sechs Tagen die äufseren Blïtenteile abfallen. Die Ostindier unterscheiden zwölf verschiedene Zustände der Bliiten nud Frucht. Von den zuerst hervorbrechenden Früchten fällt eine Anzahl ab und nur die übrigen erreichen die vollkommene Entwickelung. Anfänglich ist das Eiweifs der Frucht sehl zart, siifs, schmackhaft, nicht ölig, und bläulichweifs; wird es härter, so erhält es einen nufsähnlichen und öligen Geschmack. Je älter die Frucht, je öheicher das Eiweils. Die Kokospalme trägt vom 8. bis 100. Jalne, und zwar zu allen Jalneszeiten, jührlich etwa 60 bis 80 Friichte in vier bis füuf Ernten. Da riese Palmen meist iber $10 \mathrm{~m}$ weit von einander entfernt sind, so werden meist Zwischenpflanzungen in den Abständen angelegt. Man verwendet dazu die Baumwollstande ('Tahiti und Samoa), oder Yauns, Bataten, Pfeilwurzeln und Turmerik (Sül-Asien).

Den Kokospalmen schaden Ameisen und 'Termiten; Ratten klettem auf' die höchsten Pahmen nnd fressen die jungen Triebe und die jungen Niisse; der fliegende Fuchs, das fliegende Eichhörnchen und das Palmeneichhörnchen nähren sich gern 
won den linichten und richten oft grofsen Schaden an, und eine grofse

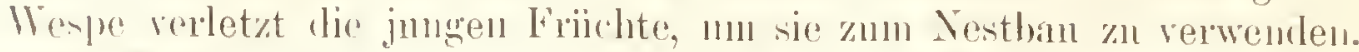
Wird Toddy geerotet, so stellt sich anch die Wildkatze als ciast ein. lis gieht kloine lusekten, welche sich in die stïmme bohen,

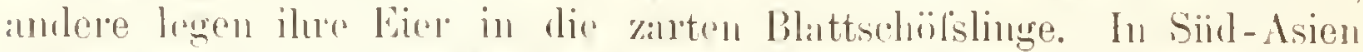

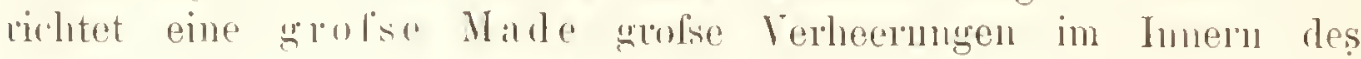
Stanmules : 11.

Zusammensetzung der Kerne. Der kirn der n11reifen Xul's enthïlt in 1000 'Teilen: Wasser 900,88, Zucker 4,43, (rmmıi 17,67. fottes Öl 28,2!), Salze, antlïslich in Weingeist 544, Salze, unantlishich in Weingeist 6,29. Die Salze bestehen vorzugswoise aus Kíli, phosplorsaurem Kalk, Chlor-Natrimm nnd essigsanrem Kalk. Der Korn der reifen liokosnufs besteht ans: Wasser 46,6. Eiweifsstoffen 5,5. fettem (̈) 35.9, Zncker 8,1, holufiser 2,9, Asche 1.0 P’ro\%

Nutzen. Wem sich dir Crefiilshiundel des Stammes der Kokospahne so dicht geschlossen hahen, dalfs sie das Absterben des biames rermsachen, ist das Holz, im Handel Porkubinenholz gomannt, vorzighlich z.ur Kunsttischlerei geeignet. Es nimut eine schöne Politnr :11. Jlan schïtzt es hesonders in England. Ans der Rinde der Kokospalme scheidet man das Kokosgummi (yomme de coro). das ron allen Grummen die gröfste Nenge Lassorin ${ }^{1}$ ) (70 bis 90 Proc.) enthält, nud womit die T'ahitier ilur Haar bestreichen. Die äulseren rindenartigen Stammteile dienen in Indien zmu Gerhen. Die Kokospalme dient nach der Volkssage der Hindus zu 99 Dingen und das sprichwort saght, dafs eine gute Hausfian verstehen miisse, ilırem Mamne an jedem Tage des Monats ein anderes Lieblingsgericht daraus zu fertiren. Die Milch der unreifen Früchte liefert ein beliehtes kiilılendes Getränk. Durch Gälırung und Destillation gewinnt man ans dieser Vilch einen starken Branntwein, den ostindischen Arrak. Die Kerne der $\mathrm{N}$ üsse geben eine nahrhafte Speise. sie werlen roh nul mubereitet gegessen. Ilie jungen schossen der Gipfelknospen ("Paluher"“) gebm einen wohlschmeckenden Palmkohl („Pahnhirn“) und anch durch Ritzen und Alschmeiden einen Sift. der mehrere lange lang ans der. Wunde, die tionglich ermenert werden mufs, gesammelt wird und durch (iärung deu Surisalt oder Toddy 2) liefert, den angenehmsten Palmwein, ron Geschmark sïls-süuerlich unl mol lichlicher, als Kokosmilch schunockend. Weil aber diener salt nalch fünff 'l'agen saller wirl. so bereitet man vor Beginn der siluren Gäinug durch Destillation ans demselhen (wic in anderen Gegenden :us Reris) einen starken $\Lambda_{r r a k}$, ein Liehlingsgetrïnk der Eingoborenen wie der linnopüer, und Ausfilurartikel. Den Toddy trinkt man frisch und segonen (heransehend), er ist dists kiihlendste Geträink. Aut

i) Siehe "(iummi" bei Verek-Gummi-Akirie (1al: 10), - ") Wird nuch ron der Wein- and rou der ölpaime gewomeu (s. 1. 2. Abt. 'laf. :3 u. 3. Alt. 'Taf. 1). 


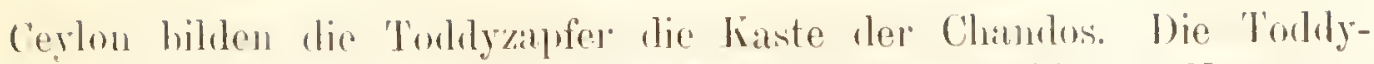

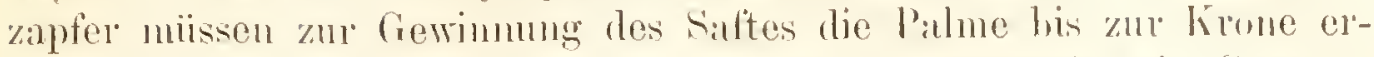
steigen. Koncht man den fischen Saft cin, so entiteht cin Sy yup, der Palmzucker oler Jiggerie (sprich Dsehagori l), (l. i. Zurker), ler in runde, hamue linchen geballt im laumelie der lliitten getrocknet

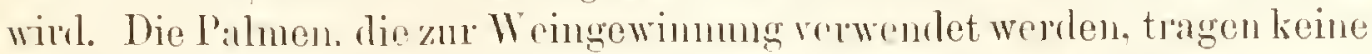
Frïchte. Die frischen Blätter stellt man hei Fostlichkeiton als Zeichen der Frende, Freundschatt und des liedens an den Thüiren anf. Ein Kokoshlatt hegleitot das gevingste Geschenk, das man gieht oder erhält nud ziert den Incrold. der Frieden dem feindlichen Volke oder dem Fremulen verkiindigt (wie das Mattelhbatt in Afrika). Diese Blaitter dienen ferner zur Bedachnug der Hütten, zu Sonnenschirmen, zu Flechtwerken, Körhen, Fulsilecken, Servietten, 'Tafeltuch und als Futter für die Elefanten. Anf trockene Blätter schreibt man mit einem Griffel von Bamhus, man verwendet sie zu Vorhängen, flicht ans ilmen Mïntel, lollt sie zusammen umd benntzt sie als Fackelı. Die Blattrippen und Blattfasern liefern Stricke. Ankertane nul Fischrensen, die Blattfisem besonters Fïlen.

Das Netzwerk am Grunde der Blattstiele lüst man in grofsen Stiicken ah und benutat dasselhe als Seihetnch oder Durchschlag, um das Kokosnulsöl und vorzïglich den Toddy oder Palmsaft (siehe unten) dnohzuseihen und ron hineingefallenen Insekten zu reinigen. Man rerfertigt auch daraus Kleidnugsstücke, die im Wasser sehr hiltbar sind und besonders rou Fischern getragen werden. Auch diesen Rohstoff bringt man unter dem Namen Roya oder Coïr in den Handel nud verarbeitet ihn wie die Kokosnulstaser.

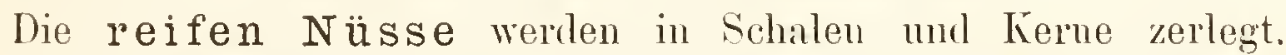
bie Arbeiter tragen die Schalen in die Somne, um sie zn trocknen, und die kerue nach der Ölpresse oder dem Iörrapparat. Zwischen der derben Oberhaut der Fruchthïlle nud der Steiuschale, welche den öligen Kern der Nuls umgieht, liegen in mäichtigen Schichten die zahlreichen Gefilsbündel der Kokosnufsfaser. Die faserige Fruchthiille sowohl als die rohe Faser derselben kommt nach Europa und Tord-Amerika vielfach in Haudel. Man scheidet die Faser aus der Fruchtrinde der mreifen Friichte ab, indem man dic linde monatelang in Masser weichen läfst, damn wäscht, tuichtig dnochklopft und an der Somne trocknet. Sind die Faseru ans einander geweicht, so röstet umd hechelt man sie und legt sie dadurch vollstindig free. lie laser heifst Cörr. Die rohe Kokosnufsfaser hat nach Wiesner eine Läuge vou 15 his $33 \mathrm{~cm}$ und eine maximale Dicke von 0,05 bis $0,030 \mathrm{~mm}$, ist an den Enden dünn, in der Mitte dick, sohr fost, widerstandsfïhig im Wassel mul schwimmt, selbst in dicke 'T'ane gedreht, mit leenlitig-

1) Soll vom Sinskritworte Sackum d. h. Lucker (lat. Succhamm, dentsch Zucker) alggeleitet sein. 


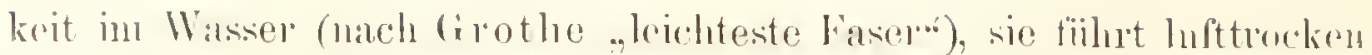

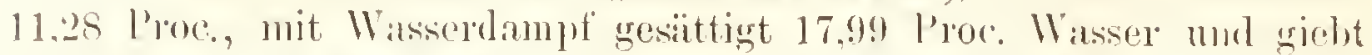

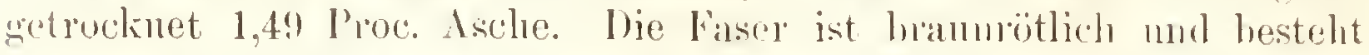
volwiegend aus liastzellen, ferner ans zarten Porenleitzellen, schmalen l'oren- mol spiralgefiifs- mol kleinen, stark rerkieselten l'arenchynzellen. Aus der Faser weht man Garm, Teppiche, mit kunstrollen Fïguren ans Wollengann geschuniickte Matten, Linterleger, Schuire. Seile, Schiffistane, Bïrsten, grohe Pinsel, Fufsolecken, Fulsalstreicher, Resen, grobe Säcke mul vorzighliche Maschinentreibrienen; die noch nicht hourbeitete Faser dient zu Schenerlappen. Die Kernschale der Kokosnufs ist sehr hart nut nimunt eine schüne Politur an. Sie wird deshalh zu allerlei Wrechslerarbeiten verwendet, zn Wasserflischen. Trinkgeschirren, Recherı, Dosen, Löffelı, Lammen, Kn̈̈pfen etc. Als Kokosmufsarbeiten kommen indes meist Gegenstände aus der harten Schinle der Frucht einer brasiliunischen Palme. Attalea funifera (die die Piassave des Handels liefert). in den Handel. In England löst man die Schale der Kokosnufs durch heifse Dïnpfe und Quetschwerke elenfalls in Fasern anf und verarbeitet sie wie diese. Wichtiger ist die

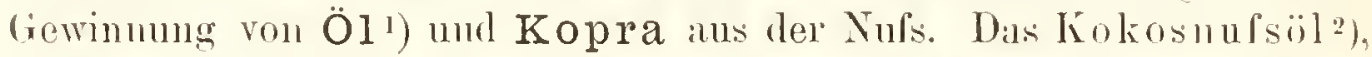
richtiger Kókosmufsfett. auch l'almöl genannt, gewinnt man ans dem Kern durch Kochen und Auspressen. Dieses Fett hiat sich, obwohl schon lange bekinnt, erst seit den letzten Jahmehnten zu grofser industrieller Bedentung aufgeschwungeu. Die linchtkerne werden sowohl in den Erzengungsländern, als auch in Europa ausgeprefst. 15 Nïsse geben 3 Liter Fett. Das Fett ist bei 16 bis $18^{\circ} \mathrm{C}$. starr. Durch kalte Pressung erhält man ein schon bei $10^{\circ} \mathrm{C}$. Hïssiges, griinlichweifses Fett, das in den Heimatlïndern der Kokospalme als Genufsmittel dient, aber nicht in den Handel kommt. Das käufliche Kokosnufsfett hat eine schöne weifse Farbe, cinen millen, eigentiimlichen Geschmack und spaiter einen mangenehmen Geruch. Es schmilat bei $20^{\circ} \mathrm{nun}$ erstarrt hei $18^{\circ} \mathrm{C}$. Es löst sich in Alkohol schon in der Kälte

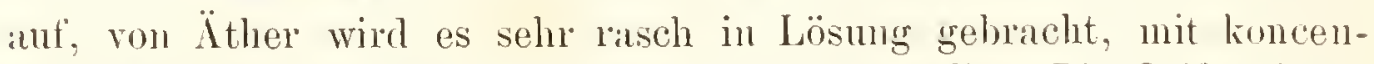
trierten Alkalien verseift es leicht und vollstiindig. Die Seife nimmt den mangenehmen Gernch des Kokostettes an (Wiesner). Sie ist die einzige Seife, mit der in Seewasser Schaum geschlagen werden kann und ist daler besonders bei den Seeleuten beliebt. Das Fett wird ferner vielfach in der Medicin benutzt. In den Er\%engungsliindern gelsraucht man es auch als ein wenig rauchendes brenü̈, sowie als Heilnittel mul (mit Sandellol\% gewiirat) \%nr Restreichung der Körperhaut gegen zu starke Ansdinnstmng lerselhen. Die Prefisriickstinde dienen als Palmkuchen zmm Viehfutter. - In nenerer

1) Siche "l'flanzenfette" bei "Gemeiner (ilbamu". - 2) Das eigentliche Palmö oder I'almfett stumut von einer sehr verlmeiteten Palme, von Elaeis guinecnsis, siche :;. Alsteil. 
\%eit werlen anch die öfiilnenden Fruchtkerne, nardelen man sie getrockuet hat, als Kopra nach Europar \%ur Anspressmug gehracht. Die Kopra vertrïgt einen weiten Seeweg, ohne wie das öl leicht ranzig

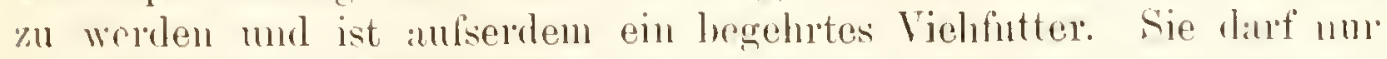
ron völlig reifen Friichten geerntet worden. Das Fett der Kopra wirl in Öllibriken ansgeprefst und unter dem Namen „Kokosinfsintter” rein als speisefett in den Handel gehricht.

Handelsstatistische Notizen. Anf Ceylon sind nach ciner im englischen Parlanent von dem Kolonialsekretiir gemachten Angabe 200000 Acres mit rund 20 Millionen Kokospalmen bepflanzt. Das giebt bei einem Durchschnittsertrag von 50 Friichten von der Palme eine Milliarde Kokosniusse jührlich. Ceylon verschifft jührlich 6 Mill. frische Kokosniisse, ferner 50000 bis 60000 Centner \% Kopra hereitete Kokoskerne im Werte ron 700000 bis 1000000 Mark. Ausfuhr von Öl ist anf' 150000 Centner gesunken (gegen 24569: Centuer im Jahre 1889). Ceylon versendet anfserdem 70000 Centner Coïr, 10000 Centner Taue, 50000 Centuer Garn und 250000 (iallonen ${ }^{1}$ ) Arrak. Man nimmt den Gesantwert der Ausfuhr 'dieser der Kokospalme entstammenden Artikel mit 6 Millionen Mark an. In der Prïsidentschaft Mardras sind 218000 Aeres Land der Kokospalmenkultur, in Französisch-Coehinchina eine Fläche von 33000 Hektar dem Anban der Kokos- und der Arecapalme gewidmet. Bengalen fuilnt jïhrlich noch жwischen 10 bis 20 Mill. Kokosniisse ein. Malabar und die benachbarten Inseln führen jährlich öl nnd Coïr in moge:ïlıen Wert von 11 Mill. Mark aus. Der Wert der Gesantprodultion des malaiischen Archipels wird mit 50 Mill. Nark angenommen. Sicher ist, dafs die Insel Amboyna 507349, Banca 122898, Ninaluassa 605300 1nnd Gorontalo 261950 Bäume kultivieren. Java und Madure besitzen zusammen 20 Kokospalmen. Nauritins verschifft jührlich 40000 bis 50000 Niisse, 300 bis 400 Centner Coïr und 130000 Gallonen Öl. Der Hafen Para in Brasilien führt jührlich 7 bis 8 Mill. Kokosniisse aus. Bei Carthagena in Nen-Granada werden jührlich 4 Mill. Nïsse geerntet. An der atlantischen wie pacifischen Küste Central-Amerikas nnd anf den westindisclıen Inseln nimmt der Anban und die bessere Benutzung der Kokøspalme zu. Die Insel Trinidard fïhrt jährlich iilser 5 Nlill. Nüsse aus, anf:angs der sechziger Jahre nur 200000 Stiick. Wichtiger als in Central-Amerika ist die Kokospalmenkultur anf den SiidseeInsehn, wo sich die Palme durch die Meeresströmungen weit verbreitete. Neu-Caledonien ist die südlichste Insel, an deren Norllkiiste diese Pahmo noch gedeilit. Tahiti entet von nngefïhr 200000 Bämmen jährlich 10 bis 13 Mill. Niisse, von denen 600000 bis 800000 und 4 Mill. IPfund Kopra zn1 Ausfuln gelangen. Von den Marquesasinseln werden 40000 Pfund Kopra jährlich in den Aufsenhandel gebraclit. Auch die

1) 1 Gallone $=1.545 \%$ liter. 
in der Sïdsee gelogenen deutschen Schntygehiete fülıren Niisse nurl

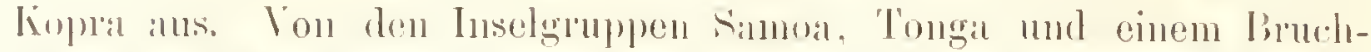
teile der Fïdschi-Insehn fïhren zwei dentsche Fimen etwa fïr 22 Mill. Nark Kopra ans. Ilic Ausfulur des Tuamotus-Arehipels an liopra

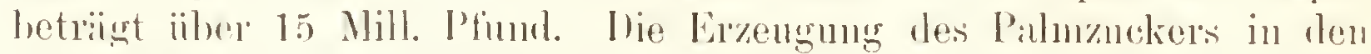
verschicdenen Kultnrgehieten. die aher anch anlere P'alunen betriffit, wirl anf jührlinh 110 Mill. Kilogramm angenommen. Dentsch-()stafrikit besitzt zur \%eit etwa I Mill. Kokospalnen. Anch im Kinnerungebiete schreitet der Mnban dieser l'alne rorwirits.

Geschichte. Hie Kokospalme soll ihre Heinat auf den Inseln ses Indischen Arehipels haben 1), ihn Auftreten in Asien vor 3000 order 4000 Jahren wird durch mehrere Silnskritnamen festmestellt. Von ihnen ist Naritisla der sicherste, dem er findet sich in den neneren Sprachen Indiens wieder. Narikela ist mit einigen Abänderungen in das Arabische und P'ersische übergegangen. Minn findet ilun selbst anf' 'T'shiti nnter der Form rom Ari ofler Haari mit einem malaiischen Simen iibereinstimmend. Theophrast heschrieb die liokospalme zuerst. Marco Polo of 1254 moh Christo) kemut diese Palme muter dem Namen "P'alne nit indischen Xiissen“. Rumph und Thunher'g nemen sie noch Kulapa- oder Calappa-Banm, wie sie bei den Amhoinensen leifst. Erst nach Magelhaen's Finhten wurde der Name Liokos bei den Seelenten bekannt. Lokos wird ron coccus, d. i. Beere oder Kern (Korn) der Baumfrüchte, hergeleitet. Tach ( Klöden namten die Portugiesen die Nufs deshalb kópuo, weil sie spmuren ron Löchern hesitze, welche den Angen und der Nase einer Meerkitze (macoco, Kokos oder Corquin) entspreclen. Martins nennt diese Palme, weil sie die Ausdiinstung des Meeres zu ihren Gedeihen verlingt, die „wandehude Secuferpalme". Kur \%eit der Entdeckung Anerikas find sie sich noch nicht dort. Auf den Sindwich-Inseln, wo sie spärliche Frinchte bringt, genussen in rorchristlicher Zeit nur die Mämner die Friichte, und den Weihern war beim Zor'ne der Gï̈tter d:ss Reriihnen derselhen verboten. Fin Hiinptlingsweib wigte es, das Verbot zu iibertreten. fand, dals es von den Cï̈tter'n nicht gestraft wurle und verschaffte $n$ inn ihren Geschlecht das Recht zum Genufs der Firiclite.

1) A. de Candolle, Der Irsprung der Kulturpflanzou. 


\title{
Tafel 2.
}

\section{Gemeine Dattelpalme')}

\author{
(Phömi.e $\left.{ }^{1}\right)$ dactyliferce $\left.{ }^{1}\right)$ L.).
}

Stellung im System siehe "Echte Kokospihme" s. 1.

Die Gattung Dattelpalme (Phönix L.). Bäume mit hohem, mitunter seln niedrigem, mit den Śchuppen abgefallener Wedel bedecktem Stamm, gefiederten Blättern mit linearen, an der Basis gefalteten Segmenten, deren untere oft stachelartig sind, verzweigten, aus den Achsehn der Wedel hervorbrechenden Bliitenkolben mit zwei!äusigen Bliiten und runden oder länglichen, gelbbramen Steinfriichten.

12 Arten.

Die gemeine Dattelpalme (Phönix dactyliferra L.) kam gegen $48 \mathrm{~m}$ hoch werden, wird aber meist nur 16 bis $19 \mathrm{~m}$ hoch und 0,6 bis $1 \mathrm{~m}$ im Durchmesser dick.

Wurzeln riemlich oberflïchlich, weithin kriechend. Stamm baumartig, walzenrund, durch die dachziegelförmig iiber einander liegenden Blattstieliiberbleibsel iiberall rauh, unzerteilt. Das Innere wird dmrch dicke, holzige Fasern gebildet, welche in einem markigen \%ellgewebe verlaufen und keinen festen Zusammenhang besitzen. Das Äulsere des Stammes besteht ans lanter Blattstielen, die unterwärts in eine ziemlich gleichartige Masse verwuchsen. Das $\mathrm{Holz}$ hat die Farbe von altem Eichenhol\%.

Blätterkrone regenschirmförmig, aus 12 bis 40 blangriinen Blättern bestehenr. Blätter von verschiedener Entwickelung. Die änfseren sind gewöhnlich vollstïndig entwickelt, wïhrend das immere ("Pfeil") die Gestalt eines bis $1 \mathrm{~m}$ langgezogenen Kegels mud an den Schaft angedriickte Fiedern hat. Ein entwickeltes Blatt mit Blattstiel umfalst mit dem Grunde den Stengel zur Ilälfte (Fig. 1). Fiederblättchen anf heiden Seiten des Stiels ganzrandig, schmal, steif, oben rimnenförnigg, in eine spitze endigend, oft nach dem Blattstielgrunde hin ganz in Stachehn ïbergehend. Die Dattelpahme erhialt

1) C̈ber diese Namen siehe die Rubrik "Geschichte". 
durch die verdorten, nirht aldallenden, nieder gehengten Bhitter ein shlor rerwildertes Anssehen.

Blüten lurch Verkïmmernng zweilü̈usig. Beide lBliitenarten sind anfinglich in einer $\Lambda$ rt ron $\Lambda$ chselscheile verborgen, welche dnreh eine seitliche Sualte die Blitenrispe hindurchlist. Männliche Blüten (l"ig. 2) sitzoml, weifshich oder dunkelgell, mit kleinem dreizilhnigen Kelel, ,lreiblättriger, dreimal grïfserer Bhmenkrone und sechs kurzen. aher mit !angen pfeilförmigen, aweifücherigen Stanlbeuteh rersehen. In etwa acht Bliitenständen ungefiihı 100000 männliche IBliiten. In der Mitte der männlichen Blïte drei verkiimmerte Finchitusitze, die endlich ganz verschrmmpfen. Weibliche Blüten (Fig. 3) griinlich-weils. Kelch erweitert, Blnmenh)iitter diinn und rundlich. Die sechs Staubliitter sind angedentet und umgeben die drei dicken nit kurgen, answïrts mmgebogenen. spitzen $\mathrm{Narben}$ rersehenen Fruchtknoten.

Früchte(lïg. 4) in Rispen. Frucht (Dattel) entwickelt sich nur bei rlen kultivierten Dattelhame, ans einer Blïte gewöhnlich blofs eine anf Kosten rer iibrigen, 80 his 100 an einer Rispe. Sellost hei den reifen I)atteln sind noch Kéch und Bhmenkione hemerkbar. Die Frncht. 5 his S cm lang. gestaltet sich wie eine Pflamme. loch ist ihr Kern in kein besonderes Kernhaus eingeschlossen (Fig. 5); Kern (Fig. 6) wakentörmig, lat anf der einen Seite eine Längsurche, anf der anderen die Keimgrulse. Die Frucht ist eine Beere. Sie wim selb. rot mul braun in allen Schattiermigen. Die Frïchte einer Rispe reifen nicht $/ n$ gleicher \%eit.

Heimat ${ }^{1}$. Seit (len prïhistorischen Zeiten finctet sich die Dattelpalme in der trocknen uml heifsen Zone, welche sich rom Senegal nach dem Indusbecken, ganz insbesondere zwischen dem 15. und 30. Breitengmale ansilehnt. Nach den :̈gyptischen und assyrischen Altertïmern zu schliefsen, kam die Dattehalme sehr hïufig in dem Gebiete ror, welches sich rom Euphrat nach dem Nil erstreckt. wals anch mit den Cherliefermugen und den ältesten Werken im Einklange steht. Die iigyptischen Denkmailer enthalten Frïchte und Zeichnungen dieses Baunes.

Verbreitungsbezirk: Nord-Afrika mit den Canaren, arabische Hallhinsel, das grïckliche Arabien heifst wegen der zahlreichen kultivierten Dattelpahmen so. und einen schmalen Strich Arabiens zwischen dem Atlasgebirge und der Sahatrat nennt man ron ihr dis Dattelland (Biledul-Djerid). ..Tannen der Sahara (Oasen)." Die Grenze der l)attelpalne, his wohn sie gute Friichte hringt, sinul die Canaren in 20 his $30^{\circ}$ nörll. Br.. Elche in Vilencia in $390044^{\prime}$, siirllicher Abhang des Atlas 33 his $36^{n}$, Tmus in $37^{0}$, Siirl-Syrien an fler Kiiste 31 his $32^{\circ}$, l'mgegenl ron Jericho $32^{\circ}$, Bagellad $33^{\circ} 19^{\prime}$.

1) A. de Cindolle, 1. c. 
Die Grenze, his zu welcher sie der Seltenheit oder ihrer blittre wegen angehant wird, ohne liviohte $/ n$ bringen: Astmien, hei Oviedo 4: his $43^{\circ} 20^{\prime}$; Route de lit corniche, geschiitzte Orte $40^{\circ}$ etwa; Rom (iinfserste

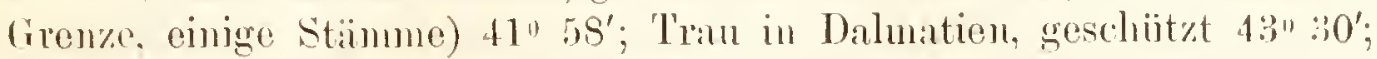
Westliiste ron Kileinasien $39^{\circ}$ etwa; Siidkiiste desselhen, geschijtzt 37

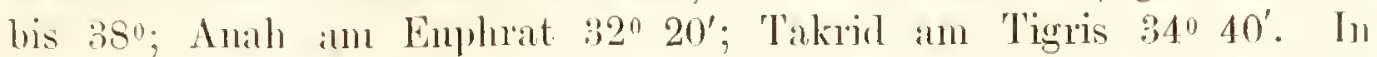
Indien tindet koine Dattelkultur (Kokospalme) statt, an Kap, in Anstralien und an einigen Orten Amerikas ist sie eingefïhnt, doch kinn dort ron einer eigentlichen Dattelpalnenkultur keine Rede sein. Die Dattelpalme ist der echte Reprïsentant der snbtropischen Zone olue Regenniederschlag 1) in der Alten Welt. In Arahien ist sio das Chanaktergewïchs, das allen Landschaften ihre Physiognomie giebt.

Von der Dattelpalme kemt man sehr viele spielarten. In Ägypten kennt man 30, in den Ländern, welche die Salıu'a bogrenzen, werden nicht wenigor als 100 geziichtet. Auch bei Medina sollen ïber 100 Spielarten wachsen. Alle Spiclarten lassen sich nach ihrer Grondfarbe in rnte, hrame und gelbe grmppieren.

Kultur. Wo die Dattelpalme Früchte tragen soll, verlangt sie 7.u ihrem Gedeihen eine mittlere Temperatur vou 21 bis $230^{\circ}$ C. Man kaun sie sowohl durch Wurzelschöfslinge als durch Samen (Kerne) fortpflanzen. Die erstere Vermehrungsweise ist rorzuzichen. Diese Palmeu gedeihen besonders da, wo die Luft am trockensten ist, doch aber die Wureln reichliche Feuchtigkeit finden, in sandigem, lehmigeu, etwas sal\%haltigen Erdreiche, wo andere Pflanzen absterben wiirden. "Der Köuig der Oasen," sagt der Araber, „taucht seine Fülse in Wasser und sein Haupt in das Feuer des Himmels." Sonst aber sind Dattelpahmen klimahart, vertragen selbst einen leichten Frost und lieben einen windigen Standort. Man wählt ebene Flächen zu Kulturfeldem, gräbt das Land tief un, pflanzt in Frühlinge die zwei bis drei Jahre alten Wurzelschöfslinge in Zwischeuräumen vou ungefïhr $2 \mathrm{~m}$ von cinauder, in $1 \mathrm{~m}$ lange und $30 \mathrm{~cm}$ tiefe Gräben, welche man acht Wochen lang täglich bewïssert und die Stecklinge durch Lauhwerk gegen die Somnenstrahlen zu schützen sucht. In wasserarmen Gegenden mufs man Brunuen graben, un nur Wasser zu bekommen, was man dann mittelst Schlïuchen durch Ochsen aus der Tiefe heraufziehen läfst. Die Verteihnng des Wassers an die einzehnen Bäume einer Pflanzung mit möglichster Sparsankeit nimmt sehr viol Sorge und Mïhe in Anspruch. Das Fortpflanzen der Pahme durch Wurzelschöfslinge hat den Vorteil, dafs man, weil sich die Bliite in kurzer Zoit entfiltet und man also weifs, ob es ein mämnlicher oder weiblicher Baun ist. das Verhältnis der Geschlechter eintreten lassen

1) Im Anfange der vierziger Jahre fiel in der I'mgegend ron Mursuk (Oase ['essan) ein siebentägiger Regen, wodureh das Salz im Bodun aufgelöst und den Wurzeln der Datteln im Übermafs zugefürht wurde. In Folge dessen starbon 12000 hochstämmige Datteln ah. 
kitnn, dis der Kultur an wiinstignten ist. Man rechnet gewölunlich

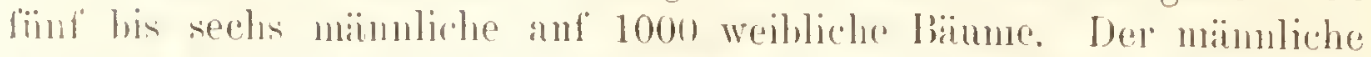
Biamm findet seine Stelle an der Soite, wo der herrschende Wind herkonnt. Junge 1)attrohalmen bilden ein kinm zu durchdringendes

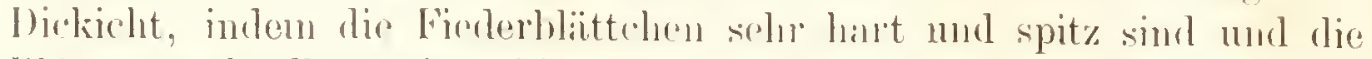

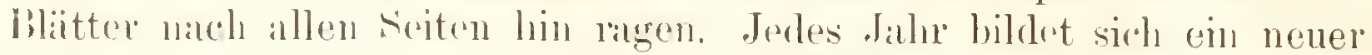
Kreis ron Bliittern. der untere verwelkt, fiilt aber nicht ab, sondern wind von den Pflegern entfernt. In wenig hewohnten liegenden, wo miln disse vertrockneten libitter nicht zu häuslichen Wwecken ibnimmt, werden die ganzen Stämme rom densethen eingehiillt. Nach vier bis sechs Jilnren bringt der Baum seine Erstlinge ron Bliiten und Friichten leeror. Im Februar drïngt sich dann am Gipfel des Stammes ans den lilattachsehn eine lederartige, iiber $1 \mathrm{~m}$ lange und eine Spanne breite, äufserlich mit rötlichem Wollenhalar besetzte Scheide hervor, wolche schon im IIai anf' zwei Seiten mit stwas Geräusch anfplatyt und woraus sich die Bliitenrispe an einer Palme (acht bis zehn) entfaltet. An einer einzelnen männlichen lispe zählt man gegen 200 Äste und jeden Ast mit 40 his 80, an der ginnzen lispe 12000 bis 16000 Bliiten, die etwa ein Pfund wiegen. Von den weniger zahlreichen weiblichen bliiten fallen viele mentwickelt ab. Die Befruchtung ist eine kiinstliche. Die mïnnlichen Scheiden werden im Februar, noch ehe sie platzen, abgenommen und anfgeschnitten. Die Rispen werden mit ihren noch unentfalteten Bliiten herausgethan und in die einzelnen Gibehn zerteilt. Diese hebt man auf, bis im Mai die weiblichen Scheiden beim Händedruck ein eigentiimliches Ger:̈̈nsch hören lassen und bringt dic männlichen Bliiten in kleinen Biindeln in die wenig geöffnete Scheide der weiblichen Rispe. um sie zu bestïuben. Die getrockneten männlichen Bliitenrispen lassen sich ein gamzes Jahr aufbewahren. Jedenfalls ist dies die älteste Kumle von dem Geschlechtsunterschied der PHlanzen. Nach der Befruchtung erhalten die weiblichen Bliiten eine grelbe Färbung, sind hart, erreichen in Herlschas Ende Juni, in Ïgypten Ende Juli, in den Oasen der Sahara erst mit den Oktoher ihre völlige Reife. Im Schatten der Dattelpahne werden noch Mais, Gerste, Klec, Tabak, Orangen. Feigen ete. gezogen. Ein ansgewachsener Dattelbaum bringt acht bis rehn Bliitenrispen hervor und tr:igt im Durchschnitt jïhrlich 150 Pfund I)atteh. Der Brottoertrag eines Fruchthames kium mit 4 Mark jährlich angenommen werden. Bei Medina kommen Fruchttrauben in Gewicht vom sol'fund vor. Nan erntet inmer reife, halb- und mureife zugleich. Dic halhreifen werden sogleich gegessen, die unreifen hroitet min auf Matten von Palmblättern ans mul lïlst sie an der Sonne nachreifen nnd trocknen. Anch die reifen Dattehn werden geprefst mul getrocknet his sie fest sind. Dir Inattrlpalmen kïnnen iiber 200 Jilne alt werden, doch lïlst man sie 11ald dem 80. Jahne absterhen, indem man ihnen oben muterhalh, der IBlitter, wo sie die meiste 'Triebkrat hahen, den 


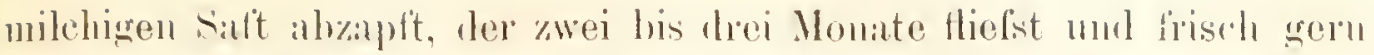
getrunken wirk. Didurch wird dem Bann der siehere Juterging hereitet. - Zugheuschrecken, Ameison mul andere Feinde aus dem Tierreiche kiomen lie grume Erute roruichten.

Nutzen. Die Dattelpalne nobst dom Kinmel maehen alloin die

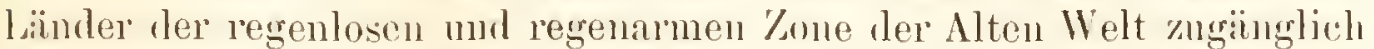
und bewohnhar, nnd es ist an diesen einzigen Wüstenbaum die krhaltung ganzer Völkersehaften (in Nord-Afrika und Arabien) gekniipft. Finige Araber schildcrten einst in einem llafenorte des persischen Goltes dem fianzösischen Orientreisenden die Wiehtigkeit der Dattelpalne mit folgenden Worten: "Sieh' dieses Sehiff, - es ist gleich scinen Masten und Rahen ans Palmenholz; aus Palmenbast haben wir diese Tane gedreht, diese Sesrel grewebt; Dattehn sind unser Proviant, nnd Dattehn fïhren wir als Fraeht naeh fermen Lïndern! So hietet uns die Palme alles. Was wir bediurfen, wonaeh nuser Herz sich sehnt:" - Die Früchte oler Datteln sind frisch, getroeknet und grekoeht senjefsbar und hilden in den Frzeugungslindern ein wiehtiges, mitunter das latuptsiichliehste Nahrungsmittel. Am gesundesten und wohlschmeckendsten sind sie mit Gerstenmehl zu einem Trig greknetet. Man verlangt dort von einer guten Hausfrau, dals sie ihrem Minne einen Monat lindurch täglieh wieder ein anders znbereitetes Dattelgericht (wie in suid-Asien von der Kokosnufs) rorsetzen künne 1). Getrocknet und in Körbe greprelst, oder in Sand vergraben, können die Dattelı gegen zwei . Tahre aufhewaht werden und lieferm das Dirtelbrot (Brot der Wiiste). Sie verderben selbst in der hrennenden sommenhitze nicht (beste Karawanemulurung, wenm genug Trinkwasser' dat ist). Da sie erhitzend wirken, geniefst man sie bei Wassermangel nieht. Den Pewolnnern Algiers sind die Datteln ein beliehtes Tauschmittel. Zn mus kommen sie als Dessertfrichte, finden aber auch vieltiche medicinische Verwendung (gegen Durchfill). Wurch Pressen gewinnt man aus den Frïchten den Dattelhonig mul aus diesem, wie ans dem Salte der Bimme, ein weinartiges Getränk (Pahmwein), das Lieblingsgeträink der Araber. Aueh benutzt man die Dittelı ihres hohen Zuckergehaltes halber zur Branutweinbereitumg. Die Dattelkerne sind eines der bosten Ersatznittel fiir den Kaffee und relon, erweieht oder zu Mehl gemahlen, ein maluhaftes Viehfutter (Kamele, I'ferde, Schafe, Ziegen, Hunde). Man prelist aueh ein Öl diraus. In Mediua giebt es Kaufliden, wo nur Dattelkerne verkintt werden, nurl Bettler lesen in den Stiidton Arahiens die weggeworfenen Kerne auf. Anch das Mark (siehe Sagopalme) der jungen Biimme ist sehr wohlschmeckend. Die zarten Blütenkolben und Gipfelknospen verspeist man als Pahnkolil mo macht sie

1) In der Oase Fezzan leben 1:/20 aller Bewohmer acht bis nemn Monate des Jahres ausschliefslich von Diattrilu. 
ein (l'ahnkiise). Dir (iipfelknospen nimnt man nur ron entwn\%elten Palmen. In Mai xiehen dio wohlhabenden Bewohner der Dattellïnder :nf einige \%eit in die Palmwälder, um sich dort zu erfrischen. Die Blätter vorwendet man \%u allerlei Geflechten, Hausgeräten und

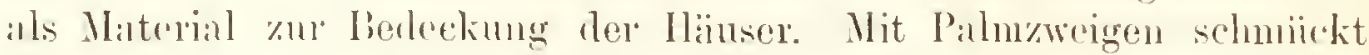
man in rer katholischen Kirche zu Ostern die Kirchen, anch dienen sie bei ïfentlichen Processionen zur Hebung der Feierlichlieit (I'alnsonutag). Dentshe (riintuer riehen die Dattelpalne in Gewirchshïnsern, mu die Wedel zun Sarrgschmuck zu rerkaufen. Aus den Blattfasern, den Battrippen, ans den Fasern, die die jungen Frnchthüschel einschliefsen und den Fasern ans den infseren Teilen des Stammes fertigt min Seile. Matten, Packkïrbe. Gewebe. Sücke u, s. w. Die Blattstiele verwendet man \%u Stöcken nud eingeweicht nul dinn geklopft \%u liesen. Aus dem Faserstoff. der zwischen IBlättern und Stamm wïchst, nacht man Seile und Segeltuch, Waschtiicher u. s. w. L'm eine andere Art I'alnwein zu gewinnen. bohrt man unter der Blïtterkione in den Stann ein Loch, ans welchem dann ein triber, sïlshicher Saft (Lagbi) thiefst. der ein erfrischendes Grotrïnk ist, nach wenigen Stunden in Gürmug iilergeht nnd dam heranschend wirkt. Das Dattelholz liefert Brenulul\% mul Banholz nur 7.n leichten Banten (Häuser in Fessinl). Es nimment Politur an.

Bestandteile der Frucht. Die Frucht besteht atus 10 Teilen Kern, 5 Teilen Schlale und 85 Teilen Fruchtfleisch. Das letytere enthält 30 Pro\% Wasser, 36 P'ro\%. Zucker, 2:3,25 Pro\% Eiweifsund Extralktirstoffe, S.5 Pro\%. Pektinkörper, 1,5 Proz. Cellulose und Cumarin (daher der Wohlgesehmack).

Warenkunde. Frische Dattehı haben eine glämende, rumzlfreie Oherfliiche, gelb-rötliche inufsere Farhe sattiges, speckiges likeisch, honigsiifsen, weinigen Geschmack und sind erquickend. Geschmmptte, runzlige, zn teuchte oler saftlose Ware tangt nichts. In alten Dattehn klappert der Kern heim Schuitteh. In Biskra, der hekamntesten mod gröisten Oase des Rezirks Zihan in der algerischen Provinz Constantine, wird die Dattelpalme an sorgfinitigsten kultiviert und hier er\%engt sie die rorkighlichsten Frïclite. Die Ungehnng ron Laghonat in Siiden der Prorin\% Algier ist ein anderes wichtiges Prorluktionsgebiet. Aus beiden Gobieten bringt nan zwei Qualitäten, Deglet nour, die bessere (30) Franken fiur $50 \mathrm{~kg}$ ) und Ghars, die geringere (16 bis 20) Lranken fiir 50 $\mathrm{kg}$ ) in den Hantel. Vor\%iggliche Datteh kommen anch aus der Oase Goleall1) in der Salara. Anch Manoklio, Thuis mul Ober-Ägypten hringen feine Batteh herror. Sach Europa

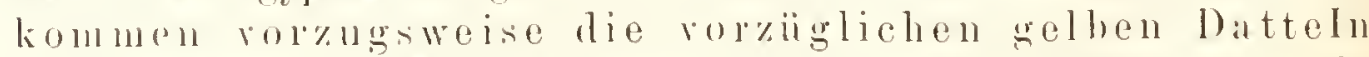
von liosetta und Burlos, welche mit besonderer sorgfalt gesehïlt, entkernt mul in \%ucker mit Citronenessenz cingekocht sind. Im

1) Wo ïbor 16000 fruchttragende Dattelpalmen septleat werden. 
Limphastgebiet unterscheidet man fiinf Sorten: Hullowi (300 Mark die 'Tome), Zohedi (260 Mark die Tomne), Khntherawi (225 Mark die 'Tome), Braemi (200 Mark die 'Tomne) mul Sayr (140 his 180 Mark lie Tome).

Statistische Notizen. Nich Deutschland gelangen jührlich iiber 10000 Pfund Datteln. In Spanien zu Elehe, siidistlich vou Alicante, ist ein heriihnter Palmenwalı von 60000 Stïmmen, der auker Wodeh zu religiösen Kwecken auch siifse Früchte bietet. Bei Bordighera (ligurische Kiiste) steht ein Dattelwald ron ïber 4000 Stïmmen. er liefert nur Palmzweige für den Palmsonntag der Christen und im Herbst für das Laubhiittenfest der Juden. Unu die teneren weil'sen l'alnzweige zu crzielen, werden von Hochsommer an die Kronen oben zusammen gebunden, so dals die immersten Blïtter, rom Licht unberührt. kein Blattgrïn erzengen können und dann ein Bild nicht blofs des Sieges, sondern auch der himmlischen Reinheit abgeben.

Nur die getrockneten Frïchte der Dattelpalme ans den Erzengungsgebieten des Nordens ron Afrika und des Sürlwestens Asiens gelangen in den Welthandel. Im suidlichen Algier sollen etwa 4 Millionen Palmen einen jülnlichen Ertrag von 3 his 4 Mill. Doppelzentnern Dattelı geben. Die Dattelpalmenstever ist in Tnnis die wichtigste Eimnalmequelle fiir die Regierung. Verstenert werden anmähernd 1 Mill. Fruchtböume. Die Jahresernte wird auf 150000 Doppelzentner in Werte ron 9700000 Mirk geschätzt. Tun fuilurt jühnlich über 20000 Doppelzentuer aus. Es werden aber wegen der hohen Stener beträchtliche Mengen ïber die Grenze ron Algier geschmuggolt. Aus Marokko gehen nur 2500 Doppelzentner Datteh ins Ausland (England). In Ấgypten geben die 4 Mill. verstenerten Finchtpalmen einen Jahresertrag von $71 \frac{1}{2}$ Mill. Doppelzentne'n Dattehn, von denen ein hoher Prozentsatz zur Ausfulm gelangt. Aden (Arabien) fiulnt etwa 32000 Doppelzentner Datteln aus. In Euplatatgeliet beträgt die durchschnittliche Jalıresernte an Dattehn l Mill. Hauptlandelsplït\%e sind liagdad und Rassorall. - Fngland bezieht jälırlich etwa 47500 Doppelzentner Datteln.

Geschichte. Keine Pflanze hat in Religion, Geschichte und Dichtkunst eine so wichtige Rolle gespielt, wie die Dattelpalme; nicht der ägyptische Lotus, nicht die celtische Mistel, nicht die französische Lilie. noch der normämnische Ginster. In der Bibel arscheint die Dattelpalme als Simulikd der Schönheit und des Sicges. Nach Aristoteles und Plutarch wurde die Palme als Siegeszeichen gewïhlt, weil nämlich Palnhlol\% sich unter Lassten werler krümme noch bengr, sonder'n sich stets gegen das drïckende Gowicht ansilehe. Siegern wurden deshall, Pahmzweige als Siegeszeichen geweiht, ilmen voratusgetragen, auch wurden die Wrge damit hestrent. Palmzweige (können nur von der Dattelpalme gewesen sein) wurden ansgewihlt, den einen

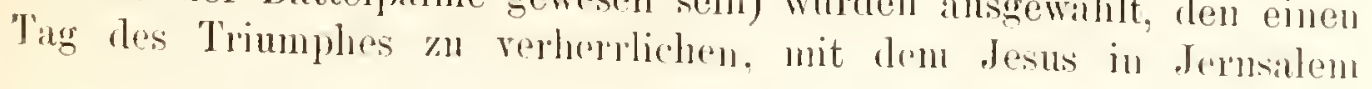




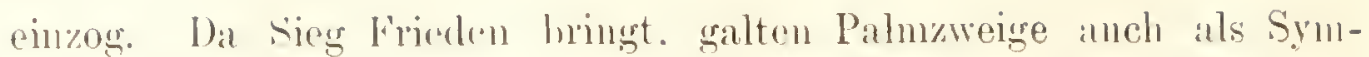
bol des friedens, nud da dor 'Tod als sieg iiber das Lehen anuxchen wirl, anch als symbol des ewigen Frierlens, der Seligkeit mud Cnsterblinkoit; anch Engel wmolen spaiter nit Pahnzweigen in den Hiinlen dil'westellt. Jer Name Phönx ist identisch mit den Phönix in der Fabel. den man ans semer Asche wieder erstohen liefs, wie die l'ahmen sich fortwïhend dureh nene Bhattriebe wieder verjïng口n. Die ältesten Nichrichten kemnen die Dattelpahne noch nicht als fruchthamm, die líunst der battelverodelmug soll an nuteren Enphrat und 'Tigris von den babylonischen Nabatïrm zuerst erfunden und geiibt worlen sein. Von hier wurde die finchttragende lattel nach Tericho, Phönizien u. s. w. verbreitet. Von den Phöniziern erhielten die Grichen den Baum, die reshalb das Land jener Phönike, 1. i. Dattelland namnten. Iuf jüdischen, phönizischen, karthagischen mul später auf gricchischen Miinzen kommt die Dattelpalme als Sinnbild des Landes vor. Die Ilias weifs von der Palme nichts. in der Odyssee wird der Palme auf Delos gerlacht. Odysseus rergleicht dort die Gestalt der kimiglichen . Inngfrau mit der schlanken Bildung der Dattelpalme, wie anch der Sänger des hohen Liedes $(7,8)$ : „Dein Wuchs gleicht rer lalme - ". Kïmigstïchter tragen in Alten Testament den Namen Dattelpalne (Tumur). Die tunica palmata war schon, als liom noch ganz klein war, mit den Blattformen der morgenlänlischen Dattelpalme gestickt. Doch wurle diese Palme damals in Italien noch nicht gebaut, anch war die Frucht noch nicht Handelsartikel. Nach Heln ist das Wort Dactyhs (I'h. dactylifera) aus dem semitischen entlehnt, welches nichts mit .Finger.. (griechisch ductylos) zu thun lat, und kommt erst spaiter zur Zeit der Antonine vor. Es ist in allo romanischen (italienisch dattero, spanisch detit. französisch datte) und anch in die germanischen sprarhen (dentsch Dattel, diinisch Daddel) iibergregangen. Andere nehmen an, dafs sich die Broeichmmng dactylus auf Finger wegen der Gestalt der Frichte heziehe. - Dem Araber ist die Dattel sein Ein mul Alles, er betrachtet sie als ein Glied der tamilie. Mls Aluh den Mensehen schut, blieh etwas von

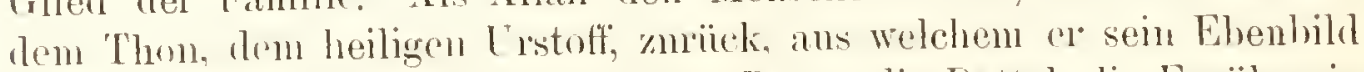
formte; darans bildete a den heilignen Baum, die Dattel, die Erubihrerin ler Hiilfsbediuftigen. Datteln gröinen neben dem Grabe rlos l'ropheten. P'alnenwildler veranlafsten die Hirtenstïnme zur Griumbng fester Wohnsitye. Hine ansgezeichnete Pahue war der eigentliche Gottrshanm. Ein Stein dabei bildete den Tisch, wo dem Gott die Opferabue. dargebracht wmole. Seme Gegenwart giebt der l'almengeist dnuch bewegung kuml. „Wen der Hanch Gottes leise sich aufmacht. lanschen die Yweige, hohen und senken sich, wiegen sich hin und wierler und erteilen Orakel, die der Kindige, der Priester mol Horracher, dentet." lin solches Orakel war in Karlesch, jenen Orte, wo die Gemeind, lsads lange \%eit himdureh den Mittelpmulit ilues sitzes 
hatte. Ans dem Palmenkultus cutwickelte sich die theokratische Verfassmug. Der Hain Mamre war ein Palmombain, in welehem der Bumdesgott Abrahams wohnte. Auch Betel war eine solche Stiitte. As dieser Kultus der Dattel in die benichbarten Iänder answanderte, artete er zum Dualismus und zur Vielgötterei ans. - In Ägypten ward die Dattelpalme zamm Zeichen fuir den Wechsel des Jilhres, die cinzehen Fiederbliittchen ihres Wedels deuteten die Monde nund Tage an. In Spanien pflanzte der Kalif A hdorrahminn uns Jalu 756 11. Chr. die erste Dattelpalme in einem Garten bei Cordova. von der alle übrigen in Spanien ahst:mmen sollen. - Dic Dattelpalme gah, dis erste Muster für Säulenreihen oder Colonuaden, wolche dir Tempelbauten in Ägypten und Griechenland zierten. Der Stamm der Palme ward zum Schaft, die Blätterkrone z:11m Kapitäl der Sänle, das später durch andere Motive ersetzt wurde. In der mittelalterlichen Architektur lat die Dattelpalue das Iotiv zum Spitzbogen gegehen, der durch zwei aufstrehonde und sich kreuzende Pahmblätter gebildet wird. In unseren Yiinstern sohen wir nicht blofs den Spitzhogen, sondern die ganze Form der Dattelpalme nachgebildet. Die Rippen, welche von den Pfeilern, die das Gewölbe stiitzen, auslanfen und sich in die Wölbung fortsctzen, haben genau den Zug und Schwmg wie die Blätter der Dattelpalme, und es ist das hinaufgezogene Kapitäl selbst, welches mit jenen anderen Pfeilern zusammenstehend, hier das Gewölbe bildet.

Phoenix silvestris ${ }^{1)}$ Roxb. in Ostindien wird daselbst zur Zuckergewinnung kultiviert und dient bei uns als Zimmerpflanze. Phoenix reclinata 2) Tacq. licfert efsbare Friichte. Ihre Blätter dienen 7.u Flechtwerk. Wird bei uns als Blattpflanze rerwendet.

1) Wild wachsend. - 2) Zuriickgekrümmt. 


\section{Tafel 3.}

\section{Echte Sagopalme ${ }^{1}$ ) (Staqu. $\left.{ }^{1}\right)$ Pumpliii²) W.).}

Die Gattung Sagopalme (Sagus W.). Bhitenkolben ohne gemeinschaftliche Bliitenscheide, von mehreren unvollstaindigen umscheidet. Blïten in stiehrunden Kätzchen, durch ein schuppenförmiges Deckblatt getrennt und mit einem becherförmigen sehr dicht zottig gebärteten Decklliittchen ungeben. Kelch dreispaltig, Bhumenkrone dreiteilig. Staubblätter sechs, pfriemlich am Grunde verwachsen; Stanbbeutel anf dem Riicken befestigt. Die weiblichen Bliiten verwachsen endlich in eine Pyrunide. Frucht zapfenförmigg.

Die echte Sagopalme (Sagus Rumphii W.) ist gesellig, hat eine vielköpfige, dichtfaserige $\mathrm{W} u \mathrm{rzel}$, bleibt lange strauchartig und ist dann von Stacheln starrend. Ist der Stamm $2 m$ hoch, so fallen die Stacheln ab. Der ausgewachsene $\mathbf{S t a m m}$ ist 8 bis $10 \mathrm{~m} \mathrm{hoch}$ und $60 \mathrm{~cm}$ bis $1,5 \mathrm{~m}$ in Durchmesser dick, cylindrisch, mit nuregelmiilsig querlaufenden Narben, die von den albgefallenen Blättern lıerrïhren. Die Palmenstämme haben die liiirtesten Teile aufserhalb und imnen statt des Kernes ein schwammiges Mark. Die Holzschicht ist nur $: 3$ bis $4 \mathrm{~cm}$ dick.

Blätter (Wedel) ziemlich aufrecht, iiber 6 m lang. Wedelstiele nuten von der Dicke eines menschlichen Schenkels, in eine $90 \mathrm{~cm}$ lange und $30 \mathrm{~cm}$ loreite, feste, lederige, den Stamm umfissende scheide verbreitet, auf der oberen Seite ansgehöhlt, anf der unteren zugerundet und vorziighich an der scheidigen Basis mit zahlieichen "querlatufenden Reihen schmahpfriemlicher 2 bis 4 em langer, gerader, graner, abfallender Stacheh besetat, inwendig mit schwamnigem Marke. Wedelspindel am miteren Teil Hach, an oberen linten rimig. Blït chen dicht neheneinander, finst gegenstindig, and'gerielitet, linealisch, zugespitzt, 55 lis $110 \mathrm{~cm}$ ling, 3 bis $5 \mathrm{~cm}$ breit, fest, glatt,

1) Sagru, siehe "Geschichte". - 2) Rumphins (gehoren 1627 in Hanan, gestorloen 1702, lebte lange auf Amboina und gab cin . Herbarium Amboinense" herans) beschrieh diese l'alne zuer'st genaner. 
dhukelgrin. Diese Palmo treiht nur eimmal in ihrem lehen einen Blütenkolben ans der Mitte der biatter hervor, narkdem der Bannm völlig erwachsen ist und alle Stacheh der Blattstielo verloren hat. Das anfings dicke, oben diinnere, geraddr Horn ist mit ricgeldachigr znsammengewachsenen Bhiitenscheilen hedeckt, ans denen, wem sie zerplatzen, acht his elf erst anfgerichtete, damm ansgespreizte oder nickende 2 lis :3 m lange Bliitenïste hervorbrechen, die wieder dichter stehende Nebenïste (Fig. 2) haben, die zweizeilig nud 25 his $40 \mathrm{~cm}$ lang sind, so dafs der Bliitenkolhen selur grofsartig anssicht. Die Blütenscheiden sowohl der Haupt-als der Nebenäiste sind röhrig, an der Niindung nnd scitwärts abgestutat, lederig und anl'sen mit feinen Stachelı beset\%t. Kätzchen (Fig. 2 unl 3) жveizcilig, abstehend 6 bis $10 \mathrm{~cm}$ lang, fingerdick, alle in derselben Linie liegend, walzenförmig, mit Deckblättern nnd kleinen Scheiden und Deckblättchen dicht-spiralig bekleidet, zwischen denen aus sehr dichtstehendem, fahlgelbem Zottenlaar die Bliiten einzeln hervortreiben. Deckblätter halbkreisförmig, cinige Millimeter hoch, lederig, bram, glänzend, Deckblättchen kamm $1 \mathrm{~mm}$ hoch, an Grinde der Bliite zilsanmengedrüickt nnd dünnhäutige Becher bildend. Blüten mngefähr $3 \mathrm{~mm}$ lang, brämnlich, vielehig, einhäusig. Kelch (Fig. 4) glockenförmig, dreispaltig, mit eiförmigen, spitzen, angedrïckten Zipfeh. Blumenkrone (Fig. 4) noch einmal so lang als der Kelch, tiefdreispaltig, mit länglich eiförmigen, ausgehïhlten Zipfeln. Staubblätter (Fig. 5) sechs, in den männlichen Bliiten von der Lünge der Blumenkrone, in den weiblichen viel kiirzer und ohne Staubbentel; Staubfäden (Fig. 5) unter der Rïhre der Blnmenkrone angewachsen, oberwärts frei, pfriemlich; Sta u b be utel linealisch, an beiden Enden ausgerandet, am Riicken angeheftet. Pistill (Fig. 6) so lang wie die Staubblätter. Fruchtknoten (Fig. 6) kngelig oder kegelfürmig; Narben drei, verlängert, zusammengewachsen.

Frucht niedergedruickt-kugelig (Fig. 7 1. 8), ott nugleichförmig, am erhärteten pfriemlichen Griff endigend. im Durchmesser 11/2 Daumen dick, mit 17 bis 18 Reihen Schuppen bepanzert. Schnp pen rautenförmig, fast knochenhart, glänzend, lange grünend, endlich eine strohgelhe bis braunrötliche Farbe ammehmend, am schmalen Rand gran oder hraun. Samen (Fig. 8) einer, fast kugelig, fein gerunzelt. Samenschale diinn, Fiweifs sehr hart. Nach der Frnchtreife wird der Stamm hohl und stirht (im 20, hïchstens 30. Jahre) al.

Vaterland. Die echte Sagopalme ist von den kleinen Insehn, welche der Westküste von Sumatra vorlagern, bis nach Neu-Guineil iiber die Inschwelt des Indischen Oceans verbreitet nud tritt daselbst vornehmlich in sumpfigem Boden anf. Anf Nen-Guinca, Celebes, Jindanao, Borneo und Snmatra bildet sie grö́fsere W:ilder.

Kultur. Die echte Sagolnalme wird nur auf einigen lnseln angehaut, olggleich sie sehr leicht durch schirifslinge fortzupflanzen ist. 
Ninnentlich Celehes suchte seine stmmptigen 'Thulgriinde durch snlche

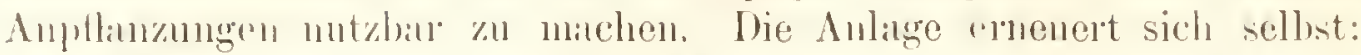
jeden Bann lisst man einen Schölshing treiben. dor seine Stelle einnimme, nachulen ar gofiillt ist. Nach sechs his acht .ahren hringt

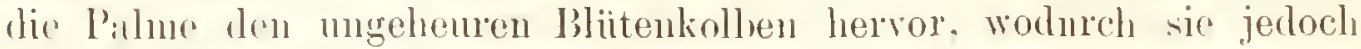
ihre kraft erschiiplt mol nach der lieife der Frucht alstirht. Fine kröiftige l'alne er\%engt (i his 5 \%entuer Mark.

Gehalt des Markes. Das Mark der Sigopalme ist etwis voll holrigen Fasern durchsetzt und bestcht gallz aus Stärkemehl. Stiorke ist einer derjenigen urganischen Stoffe. die in Ptlanzenreiche an häinfigsten mud in anzelnen Pflanzenteilen in grö̈fseren Massen rorkonmen. Sie ist unser wichtigster regetabilischer Nahrungsstoft. Stïrke entsteht nur in dem Blattgrün (Chlorophyll). und alle grünen, beblätterten Pfinzen enthalten diesen Stoff. Von ihren Erzengungsstitten wandert die Stäke durch andere Organe und Gewebe in die Pflanzenteile. in denen sie aufgespeichert wirl, nu später zum Auflatu neuer Organe bei der Entwickelung der Laubsprossen. Keimlinge etc. zu dienen. In den Speicherungsorten der Pfhumen (Knollen, Samen, Friichte und Staimme) simmeh sich also gröfsere Massen ron Stirke und es können deshall, nur diese mit Nutzen auf Stiurke ausgehentet werden.

Sagostärke oder Sago wird atus den Stamme nehrerer Palmen (Sagus Rumphii, Sagus laevis Rumph. und Sagus furiniferu Iarm.). die groifste Menge ron der er'stru. grewonnen und besteht aus teils unverinderten, teils verkleisterten Stärkckörnern. Nach Wiesner sind die Sagnkörner der echten Sagropalme aus zwei his drei 'Teilkürnern zusammengesetzt. ron denen eins durch liröfse auffällt. Die Zusanmensetzungsflichen treten an den Teilk̈̈rnern scharf hervor und geben ihnen ein selu charakteristisches Gepräge. Der Kern rou der Zusimmensetzungsfliche abgewendet, ist ausgehöhlt, mu ihn hermun liegen mehr oder "reniger reichlich matt begrenzte Schichton. Der Sagn besteht aus teils mueräulerten, teils rerkleisterten Stiirkeköruchell.

Gewinnung des Sagos. Die Sagopalmen speichern in Innern des stimmues eine grolse Masse Mark (stïrke) ant, un den mächtigen Bliitenkolben antzubauen. Nach der Bhitezeit ist das Mark relbratucht und die Palme stirht al). Man fallt deshall diese Bïume ror der Bliite, wem sie die gröfste Fiille an Stirke hesitzen. Iin sich davon zu ̈̈herzengen, hohnt ler Malaie vor den Fillen die Palmen an. Die ungehatuenen Bämue wrolen der läinge nach zerspilten umb des Mankes entleert. Mats Mark ist mit holrigen Fisern durchsetzt.

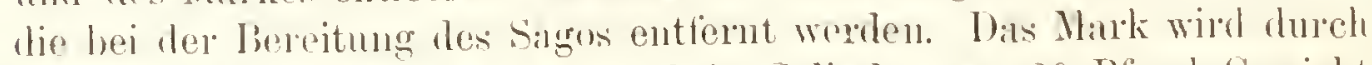
Wasser geschlinmut, das Satzmehl in Cylinder von 30 Pfund rewicht

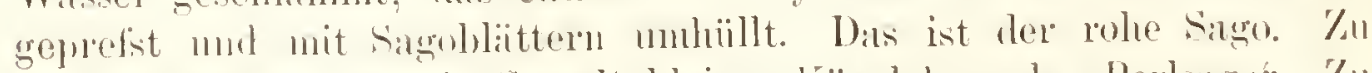

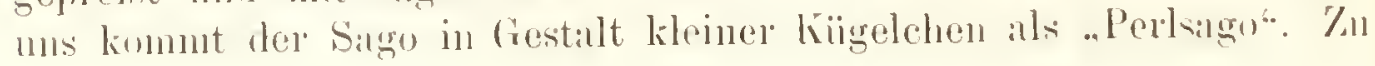


diesen wird er hesmolers in Singapore ron Chinesen durch offteres Ausaschen, 'Trorknen, Siehen. Bentehn, Rösten mul Körnehn in Gefïfsen mit kleinen. rmulen Lüchern znbereitet.

Die Zusammensetzung ron Sagostäke mul Sigromehl ist nitelı lï̈nig folgente:

\begin{tabular}{|c|c|c|c|c|c|c|}
\hline & \multirow[b]{2}{*}{$\begin{array}{l}\text { Wasser } \\
\text { Proz. }\end{array}$} & \multirow{2}{*}{$\begin{array}{c}\text { Stick- } \\
\text { stuff- } \\
\text { substanz } \\
\text { Proz. }\end{array}$} & \multirow[b]{2}{*}{$\begin{array}{l}\text { Nitirlie } \\
\text { Proz. }\end{array}$} & \multirow[b]{2}{*}{$\begin{array}{l}\text { Asehe } \\
\text { Proz. }\end{array}$} & \multicolumn{2}{|c|}{$\begin{array}{l}\text { In der 'Trockeu- } \\
\text { suhstanz: }\end{array}$} \\
\hline & & & & & $\begin{array}{l}\text { Stick- } \\
\text { stoff } \\
\text { I'roz. }\end{array}$ & $\begin{array}{l}\text { liohle- } \\
\text { hydrite } \\
\text { lroz. }\end{array}$ \\
\hline 1. Sagostärke . & 12,90 & 0,50 & 86,24 & 0,36 & 0,09 & 99,01 \\
\hline 2. Sagomehl, weilses & 16.14 & 8,75 & 79,88 & 0,22 & 0,72 & $95,25^{\circ}$ \\
\hline rotes. & 18,83 & 2,57 & 78,06 & 0,53 & 0,51 & 96,17 \\
\hline blaues & 18.47 & 2,45 & 78,16 & 0.94 & 0,48 & 95,99 \\
\hline
\end{tabular}

Nutzen. In Indien wird das meiste Sagomehl zu Brot in linchentorm benutzt; auch macht man einen wohlschmeckenden, mit Salz, Limonen nnd Pfefferschoten gewiirzten Brei daraus. Das in Kuchen geformte Mehl wird in irdene, vorher erhitzte Formen gedriickt und so werden in wenigen Minuten schmaekhafte Kuchen bereitet, welche an einem Rohrstocke aufgehängt in Ostindien anf den Markt gebracht werden und die Hauptnahrung des ärmeren ostindischen Volkes bilden. Die Malaien ziehen der Schmaekhaftigkeit wegen den Reis und andere Feldfiuchte dem Sago vor. Bei uns wird der Sago wegen seiner leichten Verdaulichkeit in Fleischlirihe gegessen. Die Blätter verwendet man zum Decken der Hiitten, die Blattstiele wie Bambus zu Zäunen, Stïhlen etc.

Warenkunde. Der echte Sago ist in kaltem Wasser manflöslich und darf sich in heifsem Wasser nur aufblïhen, erweichen und beim Durchsichtigwerden seine Form nicht ändern. Aus dem Stärkemehl der Kartoffel hat man deutschen oder Kal loffelsago bereitet. Er ist zwischen den Fingern leicht zerreihbar, wirl in heifsem Wasser breiig und zerkocht gïnzlich. Echten Sago erhalten wir selten, gewöhnlich deutschen, oder Sago vom Cycashanm (Tafel 5) odel" von Bataten.

Handelsstatistische Notizen. Singapore ist der Zeutralpunkt des Sagogeschäftes. Es bringt jälulich 350000 bis 370000 Zentuer Perlsago und gereinigtes Sagomehl zur Verschiffung. In Sawarak werden tiaglich 7000 his 8000 Pfund Perlsago fertiggestellt, Labuan auf Borneo fiihrt jährlich etwa fiir 11/2 Mill. Mark Sago aus. Auch in Brunei wirl viel Sago verarbeitet. Man herechnet die jälulich erzengten Mengen Salgo anf 50 Mill. Kílogramm.

Geschichte. Siagu, \. i. Brot, nemen die Malaien das zuhereitete Mark aller Palmen. Marko Polo († 1323) brachte die 
ersten Sigoproben nach Venedig. Ietat wird auch in Westindien (Guateloupe) und sonst noch in den Tropen Sago bereitet. Da man in nenerer Zeit fand, dafs Sago eigentlich nmr ein remeres Stärkenehl ist, so bereitet man ans dem Stïrkemehl der Kartoffel auch deutschen Sago, der denselben Nahrungswert hat, als der echte.

Sagus larvis ') unterscheidet sich von der vorigen dadurch, idals sie keine Dornen hat, liefert aber anch sagomehl.

1) Giatt (ohne Dornen). 


\section{Tafel 4 .}

Drachen ${ }^{\text {) }}$-Rotang ${ }^{2}$ ), Rattang ${ }^{2}$ ), Drachenblutpalme, spanisches Rohr (Calimmus $\left.{ }^{3}\right)$ Iraco $\left.{ }^{1}\right)$ W.).

Der Drachen-Rotang gehört anch zur Ordumng und Familie der Palmen.

Die Gattung Rotang, Schilfpalme (Calcmus L.) verlindet die Palmen mit den Gröserı, indem sie in ihren Bliiten den Palmen und in äufserer Tracht den Schilfgräser'n nahe stehen. Sie hahen abweichend ron den iibrigen Palmen keine Blätterkrone auf den Gipfel. Ihr Stengel ist diinn, schilfïhnlich, ästig und der Lü̈nge nach nit stacheligen und in eine stachelige Rankenspitze anslaufenden Fiederblättern hesetzt. Er trägt da, wo die Blätter abgefallen sind zerstreut stehende Scheiden. Die Bliitenkolben sind achselständig und tragen Bliiten rerschiedenen Geschlechts. Die Frucht gleicht einem umgekehrten Tannenzapfen, ist schuppig und ein- his zweisamig.

Der Drachen-Rotang ${ }^{4}$ ) (Culamus draco W.) bildet erst einen dornigen, 5 bis $6 \mathrm{~m}$ hohen $\mathrm{Strauch}$ mit vielen ruirlartig herumstehenden Ästen und fiederspaltigen Blättern. Aus der Vitte les Strauches wächst ein $3,5 \mathrm{~m}$ langes Horn hervor, welches sich sodann in vier bis fünf beblätterte Äste teilt. Zuletzt kommt der seilartige Stengel, der meist nur $2 \mathrm{~cm} \mathrm{dick}$ und his $190 \mathrm{~m}$ lang (längste Pflanze der Welt) werden kam. Sach mil nich kommen ans einem Strauche drei bis vier solcher Seile mit Grliedern ron 30 his $95 \mathrm{~cm}$ Länge, jedes mit einem gefiederten Blatt. Das Ende

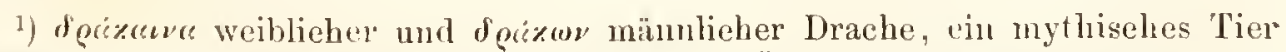
der Alten. auch ein fabelhaftes Tier, welehes die $̈$ pfel der Hesperiden bewaehen mufste. wurde auf diese l'alme (wie auch auf Iracaena draeo L.) ïhertragen, weil der blutrote Saft der Frucht als "Dracheublut" in den Handel kommt. - 2) Oder" Rotting, rotan nemen die Malaien dieses liohr. - 3) Calamus, *idocuos, bei den Arabern kalen, liohr (im allgemeinen). - 4) Abhildungen und cin 'leil der Beschreibung del Pflanze nach Blume (cognomine limphius), limnplia sive commentationes hotanicae imprimis de plantis Indiae orientalis etc. Aul'serden dic bereits oben erwähnten Werke. 
des seiles teilt sich in der liegel zangenartig in zwei lange Hörner, dren kinrzeres zn einem neuen Blatte answächst, wïhrend das längere, in eine lange sehmale linse anslanfend, das Seil fortsetrt, sich von einem Bamme zun andern schlingt und zwischen diesen in grolsen lingen herabhiangt. Das Seil des Rotungs ist vom lispung his zur lainge ron $4.3 \mathrm{~m}$ mit einer dicken Rinde bekleidet und mit geranden. nadelförmigen stacheln hesetzt; von dit ist es kahl und trïgt alle Meter cin Blitt. Unter der Rinde liegt der wahe Strung, welcher in Ostindirn Roting genannt, daumendick, sehr räh und roll kleiner Röhren ist.

Blätter oder Wedel wechselstindig, $2,3 \mathrm{~m}$ ling, gefiedert, unten sehr eng an einander stehend; Fiederblättchen bis $6 \mathrm{~cm}$ breit und his $84 \mathrm{~cm}$ lang, wechselstïndig, am Ende rugespitzt; Blattscheide röhrig, der Länge nach gespalten und zart gestreift, znletzt gellgriin; Stacheln (am Wedelstiel) liäutig, queriber verbunden. geradeans stehend, selten gebogen, pfriemlich, Hach, nach oben immer kleiner werdend, endlich mur einige Nillimeter ling, dunkel gefärbt; Wedelstiele sehr lang, fingerdick, fiıst dreikintig, am Grumle 2 bis $4 \mathrm{~cm}$ hreit. weit iiber die Blättchen hinaus in einen Strang verlïngert, schwach rötlich, im Alter bleich.

Blütenkolben (Fig. 1) polygamisch und \%weihäusig, ans den Achseln der Blätter hervorkommend, $50 \mathrm{~cm}$ hoch aufgerichtet, rou mehreren Blïtenscheiden umgeben; Blüten in lockeren Rispen. die mïmulichen schlanker (Fig. 1) als die weiblichen und mehr zusammengedrüngt; Blütenstiel innerhalb der Scheide der Lïnge nach angewachsen, unten mit kurzen Stacheh bewalfinet; Blütenscheiden je arei am Bliitenstiel (Fig. 1); Deckblätter der kleinen Blattscheide :̈hmlich gebildet, sehr klein, besonders bei den mänulichen Bliiten (Fig. 2); Kelch ku\%, krugförmig, dreizähnig oder-spaltig; Blumenkrone (Fig. 2) dreilappig. Lappen lanzettlich, birnforning; Staubblätter fast so lang als die Blumenkrone, anfrecht; staubfäden miten zusammengewichsen; Staubbeutel länglich-rmnd. Weibliche Blüten an jedem Zweige rier bis elf, doppelt so grofs als die minulichen, blafsgell, im Kelche röhrenfümig; Sta ubbliitter um $1 / 3$ kleiner als die Blunenkrone, unfruchtbar; Fruchtknoten so grofs wie cin Pfefferkorn; Griffel fehlt oder dreiteilig. Der fruchttragende Kulben ist gröfser als der bliitentrigende.

Frucht (Fig. 3 nnd 4) rundlich, eiföming, mit einer knten. dicken Spitze, rot, hedeckt mit einem schwatzrötlichen, gliinzenden, Blut- mad gummiälnnlidien Stoffe (Drachenhlut), so dals die Form der Schuppen kamm unterschieden werden kimn. Schuppen vireckig. hreiter als lang, dachriegelförmig über cinamder liegend, nach riickwïrts gerichtet: Samengehäuse, an wekhem sich die schnpen hefinten. sehe dick. 
Samen das linchtgehäuse kinum ausfiillend, moten rundlich, der liinge nach gestreift.

Heimat und Verbreitungsbezirk. Ostinlien (dival, sumatial). Das Iand der Batacks in Sumatra bringt die besten Stimme liervor:

Die liotang-Arten werden nicht angebaut; sie wachsen in Menge in sumptigen Wailderu mul mathen dieselben mit ihren seilantigen Stümmen und $̈$ isten, mit denen sie die Bäume umschlingen, und mit ihren stacheligen Blätter'u fast undurchdringlich.

Gewinnung des Rohres. Der frische Rotang greift sich klebrig an und enthït einen scharfen Schleim, der sich, in Sand und Wasser abgerieben, rerliert. Er träigt selten Friichte. Die Eingeborenen schlagen die Stämme mit einem Hackmesser ab. Das geschlagene Rohr wird zu nuterst auf ein Stïck abgeschält, dann in eine Kerbe gelegt, die in einen Bammstamm geschnitten wurle, und kräftig durchgezogen. Damit ist das ganze Rolu, so weit es von gleicher Dicke ist, in einem Zuge von Oberhant, Blättern und Dornen befreit. Die Rolure werden in der Jitte znsammengehogen und in Bïndel zu 100 Stiick zusammengebunden. so difs sie nur die halbe Länge der Rohre haben. An diejenigen Stïcke, die man zu Handstöcken bearbeiten will, hängt man Monate lang ein Gewicht oder bindet sie fest an eine Latte mnd räuchert sie. Die ringförmigen Knoten des rohen Rohres werden aut besunderen Maschinen durch Śchaben oder Schleifen entfernt.

Nutzen der Pflanze. 1. Das Rohr der Rotang-Arten wird in grofsen Mengen in Indien, China mu Japan und auch in Europa (untel dem Namen spanisches Rohr) ${ }^{1}$ ) und Amerika zu verschiedenen ' Zwecken verwendet. Guter Rotang ist fahlgelb, glänzend, geschmeidig. In den Evzeugungsländern und in Japan fertigt man ans demselhen tausenderlei Dinge, sogar Schränke mit Schublaulen, allerlei Band- und Flechtwerk, alles Tauwerk der südost- und ostasiatischen Fahrzeuge, Stühle. Kürbe, Stiele für Pfeile und Spiefse u. s. w. Bei uns rient das dünne gelbliche (weibliche) Rohr zu Stuhliohr (Stuhl-, Schum-, Bind-, Bund- und Flechtrohr), das dickere, dunkelfarlige mit enger stehenden Knoten (mïnliches) zu Spazierstöcken, die dïnnen Ranken zu Stöcken in Regenschirmen und zu Regrensehimmrippen, als Ersitzmittel für Fischbein (friber als praktisches Erziehungsmittel). Die kleineren Stücke werden gespalten zu Stuhl-, Corsettrohr, die diimmsten Stiicke werden als steifender Stoff in der Putzmacherei als Schum - oder Putzroh" verwendet. Vou Calamus motrung kommen die stiirksten stïmme, von Calumus scipionum die Malakka-Riohrchen des Handels. 2. Dio Friichte des Drachen-liotang schwitzen ans ihren Schuppen ein dunkehotes Hal\% ans, das sogellannte Drachenblut (Sanguis Iraconis). Man gewinnt es, indem

1) Wird auch vou Arundo donax gewonnen. 


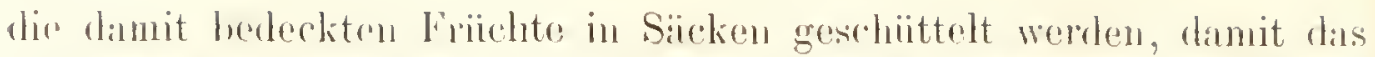

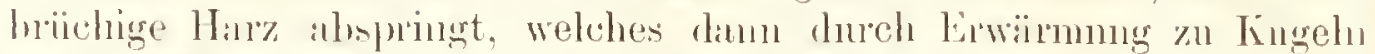

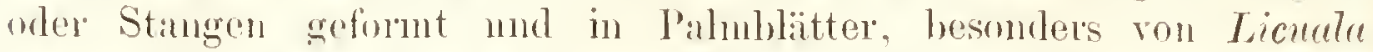

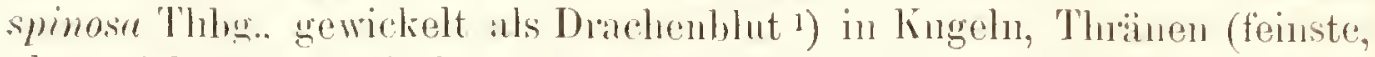
aber vielfirh rerfailschte Sorte) und Stangen in ren Handel kommet. Wurch Kochon des liestes mul der gestampften Frichte erhält man die schlechteste forte in zolldicken, viereckigen Kuchen. Das Drachenblut in 'Tafehn ist gewöhnlich nit Kohophonimm nurl gepnlverten roten Sindelholz vermischt. Das Drachenbhut lïst sich in Weingeist, Alkalien nnd Essigsänre leicht anf und besteht bis zn 90 Prozent ans einem rotgefärbten Harze, dem Dracin. Es dient seiner znsinmenzichenden Wirkung wegen zu Zahnpulver und Zahnutinkturen (bei leicht blutendem Jahnfleisch), sowie zu verschiedenen Lacken, zu Goldtirnifs-Lacken fïr Naler und Polierer und auch zur 'Tischlerpolitur. 3. Tou einigen Rotang-Arten werden die jungen Triebe gegessen. 4. Die Calammsarten siml ron grofser Schönheit und bilden eine Zierde der Palmenhämser. aber sic sind riemlich emptintlich und ats Kimmerptlanzen kaum mol erlualten.

Handels statistische N otizen. lie holländische Handelsgesellschaft führt jährlich ron . Irva und anderen hollindischen Inselı etwa 400000 Bündel (à 100 Stïck), die Engliunder etwa 73000 Biindel von ihren Besitzungen aus. In Borneo grelten 100 Bündel fïinf spanische Dollar. An der Westküste Afrikas, vorzugsweise am Niger nud Kimmerun. findet ein Handel in Rotang statt.

Geschichte. Die alten Griechen kamten den Drachen-Rotang nicht, wohl aber das Drachenbhut und nanuten es schlechtweg Indicrim, weil sie es aus Indien erlielten. Sie henutzten es zur Bereitung einer kostbaren roten Fabbe orler 'Tinte und ubertrugen deshall den Namen auch anf den Bleizinnober, minim der Rïmer, den wir Menuige nennen. Das canarische Drachenbhut (vou Dracuena draco) war friiher ein bedentender Handelsartikel von Madeira aus und findet sich anch in den Gräbern der Gmanchen (Creinwohner der Canarischen Inseln), welche dasfelhe wahrscheinlich zur Einbalsanierung ihrer leichen benntzten.

Aulser dem Drachen-Rotang sind noch ron Berleutung: Calamus Rotang W. (Routtan-liohr, spanisches Rohr), Calames verus IV. (spanisches Rohr, Stmhlrohr, Flechtwerk), Calamus viminatis II. (... Tava-

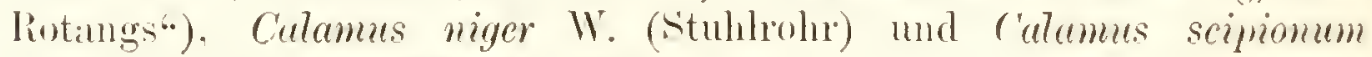
I، (1ur:2) (siehe oben „Malakka-Riohrchen“).

1) Drachenblut liefern auch Dracaena draco und Pterocarpus draco. 2) icipuo, Stab der beanten und Vornehmeren unter deu Rïmern. 


\section{T a fel 5 .}

\section{Grofsblättriger Sagobaum ${ }^{1}$ ) \\ $\left(C_{y}\right.$ cas $\left.^{2}\right)$ circinalis $\left.^{3}\right)$ L.).}

Der grofsblättrige Salgobilum ${ }^{4}$ ) gehört zur Klasse und Familie der Cykadeen, Sagobäume oder Palmfarne (Cycadeac $^{2}$ ) oder Fron(osae) i).

Die Klasse und Familie der Cykadeen (Cycadeae). Tropische, baumartige, sehr spärlich oder gar nicht verzweigte Gewïchse, the in ihrem Anssehen an die Palmen und in manchen Dingen an die Farne erinnern. Der Kieinling ist in dem grofsen Eiweifs eingeschlossen (Fig. 6) und besitzt zwei ungleich grofse (opponierte) Samenlappen. Bei der keimung springt die Samenschale am Hinterende auf und entläfst die anfangs kräftig fortwachsende Hauptwurzel. Die Samenlappen bleiben im Eiweils, um dort die Nahrung aufzusaugen, verlängern sich, und schieben dadnrch ihren unteren Teil mit der zwischen ihnen liegenden Kieinknospe (Plumula) aus dem Sameu himaus (Fig. T). Der Stamm ist anfangs ron der Form einer rundlichen Ḱnolle, später verlängert er sich zu einer plumpen Süule, nur bei wenigen Arten bleibt er knollenförmig. Die ganze Oherfläche des Stammes ist mit spiralig geordneten Blättern besetzt. Die Blätter sind von zweierlei Gestalt, schupenfürmige trockene hraune, welche die Stammoberfläche dicht bedecken, und grïne einfach gefiederte oder fiederteilige, gestielte Laubblätter von meist lederartiger Beschaffenheit, welche eine prächtige Lírone am Ende des Stammes hilden. Beide Blattarten werden ahwechsehnd periodisch gebildet; in jeden oder jedem zweiten Jahre entsteht eine Rosette von grofsen Laubbüttern, zwischen denen sich nuи die Terminalknospe des Stanunes mit Schuppen umhiillt, unter deren Schntz der nene Laubblattcyklus laugsann sich heranbildet. Die

1) Blume, Humphia sive commentationes botanicae imprimis de plantis Indiae oricntalis; Miquel, Monographia Cycadcarum. - ${ }^{2}$ ) Kúxes bei 'Theophrast ist der Aceus. plur., xoıx Gärt. eine Palme, aus deren Blättern liastdccken geflochten wurden. - ${ }^{3}$ ) Mit schneckenliniø-gerollten Blättern odcr Wedeln. - ${ }^{4}$ ) Fälschlich Sagopalme geoannt. - 5) Froudosus d. i. laubartig, laubtragend, belaubt, auch wedeltragend. 


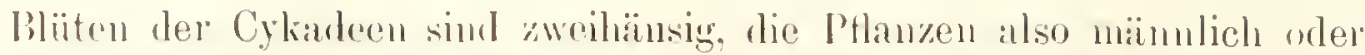
miblich, und bilden ronktämblige \%apten. Sie haben keine hesondere biitculiille, sondern bestehen ans einel Achse, welche in dem einen Falle dicht mit Stambbliattern heset\%t ist num in lem anderen die Sinnenknospen trögt. Die mämblichen Blïten bestehen ans einer mit schihlformigen Stanbhlättern, die nuterseits die Pollensäcke tragen, besetzten Achse, mol enimern sehr an die Sporangienähren ler Equiseten. Die weiblichen sind grols, mit hreitem Grunde sitzend, gerarle und entwickeln sich am rerholzenden Fruchtzapfen zu Samen, welche eine iufsere Heischige, oft lebhaft gefinbte und ene innere knöcherne Schile. ein hartes Sameneiweils nud in der . Mitte resselben cinen geraclen Keinling nit langer Wu\%el und жwei nugleichen, an ihrer spitze verwachsenen Simenlappen besitzen.

Die Cykadeen koumen an zahıleichsten in Amerika. spärlicher iu der Alten Welt rol. Einige kommen auch am Kap der guten Hoffumug und anf Neulollind vor. An der vorwelthchen Flora sind sie wesentlich beteiligt und charakteristisch fïr das Oolithengebirge. Mehrere Cykadeen nuitzen durch das stirkereiche Mlehl, die geniefsbaren jungen Werlel mul die Friichte.

Die Gattung Sagobaum (Cycas I.). Meist astlose Biume mit cylumischem Stamm, welcher an seiner Spitze eine Krone schüner; fiederförmig geteilter, lederartiger, werlelförmiger Blätter träigt, in Ieren Mitte sich die grofsen Fruchtzapfen entwickeln. Die Stiunme enthalten ein grofses, an Stärkemehl reiches MI a rk, welches durch einen geschlossenen Ḱreis von Gefälshiindeln von der Rinde geschieden ist. Diese Stränge treten in horizontaler Richtung dnrch die hinde in die Wedel. Sie bestehen ans einem Hol\% - nurl einem Lastteil. Zwischen Holz nul Bast zieht sich ein geschlossener Kambinmring hin, der das dimernule Dickenwachstum vermittelt. Der Wechsel von Schuppen und Laubblattcyklen beginnt schon mit der Keimnıg, ..indem auf die laubblattïhulichen Kotỵledonen eine Anzahl von Srhuppenblïttern folgt, welche die Kinospe der Keimptlanze einhïllen; ans dieser contwickelt sich dann gewöhnlich nul ein gefiedertes noch kleines Lanbblatt, "orauf wieder Schmpen folgen. Erst mit munehmenter Erstarknng der mehrjäluigen PHanzen treten anch die Laubbliitter, und deren immer grofsere, in Cyklen ant, nu dann, nachlen die älteren abgestorben sind, die jerlesmalige pahnenähnliche Battkrone danzustellen, wïnent greichzeitig die dariber stehenden Schuppen die Stanmbinospe einschliefsen. In dieser werden dic Ianhblätter so weit vorgehildet, dals sie schliefslich, wenn sie die Kuospe sprengen, sich

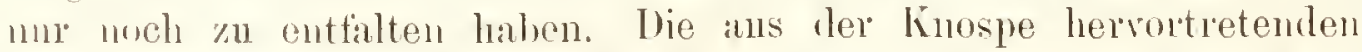

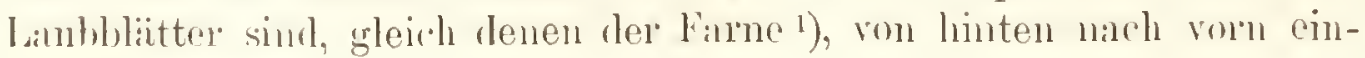

1) Sicho Zippel-Bollnaun, Reprö̈sentauten einheimischer l'tanzentamilien

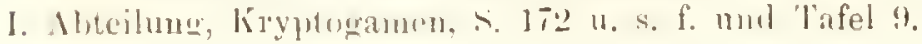


gerollt". - Dic weibliche libite ist cine mn' wenig verinderte laubblattrosette des Stamme's, „desson Scheitel iiber derselhen wieder \%nnïichst Schnpenblitter und dann nene Lambblatteyklen bihlet; der Stamm durehwächst hier also die weibliche bliite. Die mïnnlichen Bhiten durchwachsen nicht; hei ihrer (vermutlich) seitlichen Stellung (siehe muten) kiun sich der Stamm durch seine lindknospe fortsetzen, die den psendoterminalen Kapfen zur Seite wirft. Dic einzehnen finchthliitter sind zwal viel kleiner als die gewöhnlichen Laubblitter, aber in wesentlichen ebenso geformt wie diese". Frucht einer Steinfrucht iihnlich, einsaning. Kiein in der Mitte des sameneiweilses, ungekehrt. das Wiirzelchen oben, sehr lang beanhï 11 giselt (Fig. 6).

Grofsblättriger Sagobaum (Cycas circinalis L.) 1 ). Stamm 12m hoch, 60 cu in Durchmesser dick, der Stamm der weiblichen Pttanze gewöhnlich stïrker, aufrecht, einfuch, sehr selten :n der spitze in einige Aste geteilt, cylindrisch, geringelt, etwas höckerig, mannfikig, unten entrindet, nach oben würfelig-lö̈ckerig und in der Nïhe der Wedel rou breit-dreieckigen, lauggespitzten, lederartigen tilzigen, helhoten Schuppen ungehen. Wedel zahlreich, um die Spitze des stimmes in einen weiten Schopf zusanmengestellt, 2 bis $2,5 \mathrm{~m}$ l:ung, anfings steif-aufrecht, damn abstehend, im Unuange länglich, mp:tarig getiedert, an jeder Seite mit 80 bis 100 uach der Spitze hin kleiner werdenden Fiederblittchen versehen. Wedelstiel 30 bis $60 \mathrm{~cm}$ lang, stieh'und oder ummerklich vierseitig, anf dem Riicken gewölbter, an der dicksten Stelle einen Finger hreit, tief griun, am Grunde sehr verbreitet, aufsen höckerig und hier sehr filzig, fahlgelb, nach oben zerthiefsend iblerzogen, oben am Grunde abgetlacht, auf jeder Seite nugetïh 20 bis $30 \mathrm{~cm}$ iiber den Grunde mit kleinen Dornen oder mansgebildeten Bliittchen besetst. Dic Spindel des Wedels ist dem Wedelstiel gleichgeformt, unbewaffinet, ohen allmillılich bis zur Dicke einer Entenfeder verdiinnt, an der oberen Seite tief' griü, an der unteren blasser, an den Seiten aus den Grunde der herablinfenden Blättchen ein wenigr berandet, bei nenen Wedehn nit einem dïnnstehenden, feinen, bräunlichen, albwischbaren Überzug versehen, bei älteren klebrig. Fiederblättchen meist schief eingesetzt, einander sehr geniihert, ausgehreitet, oft sichelförmig riickwärts gekrimmt, linealisch, pfriemlich zugespitzt, am Grunde etwas verschmälert, ungefähr $30 \mathrm{~cm}$ lang, einen halben Daumen breit, meist sitzend, an der Spindel des Wedels etwas herablaufend, die nachfolgenden etwas kiurzer, mit Henkeln (ansata) versehen und mehr rückwärts geneigt, fast alle flach, nach dem Rande ein wenig rïckwärts gekriimmt, oft etwas wellenförmig, lederig, klebrig, glänzend, mit beiderseits stumpf hervortretendem Nerr, oben tiefgrün, unten hell-

1) Blume, Rumphia etc., siche oben.

Zippel-Pollmann, Auslindische Kulturptlanzen. Xl. 


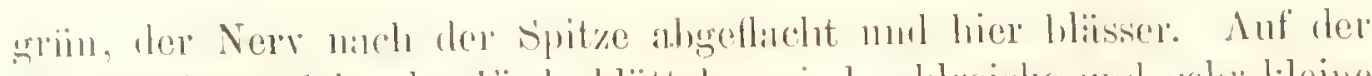

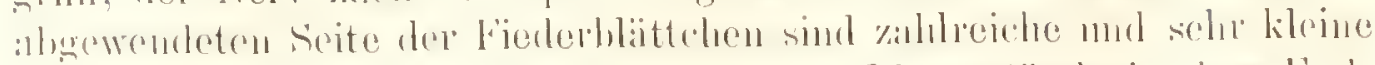

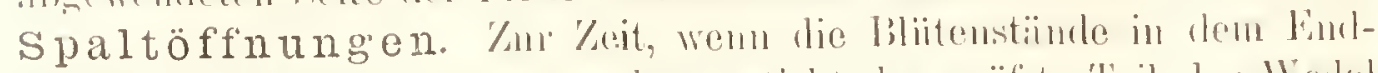

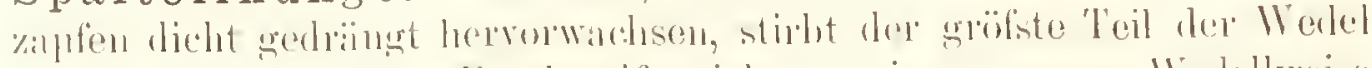

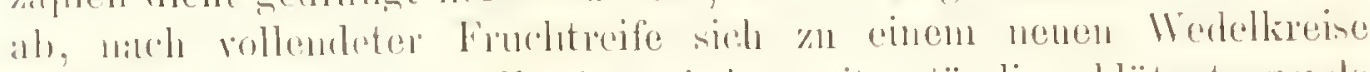

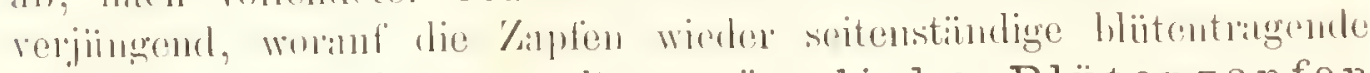
Spimbln likdrn liommen. Her männliche Blütenzapfen (lïg. 1) nicht cigentlich terminal. somblen axillar in riner der olsersten

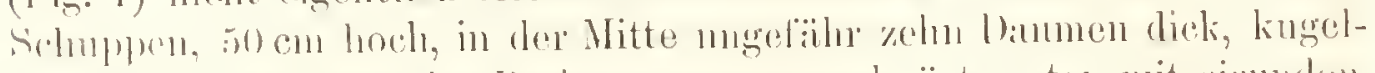

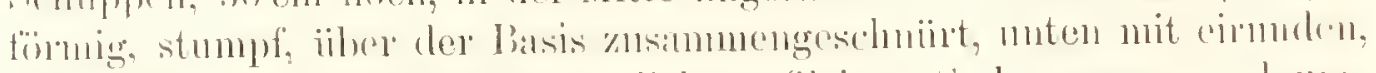

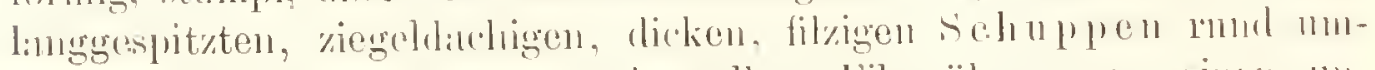

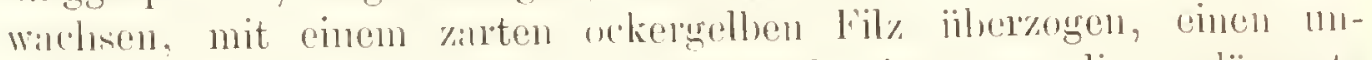
angenchmen schufen Geruch rerheitend; rings mm lie verlïngertu. gencinschaftliche $/$ anplenachse sind dicht gestellte. spiralige, schuplenfirmige. antherentragende Spindeln (ungewandelte

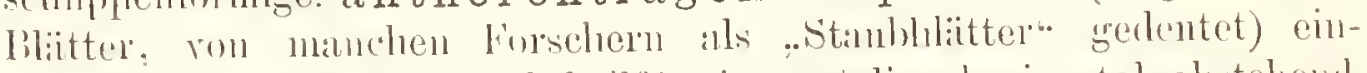
refiigt. Diese (Fig. 2) sind keilformig-spatelig, horizontal-abstehend.

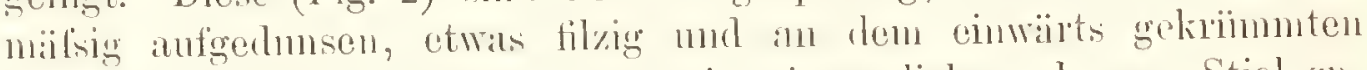
Eurle dornspitign endigend, nuten in einen dicken, knmen Stiel zu-

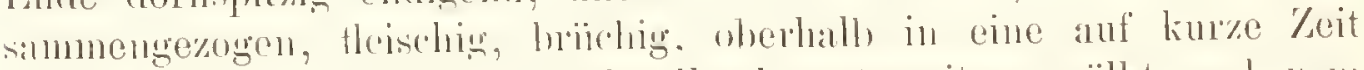

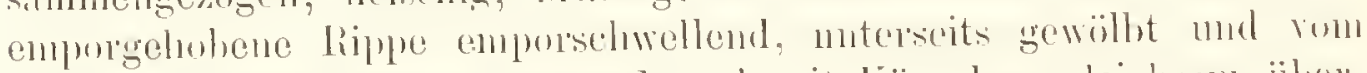

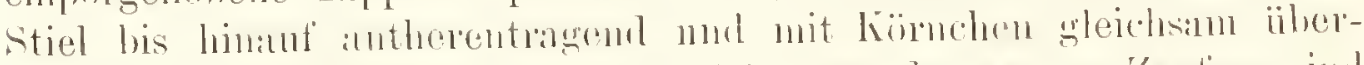
zongen. Die untersten mol ohersten sehmpen des ganzen /aptens sind

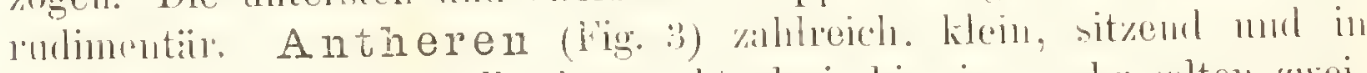

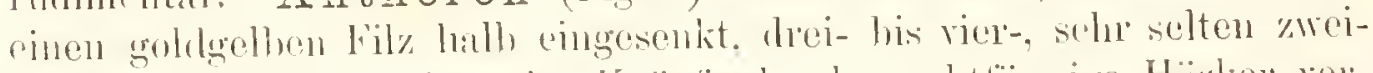

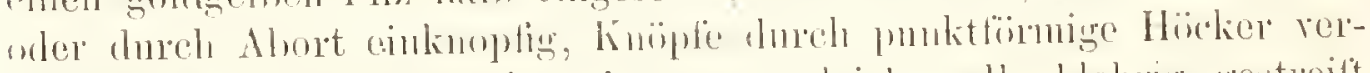

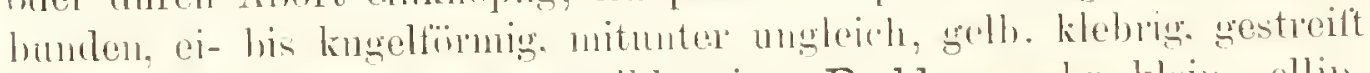
wherhall, der Längsfinche zweiklinprig. Pollen sehr klein, ellip-

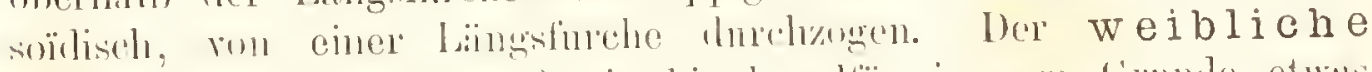
Blütenzapfen (lig. 4) ei- his kugelfömis, am cirmmle etwas

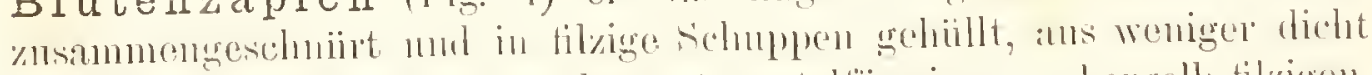
gestellten, riegeldachigen, verlingert-spatellämigen, orkergelh-tilzigen. ler rerkiirzten Achse cingefïgten, erst anfirits gekrimmten, dann murickgehugenen, Samenknospen tragenden Spinde]n (rudimentire Lanhblätre) mler Fruchtblättern musmmengesetyt. In diesen kiann man oinen langen. verflachten, drei- oder vierseitigen stiel

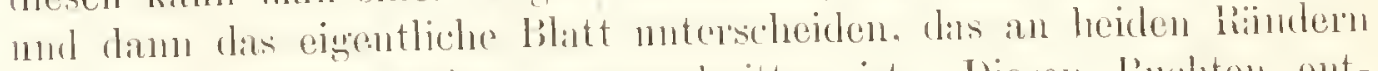

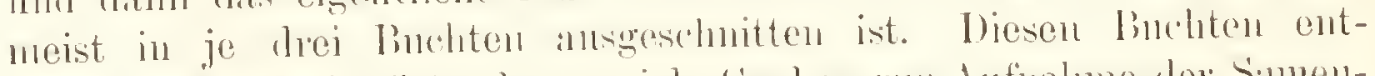

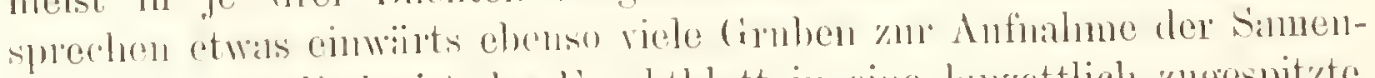

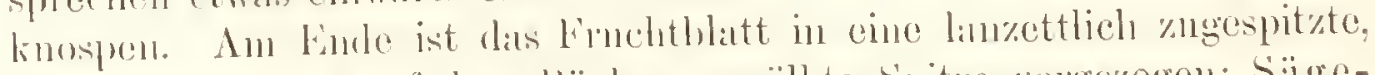

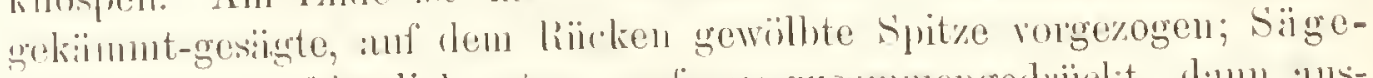

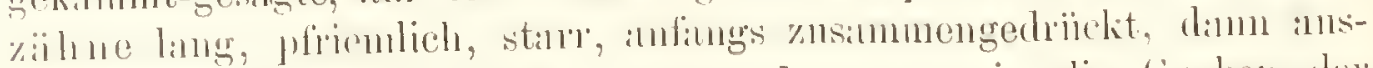
gehreitet, griunlich, klehrig. Samenknospe in die (irnben der

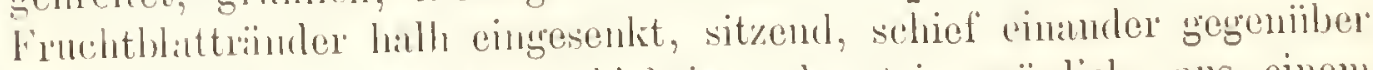
gestellt, fleischig, geglittet. Klehrig, schmutrig grimlich, aus einem 
geralden cifömmigen liene, der ron einer einfichen, dicken, an Giplel mit einer röhrchenförnigen Miindung versehenen Hiille ungehen wird.

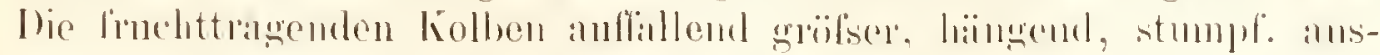

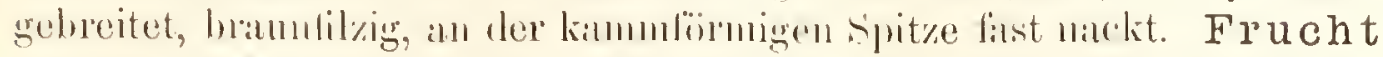

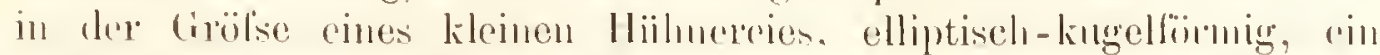

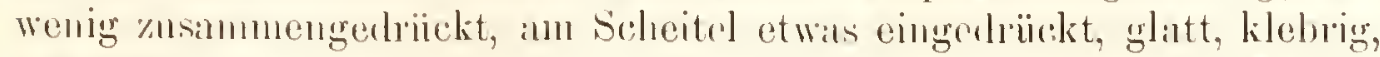

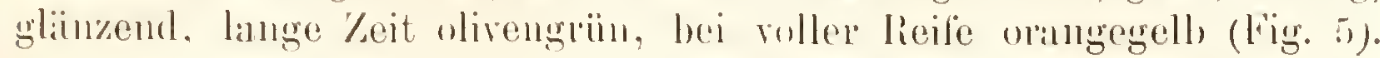
Fleisch der Fruchth ülle der S.mnensehale angewachsen, $3 \mathrm{~mm}$ dick, breiig, fleischig, hirlsgell, ron siilsen, widerlichem Gernch. Samenschale holyig, glatt, ledergelh, spit\% endigend, an oberen nnd breiteren 'Teile nit einem lïimmelen rersehen, sich bei der lieinung in zwei Klappen iffliend, inwendig bis zur Spitze mit einer hellhramen, fast papiernen IIaut unkleidet, welche nach oben diimhïutig, an Sirheitel die Nulis locker ungieht. $\mathrm{Nu}$ Ss, die lohle Samenshlale filst ausfiillend, ei- bis kugelförmig, an der Seite ein wenig gefurcht, an der Wölbung des scheitels first rund. Sameneiweifs gleichlömig, fleischig, elfenbeinweifs, ansgetrocknet hornurtig, im mittleren weiten Fach den Keimling tragend, mit einigen kleineren Fäehern, die in den unter den sicheitel eingeprä̈gten l'̈ipfeln znsammenfliefsen. Diese cylindrischen Fïicher, vertikal eingesenkt, sind mit einer diinnen Hant unkleilet; jede einzehe Ifunt ist eimen langen fadenförmigen, schlatfien Anhängsel (appendix) rorge\%ogen, welche mit dem liingeren Anliaingsel des Keimlings ein linltiges Biindel bilden. Keimling in der Nitte des Eiweilses, abwärts geriehtet, kenlentuirmig, zusimmengullïckt, mit zwei grofsen, mgleichen, dicken, Heisehigen simnenlappen, die an Grunde eine knrze Lïngsspalte haben. In diese Lïng 'spalte ist dis kleine Keim knöspchen (Plumula) eingesehlossen, es ist sitzend, anfrecht, legrelfïming, ans seheidigen Schiippchen wechselseitig zusammengesetzt (Fig. (i). W ürzelchen seln kur\%, stmmpff, zusimmengedriickt, muten in ein gedrehtes, faltiges $\Lambda$ nhïingsel (siehe oben) furtlanfencl. Disses Auhängsel hat die Eigensehaft, Fenchtigkeit aufzusangen und sich daduch auszudehuen, fiilurt bei beginnender Keimung dem Keimling l'enelitigkeit zu nud stirht ab, wenn es zu des keimlings limä̈lımg nicht mehr nötig ist. Bei begimnender Keimung dehnt sich der Keimling mehr mud mehr ans, dimu bricht erst nur der Teil, in welehen dis kileine Keimknöspehen eingeschlossen ist, mit dem Wiirzelehen ans der Spalte der Simenschale nud den Fruchtgehäuse hervor, das Wür\%elehen verliingert sich strangföimig und steigt in die Ende linal, kurze, hreite Wiirzelchen anssendend, woratuf die Keimblitter ans der Frucht gewaltsim weiter hervorquellen, alls deren erweiterter Spalte dis Keimknüspehen sich mu \%wiebelformig erhebt (Fig. 7); der obere Teil ar Keimbliatter aber bleibt im Sameneiweifs eingeschlossen, lange noch der Lruïhrung der Keimknuspe dienstbirr, so lange, bis sie alle Niahrung ans dem Samengeschöjpt und 1 mn kräiftig genug ist; daun lïst sie sich ron den Simnen- 
lappen los. Dis Keimknöspchen besteht aus zahlreichen Blättchon oler ersten Kunspendocken, die kreisstïndig, sitzend, breit-eifirmig,

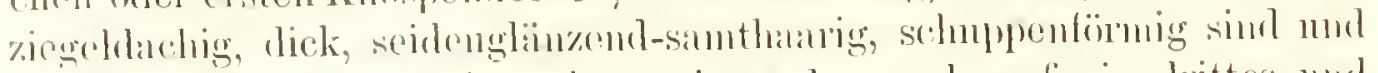
ans deren Mitte erst cins, dium an anderes, damof ein drittes nud

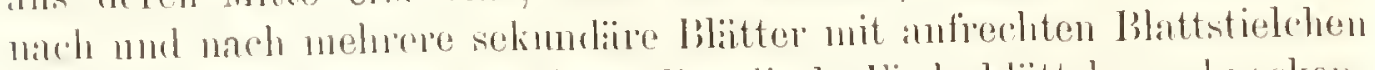

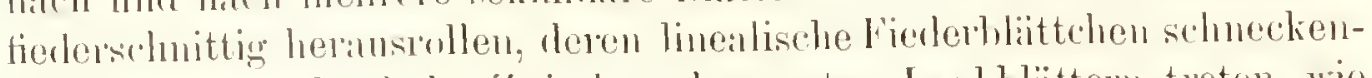
artig cingewickelt sind. Kwischen don ersten Lanbhlïtern treten, wie

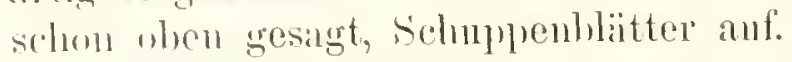

Heimat und Verbreitungsbezirk. Tropisches $\Lambda$ sien, Anstralien und Polynesion.

Kultur. In den Ileimatlïndern wïchst der grofshlittrige Sagobanm wild und wird anch angelant. Bei mos gehören die Cykasanten zи den schönsten und beliehtesten Wiamhiusputlanzen.

Nutzen, Die jungen sich eben aufrollenden Wedel dienen den Bewohnern ron Sumatra nud anderen Völkern als (iemiise und werden wie Spargel gegessen. Die Friichte verspeist man mit Zncker; aus lem Staikemehl des Stammes (siehe oben) macht man Brot und eine geringe Sorte Sago, die zu nus als Sago rou der echten Sigopalme in den Llandel kommt. Bei uns werden dir Werlel zu Leichenbegängnissen mucl zur Ausschniickung der Säigge hemutrt.

lon den 1: hekannten iilurigen Arten sei mur der „Umgerollte Palmfarn" (('yers verolutal) L.) erwähnt. Wedel kammförmigg gefiedert, 1,20 his $1,50 \mathrm{~m}$ lang; Fiederhlättchen lineallanzettlich, schard spitzig, starr, am Rande zuriickgerollt, glïmend. China und Jipran. Sutzen wie hei roriger. In China mol Japan war die Ansfuhr dieser Pthanze bis anf die neuere Zeit bei 'Todesstrafe rerboten, weil die Silgo darinus zur Nahromg fïr die Soldaten in Kriegsreiten anfhewalnt wirle.

1) Umgerollt, zurückgerollt (l'iederblättchen). 


\section{T a fel 6.}

\section{Gemeines Bambusrohr \\ (Bambusa $\left.{ }^{1}\right)$ arundinacea ${ }^{2}$ ) Willd.).}

Anch das gemeine Bambusrohr gehört zur Orduung der Spelzenhiitigen (Glumaceae), und zwar zur Familie der Gräser (Gretmincac).

Ueber die Ordnung der Spelzenblütigen und die Familie der Gräser siehe die I. Abteilung "Echtes Zuckerrohr" S. 114 ul. s.f.

Die Gattung: Bambusrohr (Bumbusa Schreh).). In dieser Gattnug erreicht die Familie der Gräiser ihre höchste Entwickelung. Banmirtige Gräser mit ver\%weigtem IIalme und grasartigen linealischlinzettförnigg schneidigen, zweizeiligen Bliitter"n und hisweilen riesigen Bliitenrispen und Strï̈lsen. Die Bambusrohre bliihen nur selten, und deshalb gehen mitunter ganze Waldungen zu Grunde.

Veber 180 A rten in Asien, Amerikil und Afrika.

Gemeines Bambusrohr (Bumbusu arumdinucea Wilh.).

Busch lis $50 \mathrm{~m}$ hoch nnd weil ans 20 bis 30 holzigen, ästigen Italmen bestehend, his 6 m im In uchmesser, einzelner Halm 5 his $26 \mathrm{~cm}$ im Inrehmesser dick; ans den Knoten stark verzweigte Äste (Fig. 2) und unten stets nene Schöfslinge (Fig. 1) treilend. Wiichst sehn schnell und nimmt in 24 Stunden 6 his $36 \mathrm{~cm}$ an Lïnge $2 u$.

Blätter $16 \mathrm{~cm}$ lamg, $1,3 \mathrm{~cm}$ breit; die Endzweige voller Bliiten olme Blitter.

Rispe :istig, ausgespreizt (Fig. 3), mit quirligen $̈$ hırchen; Ährchen (Fig. 4 u. 5) vielblïtig, mit zwei kleinen stmmpfen Deckspelzen, die nuteren Blïten der Ährchen geschlechtslos, nur ans einer spelze gelildet, die iibrigen alle zwitterig oder nur eine zwitterig, die anderen nïimlich; Staubblätter sechs (Fig. (6); Griffel ein, sehr limg; Narbe (Fig. 6, die Spelze ist kiinstlich nich muten zurickgeschlagen)

1) Die Portugiesen brachten das hohr unter dem Namen Bambos nach luropar, Sehreber bildet daraus ren Gattungsnamen Bambusa. - 2) Rolurartig. 


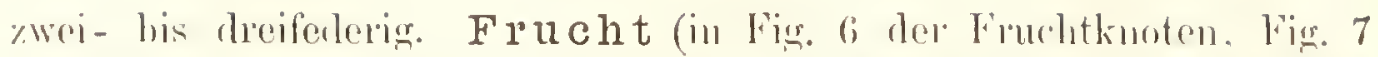

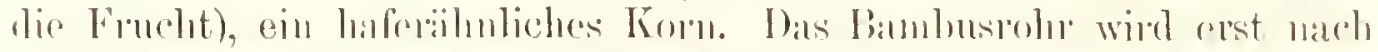
28 Jaliven trashiar mol stirlot dimm ill.

Standort. (irdeilit an hesten anf Sumpflboden an schlammigen Tleru, wo riesige Wilder entstehen. Heimat unbekannt. Verbreitungsbezirk. Tropen\%one heider ILemisphïren, Agerien un Siidframkreicll.

Wird angebaut.

Dis Holz ist wegen seitler $\mathrm{k}$ ieselhaltigen Rinde schr

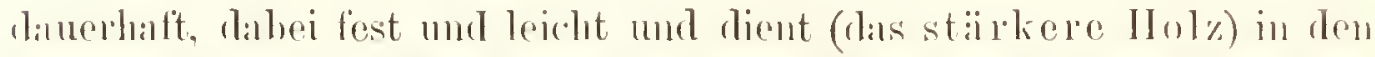

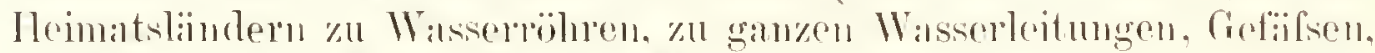

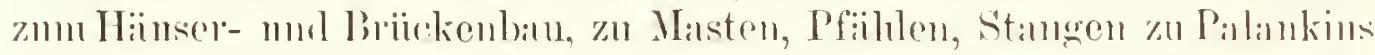
(Sïnften-Tragstangen), leitern, \%ur Verfertigung velschierlener Ilans-

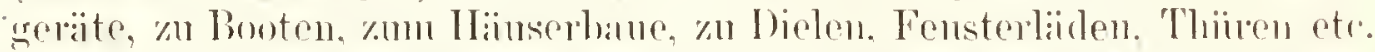

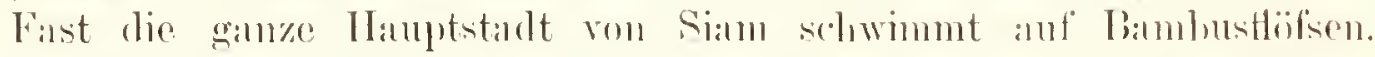
1)al altes Bambuspolle so halrt ist, dals man es kamm mit Stahl quer durelschueirlen kamu, so verwendet man es in den Em\%engungslindern

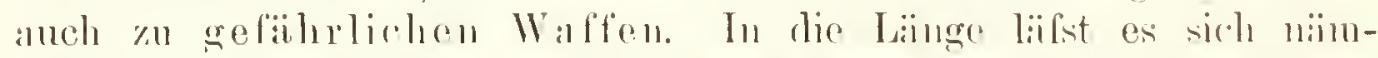
lich schr leicht spalten und ron dem gespaltenen Teile löson sich laartörmige Fasern ab, welrhe gewïhnlich in den Wunden zurtickhleiben mo diese sehr bisartig machen. Ganze Ortsulaften sind 5) bis dim breit von in die Firle gesteckten Bambustiblon nmgeben. die nur etwa zwei Handhreit iiber den Poden hervorragen, so scharf zugespitzt sind wie Messer und unter dem Grase nirht gesehen werden. Zwischen ihnen gehen die meist schlangenfïmug gewurdenen Pfade hin. Wer in jene scharfen Pflöcke fïllt, ist ohme Rettmug verloren. Auf lavir sind anch Erdwïlle auf der Aufsenseite mit Flechtwerk aus

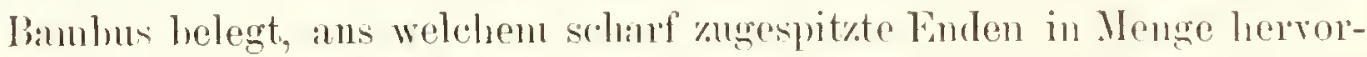
ragen. Einen solchen Wall \%u stiirmen, ist ganz nnmö̈glich, wenn man nicht zuror das Flechtwerk durch Fener zerstïrt hat. Aus den hohlen (iliedern macht man allerlei (iefïifse (lange Wassereimer) nmI nunsikallische Instrumente (Flöten, Otalieiti). Das jüngere llol\% rerwendet minn zu Flechtwerk, Wïnden, Zïunen um Gïirten, Kïrben, Matten, Segreln, Rollvorhängen, Regen- nnd Sonnenschirmen, Hiiten. Stricken. zи Schnit\%werk, gravierten mul eingelegten Arheiten. Langes kranses

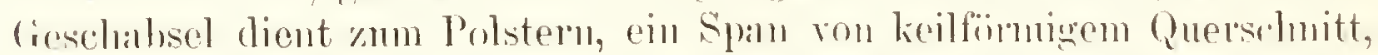
drsen scharfe Kinte von der kiesehreichen ïnfseren, ungemein harten

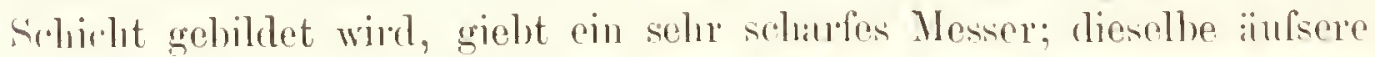
Seluirlut dient als Wetzstein fïr ciserne Messer. In einer Bambusröhre,

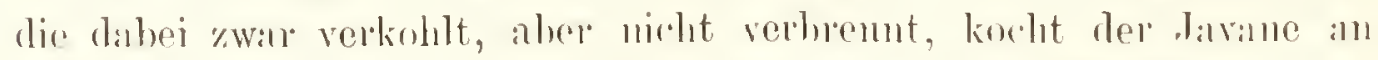
rinem Bambusfener junge Banbustriebe. Die gelblichen, \%:ihen, knoti-

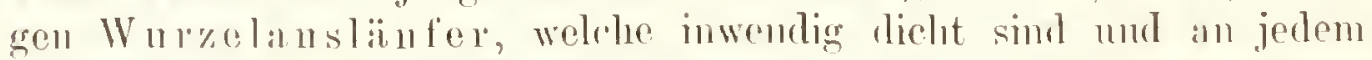
Kunten rinerseits rine Furche hahen, in welehor der Bbittsticl gestanden, werden als Bambussparierstöcke zon ms gebraclit. Ans der Bambusrohrfaser bereitet ntan in Chinia das clinesische 


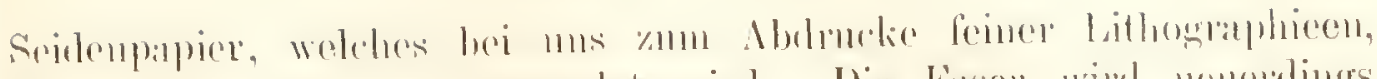

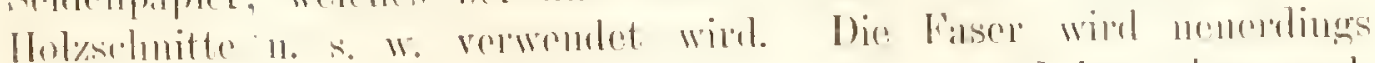

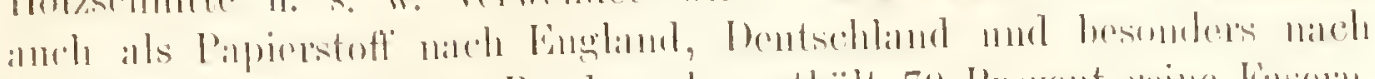

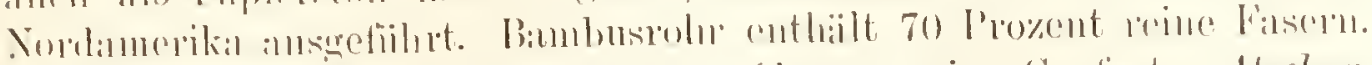

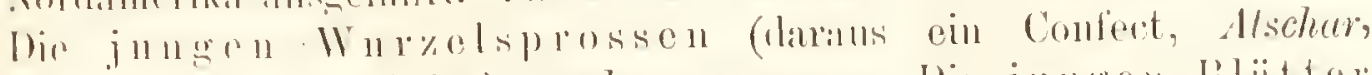

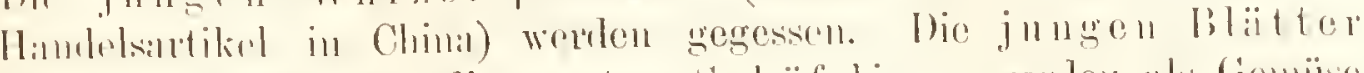

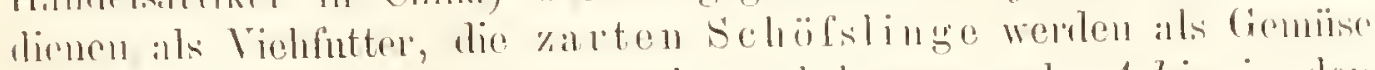

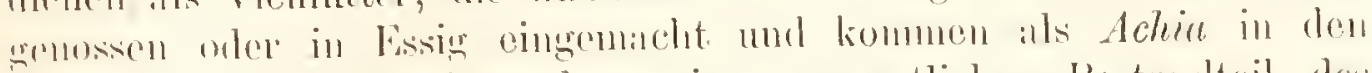

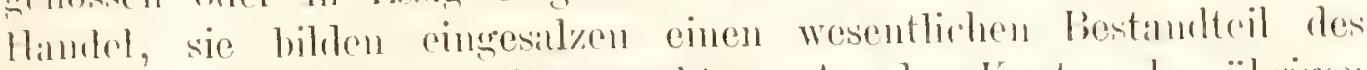

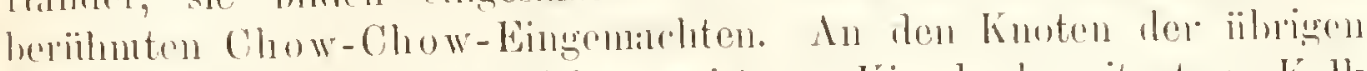
Halme setzt sich eine woilshiche, moist ans Konelonde mit otwas Kalk

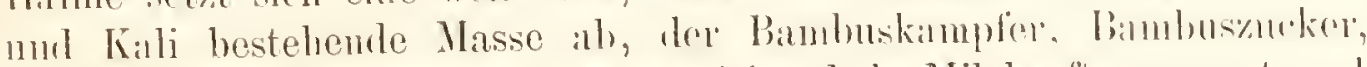

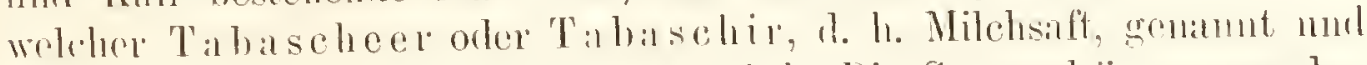
als Heiluittel sehr hoch geschaitst wiml. Die Samenkiirner werten mit lieis mul Honig gemischt genossen und halen als Brotfrucht pine grolse Bedentung.

Geschichte. Dis bambusmohr wurde zuerst von den P'onturiesen unter dem Namen bambos nach Buropa gelnacht. IJmboldt cröilut, dils Mntis 20 Jahre lang in Gegenden botanisiert habe, wo Bumbrise cinudua meilenlange smmptige Waldungen bildete, olme cin einciges Exemplar in Bliite gefinden zu haben.

Auf die übrigen Arten kilnn hier nicht näher cingegangen "erden. 


\section{Tafel 7.}

\section{Wohlriechender Schraubenbaum ${ }^{1}$ ) (Pondănus²) oderatissimus ${ }^{3}$ ) L. f.).}

Der wohlriechende Schraubenhaum gehört zur Klasse der Einsamenlappigen (Monocotyledon's), zur Ordnung der Kolbenbliitigen (Spadiciflorae) mol zur Familie der Pandanggewächse (Pandaneae).

Die Ordnung der Kolbenblütigen ${ }^{4}$ ) (Spadiciflorce) i) Ihre Bliiten ${ }^{6}$ ) stehen dicht gedrüingt $z u$ vielen beisammen auf einer kolhenfürmigen, meist ziemlich dicken Spindel (spudix), wenigstens anfangs nungeben von einem gemeinsamen nicht grünen, scheidenartigen Hüllblatte (spatha). Die gewöhnlich diklinischen Bliiten besitzen keine, oder doch nur eine sthnppenförmige Irïlle, deren Blïtter ihrer Zahl nach nubestimmt und unsymmetrisch sind. Die Simen enthalten Fiweils (Thomé).

Die Familie der Pandanggewächse (Pandeneae). Ausdaneme Pflanzen mit baumartig anfrechtem, oft auf hall, ans dem Boden hervorragemlen Wurch stehendem oder mit schwachem, niederliegendem Stamme. Die Bliitter sitzen meist büschelfürmig dicht beisammen. Die eingeschlechtigen Bhiiten stehen anf einfichen oder ästigen Kolben und besitzen eine ein- oder mehrblïtterige, oft gefirbte Hiille. Die Staubhlattbliiten sind nackt orler mit cinem mehrblitterigen, regehnïfsigen Perigon versehen und enthilten zahlreiche Stanbh)itter. Die (iriffelhliiten haben selten eine biiitenhiille; sie hestehen ans mehreren einficherigen l'rucktknoten, die mit einer sityenden Narthe endigen. Die beeren- oder stembecrenartige lirucht ist entweder aus mohreren verwachsenen Fruchtknoten zusimmengesetzt orler ein-

1) Die Bhatter an der Spitze der Äste sind schraubig gestellt. - ") Von den Malaien "l'andang" genamt. - 3) Seh" wohlriechemt. - ") siche ZippelBollmann, Reprïsentanteu einheimischer P'flanzenl'amilien II. Abeilung, 1. Lieferung, S. 59 u. 8. f. - ") Spadix, liolben. - ") Litteratur: Aufser den oben genammen Werken, Semler, Die tropische Agrikultmr III; Roxburgh, Plants of the const of Coromandel; Gaudichaud: Voyage autour du monde ete. 
fïcherig. Die Pandanggewiichse finden sich in den Tropenländern der alten Welt. Die Frïchte sind meist ofshan und the Stïnme nund Bliitter werden zun Bancn benutat, die Bliitter zweier Arten enthalten zïhe Fisern.

Dic Gattung Schraubenbaum, Panding, Pandine (Pandăms I. fil.). Baum- oder strauchantige Gewïchse vou palnenëilnlieher 'Tracht. Der mugeteilte, oder nur an der Spitze verïistelte Stammn ruht iuf einem Gerïst vou Luftwureh. Die Blitter stchen in einer dreifachen Spirale („Schratubenhaun “), sind grofs, einfich, lincal, an Rand und an der Mittelrippe dornig. IBiiten einhüusig. Ter nïmliehe Kolben ist in der Regel verzweigt (Fig. 4), der weibliche kolben dagegen einfach (Fig. 1). Die liriiclite stehen meist in zilpfenälin-

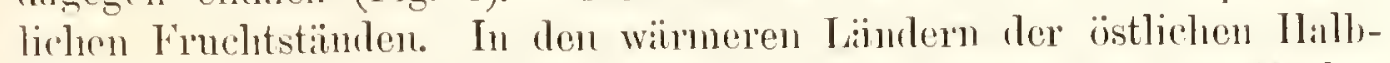
kngel, besonders auf den Insehn des Indischen Oceans und den Miskilrenen bedecken sic gewöhnlich grofse Strecken an Meere mit einer undurhringlichen Vegetation, werden aber anch angebaut. Mehrere Arten haben ein so schmelles Wachstum, dals nan disfelbe sichtbar verfolgen kann, ;indem man die gröfste Lä̈ngenentwickelung an den Blitentrauben his $1,18 \mathrm{~m}$ in Verlante von vier his fünf Stunden beobachtete. Niquel sah, dafs der Bhiitenkolben sieh in drei Stunden $\mathrm{mm}$ $93 \mathrm{~cm}$ verlingerte“. - Die Exde hat in ihren Jugendjahren, in der Zeit der Jurabildungen, diese spertheinigen Pandangwaldungen in einer weit gröseren Ausdehmung gchialbt. Jil sclbst Europa 'soll in seinem Pflanzenkleid vielfach P'roben davon besessen hathen.

Wohlriechender Schraubenbaum (Pondmus orlorttissimus L. f.). Fin palmartiger Strauch, dessen Stamm $7,65 \mathrm{~m}$ hoch wird und zilhlreiche Luftw urzeln iiber dem Boden hat, so dafs der schöne Stamm gleirlssim stelzenartig anf seinen linngen Wurzeln reitet. Die Wurzhn entspringen am unteren Eude des Stammes, boi iluem Wadistum hehon sie den letzteren über den Fufsboten his zu ziemlicher llïhe empor, wäluend sic selbst wiedernm durch ilre Nelsenwurzehn rmpor geschuben worden. Der gabelig verzweigte Stamm gefïllt durch seine, in schöne Schranbenlinion gestellten, starren, iiber $90 \mathrm{c} \cdot \mathrm{m}$ langen, fast schwertförmigen, an Eunle der Zweine in Biischeln stehenden Blätter und hï̈ngenden Bhiitenstïnde. Die Blïtter sind lineal und stehen in dreificher Spirale, sind am Ratule und an der Mittelrippe nit griinen oder rötlichen Dornen besetzt, zienlich $1 \mathrm{ml}$ ling (siche anch obent) und sthön griun. Der weibliche Blütenkolben (Fig. 1) entsmringt in ter L(hsel eines

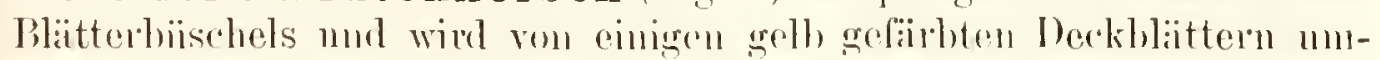
geben. Perigon fehlt. Dep weibliche Bliitenstand weicht von dem mïnnlichen diulurch ab, dats er sich nicht verzwerigt nund wie joner von berkblïtern unterbrochen wided. Die griinen weihlichen Bibiten sitzen am Kolben in kleinen Grupren (Fig. 2) dicht sordräingt. Jerle weibliche Bliite besteht inls cinem einfiicherigen frushtknoten mit jo riner 


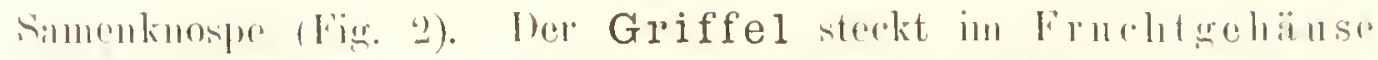

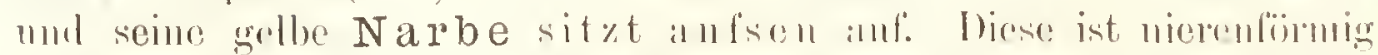

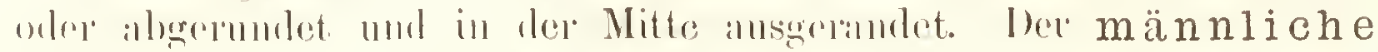

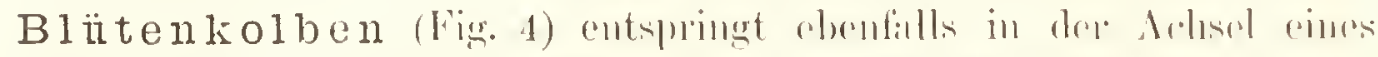

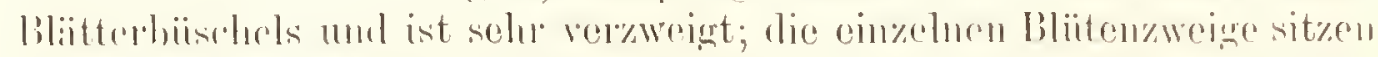

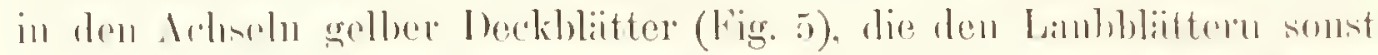

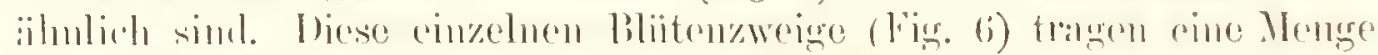

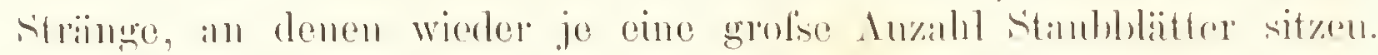

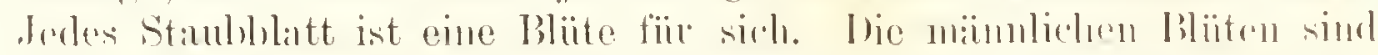

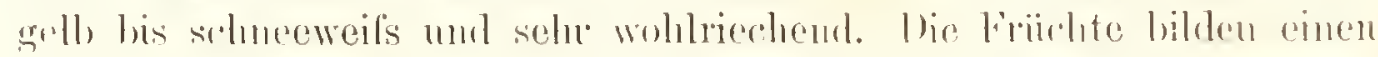

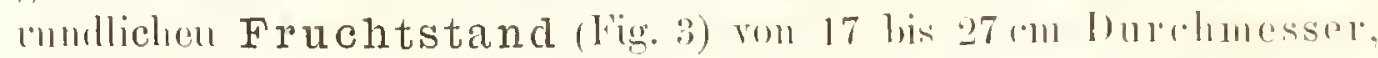

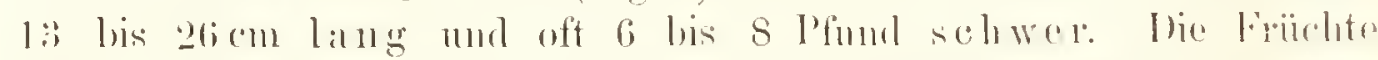

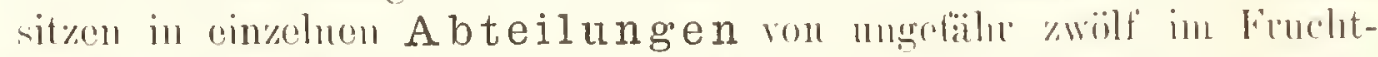

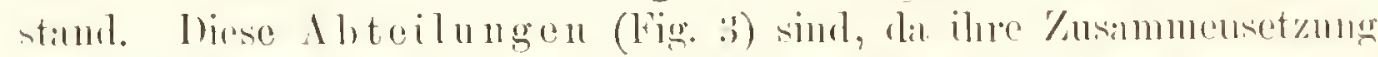

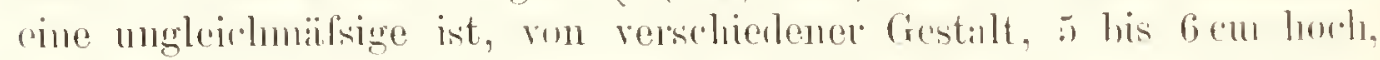

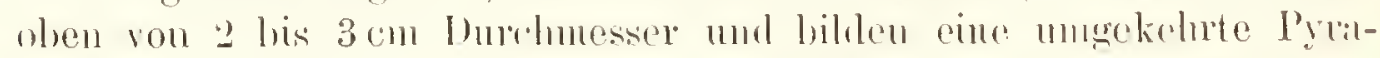
mirle. Lie Früchte stelon in zwei lieilen in den Ahteilungen,

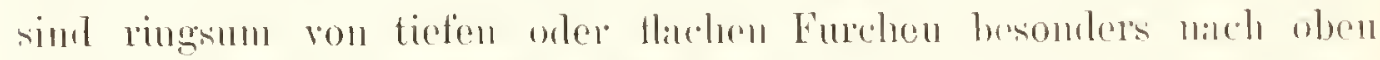
lin vou einamler gesomblot. Ohen ist jerlo einzelne Frucht rom

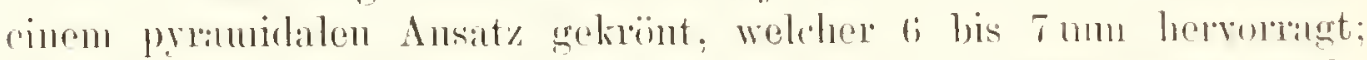

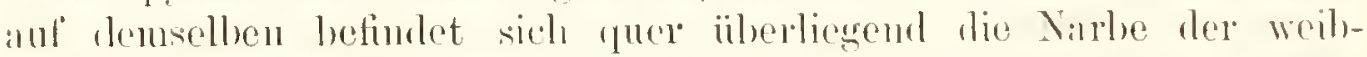
livhen Bliite (der schwarze P'unkt). Oben sind rie Filichte lehlart rot, muten orauge- lis liellgell,. Samen liuglicl, glitt.

Heimat und Verbreitungsbezirk. Siidasien un Inselu les stillen Mecres. Sie ist in der liegol cine der ersten I'tlanen. die sirh anf den neu entstandenen Lusehn der siidsee ansicrloln.

Der wohlriechende Sohranhenbaum wächst wild (in Kokos-

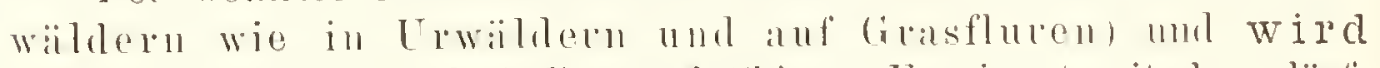

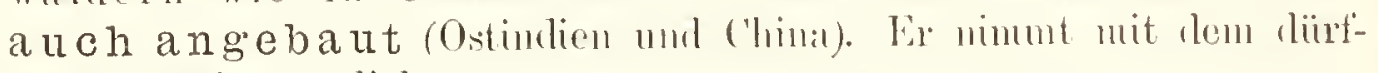
tigsten Torlen vorlieh.

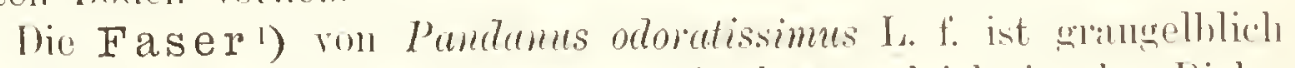

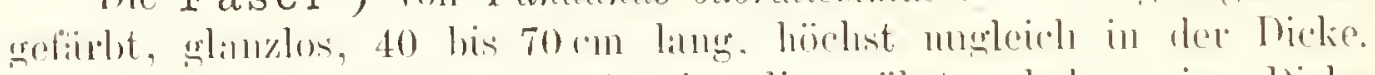

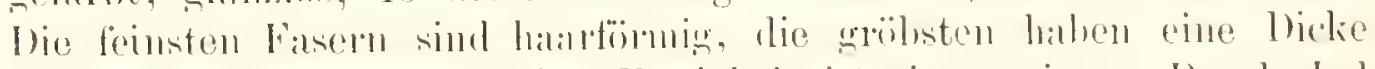

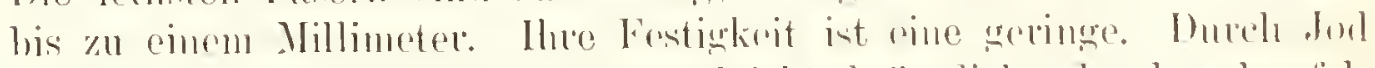

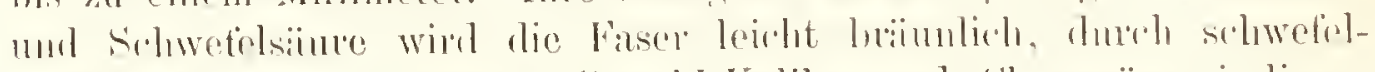

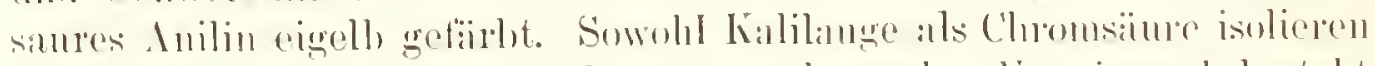

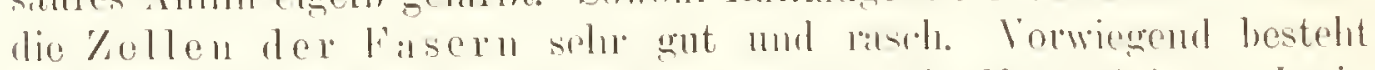

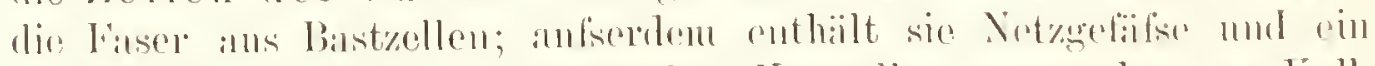

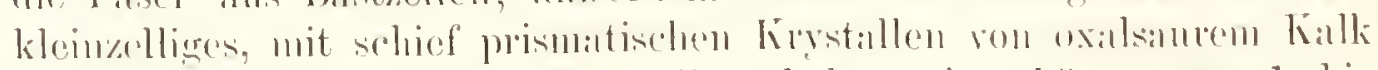

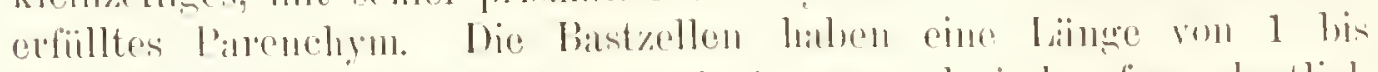

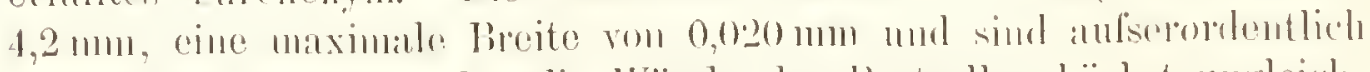

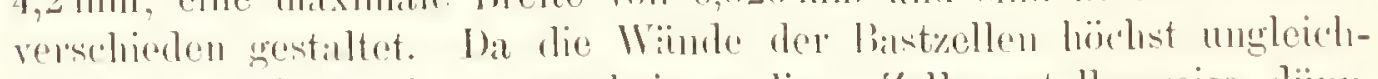
forming verdickt sind, so erscheinen diese \%ellen stellenweise diinu,

1) Wiesn'r, lohstofle des l'llanzenreichs. 
stellenweise diunwandigr. Lafteocken fïhrt die Faser 7,02, mit Wasserdimlut gresittint 18,35 Pro\% Wasser.

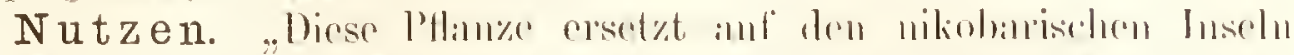

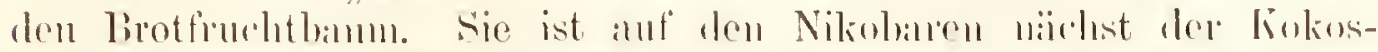

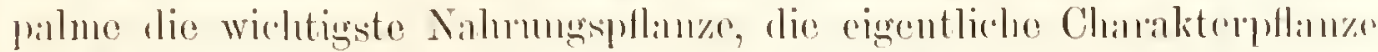

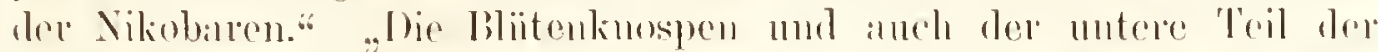
[B:itter werden als Gomïse grogessen; die Bliiten werden des Woll-

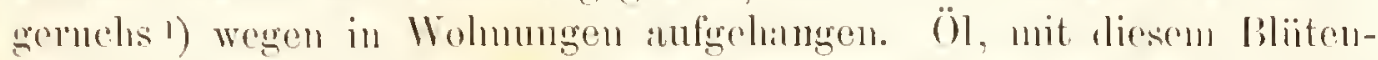

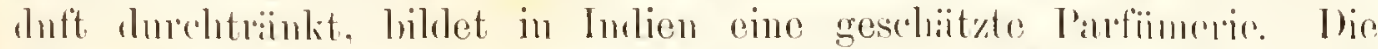

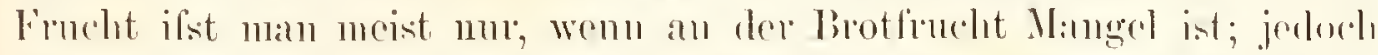
malchen die Friichte meluerer Sprielarten anf den Luselu des Mnlghivo-

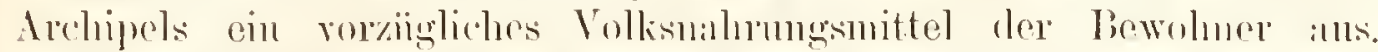
Man kloplt die linichte mit einem Steine weich mul simgt den anomatischen Saft der Fisem ans; anch latekt man die Friblite mul hereitet Mogan, ein wiirziges, trockenes kontekt, ans denselhen, woleloes

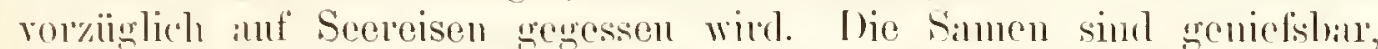
ehensu die weichen, weifsen Blitterfiifse. Die jungen selowammigen Zweige werden als Viehfutter benutyt, lie Blitter dienen ur Be-

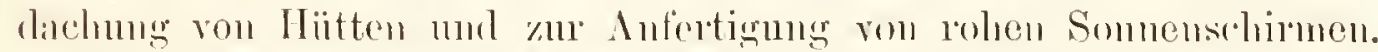
Aus ihren Fasern werden Matten, Schiü\%en und Scile hergestrollt.

Es seien noch einige andere Arten erwïlnt: 1. Schraubenbaum (Pondumes spriralis ${ }^{2}$ ) R. Br.). Neuhollant. Aus den F'aseru der langen laftwm\%elı werden Stanbbesen gemacht, deren Handgriff man mit dem eleginten Geflechte der ägyptischen Netzgurke (Iuffa) (Momortica luffa l.) iiber\%ielit. 2. Nützlicher Schraubenbaum (Pundanus utitis") Bory) kitmu his 9,20 m loch werden, wird rewöhnlich 2,95 lis $3,05 \mathrm{~m}$ gezwergt; Bliitter selur ling. Wird besomders auf den Antillen und anf Mauritius kultiviert. Friichte goniefsbar. Aus den Bliattern gewinnt man Fasern, die zu Palckmaterial (Vignosïcke) verarbeitet werden. Zimunerpflanze. 3. Gabelästiger Schraubenbaum (Pundunus furcutus ${ }^{4}$ ) Loxl).). Indien. Auch hei nns (Gewïchsh:ïuser) eingefïhnt. I)er Bliitenkolben verlängert sich in drei Stunden first um 1 n. Erreicht anch bei uns kolorsale Ausdelumng. 4. Javanischer Schraubenbaum (Pondumus javanicus $\left.{ }^{5}\right)$ Nort.). Fine selu schöne Blattpflan\%e mit panachierten IBhittem (in mseren Glishïusern).

1) Auf diesen Wohlgerueh finden sieh in den Sanskritgedichten unter dem Namen lietaka häufige Anspielungen. - 2) Schraubig. - 3) Nützliel. - i) Gabehg, gabelïstig. - ${ }^{5}$ ) Javanisch. 


\section{Tafel 8.}

\section{Fig. I. Kapselfrüchtige Jute (Corchorus ${ }^{1}$ ) capsularis ${ }^{2}$ L.).}

Die kipselfriichtige Jute gehört zur Klisse der Zwoisamenlappigen (Dicotyledones), mur Unterklasse der Getremthlätterigen (Elcutheropetalue orler P'olypetalae), znr Tieihe der Boslenblitigen (Thalumiflorae). zur. Ordnung der Sänlentriichtigen (Columniferce) und zur Familie der Lindengewächse (Tilicacece).

Über die Reihe der Bodenblütigen siche I. Abteilung S. 24 „Chinesischer Theestrauch", iiber die Ordnung der säulenfrüchtigen Pflanzen siche I. Alteilung S. 39 "Krilutige Baumwolle".

Die Familie der Lindengewächse (Titiucrer)'). Crowöhnlich Päinme oler Sträncher, doch anch einjührige kriuter mit alswechsehulen, einfachen Blittern und abfallemlen Nehemblitteru. Erinnern durch die Knospenlage des Kelehes mul der Bhnurnkione

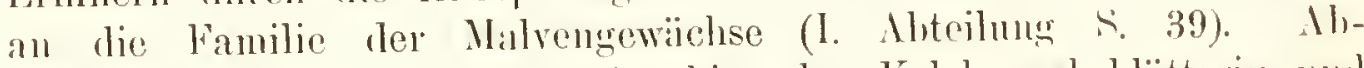
wrichend rou den letzteren ist hior der Koleh mohrlibitterig und oft bhmenlblattartiog gefärbt nud sind die Stamblätter frei oder vielbriiderig nit zweificherigen Stanhblittern. Kelch meist alfallent. Die Foncht ist eine zwei- bis zohnfïcherige Kansel, selten eine Becre oler Steinfincht.

In 32 Grattungen iiber 250 Arten.

Lie Gattung Jute ('orchorms L.). Kirinter onler kleime Strïncher mit einfachen Biattern, einzehn oder in biischeh stehenden

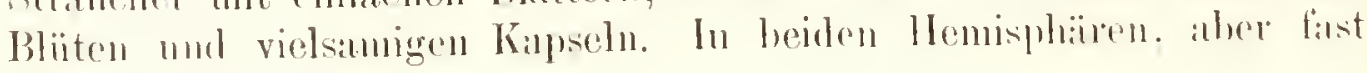

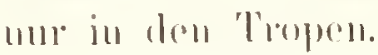

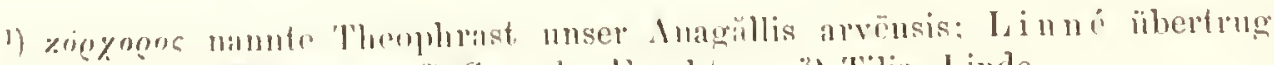
den Namen dieser P'fanzc. - 2) Calpsu'a, Frneht. - is) Tilia, Linde. 
Kapselfrüchtige Jute, indischer lilachs, Dsehnt- oder

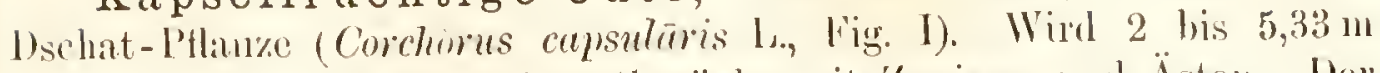

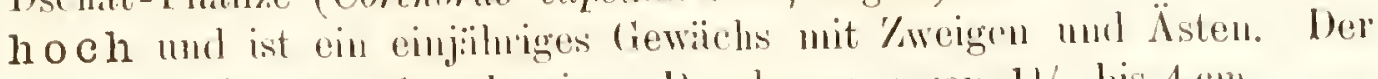
Stengel hat : 1 m (irunde cinen Durchmesser ron $1 \frac{1}{4}$ his 4 cm.

Blätter eilörmig, mugespitzt, gesïnt, stank gerippt nul genervt, 10 his $15 \mathrm{~cm}$ lang nud : bis 6 cm breit, nesselartig, die heiden unteren 'Ziilne pifrienformig verliingert und stichelig.

Blüte (Fig. 1) weil's-gelh, ans fiinf Bliitenblittern gebildet, Bliitenhliatter owl, oben mit einem lïnschnitt, Sta ubblätter zahlreich, Griffel muterstindlig, kur, zwei- his fiunfunhig. Kelch

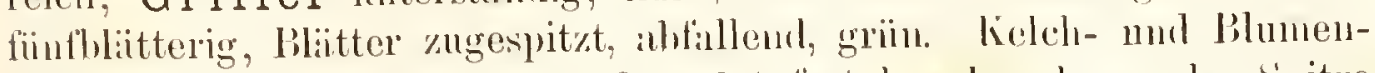
b) litter wechsehn all, Kapselfrucht fisst kngehrum, an der Spitze eingedriickt mul ron Lïngssriplen eingefafst, mit fïnf Seitenwïnden (lïg. 2, anfigesprungene Kinsel). Samen in zwei Reihen.

Vaterland: Dic Jungles ron Bengalen; Verbreitungs. bezirk: Anfser Bengalen die Inschn un Indien, China, Westindien, Francösisch-Guiana und Algier.

Aufser der eben beschriebenen I'flanze kommt von der Gattung ('orchorus L. himp,tsichlich noeh 2. die Gemüse-Jute (Corchorus olitorius ${ }^{1}$ ) L.) als Faserptlanze in Frage. Dic Fisern dieser beiden angebauten Arten sind einander so :ihnlich, dafs weder in Handel noch in Ackerbau ein Untersehied zwischen ihnen gemacht wird. Anch die PHanzen selhst besitzen eine grofse Ähnlichkeit, nur in der Form der linichte ist eine Abweichnng vorhanden, denn die Samenschoten von Corchorus olitorius L. besitzen die Gestalt eines langen, diinnen Cylinders, etwat wie ein lederkiel. Anch wird ron Botanikern das höhere Witchstun von Corchorus capsularis L. herrorgehoben. Sonst sind beide Arten in zwei spielarten gegliedert, in eine sogenannte weifse und eine rote. Der Stengel und die Blätter der ersteren sind hellgrïn, während die letztere einen rö̈tlichen Stengel und Blätter mit rö̈tlichen Rippen besitzt. Die Blätter der GenüseJute werden iiberall als wohlschmeckendes Geniise benntrt. Die Heimat der Gemiise-Jute ist Indien, Sie tindet sich weit verbreitet in den 'Tropen, bis her:uf' nach Griechenland. Anch $\%$ die braune Corchorus fuscus ${ }^{2}$ ) L.) mod 4. die zehnkantige Jute (Corchorus uccom-(nngulatus $\left.{ }^{3}\right)$ Rioxb.) in Indien liefern Jute. 5. Die SchotenJute (Corchorus siliquosus ${ }^{4}$ ) L.) in Westindien mul im tropischen Amerikit wird ron Negern zur Anfertigmng ron liesen benutz; die Blätter dienen in Panama als Lissitzmittel des chinesischen 'T'hees.

Kultur. Ein grolser Teil der Provinz Bengalen wird oft rom Ganges, dem Brahmaputra nud dem Megua mol ihren iufserst zahlreichen Nebentlüssen, die meist von mit Lis und Schnee bedeckten

1) Zu Gemüsepflanzen gehörend. $-{ }^{2}$ ) Braun. $-{ }^{3}$ ) Zehnkantig. - ${ }^{4}$ ) Schotenartig. 


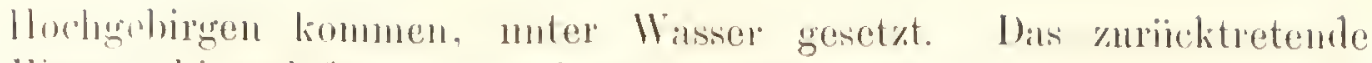

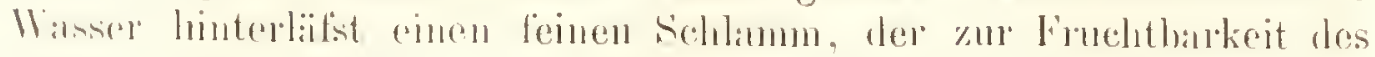
dandes riel heitriggt. Nieht solten surhen sich diese Ströne und

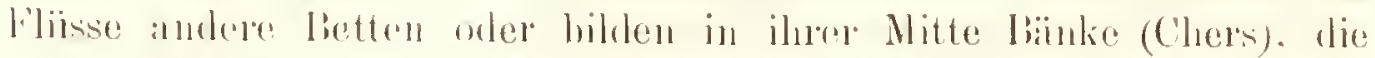

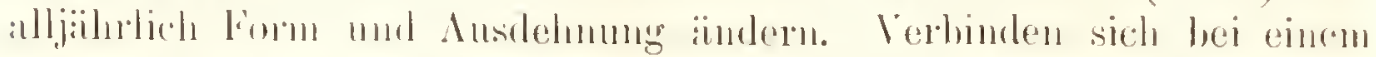

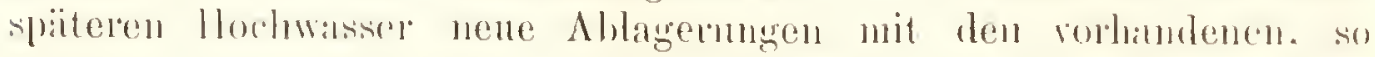

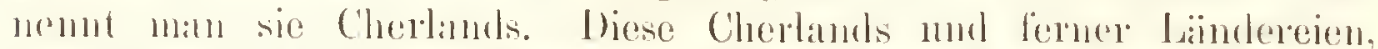

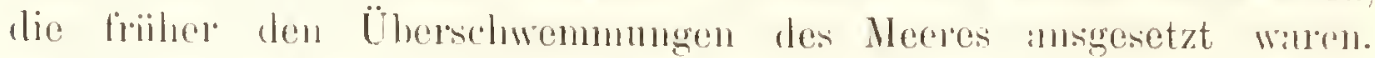
seloen den hesten Kulturhorlen fiir die Jutephan\%en. Diese Pflan\%en

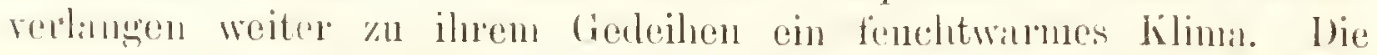

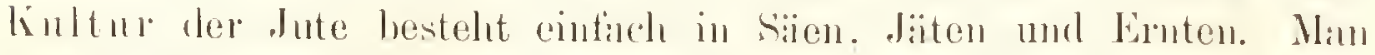

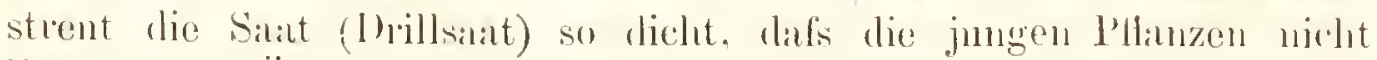

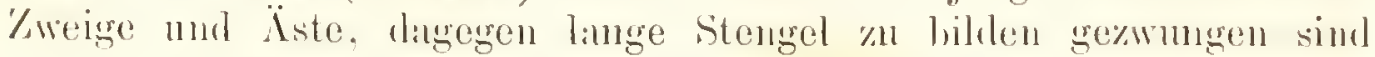
und die somme nicht eine liöh\%eitige Verholzmog der \%ellen hewirken

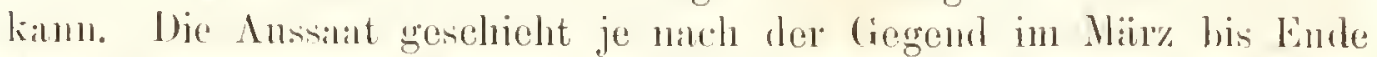

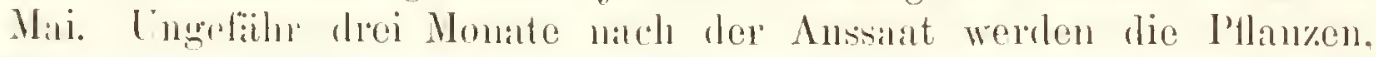
mährend des Fonchtinsitzos, geschnitten. Schncidet man erst, nachdem die fruchtreite eingetroten ist, so verhol\%t sich der mutere J'eil des Stengels nud die Faser wirl geringwertig. Die Menge ron latserstofl, die ant einem gegolnenen Stiick Landes er\%engt wiml. schaitzt

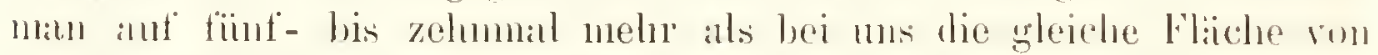
IIanf oder Flachs bringen wïnde. Sollen die geernteten Ritengel zu grohem l'lechtwerk dienen, so werden sie unter Ibich getrocknot.

Gewinnung der Faser. Ln alser die taser \%u gewinnen.

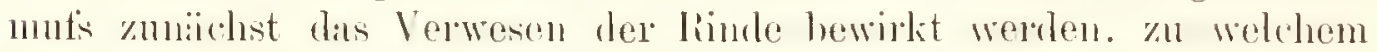
Zwecke man dic alogeschnittenen sitengel in Biindel ecommolen in

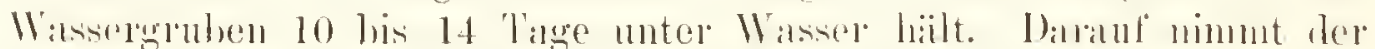

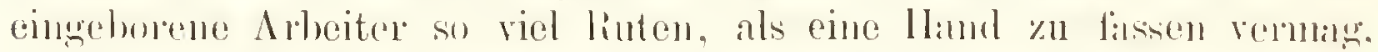

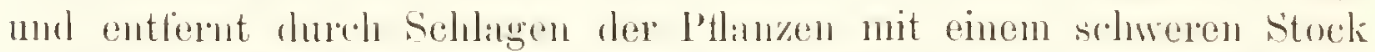
die Rimbe, oder streift sie sellost mit den lländen ah, ohne wader das

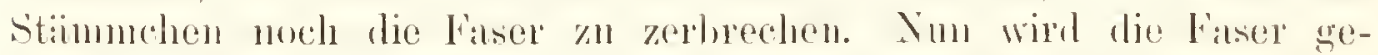

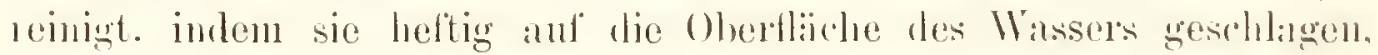
dianat in der Luft geschwomgen wirl. Dabei steht der Arheiter his

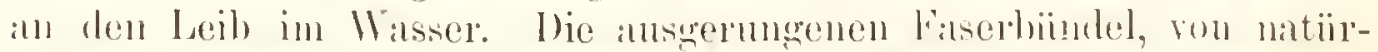

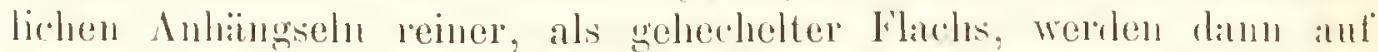

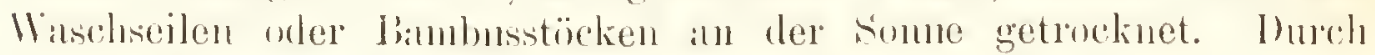
Ilecheln kimm die Ware nowh verfeinert werden. vie litist sich anch heichen (1) undee) mud hat damm einen starken, fast seidenartigen Gilill\%.

lie Pflanzenfasern') sind entwerler II a te (Simenhatre

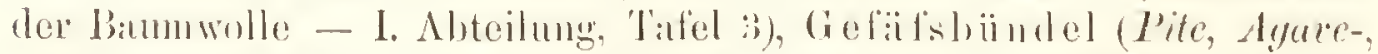

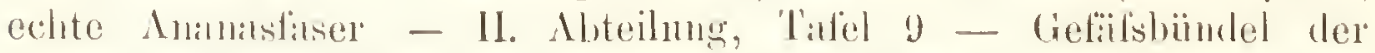

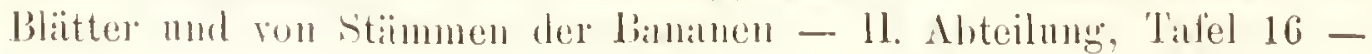

1) Wiesner. 
mler Gefäshïndelbestandteile (Ilanf, Flans, Jute, Snun ans

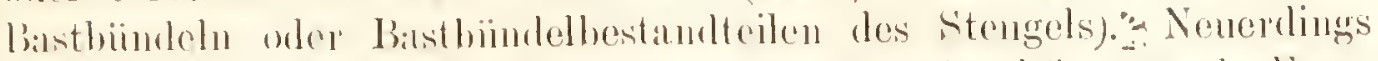

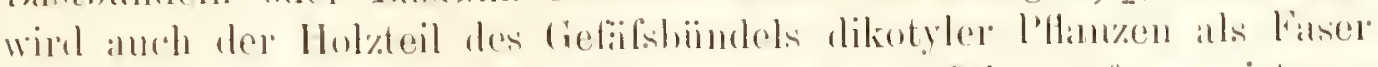

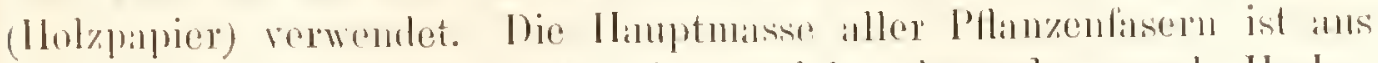
Cellulose \%nsmmmengeset\%l, nehen wehoher hesonders noch Hol\%-

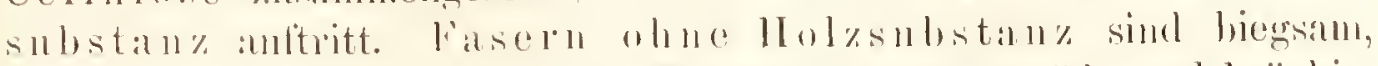

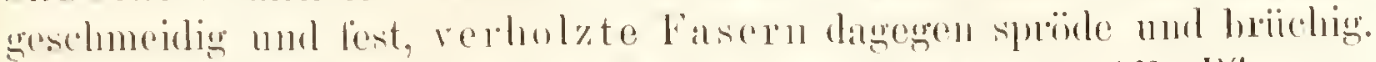

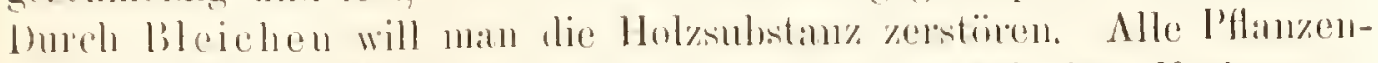

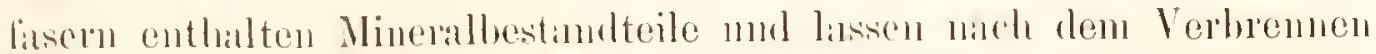

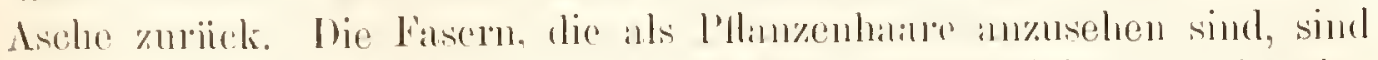

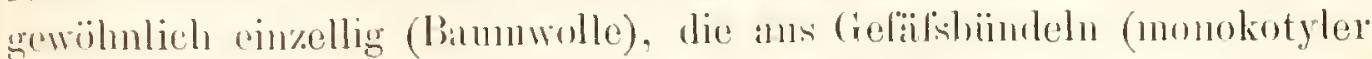
P'llangen) bostehenden sind in der liegel hlofis ans bistzellen ge-

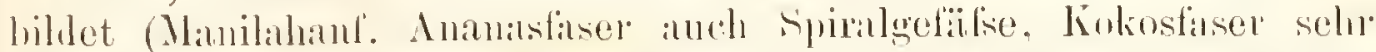
zusammengeset/t). dic aus dem bistteile des (iefifishiindels gebildeten fisernenthallen entweder nur liastzellen, orler nehenbei noch bastpalenchymollen, seltener lieste von liastmatistralulen oder Fiebröhren.

Die Jutefase ${ }^{2}$ ist im Mittel $0.8 \mathrm{~mm}$ lncit nnd gewiinhlich 1,5

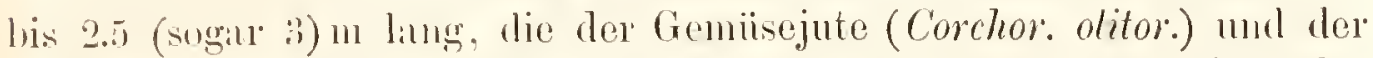

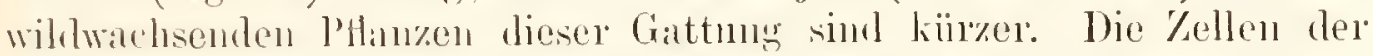
Fascl sind 0.8 his $4,1 \mathrm{~mm}$ lang. Dic Fasel hat emen stalken sei-

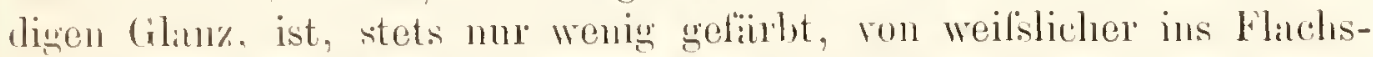

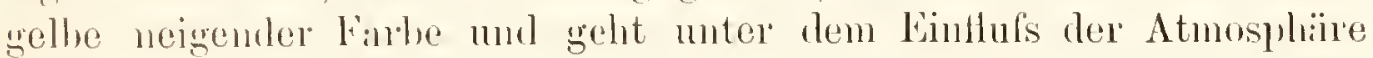
ins Branne ibber. Die rom oberen Stengelteile herriiluenden Fasern sind feiner. als die rom unteren sitammende kommenden. Nur an den feinsten Jutesurten ist die Kerlegung des Bastlündels so woit fortgenchuitur, dafis einzelne bistzellen isolient erscheinen. Fische. fist weilse Jute enthät in lufttrockenen /ustande nur o Prozent Wisser, in einem mit Wasserdampf gefiillten Ratume nimmt sie 23.3 (Sumn 10.37; liammwolle 20,29; l'ite 30,00; Manilahınf 40,00), bräinnlich reworlene Jute $24.01 \mathrm{Plor}$. Wasser anl. Viillig trockene Jute enthiilt (),!) his 1,71 Pro\%. Asche. Durch verdiinnte Chromsäure, anch

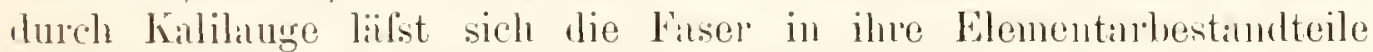
zerlengen und miln erkenut dinn dureh dis Mikroskop, dils die Inte

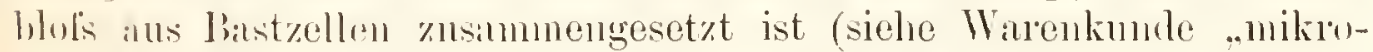
skopische Untersuchungen"*). Die \%ellen sind anmihernd cylindriseh, anlsen jedoch stets etwis alygeplattet, fïinf- bis sechsseitig und am Ente kegelföming mit etwas abgermuleter Endllähe. Hie \%ollwinde

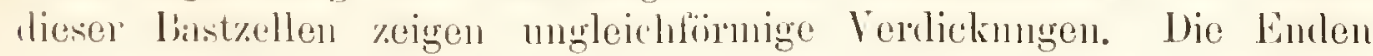
ler bistzellen der kapselfiointigen dute (Corchor. capsul.) sind gewiilnulich schwach, die der Gemiisejute (Corchor. olitor.) stark rerlickt. Die l'aser lälst sich far hen. Da die Faser ron ungleichnälsiger Stiinke ist, steht sie in Stiirke und /aihigkeit denen des Hinfes und liluchses nach.

Verarbeitung und Gebrauch. Die Jutefiser wird in der Heinnt der Pflanze, in Amerika und Emopar zu Gewebeu und 
Seitorwan rermbeitet. Die besseren Sorten dieser Eryengnisse fülnen in bemgalen den Namon Megila, die geringeren, die mo als Lackleinwand henutzt werlen kïnnen, 'Tat obler ('hoti (Jute). Am meisten

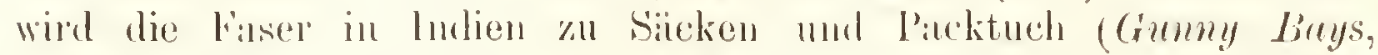
Gumm Cloth), dic indes anch aus Sunn gefertigt werden, verarlecitet. sie dienen zur Verpackmug von Banmwolle. Wolle, Kaflee. Kucker, lieis 1. s. w. Die rohe Jutefaser wird in newerer \%eit in grolisen

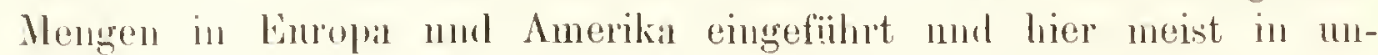
gehleichten /ustinde zn groben Kengen mud säcken (Sackings und b:aggins, die feineren ,Hessims", Schottland) verarbeitet. Sie wirt

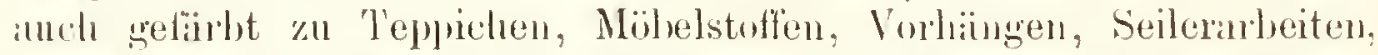

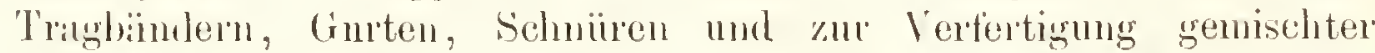
Gewehe in Anwendnng gebracht. In die Fiser den Weelsel ron Trockenheit nurl Fenchtigkeit nicht grnt rertrïgrt, dagegen in fortwïhender Nïsse dinert, so wird sie nenerdings zu nutersecischen Telegraphenkilhehn als lliille der hupferdrähte, welche dam mit bisendribten nnwumlen nud mit geteertem Manilahand ibersponnen ist, rerwentet. In nenester \%oit dient in Dentschlind die Intefiser als Wundenverhandmittel. Die ron der liser ror der Verschiffung abgetrennten Wn\%elenden kommen als hoots oder C'uttimg in den Intmdel nurl werden zu ganz groben Silckgeweben, wie anch namentlich in rer Paprerfabrikation benntat. Die liläter der Genuisejute und die jungen 'Triebe beider Arten werden in den Erzengungslïndern gekocht und roh rerspeist, und ein Aufgnl's der Blitter gilt in Indien fiir misgenstälkend.

Warenkunde. An wertrollsten sind lange, weilsliche oder weifsgelle, d. l. unverholote, geringwrotig hatume, d. l. hereits ver-

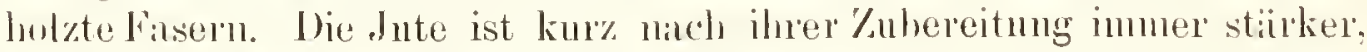
glänzender, geschneidiger und weilser, als wenn sie eine \%eitlang gelagert hat. Alter, licht und Istt mathen sie brännlich, ratuh und spröle. Xur ein lienner kamm die Jutefiser mit Gewilisheit ron den Fisern anderer l'llan\%en, mul zwill nur vermittelst des Mikroskopes (siehe oben ,Jutelisen...) unterscheiden. Oft ist lieser liohstoff nit den Fasern anderer I'fluzen rermischt. Cm die Fiser von Hant mud

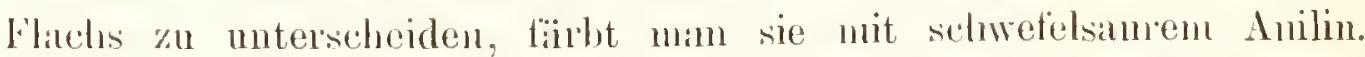

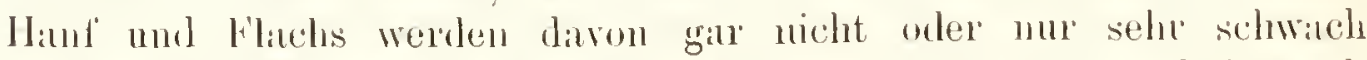
gelblich, die Jutefaser aber gold- his orangegelb geläbt. Allein anch andere (verholzte) Fasern verhalten sich zon diesen lieagens wie die der Jute.

Handelsstatistische Notizen. Jute kam lilliger erzeugt und \%ubereitet werden, als ein anderer latserstofl. In bengalen sehwankt dis lirnteergehnis zwischen 5 und 30 \%entuer pro Acre, im Mittel beträgrt es $131 / 3$ Kentuer, ouler $1500 \mathrm{~kg}$ pro Hektar. Nimmt man dis beste Ergebnis: 30 Kentner pro Acre oder $3375 \mathrm{~kg}$ pro Hektar mud stellt es dem bis jet\%t erreichten besten Ernteergebnis ron biammulle: $750 \mathrm{~kg}$ 
pro Hektal, gegenüber, welcher I'nterschied. besonder's wenn man elwïgt, dals in Bengalen die Jutekultur eine sehr schwerfillige, die banmwollenknlut in Nordmerika eine sehr rationelle ist! Bengalen nimmt in der Juteerengung dieselhe herrschende Stellungr ein wie Nordamerikir in der Baumwollenproduktion, dem es stellt \%u der (iesanter\%engung etwal ein Fïnftel. Die wichtigsten ,Jutedistrikte Bengalens sind: P'ubea $(122000$ Acres), Dinajpur (117000 Acres) und liangpur (100000 Aeves). Bengalen fïhrt jährlich rund 11 Mill. Zentner Jute (100 Mill. Mark), aufserdem 61 Mill. Jntesiicke (20 Mill. Mark) ans. Die Anfertigung der Sücke geschieht zu kimm nemnenswerten Preisen. Die feinere Jnte wird roh ansgefiihrt. Die meisten bengalischen Jutesäcke gehen indirekt nach Enropa, wo sie gröfstenteils zu Matten verarbeitet (England) werden. China, der malaiische Archipel. die Siidsee-Inselı. Ïgypten und Nord-Amerika bringen zusammen nu' den fiuften 'Teil der Gesamtproduktion hervor. Schottland (hundee) ist in Emropa Hauptsitz der Juteindustrie. In Bengalen wird teils ron den Eingeborenen mit der Hand, teils von den in nenerer \%eit entstandenen zahlreichen Maschinen-Spinnereien und - Webereien der bei weitem grö́fste Teil des Rohmaterials verarbeitet. Cillcutta ist der Weltmarkt fiir den Rohstoff. Es wird immer mehr rohe Jute in Indien selbst (zu Siicken und Emballagen) rerarbeitet und dam als fertige Ware ansgefiihnt. Diese indischen Jutefahriken werden meist ron hritischen Firmen etabliert. Um die Mitte des Jahres 1876 sollen in Bengalen schon 4500 Jutestiihle (Pawer-looms) im Ginnge gewesen sein, welche jührlich 96 Mill. Jutesäcke herstellten. Die Hauptabnehmer für Rohjute sind Grofshritannien und Irland (Dundee, London und Glasgow) und die Vereinigten Staaten von Sord-Amerika (Massachusetts mul Rhode Island), dam nebenbei der curopäische Kontinent und China. Die gröfste Menge der Jutes:icke hedarf Indien selbst znr Emballage seiner eigenen Stapelartikel. In England hat sich die Produlstion und in noch höherem Grade die Insfuhr gesteigert. In Deutschland werden etwi 300000 Zentner Jutegarn (in Braunschweig, Prenfsen, Sachsen, Reufs jïngere Linie, Oldenburg und Bremen) fahriciert. Aufserdem werden in diesen Fabriken auf Kraftstihlen Jutegewehe hergestellt.

Geschichte. Die Verwendung der Jutefaser zur Herstelhung ron Stricken, Seilen mol Geweben in Bengalen ist alt. Anfinglich bedeutete in Bengalischen Jute Zeug, jetzt nemut man die Faser der Gemïsejnte so, wïhrend die der kapselfrïchtigen Jute Naltajute genamnt wird. Die Ostindische Kompagnie hemiihte sich sehon in den Jahren 1796 und 1797 dureh Aussendung kleiner Quantitiiten nach Europa, Anerika nud England die Aufmerksamkeit der Industriellen auf diesen Artikel zu lenken, jerloch olme Erfolg. Erst 1820 tingr man in England (Abinadon) an. Versuche zn machen mod rewwendete

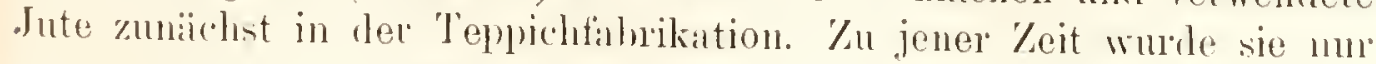


mit der Hand gesponnen. In Jahre 1828 wnden 36 Zentner roher Jute im Werte rom 6.2 Pfond Sterling, und um das Jahr lsing bereits gexen 700000 \%entuer im Werte ron nahezn 300000 Pfmul Sterling aus (ostindien eingefiihrt. Hauptsïchlich ist es von da an der Inergie, Geschicklichkeit und Ausdimer des Schottlinders Watt (Dundee) zu verdanken, dafs dieser Rohstoff in immer gröfseren Massen zur Verwenlung kam. I Hrrch den Krinkrieg (1853 bis 1856) wurde den Englinulen der Bezng ron russischen Hamf und Flachs abgeschnitten mul es hiitte eine grofse Anzahl von Simnereien in England mud Schottland still stehen miissen, wenn sich nicht in der Jute cin ersetzendes Arbeitsmaterial geboten hïtte. Resonders hat anch die Batumwollennot zur Zeit des anerikanischen Biirgerkrieges höchst beginstigend auf die englische Juteindustrie eingewirkt. In Deutschland wurde die Jnteindustrie in Jahre 1861 durch die Jutespinnerei in Vechelde (Herzogthum Branuschweig) eingefiihnt und es bestehen jetzt eine ansehnliche Zahl grofser Jutespinnereien und - Webereien in rerschiedenen deutschen Staaten, ron welchen das crwïhnte Läindchen die bedentendste besitzt. Anch in Frankreich (besonder's in Departement du Nord), Österreich, Belgien. Holland und Nord-Amerika, das in letzter Zeit gröfsere Jute-Spinmereien und -Seilereien angelegt, hat diese Industrie festen Fufs gefafst. Den stärksten Fortschritt in der Juteindustrie weist indes Ostindien, diss Heimatland der Jute, anf', wo seit 1870 selı bedentende mit englischem Kipitil finndierte JuteWebereien errichtet worden sind. Die junge Juteindustrie last in Umfange schon die alte Leinenindustrie iiberfligelt.

\section{Figur II. Ramiepflanze'), Chinagras} (Boelmeria ${ }^{2}$ ) tencecissima ${ }^{3}$ ) (Gaud.).

Die RiamiepHtanze gehört zur Lnterkliasse der perignbliitigen Dikotyledoneu, zur Orduung her Yesselgewächse (Urticince) ${ }^{4}$ ), nnd zwä zur Familie der Brennesselgewächse (Crticuccur) ${ }^{4}$ ).

Ilie Ordnung der Nesselgewächse (Urticinae) ${ }^{4}$ ). Pïume. Strä̈cher oder Kr:̈inter, deren Bliitter und junge Zweige mit steifen Iianen, stechenden Borsten oder Brembanen verschen sind. Die Inialle der diklinischen orler polygamen Di!iten hesitzt in der liegel eine dachriegelföronige Knospenlage. Der Fruchtknoten ist oherstindig.

1) Ramic. Name ter l'tanze anf den malaisehrn Archipel; in Indien nemut man den Faserstoff derwelben lihea, in China 'Tehou-ma, in Tapan 'Tsio oder Karn. - 2) G. L. Böhmer (1723-1803), gestorben \% Wittenherg als P'rufessor der Anatomie und lintanik. Verfisser von Flora Lifsiac ete. - ${ }^{3}$ ) Sehr zähe. 4) Von uro, ustun oder urtum, luemen, urtica, Bremesecl. 
Die Frucht suringt nicht anf". ist ein- his zweificherig und enthïlt in jedem Fance einen eiweifshaltigen oder eiweifslosen simen.

I) Familie der Brennesselgewächse (Urticuccue) enthiilt kräuter oder Strincher, deren griine T'eile meist nit bronnlialiren (die Ramneptlanze nicht) bekleilet sind. I) ein- orler zweihïusigen, selten polyganen Bliiten stehen in rispigen, kopflömnigen nder gekn̈̈uelten Blïtenständen. Dis Perigon ist zwei- bis fünfteilig, seltener ungeteilt. Die Staubblitter sind im Grmude des P'erigons vor den Blïttern desfelben in der nämlichen Kailhl eingefügt und laben einwärts gekehrte Staubbentel. Ist das Perigon ungeteilt, so ist seinem (nounde nur ein Staubblatt eingefïigt. In der Regel sind die stanbfïilen in der Knospe bogrenförmigg gekrümmt, so dals sie bein Aufb)ïhen elastisch emporgeschnellt werden. Der Frnehtlinoten ist einfüicherig und entwickelt sich zu einer einsanigen sichliefsfrucht. Der simnen ist anfrecht und besitat in der Nitte des fleischigen Eiweifses den geraden Kern (Fig. II 3). Die Bremnesselgewïchse besitzen feste, zu Gespinsten und Geweben rerwendbare Bastfasern. - Siehe unsere „Repräisentanten einheinischer Pflanzenfamilien", "Grofse Brennessel“. Zur Ordnung der Nesselgew ächse gehören noch die Familien der Hanf-, der ILaubeer-, der Brotfrucht- und der Ulmengewächse. Siehe unsere „Repräsentanten einheimischer Pflanzenfamilien" unter Gemeiner II anf und Feldriister" und "Ansländische Kulturpflanzen II" unter Echter Brotfruchtbaum und Gemeiner Feigenbaum.

Die Gattung Boehmeria (T'acq.) umfafst Krïuter und sträucher. welche unseren Bremesseln sehr ähnlich sind, aber keine Brennhaare besitzen. Erst in neuerer Zeit sind die bezüglichen Arten ron der Gattung Urtica abgetrennt und unter einem eigenen Namen gruppiert worden. Noch jetzt wird die Ramie hïufig als Crtica utilis ${ }^{1}$ ) und Urtica tenacissima ${ }^{2}$ ) auf(gefiihrt.

Die Ramiepflanze 2) (Bochmoria tenacissima ${ }^{3}$ ) Gand. Fig. II) ist lirantantig und besitzt einen ansdinernden Wurzelstock, der bis zu 15 Stengeln anstreibt. Der Stengel erreicht eine llöhe ron 1,85 bis $2,15 \mathrm{~m}$. Die Bliitter sind breitoral, an der unteren Seite weifslich, Hinumig, an der oberen Seite glatt, dunkelgriin, sie sind geziihnt und ron einer starken Mittelrippe durchzogen. Die Blïtentratuben treten 1n1. teilweise ans den biattwinkehn. teilweise anch ans blattlosen Stellen des Stengels. Die Blïten (Fig. II 1) erimnern stark an die der gemeinen Bremnesselt) (siehe olen Ordnung der Nesselgewärhse und Fanilie der Bremnesselgewäichse) und disfelbe gilt von den sehr kleinen Simen (Fig. II 3).

Über die Artenungrenzung herrscht noch keine rollstïndige Übereinstimmung. Die in China ann hïutigsten lultivierte Form wirl

1) Nüt\%liclı - 2) Sehr zähe. - 3) Nach Siemler lll. - 4) Zillul-bollmann, Rejräisuntanten cinhcimischer I'tlanzenfanilien II, 2. S. I u. s. fo 
mit Bochmeria 1) nivea ${ }^{2}$ ) he\%eichnet. Sine andere Form. die weniger in ('hina als anf den malaiischen Archipel verlneitet ist, wird von einigen als Art ancrkinut, unter dem Ninnen Boehmeria tenarissima, von anteren als cine Spielint, die sie Bochmoria nivea var. tenarissimm nemen. Fine dritte Form, die in Jara ronkmunt, alher verlneiteter in Indien ist, namentlich in Assam, wird bald als Art, Boelmeria candicans, balld als Spielart, Boehmeria nivea var. candicans hezeichnet. Eine vierte Form, die sich in Java findet, wird ron einigen als Art anerkannt, Bochmeric utilis, von anderen als Spielart, Bochmeric nivea var. utitis; es ist aher auch die Behauptung anfgestellt worden, difs sie nit der vorhergehenden vollationdig iilscreinstimmt.

Bochmeria frutescens in Nepal, Sikkim und anderen Teilen des Himalaya in der Höhenlage ron etwa $1000 \mathrm{~m}$ und Bosheria pmya und andere wild waclssende indische Arten werden nicht angebant und geben gröbere Fiscrin.

Heimat: Indien. Verbreitungsbezirk: Sïd-Asien, Smdainselı. Dolukien. Marianen, China nud Japrun. Anbanversuche in Nordamerika, Kalifornien, Mexiko. Venezuela, Brasilien. Australien, Ägryten. Algier und Siid-Frankreich.

Kultur. Di die Lamiepflanze einen anstanernden Wurzelstock hesitzt, kam ilı Auban nur in Ländern mit fiostfreien W'intern mit Erfolg geschelien, am sichersten da, wo anch die Baumwolle gedeiht. Selbst in den Tropen gerleihen sie in einer Höhe ron $1000 \mathrm{~m}$ nicht mehr. I) Ramiepflanze mufs rasch in die Höhe schiefsen, wenn sie eine feine, geschmeilige Faser liefern soll, und lazu siml die Bedingungen erforderlich, welche für die Jutepthnze angegehen wurden. Locker und humusreich mufs der Boden sein, eine stirke Fenchtigkeit dauf ilm nicht fehlen, doch mufs Crrundwasser fern bleiben. Wo die natiirliche Fenchtigkeit fehlt, sind Bewässermugsanlagen erforderlich. Dis die Ramiepflanzungen anf die Diuer ron 20 his 25 Jihren ananelegt werden, so darf zur Anlage nu finchtharer, aber nicht schwerer Iborlen gewïhlt werden. Die Anpflanzung kimm durch samen, durch Silitwmzehn und dureh silitwmzeh und Absenker in Verhinhung mit einander stattfinden. An empfehlenswertesten ist die Anpflanzung durch Siatwurzhn. Ineselben miissen ron den Mntterwurghn in einel Lïnge von 10 bis $12 \mathrm{~cm}$ scharlf abgeschnitten werden. Sie werden ähnlich wie Kintoffehn gepflanzt. Schuittreif ist die Riamiepflanze gronen Ende der Bliitezeit nul wenn die griinlichen Stengel am Fulse

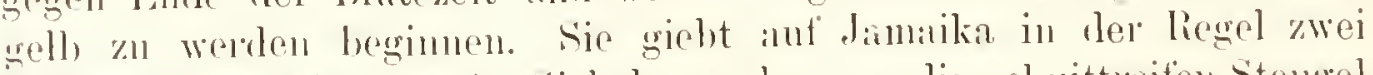
Jihrescruten. Nit scharfen Sichehn werden nur die schnittreifen Stengel

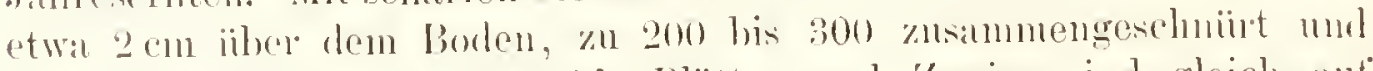

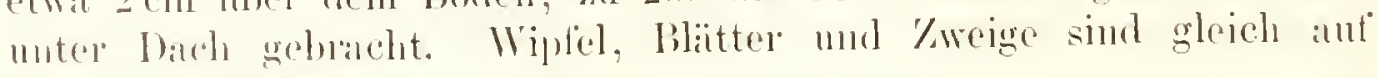

1) Nur diese Form ist wild gefunden worden, Was die Anuahme lwhiaftigh, diffs die anderen formen in den linlturen aufgekonmene larietäten sind. -

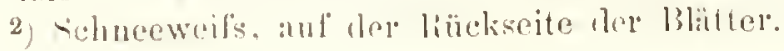


dem Felde entfornt worten. lieide .Jahresernten angehen fïr den Hektar etwa 1200 kig gerenighte Fiscrus.

Gewinnung' und Verarbeitung der Faser. Dic liamieptlance kamm nicht, wie die Jute, der Hant oder liachs dem liostpromesie nuterworten werden, ilue Fiser winl in Asien noch \%nr Zeit Anrch Handinbeit ans dem linschen stengel losgeschäilt. Klehstoffe (Vilsculose, Cutose mul l'ectose) verbinden die limole nit rem holzigen liern mul gehen hei Torhandensen von Fenchtigkeit leicht

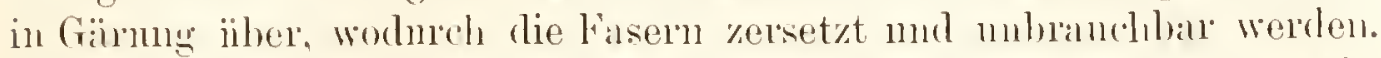
Die Stengel werden mit dem Jessor und den Fingen niggeh geschiilt, in Wasser gebatet mul gebleicht mul an der Somme getrocknet. Franen trennen die Streifen mit den Fingernïgehn in einzelne Fasern, kochen diese dam mit gehacktem Stroh in Wasser, nm sie zu bleichen. Jach dem letzten Trocknen in der Sonne werden die Fasern in Strähne und ballen verpackt. Eine Arheiterin kam im Durchschnitt tïglich nur $" / / \mathrm{kg}$ Fasern losschïlen und schaben. Neuerdings rersteht man aus lem liohstoffe teils auf chemischem, teils aut mechanischem Wege eine sehr feine und schöne Faser zu gewinnen, so dafs ihre Verspinnmug zu seidenïnnlichem Garne enmöglicht wird. Es gelingt dem verbesserten Verfahren, die feine Faser fiir die Firbung in den brillantesten Schittierungen, wie tïr die Bleiche zu reinem Weifs rorzubereiten. Die fertigen Garne haben einen seidenartigen Glanz und lissen sich vor\%ïglich nach einfachster Baumwollenfarbmanier färben.

Die Ramiefaser. Die Bastfaser der Ramieptlanze ist ron anfserordentlicher Festigkeit und Zïhigkeit, sie setzt dem Zerreifsen einen dreimal grö́seren Widerstand entgegen als die Hantfaser. Dic Bastfaser 1) besteht nicht nur aus Bistzellen, sondern auch aus anderen benachbarten histologischen Elementen les Stengels. Der Bast liegt unter dem kleinzelligen Parenchyngewebe, hat eine schmutzig griüliche orler graubräunliche Farbe und seme Zellen sind nur sehr schwach verholzt. Die kotonisierte Ramiefiser hat einige $̈$ hnlichkeit mit dem kotonisierten Chinagras, unterscheidet sich aber von diesem durch einen geroingeren Glanz. Die Gestalt der die Ramiefaser zusammensetzenden Bastzellen stimmt mit der Form der Bastzellen des Chinagrases vollkommen überein, nur in den I singen- und Querdurchmessern derselben zeigen sich Unterschiede. Die kotonisiente Ramieptlanze hesteht blofs aus Bruchstiicken ron Bastzellen, von denen immer mehrere aneinander haften.

Nutzen. Die grünen Bliatter gehen ein branchbares Viehfutter, aus den trockenen läist sich aber jenes anfiserordentlich rähe Panvicr hereiten, das in China und Japan zu den verschiedensten /wecken: Gefäsen, 'Teppichen mul allerlei Gegenstïnlen, benutat win, welohe

1) Wiesner, Rohstoffe des Pflanzenreichs. 


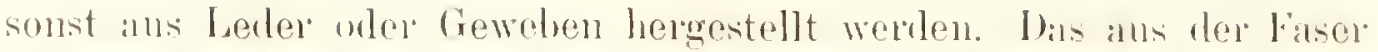
hergestollte Gan ist infolge seiner '/ähigkeit in China zur Verfertignng von Seilen. Fischernet\%en und den feinsten fiewehen remandt wordron und wirl jetrt in vielseitiger Weise somohl mit Wolle. Scoide. Leinen gemischt als rïr sich verableitet. - Die Anzahl der Artikel. welche ans liamie herosestellt werden, wichst in jerlen Jalne; als die wichtigsten sind m nemen: 'Tnche, Game, Chenille, Kondelı. Vurbänge. lorten. Taschentiicher mul Shawls.

Handelsstatistische Notizen. Infolge ler lischen Entwinkelung dieser Industrie limute ler gesteigerten Nichfiage narh lohmaterial nicht immer genuigt werlen. Trutz ilner schwerfilligen Kulturnethorle brachten die Chinesen ihre Ausfull ron limmiefaser von einem Versuchshallen anf die gegenwirtige Höhe ron 11 Mill. Kilogramm in Ialne. Die Ausfuhr der malaischen Inseln läst sich nur sehr schwer ermitteln. In Indien wird sich dic Ausfuhr dieser Faser erst nach Einfïhrung einer gecigneten Entfiserungsmaschine hehen. Italien, siid-Frankreich, Spanien. Portugal. Algier, Ägrpten. Nord-Amerika, Kalifornien. Mexiko, Venezuela und Brasilien laben grösere Anbaurersuche mit der vielverheifsenden Faserjthanze rorgenommen, doch muls der Fifolg noch weiter abgewartet werden. Frankicich hofft ans dem Anban der Ramieptlanze fiir Tonking eine Quelle des Wolnstinder zu machen.

Geschichte. In der Heimat der Pflanze, in Indien. Siam. Camborlscha. Cochinchina, Siid-China, Japan mul anf der ganzen siirasiatischen Inselwelt hahen es die Vïlkel seit unlenklichen Zeiten rerstanden, die seidenglinzenden, geschmeidigen, anffallend starken Fasern derselhen zur Herstellung einer Anzahl Artikel zu verwenden, an deren Spitze rlas feine, elegante Tuch steht. Welches als Cantouseide orler Seersucker im Handel bekannt int. und dem andere ciegenstiunde in Abstufungen rer Feinheit und des Wertes folgen. his herunter zum groben Segeltuch mul Fiselmet\%. Im 16. Jahrhundert soll die Rimmiephanze in den Niederlanden zur Verwenhung gekommen sein. crwiesen ist, dals in Jalue 1810 rer erste Iballen in England eingefiihnt und von John Marshall in leeds ïhernommen wurle. Erst nach 40 Jahren latte Marshall die Schwierigkeit. mit Hilte eines chemischen Prozpses die gummiantigen Anhängsel zu entfernen, in soweit iiberwmulen, dals die Verarbeitung stattfinden komnte. Anf der Londoner Ausstellung rom 1851 zeigte Mamshall sein Gewebe und fand damit allseitige Be-

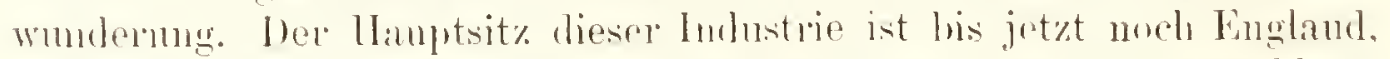
daneben hiilst sie abre anch in Frankreich anf und in Dentschlanu ist sie nicht mberlontend. Die erste deutsche Chinawasmannfulitur in Zittan hat in Dontsehland den Anbaln diesel Ptlanze vielfald an-

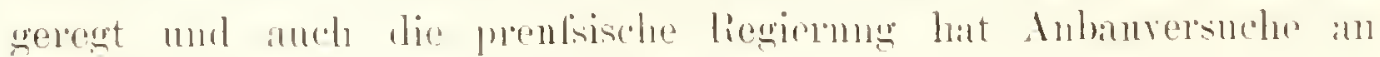
verschiodenon ().ten anstallen basion. 


\title{
T a fel 9 .
}

\author{
Figur 1. Echte Ananas ${ }^{1}$ ) \\ (Ananasect ${ }^{1}$ ) sativa $\left.{ }^{2}\right)$ Lind.).
}

Auch die cchte Ananas gehört zur Ordnung der Schwertlilien (Ensatac), und zwar zur Familie der Ananasgewächse (Bromeliaceae) ${ }^{3}$ ).

Die Ordnung der Schwertlilien (Ensutue). Pflanzen mit steifen, parallehnerrigen, schwertförmigen Blätter'n. Perigon regelmäfsig oder unregehmälsig, sechsteilig, oberständig. Staubblätter drei oder sechs, selten mehr freie Staubhlätter. Fruchthnoten dreitächerig, entwickelt an seinen mittenstïnligen Samenträgern zahlreiche Samenknospen. die zu eiweilshaltigen Samen heranwachsen.

Die Familie der Ananasgewächse (Bromeliaccae). 'Tropische Kräuter oder Halbsträucher, manche (als Luftpflanzen) anf Bïnmen schmarotzend. meist mit starren, an Grunde scheidigen, dornig-gezähnten Blättern. Über denselhen erhebt sich der Stengel, um eine Älne, Traube oder Rispe zu bilden, an deren Ende bisweilen (Ananas) nochmals griune Blätter erscheinen. Das Perigon besteht aus sechs Abschnitten, von denen die drei äufseren kelchartig. die drei inneren bhmenkronartig gestaltet und gefiirbt sind (Fig. I 1). Jede Bliite besitzt sechs Staubblätter (Fig. I, 1 u. 2) und einen unterstiindigen, manchmal auch nur halbunterstinndigen Fruchtknoten. Der Griffel hat drei Narben. Die Frucht ist eine Kapsel oder Beere (bei der Ananas, siehe unten, eine ..Steinfruclit").

In 18 bis 19 Gattungen iiler 200 meist im tropischen Amerika heimische Arten.

Die Gattung Ananas (Anănas Lind.). Die zahlreichen Fruchthnoten sind innig mit der Achse des Bliitenstandes verschmolzen und bilden so eine tannenzalfenïhnliche, fleischige, wohlschneckende Scheinfiucht.

1) Anăna, anāssa, auch nanas wird die Pflanze von den Tupis in Brasilicn genaunt. Der Name kommt schon 1580 bei llernandez vor. - 2) Angebauet. 3) So genannt nach liromel. Botaniker und Arzt zu Gothenburg (gehoren 1639, gestorben 1705); er sehrieb eine Chloris gothuin 1699. (Verzeichnis der bei Gothenburg wachsenden Pthanzen). Jeunis. 
Echte Ananas (Anunussa sution Lind. Fig. I) liat etria 100 Spielarten. W urzelstock ist ausdanemd. Stengel in den

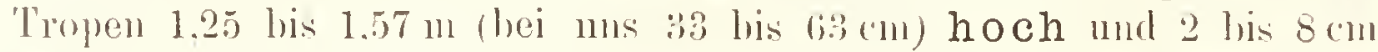
im Durchmesser dick. Blätter ${ }^{1}$ ) 14 his $26 \mathrm{~cm}$ lang, aloiiartig, lineal. starr, dornig-gezïhnt, stehen sprialigr. Blütenähre schopfig; Blüten (-spindel) -stiel emligt in einen Blittschopf; Blüten in den A diseln gelher Deckblätter (Figr. I. 1) mahlreich. erst biur, dann purpur-, zuletzt lilafirlig. selmell verbliihend, klein; drei trockenläintige :̈ulsere grine $\mathrm{H}$ üllblätter (kelchartig) mngehen drei innere (hlumenkionartige), innerhall, der letateren stehen sechs staubblätter (Fïg. I, 1 u. 2) um einen Griffel mit dreilinpigem $\mathrm{Narbenrande;} \mathrm{der} \mathrm{dreificherige} \mathrm{Fruchtknoten}$ und (ler Grund der Deckblätter, die nach der Befruchtumg Heischig werden, sind mit einander verwachsen. weshill, die Frucht eine Scheinfrucht, Haufen- oder Simmelfrucht ist, deren Obertliche ans einzehen liecren zu hestehen scheint nud die iiberall ron Deckblätem durchwachsen ist. Sie ist anfungs griun. reifend gell, fleischigr. angenehm riechend und nach Erdheeren (Erdbeerapfel) schmeckend. einem Tamnenzapfen :ihnlich, oft 5 his 25 Pfund schwer. Die Farbe der Friichte ist purpurrot, scharlachrot. schwarzrot. gelb, griin und weifs in den verschiedensten Schattierungen. Die spindel setzt sich hoch über die Frucht hinaus fort und endigt in einen Blätterschopf. Die Samenbildung ist durch die Kultur gesrhwïcht. Die Samen schlagen zu Gunsten des FruchtHeisches oft fehl.

Heimat: Amerika ${ }^{2}$ ) (Mexilso bis Brasilien), frihtreitig von den Europiern nach Asien und Afrika eingeführt. Verbreitungsbezirk: In allen Tropentindern, bei uns in Gewiichshïusern kultiviert.

Kultur. Die Ḱnltur der echten Aninas ist in den Tropenliindern höchst einfach. Die kultivierten PHanzen hringen gröfsere Frïchte, als die wildwachsenden, sind aber meist ohne Samen. die verwilderten (Celebes, Brasilien) haben guten Samen, aber mschmacklafte Früchte. In Westindien bepflanzt man ein Stiick Land rom 25 Ar mit 1600 bis 2000 Dutzend Setzlingen bei Reginn der Regenzeit und gewinnt nach zwei Jahren bei der ersten Ernte etwa 1500, hei der zweiten und dritten 1000 Dutzond Friichte. Die Vermehrung seschieht :m besten Aurch Wurzeliprossen, welche man ron reifen Frïhten abbricht. Wïhrend der trockenen . Nonate wird die Anamas in den 'Tropenlïndern weniger saftig, als in unseren Treibhäissern, wo man Exemplane bis zu 9 Pfund Schwere rieht. Vielfich indes werden

1) I egt man Ananasblïter für die Sammlung ein, so maehen sie das l'apier", wenn sie anch frisch sind, nicht feucht mul bedürfen oft mehr als cin rolles Jahr, $1 \mathrm{~m}$ gan\% troeken zu werden. - 2) ,Alle ichriftsteller, die zuerst üher Amerika geschrichen haben, sprechen von ilrr." 1 de Candolle. Der Ursurumg der Kulturptlanzen. 
die Ananas und ihre Verwindten angebatut, mu aus ihren Blittern lasern zu gewinnen. Zn diesen Zwerke zieht man junge Pllanzen im Sohisten grofs (Philipuinen) nud rerhindert die Fruchthildung, nun allen Sift der Pthanze den Blïtern zuznwenden. In Europa (besunder's Lngland), anch in Deutsehland (in l'lagwitz bei Kwickin, (iinlit\%

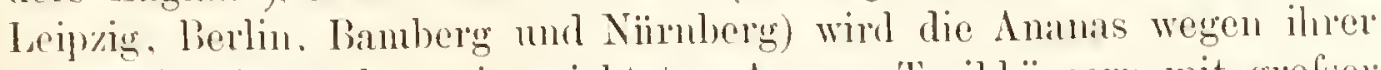
Frucht in eigens dazn eingerichteten Ananas-Treiblüusern mit grofser Nlühe und grofsen Kinsten gezogen und ist hier ihre Kultur in drei Perioden eingeteilt. Die jungen Pflanzen heifsen .Kindel“ (Kinder), die älteren Folge- und die reifen liruchtpflanzen. Die Frïchte leiden oft unter Krankheiten (Flecken. Pilze etc.), entarten öfters zu Moustrositiiten. sondern Gummi ah und werden durch Schildlïuse (Coccus Bromeliae Bouché) heimgesucht.

Gehalt und Wirkung. Die Ananasfrucht wird wegen ihres aromatischen Saftes. der erfrischend wirkt, sehr geschätzt. Sie ist das wohlschmeckendste Beerenobst. Das Aroma ist in den in den Tropenlïndern gebauten Frïichten gröfser und lieblicher, als in den in unscren Gewächshäusern gezogenen. Durch häufigen Genuls werden indes Zahnfleisch, Zühne, Nagen und Harnorgane schmerzhaft davon ergriffen; das Zahnfleisch blutet nicht selten davon. Man hat anch anf die Ananas als eine Zucker liefernde Pflanze anfmerksam gemacht, weil sie 11,5 Proz. krystallisierbaren Zuckers enthalte; leider aber sind demselben 2 Proz. nicht krystallisierbaren Zuckers beigesellt. Nach Buignet ${ }^{1}$ enthält die Ananas 1,98 Proz. Invertzucker, 11,33 Proz. Rohrzucker, also 13,31 Proz. Gesamtzucker.

Faser der Ananas. Die Ananas- oder Bromelia-Arten gehören zu den Pflanzen, deren Blätter eine grobe Faser²) liefern und die deshall, angebaut werden. Die Ananasfaser ist weilslich, ziemlich glïnzend, steif, rund, etwas glatt, bis $1,2 \mathrm{~m}$ lang und 0,15 bis $1.2 \mathrm{~mm}$ dick. Sie setzt sich grö́stenteils aus Bastzellen zusammen, in den stïrksten Fasern treten anch Spiralgefïse auf. Die Bastzellen sind cylindrisch und 1,4 bis $6.7 \mathrm{~mm}$ lang.

Gebrauch. Die Ananasfrucht gilt fiir die köstlichste aller Frïchte und dient in den Tropenlïndern als wohlschmeckendes Obst. Auch liifst man dort den Saft giiren und gewimnt daraus Wein und Branntwein. Bei nus ist sie roh wenig wohlschmeckend nul wird in diesem Zustande in Stïcke geschnitten und mit Zucker und Rotwein als Leckerei gegessen. Aus dem ausgeprelisten Safte bereitet man durch Gä̈rung Ananaswein, Ananaspunsch und Ananaseis. Anch verwendet man die Frueht (Frankieich) \%n einem beliebten Likör, Nanaja genannt. In Indien bildet die Frucht ein Heilmittel gegen die verschiedensten Krankheiten. - Bei uns wird die Anamas teils in ganmen

1) Ann. de Chim. et de Phys. III, Bd. 61, S. 233. - ${ }^{2}$ ) Siehe Kapselfrüchtige Jute "Pflanzenfasern", S. 46. 
Friichten nach Pfumd. teils in Scheiben geschuitten und in Zucker gesotzt in den Handel gelbriachit.

Die A uanasplanze dient in Brasilien und Guyana zum Einfissen der Felder. Ian gewinnt die Faser (hauptsä̈chlich aus $A$. sylrestris) ${ }^{1}$ ), indem man die Bliitter zer(puetscht, in Wasser einlegt, das lockere \%ollgewelve alschalst, die festen Faserbïndel wieder in Wasser legt. bis sich die einzelnen Fasern von einander lïsen, diese alspiilt nund diun hleicht. Sie dient zur Verfertigung der Ananasseide. des schönen L'imna- oder Ananaszeuges. Ihre Verarbeitung gewälurt bei Minnila ganzen Dorfschaften Unterhalt. Die Faser eignet sich hauptsïchlich zur Herstellung von Seilerwaren. Mau benutzt sie auf Zwirn anch zu feinen Gewehen (die Tagals auf den Philippinen), die sehr teuer sind.

Warenkunde und Handel. Yon den zahlreichen Spielarten sind in Europa hesonders geschïtyt: 1. der sogenamite Zuckerhut (Sugarloaf), nit Kegelform und gellfarbigem Fleische. soll nuiibertrefflich an Siifse und Aroma sein; 2. der Jajagnil. mit gelbem Fleische, aher klenerer, eiformiger Frucht, Sugarloal 2 ) wird hesonders in Westindien angebant. Dann folgen in der Crïte lippley, Muscow, Queen, Antigua und St. Yincent. Dis prangendste Anssehen lat Prince Albert; am gröfsten sind Trinidad und Erville (25 Pfund). Spanish ist klimalnat, das Fruchtfleisch fest. Kew soll 20 Pfund erreichen und einen ansgezeichneten Gesclmack besitzen. Yon den Bahamas werden durchschnittlich 600000 Dutzend Ananas im Jahre ausgefiihnt in einem Werte von 800000 Mark. Nur selten steigt die Ausfuhr auf 650000 Dutzend Ananas in einem Werte ron 1 Million Mark. Yon den in New-York ankonmenden Friichten werden etw: 20 Proz. als faul ausweschieden. Friiher hezifferte sich der Verlust anf 24, 34, sellost bis 40 Prow. In Nord-Amerikil, nenerdings sher auf den Bahamas und einigen westindischen Insehn werden: die Aninas in grolsen Fabriken prïiserviert. Yon der Ananasansfulur der westindischen Inseln gehen drei Viertel nach Xord-Amerika (NewYork). Cuba schickt durchschnittlieh 100000 Dutzeml nach New-York unl St. Bartholomens 25000 bis 30000 Dutzend. In neuester Zeit crongen anch Jannitika. 'Trinidad mul andere westindische Insehn

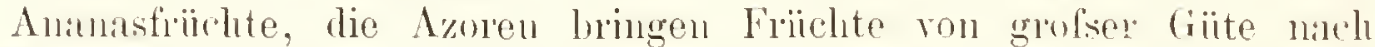
kinglind und selbst nach New-York. Die Aninas ron Guayaquil sollen die hesten der Erde sein. Niilan, eine der Sinndwidh-Lnsehn. loringt besore Anamas herror als der liest der Gimpe. Sie verden nach Sinn F'anzisko ansgefiiln't. In Indien und ant den malaiischen Insehn

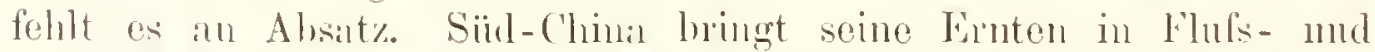

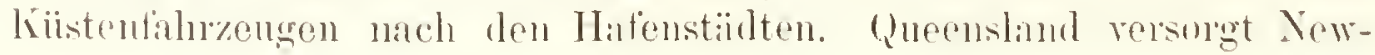

1) Ihe laser dieser Art wird "lstle" genamnt, - H Ilat, mach dem amerikanischen fiestlande verpolingt. hetrïichtlich an Güte verloren. 
Sonth-Wales mud Viktoria mit Frucht. - Die zmm Vorsand hestimmten Frïchte lialst man nicht gan\% reif werden; die abgelösten linichte behalten ihren Wohlgeschmalek nur wenige Tinge. In Europa ist die Zucht der Ananas nicht mehr so lohnend, seit Dimpter sich an den 'Transporte lev trepischen liviichte, also anch der Ananas, heteiligen, mod ihre Maschinen und Banart, in Bestrehen. die Reise abzukiirzen, rerollkommnet werden.

Geschichte. Die Mnanas kam 1514 mach Spanien an den Iof Ferdinam des Katholischen. Hermandez de Ovicdo gah in seiner ..Naturgeschichte Indiens" 1535 die erste Beschreibung und Abhildung der Pflanze. Nan hatte eine Ananasfincht an Fial $V$. gehracht, welcher der Sache milstraute und die Frncht nicht kosten wollte. Die Pflanze wurde 1555 genaner hekannt. Im Jahre 1650 rersnchte Le Conr. ein hollïndischer Kinfmann, in seinem Garten zn Driehock bei Lerden mit Erfolg ihren Anbau. 1690 brachte der Earl of l'ortland die I'thanze nach England, während der erfolgreiche Anbau derselben erst 1712 Sir Mathew Decker bei Richmond gelang. 1703 brachte Dr. Faltschmidt in Breslau die Ananas zum Bliihen und schickte sie als Seltenheit an den kaiserlichen Hof nach Wien.

Figur II. Amerikanische Agave'), grofse Aloë, Wunder- oder Baumalö̈, Magney ${ }^{2}$ )

(Agāre ${ }^{1}$ ) americāna L.).

Die amerikanische Agave gehört zur Ordnung der Schwertlinien (Ensatue, S. 55) und zur Familie der Agavengewächse (Agureae).

Die Familie der Agavengewächse (Agaveac). Riesige tropische Pfanzen, die den Ananasgewächsen und den Amaryllideen nahe rerwanit sind. Sie unterscheiden sich ron den ersteren dadmrch dals ihr Perigon nicht in einen kelchartigen und einen blumenkronartigen kireis zerfitlt, von letzteren mur durch ihre Grölse, ihre Tratht. die biischelige Wurzel und den heblütterten Schaft.

Die Gattung Agave (Agave L.). Der ganz kurze Stamm trägt eine grmudstiundige Rosette rom dicken. stacheligen Blittern; wenn er hinreichend erstarkt ist, verlingert er sich zu einem viele

1) úveví, die Frlauchte. die Ierrliche; ein weiblicher Eigenname (z. B. einer Tochter des hadmos). - ") Maguei oder Metl nenuen die Mexikiner die Pflanc; die liotaniker wenten den Namen bald anf die obige l'flanze. hald anch auf Agave mexicana lam. all. 
Meter hohen heblitterten schaft, der in reichlicher Verzweignng von wramilalem C'mrils zahluciche Bliiten trïgt (l'rantl).

Amerikanische Agave (Agace americuna L.. Fïr. II). In ler Luave und cinigen Mö̈arten erreicht anch die Ordnung der

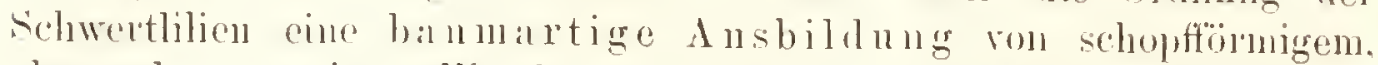
aho pil huchartigen Wuchse. Sie wïchst vollkommen regehecht, jede l'flan\% in einer Anlage ist genan wie die andere, die Gröfsenverhältnisse allsgenommen, und wenn sie ilhre lieife erlangt hat. ist sie in ihrer chemmilsigen Gestalt mol ihrer hochragenden IBhitenpramide eine Erscheinnng, aul der zu ruhen das Ange des simnenden Menschen nicht miide wird.

Wurzel ansianernd, sehr dick. Stamm ganz kurz mul sehr dick; der als Fndtrieb erwheinende Blütenschaft wird 6 lis $1+\mathrm{m}$ hoch nnd 32 bis $130 \mathrm{~cm}$ im Durchmesser dick mol ist oben istig, kandelaberartign.

Blätter, an Grumde des Schaftes gehïuft mod eine liosette bildend, Heischig. brettartig hart, dick. dornig gezïhnt, 1,26 bis $1.9 \mathrm{ln}$ lang mo 10 bis $16 \mathrm{~cm}$ dick, neergrïn, lanzettlich, gerimnelt, glatt, spiralig ansitzend, die äulseren sich zuriickbiegend, die mittleren ab)die inneren anfrechtstehend. Blüten stehen in einer durch die horizontulstehenden Äste gebildeten kolossalen pyramidalen Bliitenrispe, lis zu 4000; Perigon glockig-trichterfümig (Fïg. II, 1) mit sechsteiligem Saume, der kürzer als die pfriemlichen Staubblätter (Fig. II. 1) ist, zierlich, gelb, narzissenurtig, in der Mitte eingeschniurt, sehr ingenehm duftend, Griffel mit dreieckig-knoptiger Narbe.

Frucht (dattelirtig) eine dreikantige, vielsamige Kinsel.

Blüht in Süc-Amerika schon nach vier bis fïnf Jahren (August. und September), in Nexilo in 8 bis 16. in unseren Treibhïusern erst nach 40 bis 80 Jahren (siche Geschichte). Am Blïtenschafte können sich bis 4000 Bliiten entwickeln.

Vaterland: Wahrscheinlich Nexiko, in Hölıen his zu $3000 \mathrm{~m}$ (auf diirrem, unfruchtharem Boden); Verbreitungsbezirk: Alle warmen Lüuder, anch das südliche Europa, häufig in den Mittelmeerliindern, besonders anf Sizilien und in Tord-Afrika, zun Teil verwillert, anch in Madras, Mysore etc. Nördlichster Punlit in Europa: Bozen. Bei uns in Wirmhïiusern.

Kultur. Die l'thanze ist in den meisten Tropenlïndern verwildert, wirl ilber anch vielfach, besonders in Mittel- und Siid-Anerika, kultiviert. Zu dem Zwecke rermehrt man sie dnreh die zahlreich hervorkommenden Seitenschöfslinge. Nach den Verbliihen stirht der Hamptotock al), die Nobentriebe aber schligen wierler ans. Dats Al)sterben des Hauptstockes geschicht in der heifsen Zone nit dem vollendeten 5., in Siid-Europra nith den 1.5. Jahre. In Mexiko gredeilht. sie anf den diirsten Porlen. treiht indes elst nald dem 8. his 15. Jahne ihnen riesigen bilitenschaft. Criebt sich dies durch pö̈triches Anf- 
richten der indseren Bliitter zu erkennen, so wird las ganze Bïndel der mittleren Blitter heransgeschnitten, die dadmeh entstehende klatfende Wimde noch (anf $0,5 \mathrm{~m}$ Dnrelmnesser) rergröfsert mud mit den rusimmengebundenen :̈ulseren Blïttern bedeckt. In die Höhlung strönt mu der zur Frnährmmg des Blütenschates bestimnte Sift, den min tïglich zwei- bis nemmnal schöpft. Starke Stöcke selen tiiglich bis acht lilaschen. im Ganzen (in ein his sechs Monaten) bis $2000 \mathrm{~kg}$ Saft. In \%weiten Monate ist der Saftertrag ann stïristen.

Gehalt und Gebrauch. il) Der Saft der I'flinze ist zucker- und schlembaltig (8s.65 Proz. Wasser, 1.01 Proz. Liweils, 6,17 P'roz. Glycerin, 2,65 l'roz. Bernsteinsïure. 0,35 P'roz. Äpfelsïmre. 0.55 l'ro\%. Gimmi, 1.01 P'roz. Eiweil's) 1). molkenartig, triil), schmeckt angenchm sïuerlich nun gerït leicht in Gärrung. Um ihn schnell in (iiirung zu hringen. rersetyt mim ilm mit schon gegorenem Safte. Der gegorene Saft oder Pulque (sprzif. Gew. 0,976, Alkolol Vol. 5,S7 Proz., Glycerin 0.21 Proz., Bernsteinsïure 0.140 P'roz., Gummi 0,05 Proz., Äpelsäime 0.54 l'roz., Asche 0.250 P'roz. Kali 0.(185) Proz., Kohlensïure 0.061 Proz.) 1). ist ein berinschendes Nationilgetränk (Mexiko), hat zwar infolge des Auflewalrens in Schweinshïnten einen widerlichen Fleischigeruch, ist aber wegen seiner nührenden, kiihlenden und erfrischenden Eigenschaften sehr beliebt, doch wirkt er in grölseren Gaben genossen selı berauschend. In der Hanptstadt Mexiko geht tiiglich ein Extrabalutzog, "Pulquezugg" genimut, nach Apam, um schwer beladen mit dem Lieblingsgetränk zuriickzukehren. Wem der Kopf, aus dem sich der Bliitenschaft entwickelt, anschwillt und sichtbar wird, wird er gern ausgeschnitten und als Gemüse verspeist. In Gestalt einer grolsen Birne ist er sehr zuckerreich nud schmacklaft Die Köpfe werden auch gedörrt. Die Indianer in Sonora und Arizona rerbranchen bedentende Mengen dieser Köpfe wilder Agaven, und einem Stamme dienen sie so rorwiegend zur Nahrumg, dils ihn der Name Mescalindianer gegehen wurde. Sie gebrauchen die Agaveköpfe rorziiglich als Reiseproviant. Nachdem diese Köpfe geröstet sind, werden sie mit Kenlen zu Kuchen von der Dicke einer Hand geschlagen, die, an der Somne getrocknet, sich jalneling hialten. Durch Destillation gewint man den Mescal oder Mexikil, einen sehr beranschenden bramtwein, aus den Köpten oder dem Safte. Man damplt anch den Sift der Blïtter ein und benutzt ihn als Seife. Der siifse Ilonig der Bliiten wirkt alfuihrend. Auch wird das Mark der Blïtter frisch und znbereitet gegessen. Die regenarmen Wiisten Nord-Mexikos mud Arizonas wïrden whe die dort herolieh gedeihenden Agaven rom Menschen nicht bewohnt werden kïmen.

b) Die Blïtter enthalten wie die Ananas sehr rïhe Fasern, die unter dem Namen P'ite, P'ita (spanisch) (auf Barbarlos .,Silkgris").

1) J. Boussingault. 
anch Alö̈lanf in den Handel kommen. Un die Faser zn gewimen, muterwirft man sie einem linmen liostprozels, welcher alle Gewehe bis

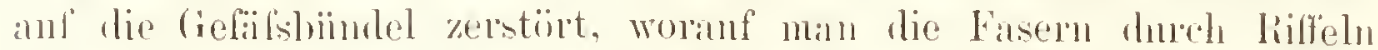
mittels Eisenkïmmen orler nit dor freien Iland liost. Die Faser ist ungefïhr $1 \mathrm{~m}$ lang. hart, wenig hiegsinn mul nimmt nach der Vitte hin an Dirke \%n. Sie hesteht rorwiegend ans diinnwandigen Bastzellen, enthiilt aher anch Spiralgefiifse und lamggestreckte Parenchymzellen 1). The Faser ist leicht, die darans gefertigten Tane schwimmen im Wasser. Es werden teinere und gefïrbte Seilerabeiten. Packtiicher, Kalfeesiicke, Teppiche etc. daraus gefertigt. Die daraus gearheiteten s.chiffstane (nordamerikanische und belgische Manmen) brauchen nicht geteert zn werden. In den westfiilischen Kohlen- nurl Bergwerken bemutzt uan anstatt der Drahtseile aus Belgien eingefiilnrte Breitseile ans dieser Faser: Anch rerfertigt minn ans den Blättern, die man finulen liifst. his sich das Zellgewebe gelïst hat, woranf nan die Gefiilsbiundel anf' einander klebt, ein brauchbares I'apier. Nenerdings dient die Faser als Ersatz für borsten und Rolshaare. Der vertrockinete Bliitenschaft dient zn Streichriemen für Rasiermesser und als Ersitzmittel für Kork, sowie man in Griechenland auch das Mink des Schaftes als solches bentyt und als Balzerhol\% Insektenkïisten danit auslegt. Die Blätter dienen zum Dachdecken, die Dornen daran als Nägel nud Nadeln. Wegen ilner dornspitziggesiigten Blätter wird die Pthanze in den sïdlichen Ländern (in Dalmatien sogar zum Schutze der Festungen) als beste Heckenpflanze zur Einzämmmıg von Grundstiicken rerwendet, da derautige Zümne das Vieh wirksan abhalten. Bei uns ist sie anf Manern und Vorbanen eine selı beliebte Kiilıelzierptlanze, die man sogin aus Blech nachalunt. Die Wurzelfaseru (Rarices ayaves, Mageywurzeln) sind ein bekiluntes Arzueinittel und kommen oft statt der Sassaparille in rlen IIndel.

Geschichte. In Jahre 1561 wuden die Pflanzen ans Mexiko nach dem siidlichen Europar gebracht und werden seitden häntig in den Mittehneerländern angehant. Ihre Faser wie die der Aguce mexicanu Lann. licferte ein schon den alten Mexikanern bekanntes I'ippier, eine Art Pangruspapier. Worat sie ihne Hieroglyphen schrieben. Sie ist ilnes bei uns seltenen Pliilens halber die alle .humdert follure hlïhende Aloë“ des Volkes. Die Azteken betrachteten die Agare als das simmlild ron des Himmels Giite gegen rlie Rrdenhewohner und "rwiesen iln religioise Verelnung. An genissen 'Tagen tanzten sie $11 n$

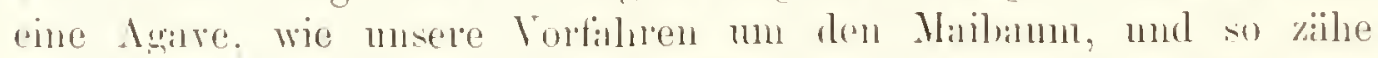
hielten die Indianer an diesen Gebranche, dals ihn die christlichen P'riester in die kirchlichen Zeremonieen anfuehnen mulsten, doch gahen sie inm eine andere Berlentmig.

1) Wiesurr. Liohstolle des Pllanzemeichs. 
Die Llyare mexicana wurde schon erwähnt. Alyare Sisilana ${ }^{1}$ ) in Vueatan liefert den sisilhnul' oder Hemequin, Grashant. Die Pflanze hat ein lange fortglimmendes Mark, welches zur Luterhaltmug des Feners dient mul, mit einem hiirteren Holzstiickchen gerichen, sich schmell entriindet. Anf diese Weise macht man sich in den amerikanischen Wïldern Fener an.

1) Sisil ist der vaterlïndische Name. 


\title{
Tafel 10.
}

\author{
Verek-Gummiakazie') \\ (Aracia") Verck") Guillemin ${ }^{4}$ ) et Perrottet $\left.{ }^{-1}\right)$.
}

Auch die Verek-Gummiakazie gehört zur Ordnmurg der Hülsenfiuchtigen (Leguminosue), und zwar zur Familie der Mimosengewächse (Mimoseac) s).

Ile Familie der Mimosengewächse (Mimoseae). Der Kelch hat eine klappige Knuspenlage, die Bhumenkrone ist regelmälsig und liautig. Verwachsenblïtterig.

In 20 Gattmngen gegen 600 Arten meist in der heil'sen Zone, wo sie in manchen Gegenden den Landschaftscharakter bilden. Viele scheiden Gummi aus, andere enthalten Gerbstoffe und adstringierende Bestandteile.

I le Gattung Akazie (Acacia W.). Meist dornige Bïume orler Sträucher. Bliiten klein, Hiilsen vielsamig, in zwei Klappen anfspringend, ohne Querseheidewïnde (Fig. 4).

Verek-Gummiakazie (Aeacia Verek Cruill, et Perr.). Bäumchen oder Strauch, stachelig, knorrig gewmulen, sich neigend, ron 4 bis $6,6 \mathrm{~m}$ Höhe und 10 his $15 \mathrm{~cm}$ licke im Durehmesser, nit granlich-weilser $\mathrm{R}$ inde und sehr rielen $\mathrm{Zweigen}$, Gummisaft ansschwitzend. Holz weil's und sehn hat; Zweige mit Stacheln rersehen.

Blätter doppeltgefiedert, Fieder'n drei- his fünf-, Fiederchen zehn- bis fïnfzelnuparig, linealisch, etwas stumpt, 2 bis 4 mm lang, einander sehr nahe stehend, kleberig, grangriun. An stelle der Neben-

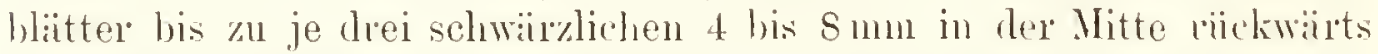
gekriummten (daron ein oder zrei nach oben gekrimmt) Stacheln.

1) Guillemin, l'errottet et Richard, Florae Sentgmbiar tentamen; śchweinfurth. In himnea 1s67; Flückiger, Gummi und Bdellium von

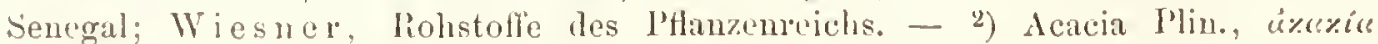
l)iose, ägrutische Akirie. von úxi, splitze, wegen der stacheligen stïmme und Äste. - ${ }^{3}$ ) In IVest-Afrika so genannt. - ${ }^{4}$ ) Wiehe Geschichte. - 5) Bezielıt sich auf die lieizharkeit der Blitter mehrerer Arten (von "riuos, Sintter, Siuchahmer Schauspieler). 
Blütenähren schr gedrängt, langgestielt, 4 his ficm lang, walzig. aus den Blittwinkeh lommend, einzeh, anch zu zweien mul \%n dreien. Kelch (Fig. 1) glockenlömng, mit fiinf kurcn Ziilnen, weifich; Blumenkrone (lig. 1) fitst noch cinmal so grols als der Relch, finthliitterig, Bhumenbliitter iiber der Mitte mit einander rerwichen. an Gronde des Kelches eingefïigt, Lappen lanzettlich; Staubblätter (Fig. 1 und 3) ungefiilı 100, gelblich; Staubfäden lin- mul hergehogen, muten zus:munengewachsen, die Scheibe innen knotig, röhrenförmig; Staubbeutel (F"ig. 3) sehr klen; Fruchtknoten (Fig. 2) linglich, mit weichen Härehen bedeckt; Griffel lang, fällich, gebogen; Narbe algestutıt.

Hülsenfrucht (Fig. 4) lineallänglich, nach beiden sciten zngespitzt, an den liïndem fast ger:ude, schr zusanmengedrïckt, diinn, an fsen netzartig geadert, aufplatzend, sechssamig, nugefiilur 7 bis $8 \mathrm{~cm}$ lang und $13 \mathrm{~mm}$ breit.

Same (Fig. 4) kreisrund, sehr zusimmmengedrückt, an langen, gebogenen Stielchen hängend, schwïrzlich glïnzend.

Heimat und Verbreitungsbezirk: Östliches Sudan bis zum Flufsgebiet des Altbara, von rechten Ufer des Senegal bis an die Grenze der Sahara und in den Oasen derselben. Liebt einen trockenen und sandigen Standort.

Gummi, einer der gemeinsten Pflanzenbestandteile, ist bis jetzt in der Zellmembran, nicht aber in Zellsafte gelöst gefunden worden. Wenn es im Imneren von Zellen anftritt, so ist es durch chemische Umwandlung ron Stärkekörnern lervorgegangen. Es erscheint hauptsächlich im lebenden Rindenkörper vieler Pflanzen und verbreitet sich ïher die Oberflïcle der Brrke, kommt aber im Holzkörper selten und dann in sehr kleinen Mengen vor.

Eigenschaften und Gehalt des Gummis. Alle Gunmisorten sind in Alkohol völlig unlöslich, gehen durch das Zwischenglied des Dextrins (Stïrkegummi) in Zucker über und enthalten hamptsäichlich Bassorin, Arabin und Cerasin. Das Bassorin (Traganthin) ist farb)-, geruch- und geschmacklos, rïh, in Wasser und Alkohol mulöslich und quillt in heilsem Wasser zu einer Gelatine auf. Dis Arabin ist eine saure Verbindung von Arabinsinure mit Kalk, ehenfalls farb-, geruch - und geschmacklos und von samer Realition und löst sich in Wasser zu einer klebenden, geschiittelt etwas schänmenden Fliissigkeit. Das Cerasin, eine Verbindung der Metagumnisäure mit Kalk, ist farblos, in Wasser und Alkohol mulislich, doch in Wasser zu einer Gelatine aufquellend, spröd. Wird es mit kohlensauren Alkalien gelïst, so geht es unter Abscheidung von kohlensinuen Kalk in Lösung. Anfserdem enthalten die natiirlichen Gumniarten noch Wasser, Dextrin, Zucker, Gerbstoffe, larbstoffe umb Mincralbestandteile. Sie liefern 2 bis 3 Prozent Asche (nach Wiesner). 
Das Gummi entsteht in der l'flanze Anreh Ausscheidungen. bie binsicht in die imeren bedingnngen. welche bei der matsendatten

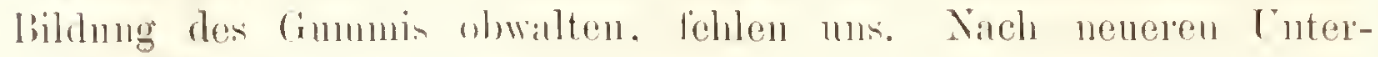
suchungen steht fest, dafis wenigstens einige (inmmianten durch Lum-

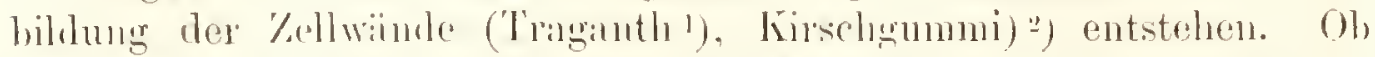
sich anch das Mkatiengmmmi anf diese Art bildet, ist nicht festgestellt.

Die Gummiarten lassen sich narh Wiesuer in folgenler Wrise einteilen: 1. Arabinhaltige. Sir bestehen der Hanptmatse

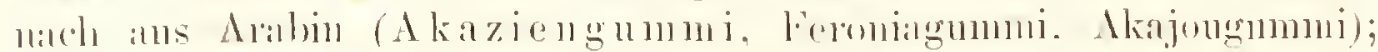
2. Cerasinhaltige. Sie bestehen ans C'erasin mul Alabin (Kirsch-, P'tanmen-, Aprikusen- mud Mamlelgummi): 3. Bassoribhaltige. Gemenge ron Bilssorin nul einer den Arabin nahestehenden Gummint ('Tragantl, Kuteragummi, Barssolagnmmi, Kokusgnmmi, Moringagummi); 4. Cerasin- und liassorinhaltige. Gemenge ron Cerasin und Bassorin (Gummi ron Cochlospermum yossypinm).

Akazien-Gummi. Inter diesem Ximen rerstehen die neueren Forsher das (immmi der echten Akazien, also arabisches, Senegal-, Kipp- und nenholländisches Gummi. Die grofse Clbereinstimmung dieser Gummen in physikilischen und chemischen Verhalten ist nachgewiesen. Alle rom Akazion herrïluenden Gummen sind dem sogenilnuten arabischen nahe verwandt und hauptsïichlich ans Mrabin zusimmengesetat. Man hat bis anf die neneste Zeit angenommen, dals das arabische Gommi ron Acacia wabica Willd., von Acacia Ehenbergiunu Hayne, Acurie Seyul nnd Acucia tortitis komme. Die Angaben sind unrichtig. Nach den zuverlässigsten Ermittelungen Dr. S.hweinfurths ${ }^{3}$ ) rïhren alle guten Sorten ron Gummi ans den Nilländern. wie ans Senegambion von der Verek-frmmulakazie (s. unscre Abbildmog). Acrecin Terel, (inillenin et P'errottet her. Die obenge-

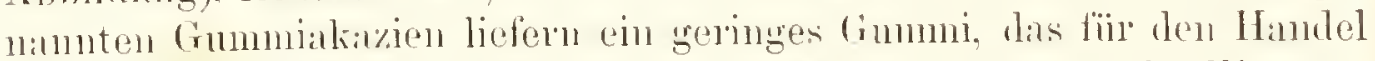
wenig Bedentmmg hilt. Dis (immmi der Akizien bildet nach Wiesner sewöhnlich runde, manchmal lingliche Körner ron unregehnifsigen Begrenzungstlichen. Inicht glasartig (glanzlose Bruchflichen nur beim anstralischen (immmi), liilist vich leicht pulverisieren und list sich in kaltem wie warmem Wasser. anch in Glycerin. Es enthialt 12 his 17 l'ozent Wisser. 0,36 lis I l'rwent lirimelzncker und spuren ron Han\% und Farbstoffi. Die Asehenmenge (kohlensimer lialk und liohlensalures Kali) heträg etwa : P'rozent. Dis Akaziengummi enthiilt mach Fläckiger weder \%ellhäute. noch irgend welche organisierte oder krrstallisirete Inhaltskïrper etwal zuror zerstiorter Gewehe.

Gewinnung des Verek-Akaziengummis. Wiihrend ler. Legenreit, die in Senegimbieu rom Juli bis Oktober wïhrt, er-

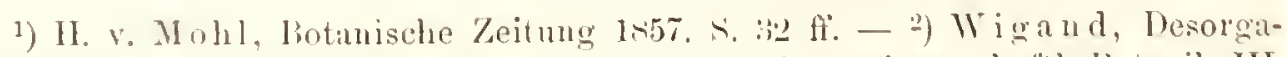
nisation der lollanzongelle. I'ringsheims Jahrluch t: wiscensehatt. Botanik III,

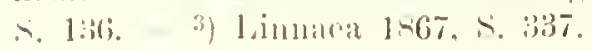


reicht anch die Gummiakizie ihren gröisten Saltumnlanf und es lildet sich in ilner linde dis Gmmmi. Nach der legenzeit erhehen sich heftige. trockene und heifse Ostwinte, die dem Anlschwellen der linde ein plöt\%liches linde setzen, dieselle in kumor Keit anstrocknen mnd darhech dis: spalten derselhen verursachen. Aus diesen Spalten und lissen läut gedhängt von der immer mehr zusammenschumptenden Rinde diss Gimmoni und rerdichtet sich zn 'Thrïinen (Har\%). Te heftiger" die Ostwinde andtreten, desto gröfser ist die in Dezember stattfindende Ernte. Die zweite Ernte, dhrch die im . Tunnar und Februar cintretenden Seewinde, die reichlichen 'T'un, oft anch liegen bringen, hervorgernfen, tindet im Mair statt. Das Gumni wird in Senegannien durch die Kriegsgefungenen der Wanderstimme mit der IIand oder scheerenartigen und liffelartigen eisernen Werkzengen, die an Stmgen lefestigt sind. geerntet. (immmistiicke, die in Folge des Windes nud der' Trockenheit rorher al,fielen, sind gewöhnlich dn'ch erdige Bestandteile, Bamminde und Bliitter verdorben. - Monate lang haben die armen Lente lieine andere Nahrung, als dieses fate Gumni. Nach Duveyrier sollen anch die Thareg-Stämme der Saltana ganz regelmïlsig dis Gummi der Acacia arabica IV. verspeisen. Die gnmnisammelnden manrischen Stämme am Senegal (Stämme der 'Trarzas, Braknias und Donaïchs an rechten Senegalufer bis Bakel) bringen ihre Ware nur selten in die festen Niederlassungen der Franzosen, sondern vielmehr an bestimmte, in gegenseitigem Einverständnisse gewïhlte Stellen am Strome, Escales genamut. Sie erhalteu für das gesammelte Grummi ron den Franzosen Gold, Baumwollenzenge, Korallen und Bernsteinschmnck, Waffen, Pnlver, Getreide (Nil) und verschiedene Kileinigkeiten.

Gebrauch. Gummi wird bedentend und mingemein vielseitin rerwendet. Es dient in den Apotheken zur Darstellnng vou Hustenzucker. Gummischleim nud -Syrup, als Bindenittel fiir l'illen, in Zengdruckereien zur Verdickung der Farben, in Kattun- und Seidenfabriken zum Appretieren, ferner als Zusatz zu Schreibtinten, Tusch- und Wasserfarben, Zïndholzmasse 1 . s. w., als Kleb- und Bindemittel am besten mit 1/4 Kandis rermischt zn zahlreichen Fällen (Postmarken, Etiketten, Kouverten, Aufkleben), als Vittel, nm Gazen und leichten Stuffen Steifheit und Glanz zu geben (Vorhäinge damit gesteift), hält dam sehr fest und schimmelt nicht. Anch Likïre verdickt man damit. Im Steindenck ist ohne Gmumi der Druck nicht möglich. In Konditoreien wird Gummi in Knchen verwendet, anch $1 \mathrm{~m}$ Suppen und Saucen schleimiger zil machen und forner als Grundstoff mancher Pasteten.

Warenkunde. Das Gnmmi der Verekakazie rerfillt in 1. arabisches und 2. Senegalgummi. Die geringfügrigen Unterschiede zwischen beirlen liohstoffen haben ihren Gimnd in inlseren (meteorologischen) Finflüssen, die im Osten Sulans (kontinentales Klima) andere sind, als in den westafrikanischen Kïistenländern (oceanisches Kilinia). 
1. Aralisches finmmi. Wichtigste Sorten Kordofan-, Sennaalr-, Suakin-, Geddah- und Mogadorgmmmi. Das Kordofangmuln ist dis beste. Es bildet nach Wiesner rmoliche Körner mit eincm Lïngsdurchmesser bis z.11 $2 \mathrm{~cm}$, ist meist blal is weingell, seltuner farhlos oder dnukelgell, wird hesonders im Bezirke Para gewomnen und koumnt ron Kordofan über Dongola und Kairo nach 'Triest und Marseille in Handel. Das Sennangmmmi kommt an Giite gleich nach dem Kindofangummi und hat blafsgelbliche Körner. Das suakingnmmi ist gelb gef:̈rrbt mit dunkelrothraunen Kïrneru unternischt, oft kleinkiornig oder staubig. wird auf der Hochehene ron 'Takka gesammelt und ron Suakin an Roten Meere verschifft. Das Geddahgummi ist unrein. honiggcolb bis hrännlich oder schwärzlich. schwieriger als die erwähnten Sorten in Wasser lïlich. hinterlailst oft einen Riirckstand und lat einen süfslichen gewiirzhaften Geschmack. Diesen ist das marokkanische Gummi (Acucia gummifera) seln ähnlich.

2. Das Sencgalgumui rerfiillt nach den Sammelgegenden in folgende drei Hauptsorten: 1. Gumni rom Unterlauf des Senegal (gomme du bus du fleure). Häufigste und gemeinste Sorte, in runden oder dicken, wurnförmigen Stiicken ron gelhlicher lis branner Farbe. Oft mit Sand und Rindenteilchen vernischt (rom Boden aufgelesen). 2. Gummi vom Oherlauf des Senegal (gomme du haute du fleuve, gomme de Galcml. Sehr rein, weils, spröd, leicht löslich in Wasser, diunner wie das vorige. 3. Gomme friable (ou Salebredu). Besteht aus rahlilreichen wurmförmigen Stücken, die farblos oder nur selur wenigg gefärlst sind, mit vielen Bruchstiicken. - In Bordeaux werden die Arten des Senegalgummis sortiert. Handelssorten: Ciomme blanche, gomme blonde, yomme vermicellée etc.

Handelsstatistik. a. Arabisches frummi wirl ron Aden (wenig). Ägrpten, Nubien, Ahessinien, Korlofin, der Somalikiiste, Tunis, Marokko, dem Kap der gnten Hoffnumg und ron einigen portugiesischen Kolnnieen Afrikis in den Inandel gehracht. Handeliphlitze: Marrseille. Triest. London. b. Die jührliche Anshente des śenegalgummis ist ron der Erntewitterung und daron abliningig, ol, dio (immmi sannmelnden stïnme Krieg oder Frieden haben, und schwankt zwischen $1 / 2$ lis 5 Millionen Kilogramm. Inaupthanlelsplatz: Bundeanx. Die Senegalware ist wohlfeiler als das arabische (immui.

Geschichte. Der Gelnauch des (immmis der Nillinder reicht bis ins Altertum. Arabisch (arabicum, schon friihzoitig) wurde es wohl hamptsächlich deswegen genanut, weil :labische kiurwanen gelegentlich etwas Gummi nach Kiniro hrachten, das möglicherweise schioner war als die Ware rom oberen Nilgebiete. Gewil's wurde anch afrikanisches (immni ziber das Rote Meer nach Arabien geschafft, $11 n$ von da woiter nach Nordwesten zu gelangen. Die ersten Nachrichten iiber die Inshoute des entsprechenden Produktes won Westafirika

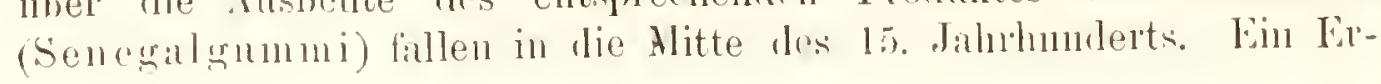


zeugnis Senegambiens (Piper habzctia D. (.) wurde im Altertume nach dem Liulturgelicte des Mittehneeres susgelïlurt. F'ortugiesen und

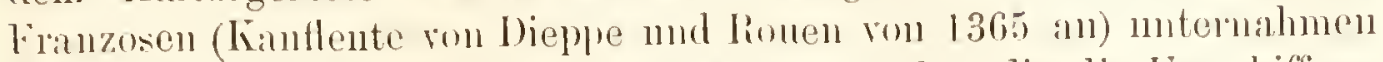
deshallh oft Faln'ten an die Kiisten dieses Landes, die die L'mschiffung desselhen zul Folge hatten. In Jahre 1449 bauten die l'ortngiesen anf der Insel Arguim an Kay B Banco ein Kastell zu Handelszwecken. Willuend des baues fanden sich dort Eingreborene mit Gummi ein. Bald erlingte dis (innmmi bedentung und 1555 tinden wir es schon in Seb. Minnster"s Kosmographic erwähnt. 1638 nalumen die Hollinder das Kistell Arunin ein, um Herren des Gimmihandels zu werden. Sie mufsten die Eroberung aber im Jahre 1678 den.Franzosen iiberlissen. die den Gummihandel nach den "Lscales" (siehe oben "Gewimnnng.*) am Senegin ablenkten, da das Land von dem Strome aus leichter zugünglich ist. Von 1758 bis 1779 besetzten die Englïnder die Kolonie. traten sie indes wieder an die Franzosen ab, die den Handel mit dem Prodult hestimmten Handelsgesellschaften überliefsen (Flïckiger). Die Pttanze selbst kennen wir erst seit 1830 durch die rortreffliche Ablildung und Beschreibung ron Guillemin, Perrottet und Richard. In West-Afrika wird der Strauch Verek, in Ost-Afrika Hadschab genannt. - Das Gummi der Acacia vera, dem arabischen ähnlich, will schon den Alten bekannt, die dassellıe vielfach als Heilmittel bemitzten, sowie sie die Bliite zn der wohlriechenden ïgyptischen Salhe gehrauchten. Nit den Blumen parfümierten die Ägypter die Zimmer und bei Gastmälern strenten sie dieselhen in die Säle; anch dienten sie zu Guirlanden und Kränzen. Man fand Mumien, die rom Kopfe bis zu den Fïfsen mit Mimosen-Guirlanden umschlungen waren. - Nenerdings wird auch viel australisches Akaziengummi in den Handel (England) gehracht. Nach den Berichten der Reisenden bewirken die australischen Akarien in den dortigen Wäldern das ..feenlatte Halbdumliel".

Andere Arten, die ein greringes Gummi abscheiden, sind schon oben erwähnt worden. 


\title{
Tafel 11.
}

\author{
Brechnu (s baum ${ }^{1}$ ) \\ - (Stryclmos $\left.{ }^{2}\right)$ mi. $\left.^{3}\right)$ vomicus ${ }^{-1}$ L.).
}

Der Brechnnfsbam gehört zm Klasse der Zweisamenlappigen (Dicotyledones), zur Unterklasse der verwachsenblïtterigen Dikotyledonen (Sympetalue, Gamopetulue oder Monopetalue). zirr Ordnung der Drehbliitigen (Contortue) ${ }^{5}$ ) und znr Familie der Strychningewächse (Stryeluneue).

Über die Unterklasse der verwachsenblätterigen Dikotyledonen siehe die I. Alsteilung S. 1.

Die Ordiung der Drehblütigen (Contortuc) s). Bei den meisten liommt eine in der Regel rechts gedrehte Kinospenlage vor. Kelch frei, Blumenkrone regehmälsig. Die Staubblättcr sind entweder an Zalıl den Bhmenkronzipfeln gleich, gewölnlich fünf (Contortue verae) (Fig. 2) und wechsehn mit ilmen ah, oder es sind nur zwei (Diundrue) rorhanden; immer aber sind sie der Kronenröhre eingefügt (Fig. 2). Der Frnehtknoten ist oberstïndig und wird ans zwei Fruehtblättern gebildet. Die Samenkuospen sind gegenläutigg.

Über die Familien der Seidenpflanzen-, der Hundsgift- und der Enziangewächse siehe mscre Repräscntanten einheimischer Pflanzenfamilien.

Die Familie der Strychningewächse (Strycheac). 'Tropische Bämme oder Strïneher mit gegenstïndigen, einfichen. dreiDis fünf-oder federnervigen Blätterm, oft mit Xebenhliittern begleitet. Bliiten in Trugdolden, Trugdoldentrauben oder Wirteh. Kelch fï̈nfbis vierteilig. Blumenkrone mit fïnf- bis vierlippigen Sinnm und klappiger linospenlage. Stanbhiitter fünf his vier, selten weniger; Stanblbentel mach imnen gewentet. Eiweif's reichlich. Wiirzelehen

1) Litteratur siolie oben; besonters Berg, Ofticinelle l'flanzen (siehe ohen).

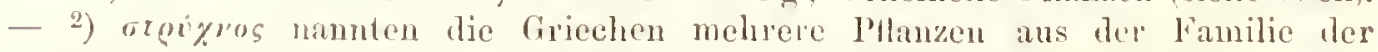
Nachtschatten, vielleieht von atozy(n, umreifsen, wegen der giftigen Wirkung. ") Nuls. - t) lirechen crregend. - ") Bezicht sich anf" die gedrehte" linospenlage. 
wal\%onförmig. Samenlappen blattantig. Die meisten enthalten starke Stickstofte (Strychnin oder Brucin).

Die Gattung' Brechnufsbaum (strychnos L.). Bänme oler Strä̈ncher, die hïnfig durch achselstiintige Ranken klimmen nurd liswcilen bewatthet sind. Bliiten weifs orler griinlich, häufig wohlriechend. in achsel-oder endständigen 'Trugdolden. Beere von einer derben Rincle ledeckt, einfïcherigg, cin- l,is vielsanig.

Brechnu fs baum (strychos mux vomica L.). St a m m baumartig. dick, oft kirumm; Äste stumpf rierkantig, glatt; $\mathrm{ZW}$ eige $7.1-$ sammengedriickt, wiederholt gabelteilig, kahl, mit ein bis zwei Blattpaaren besetzt. Knoten verdickt; Rinde schwärylich aschgran, ins Gell)liehe ziehend, der Äste grau, der '/weige grïn und glänzend; Holz strahlig, hart nud danerhaft, sehr bitter, besonders das der Wurzel. Blätter gegenstïndig, gesticlt, häutig, eiförmig, sehr kur\% stumpf zugespitzt, gamzrandig, drei- oder fiinfnervig, netzaderig. kithl, glïnzend griin. 5 bis $10 \mathrm{~cm}$ lang, 4 l, is $8 \mathrm{~cm}$ breit; Blattstiele kihl, rimnenfïrmig. an Grunde mit ciner Querlinie verbunden, ïber dieser gegliedert. 5 bis 10 mm lang. Trugdoldentrauben endständig, anfrecht. zweigliederigr, von der dolpelten Länge der rlattstiele; Spindel mi Blütenstielchen rauh; Blüten zul dreien, mittlere sitzend, seitliche linrz gestielt und später anf'bliilıend. Deckblättchen unter den Ästen mnd Bliitenstielchen gegenstiindig klein, spitz. Bliiten regelmïlsig, 8 his $11 \mathrm{~mm}$ lang. Kelch sehr klein, napfförnnig. fünf-. solten vierspaltig. rauh. Blume stieltellerförmig (Fig. 1), anfsen kahl, grïnlichweifs bis gellhlich, alffallend; Röhre innen etwas raul (Fig. 2); Sanm fünf-, seltener vierlappig, in der Knospe klappig mit eingeschlagenen Rändern. nich dem Blïhen eingerollt. Lappen länglich, mit eingeschligenen Rïndern. Staubblätter fiinf, selten vier, im Schlunde der Blume, mit deren Saumlappen wechsehnd (Fig. 2); Staubfäden mit der Bhumenkronröhre verwachsen. im Schlunde frei; staubbeutel eiformig, an beiden Enden ausgerandet, iiber dem Grunde des Rïckens angeheftet, zweifäicherig, der Lünge nach an den Rïntern aufspringend, gelb. Pollenkörnerªngelig-dreiseitig, dreiporig. Stempel frei, von der Lünge der Blume; Fruchtknoten (Fig. 3) eiförmig. lïnger als der Kelch, zweifächerig (Fig. 5), vieleiig; Scheidewand durch das Verwachsen von zwei gegenständigen wandstindigen Simentrïgern entstanden, welche ans der Vitte der Fruchtbliatter entspringen, nach imen Hiigelartig auswachsen; Samenknospen zahlreich, hallogegenlintig; Griffel fadenfirmig, 8 lis $9 \mathrm{~mm}$ lings, wah dem Abfallen der Blume? noch einige Zeit hleibend; $\mathrm{Nar}$ be kopflörmig, ausgerandet (Fig. 4). Beere lingelrund oder gegen den Grund ctwis verschunilert, ron der Groil'se eines Aptels, durch Fleischigwerten der Scheidewand einfächerig (Fig. (i); Schale glatt, orangefulben; Fleisch weich, gallertartig, weifslich. Samen (Fig. $T$ um s) drei his and, senk- 
recht gestellt, platt, fast kieisund, schildförmig, 2,5 cm Durchmesser, mul 0,5 cn dicke, mit kumen hellgranen oder gell,lichuranen, seidenglïnzenten Haaren hedeckt, an ciner Stelle des Iiandes mit dem ein wenig hervortretenden Kinospenmund (Figg. 7 b), der fast mit dem Kinospengrmul (Fig. 7 a) zusimmentüillt, versehen. Eiweifs hornartig, von der Gestalt des Samens, schmntrig weifs, im Innern mit einer weiten, flachen, kreisinulen Spalte versehen. Keimling klein, nit seinen fast horyfïrnigen, zngespitaten, fïnthervigen Samenlappen in die Spalte des Fiweilses hineinreichend, mit dem kurzen, walzenförmingen, dem Knospenmund zugewendeten Würzelchen in dem ungespaltenen Riand liegend i).

Heimat und Verbreitungsbezirk. Auf den Kïisten ron Koromandel mul Malabar, anf Ceylon, in den Wiilder'n ron Kotschinchina unt in Siam.

Kultur. Die Brechnnfshïnme werden zur Zeit wohl nicht angelout.

Gehalt und Wirkung. Die Beeren des Brechnufshammes, Brechniisse, anch Krähenangen (Nuces vomicae) genannt, sowie die Rincle des Bammes (falsche Angosturarinde) sind sehr griftig mod enthilten neben Brucin und Igasurin hesonders Strychnin. Strychnin, $\mathrm{C}_{21} \mathrm{H}_{22} \mathrm{~N}_{2} \mathrm{O}_{2}$, Alkaloüd, billet farblose Prismen, scluneckt äil'ser'st bitter, hinterher metallisch, ist sehr schwer löslich in Wasser, Alkohol und Äther, etwas leichter in Chloroform, Iienzol, reagiert alkalisch. zersetzt sich ror dem Schmelzen bei $312^{\circ}$, ist nur in sehr geringen Mengen sublimierbar und bildet meist krystallisierbare, äufserst bitter schmeckende Salze. Strychnin ist eines der stärksten Gifte ${ }^{2}$ ) und wirkt hesonders anf (lie motorischen Teile des Nervensystems. Es gelangt durch Magen, Haut u. s. $\mathbb{\text { . }}$ schmell ins Blut; am schnellsten treten jerloch seine verterblichen Wirkungen ein, wenn es unnittelbar (Pfeilgift, siehe muten) in eine Blutader gelangt. Sehr greringe Mengen erzengen Starkinupfanfïlle, und meist wird durch 'Teihnahme der Brustmuskehn an dem Starrkrimpf Pulslosigkeit (Scheintod) nud der 'Tor je nach der Grörse der Gabe in sechs Minuten bis einer Stmole herbeigeführt. Fine ganz geringe Gabe aufgelïsten Strychnins tötete einen Hund, dem es in die Brust gespritzt wurde. Strychnin ist fuir alle höheren Tiere ein furchlathares Gift. Inorphium, Blausïure, Aconitin, Cnrare, Chlorallyydrat wirken als Gegenmittel.

Gebrauch. Strychnin gehört zu den am schnellsten wirkenden Heilmitteln, leren Hanptwirknng ant' das liiickenmark geht und deshall, als ein vorziïgliches Mittel gegen Lïhnnungen vom Riickenmake ans, segen Krampfkrankheiten, Wechseltieber,

1) Berar. 1. c. - 2) Vergleiche Falk, Die Wirkungen des Strychnins, Jeijrigh linit. 
Dianrhïen ote. häutigg (namentlich ron Homöopathen) gehrancht wird. In nenerer Zeit sind mit Strychnin mehmals verluecherische Vergiftungen mit Menschen rorgekommm. In den $\Lambda$ potheken dart dieses Gift ohne itratliche Verordnung nicht mehr verkatuft werten.

Geschichte. In die Molicin whrlen die Brechniisse vielleicht durch die Araher eingefiihnt und in Dentschland durreh Valorius Cordus. Bamhin mul Gefsner in 16. Jahnhundert näher bekmut. Die Rinde des baumes kam zu Anfung dieses Jahrhumblerts, der Angosturarinde heigemischt. in den Handel (finlsche Angosturarinde), ist jetzt aher wieder rou Markte verschwurden.

Andere Arten: 1. Upasstrauch, Tschettek (Strychnos Tienté $\left.{ }^{1}\right)$ Lesch.). Eine 25 his $30 \mathrm{~m}$ lange, einfiche, astlose, armdicke Schlingpttanze, welche mit ihren Ranken in den Urwäldern Javas die Bänme erklettert nud aus deren Wurzelrinde ein furchtbares Pfeilgift, dias Upas-Tienté, gewomnen wird. 2. Curara ${ }^{2}$ )-Pflanze (Strychnos toxifur(:) Schomb.). Ein seltener nud interessanter Baum Guineas, der das furchtbare Lrari²)- oder Woarari-Gift liefert, mit welchem die Indianer ihre Pfeile vergiften (wird anch ans dem Uraribanm ${ }^{2}$ ), Strychnos gujoninsis ${ }^{4}$ Mart. gewomen). 3. Ignatius-Strauch (Strychnos Ignatii $\left.{ }^{\circ}\right)$ Berg.). Ein Schlingstranch auf den Philippinen. Die Samen, Ignatinsbolnen, enthalten fast dieselben Bestandteile wie die Brechniisse, und werden daher auch als Heilmittel, aber selten, besonder's gegen Wechselfieber gebrancht. 4. Wasserklärende Brechnufs, Atschier") der Indier (Strychnos potatorum b) L.). Ein Baum Indiens, dessen Früichte von der Gröfse einer Kirsche und geniefsbar sind, nud dessen Samen (Klärnuisse) nnd Holz (Brumnenröhren) schlammiges Wasser klar und trinkbar machen sollen. 5. Schlang'enholzbaum (Strychnos colubrina ') L.). Ostindien. Liefert das Schlangenholz, welches ron den indischen Ärzten gegen Schlangenbifs (Bifs der Brilleuschlange) als unfehlibares (!) Nittel gebraucht wird.

1) Upas tieuté, französische Benennung für Upasgift. - "2) Von den Eingeborenen so genannt. - ${ }^{3}$ ) d. i. Pfeilgift tragend. - ${ }^{4}$ ) In Guiana wachsend. 5) Der Jesuite Camelli lerute den Strauch 1699 zuerst kenuen. Daher uannte mau ilın auch nach dem Stifter des Jesuiten-Ordens, Ignatius I.oyola. - ${ }^{6}$ Potutor, Trinker. - ¡) Colüber, Schlange. 


\section{Tafel 12.}

\section{Gemeiner Ölbaum $\left.{ }^{1}\right)\left(\right.$ Olea $\left.^{2}\right)$ europaea $\left.{ }^{3}\right)$ L.).}

Auch der gemeine Öllaum grehört zur Ordnung der Drehbliitigen (Contortee, siche S. T0), und zwar zur Familie der Ölbaumgewächse (Oleuccac).

Die Familie der Ölbaumgewächse (Oleacene). Bäume oder Sträncher. Inre Bliiten sind zweigliederig gebant (Fig. 2 n. 3). Kelch nud Bhmenkrone sind regelmälsig, vierspaltig oder vierblätterig (fehlen bei der Esche). Die Sammilssehnitte der Blumenkrone haben klappige Knospenlage. Die Fürlen der beiden Stanbbiitter, die zwischen je zwei Abschnitten der Blmmenkrone stehen, sind mit der letzteren verwachsen (Fig. 3), ihre zweifücherigen Staubbentel springen mit Läingsspalten nach imnen anf (Fig. 4). Die zwei Fäicher des oberständigen Fruclitknotens wechsehn mit den Staubblittern al, und enthalten meist zwei hängende Simenknospen in jedem Farh (Fig. 4). Der Griffel ist sehr knrz (Fig. 4), die Narbe einfach oder zweispaltig (Fig. 4). Die fleischigen oder trockenen Friichte sind Kinseln, Beeren oder Steinbeeren mit eiweifshaltigen Samen. Die hierluer gehörenden Gew iichse kïnnen alle a uf einander gepfropftwerden. Dic Ölhammgewächse sind hauptsächlich in ler gemälsigten Zone. besonders der nördlichen Halbkugel, heimisch. B at tiiberreste sind fossil in Tertiärschichten gefinden worden von den Arten der Giattungen Elucoüdes Ung., Oleu und Fruximus.

Die Gattung Ölbaum (Oleu li. Br.). Bliitter gegenstinılig, lederartig, einfich nud ganzrandig. Bliiten in achselstïndigen Biisehehn, Tranhen oler Rispen, dnreh Fehlschligen polyganisch; Steinfrucht Heischig, einsanig, sclten \%weisamig; Steinschale knöchern, ein-, selten zwrilätcherig. Keimling in der Achse des Viweifses; Wiirzelehen nach oben gekehrt; Samenlitplen hlittartig. Die etwa 35 Arten kommen

1) Littratur wie oben, besonders Berg, l. e. und Wiesner. liohstoffe des Pflanemeichs, Klencko, Jexikun rer Verfïlschungen, Wittstein, Tasehnbuch

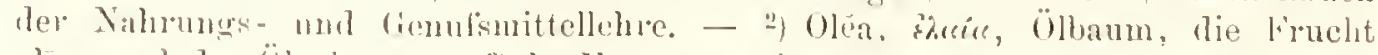
oliva mul das (i) olemm. - 3) ho Europa wachsend. 
zerstrent ror, von der Mittelmeerkiiste Europas bis znm siiden Afrikis. rom mittleren Asien bis Nen-Secland.

Gemeiner Ölbaum (Olea mropuen L.). Der wilde Ölba um (Oten curopace cur. oleaster 1). C. niler Oten oleaster L.) bildet ein niederiges, sparriges, in allen 'Teilen kleineres Gestrïnch, dessen Zweige in Dorne anshufen. Der kultivierte Ölbaum (Olen curopaen var. sutive D. C.) schlïgt leicht wieder in das Gestrii]'l zuriick, wie am Felsen bei Nizan, um Lissibon ete. Fr ist im verwilderten Zustande über gan\% Griechenland verbreitet und bildet undurhdringliche Ilecken. Der Öllsum erinnert durch seinen lichten Bliitterstand und die lanzettliche Forn seiner unten sillergrau beschuppten Blaitter an musere Silberweide. Stamm (des kultivierten Baumes) hammartig, 11 his $16 \mathrm{~m}$ hoch, mit selır rerästelter. unbewaftneter, immergriner Krone. Rinde gringran, glatt, im Alter rissig. Blätter gegenstänlig, manchmal zu dreien, sehr kurz gestielt, lanzettlich, in Form rerschieden, kur\% stachelspitzig, ganz:andig, oben grïn, aderig, unten dichtschuppig und silherweifs, grau, golden oder rosthraun, eimnervig, lederartig. Blüten klein, rurch Fehlschlagen vielehig (polygamisch), nur wenige fruchtbar; Blume (Fig. 2 1.31 aus sehr kur\%er liöhre glockig, vierspaltig, weils, abfallend; Zipfel eiförmig, ausgebreitet, in der Kmospe (Fig. 1) klatpig; Kelch (Fig. 1) häutig, glockig, spitzicrzähnig; Staubblätte1 (Fig. 2 u. 3) zwei, in der Blumenöhlıre aufsitzend, etwas kiurzer als die Zipfel der Blume; Staubfaden kiurer als der Stanbbentel; Staubeutel oval, am Grunde ausgerandet. auf dem Rüicken angeheftet, zweifücherig, Fïcher der Länge nach aufsuringend (Fig. 2); Pollen rundlichdreiseitig, dreinabelig; Stempel (Fig. 4) oberstaindig, sitzend; F puchtknoten (Fig. 4c) rundlich oval, so lang wie der Kelch. zweif̈icherig; Samenknospen zu zweien. von der Spitze des Faches herablïngend (Fig. 4); Griffel (Fig. 4 b) liurz; $\mathrm{Narbe}$ (Fig. 4 a) zweiteilig, mit etwas abstehenden Lappen.

Steinfrucht der wilden Form rundlich-linglich, schwar\%, der kultivierten (Firg. 6) gröfser oder kleiner, kugehund. umgekehrt eirund oder oval. stumpf oder zugespitst, grïn, weilsich, rötlich, reilchenbliu orler schwar\%, mit griülich-weifsem, öligen Fleisch (Fig. T); Fruchthaut aus derhwandigen, mit einer violetten Farbstofflösung erfiillten Zellen bestehenl; steinschale (Fig. T) keulenfürmig, etwas zusammengedriickt, schief, knochenhart. einfücherig, einsannig. sehr selten zweisamig, zweifïcherig. hram, heller geadert.

same (Fig. 9 n. 10) von der ahgesprengten mul geschwundenen, einen fadentörmigen, am (irunde der Steinschale entspringenden und an der dickeren Suite der Steinschale bis zu Spitze des Fachs rerlaufendeu Samenträiger oder Stiel (funiculus, Fïg, 9 b u. 10) darstellenden Scheidewand herahhïngend, mogekehrt lïnglich, netzaderig, eiweifshaltig. Eiweifs (Fig. 11 c) ölig-Heischig, weils. ans einem 
schlaffin Füllgewele ans last wïrlelfömigen Zellen bestcheml, deren jerle einen grofisen (i)lroplen enthïlt. Keimling in der Mitte des fiweilses. mugckehrt; W iirzolchen (Fig. 11 a) kur\% nach oben gelichtet; sanneulilplen zwei (Fig. 111), llattartig, in ihren /ellen ö enthiltend.

Vate $1^{\circ}$ land: Nicht sicher ermittelt, sïlliches Vorderasien, Syrien, Pallïstinal unl Anatolien. Verbreitungsbezirk: Aufser jenem Spanien, Portugal, Italien. Istrien, Dahnatien, Griechenland, mankkanische Kiiste, kirim, Inseln des Mittelmeeres, Siid-Afrikil, Chile, Peru, Mlexiko, Anstralien (besonder's Queensland) und - China. In SiidEuropa üherall zwischen dem 44. bis 46. Grad nördlicher Breite. Er ist dis Charaktergewïichs des Mittelmeergebietes, der vorziiglichste Reprïsentant der immergrïnen liegion. Er steigt in der Sierra Nevida

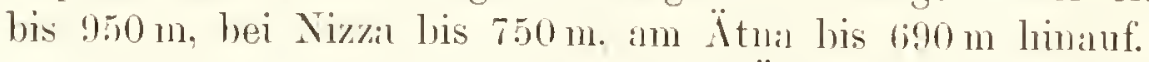

Kultur. Nur die kultivierten Ölläume liefern Oliven zur Ölpressung. Der liultivierte Bamm hat 43 Spielarten, ron denen die wichtigsten Olca curop. var. pigmola (Genua und Provence, hestes Öl) nund Olca europ. hispanieu (Spanien, grölste Menge öl) sind. Die wilden OHbäume werden durch Okulieren veredelt, die damn nach fï̈nf bis zehn Jihren schon Früchte licfern. Man kann den Ölbaum anch dnrch Simen und du'ch Stecklinge oder alogeschnittene Zweige, wie Weiden, fortptlanzen. Die Spielarten vermehrt man durch Pfropfen, nenerdings in den Spalt oder durch Okulieren anf die gemeine Rainweide (Ligustrum vulgure). Die Fortpflanzung durch samen ist langwierig, aber das beste Mittel, um die Ansartung der PHanze zu rerhüten. Der Baum verlangt Seeluft und Kalkboden und gedeiht am besten an den Ufern und auf den Inseln des Mittehneeres, doch genügt ihm anch der Spiegel des Gardasces. Im mageren und sandigen Boden wird der Ölhatum zwar nicht so grofs als in nahrhafter Dammerde, doch werden die Friichte in jenem desto besser. Zwischen die Ölbäume sïiet man Getreidekörner oder Hiilsenfrüchte, weil ihnen der Dïnger und die öftere Bearbeitung des Bodens, welche jene P'H:mzungen erfordern, vorteilhaft sind. In Siid-Europa blüht der Ölbaum im Iai und Juni, und im Oktober beginnen die Frichte z.n reifen, gelangen indes erst im Dezemler zur vollständigen Reife. 'Zwei reiche Jalnresernten hinter eininder sind sehr selten. Die eben gereiften Friichte müissen Stïck für Stiick mit der Haund albgepHliickt und ohne \%eitverlust unter die P'resse gebracht (Provence, Genua, Incca, Algier) werden. Anderwärts (Kalabrien, Sicilien. Sardinien) schliigt man die zarten Oliven mit dem Stecken al, oder läist sie gar hängen, l,is sie iiberreif von selbst abfallen und dann in Itanfen liegend leicht in Giipung geraten. Die Zailhlebigkeit des baumes ist so grofs, dafs er von oben eigentlich gar nicht zu vertilgen ist, da der in der Erde gel,liebene Stumpf immer" wieder :unstreibt (Ölberg. siehe Cieschichte). Doch bilden sich leicht Fiunstellen am Olivenlanm, die ansgeschnitten werden 
mïssen, anch wird er ron rahlleichen Schïhlingen, von denen Decus olene, Fimmeare olcar und l'sylla olea die wichtigsten sind, heimgesueht.

Die Pflanzenfette ${ }^{1}$ ), zu denen anch das Olivenöl gehört, siml Verhintungen ron einer oder mehreren Fetsïmen mit filycerin,

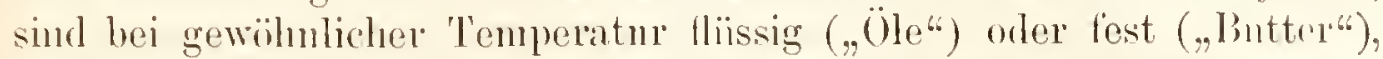
erzeugen lleibende Fettlecke anf Papier, lösen sich im siedenden Alkohol, in kalten oder wannen $\ddot{A}$ ther anf mul hahen stets eine geringere Dichtigkeit als das Wasser, gehören zu den verbreitetsten Pflumenstotfen, treten in gröserer Menge als lieservenahrung in Fridichten mul Samen, seltener in unterirdischen Pflanzenstoffen, in kloinen Mengen tast in allen Geweben der Gewiichse anf. Über die Entstehnug des Fettes in der /olle ist fast noch nichts bekannt.

Das Olivenöl, Gehalt. Die Oliven enthalten ungefähr 20 his 24 Gewichts-Prozente Olivenöl. Das Olivenöl ist en flüssiges Ptlanzenfett, das aus 72 Prozent Hüssig bleibenden Öls (Oleï) und ans 26 his 25 Prozent gerimbaren Öls (Palmitin und Stearin), anlserdem aus etwas Cholesterin besteht. Fs siedet bei $315^{\circ} \mathrm{C}$. und crstarrt schon bei $+6^{\circ}$. Auf $120^{\circ} \mathrm{C}$. crhitzt, wiol es heller, bei $220^{\circ}$ farblos mol riecht und schmeckt nach dem Erkalten ranzig. Es ist ras leichteste der fetten (j) und hat ein sperifisches Gewicht von 0.91. Aus älteren Stïmmen schwitzt ein Hal\%, das wie Vanille riecht, ()livin enthält mud in Italien zum Riiuchern dient.

Die Gewinnung des Olivenöls. Warenkunde. Die Güte des Baumöls hängt ab von der Verschiedenheit des Klimas und res Bodens, worauf der Ölbaum kultiviert wird, von der Spielart des Baumes, von der gröfseren oder geringeren Reife der Friichte nud ron deren Behandlung beim Auspressen. Gutes Olivenöl soll gernchlos, grimlichgell. dickttiissig, von Geschmack milde, ölig, das Gefühl stark fettig sein. Das beste und feinste Öl, Jungfernöl oder Provenceröl, Hiefst ron selbst aus den völlig reifen, gut sortierten und sorgfältig eingesammelten Früchten oder wird nach Entfernung der Kerne durch gelindes Pressen (kilte Presse) des Fruchtfleisches gewomen. Fs ist gr iinlich, schmeckt und riecht sehr angenehm (Aix in der Provence. Bari in Apulien. Lucca, Calci, Buli, Umbria, Liguria, Otranto mud Lecei und einige Orte in Algier). In Frankreich wird die Kultur hauptsächlich in den Departements Tancluse, Bouches du Rhône, Gand mud Alpes Maritimes betrieben und durchgïngig anf einer lohen Stufe, mit Ausnahme des Kiistengebietes mod ron Nizza, wo die Ḱnltur und die Ölgewinnung noch ziemlieh urwïchsig sind. Die schon schwach ansgeprelisten Oliven gelien nach stïrkeren Pressungen mit hoilsem Wasser (heilse Presse) eine mureinere, ölïrmere Ölsorte, das gewöhnliche Baumöl. Das gewöhnliche Banmöl hat eine blafsgelbe Farbe und wird leicht ranzig. Wenn man die Oliven

1) Wiesner, 1. c. 


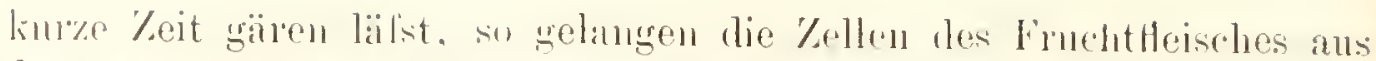

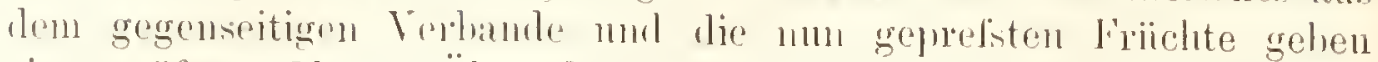
wine gröbsere Menge öt. Dabee sind anch die kerne (siche oben

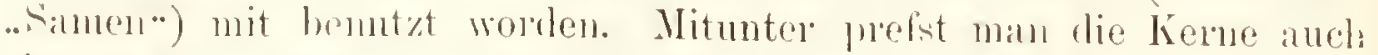
einzehn ans. Dien Sorte ist gliin und schleimig. Die Ölknchen (Prelsriickst:inte) werien dureh die .heifse P'resse" weiter ansgenntyt. Dilnacld werden die liiickstänle cutweder in einer Fabrik anf chemischem Wege villig ontoilt oler in tiefen, nit Wasser hall, gefiillten Cisternen Monile lang anfhewaln't. Wïhrend wekher \%eit sich unter Entwickelnuy rines widerlichen Cieruchs an dor Oberflïche eine inmer noch rerwenthare Ölsurte. das Schmier-, Lampen- odr Höllenöl (huile donfer) alsoulert. Lis ist griil. Nur das Jungfernöl ist gleich nach der gelinden Pressung helle, alle anderen Öle siml aher triibe. da darin infolge der stïrkeren Pressmog zerrissene Kellenstïcke hermmschwimmen. Dirse Öle niissen dilher erst in Cefilifen einige Wochen ruhig stehen (ablagern), chr sie ant Flischen gexngen werlen. Die feineren Sorten liifst man in Cisternen mit Boden ans Porzellanplatton klïren und filtriert sir durch BanmWolle. Will man firlhose Olivenïle erhalten, so solniittelt man das (i) mit Tierkohle, oder nan läfst es in Glasgefiilsen, ner Luft und dem Lichte ausgesetzt, stehen, oder miln prefst Oliven aus. die man den Winter ïber an den bïmnen liefs. - Das Olivenöl wird leieht ranzig. Das kann man rerhindern. wenn man ihm einige Tupten Salpeteriithor zusetzt. Inreh Ilinzufïigen ron etwas Salpeteräthergeist nimmt man den ranzig gewordenen Olivenöl den widrigen Geruch. Min klïrt es dhuch Enhitzen nit Weingeist. Cm eine Verfä1schung des Baumöls nit Inhmöl oder einem anderen trocknenden ̈̈) zn entdecken. versetze man das erstere mit salpeteriger sïure. Reines bammïl wird sich dam leirht in eine feste weife Malse relwandeln; ist aber Mohö̈l oder ein anderes trocknendes ïh dirunter, so

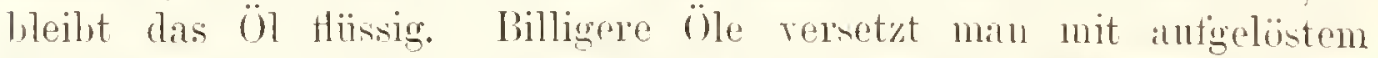
(iriinspan nul hringt sie dam als griines Banmöl (Malagaïl) in den

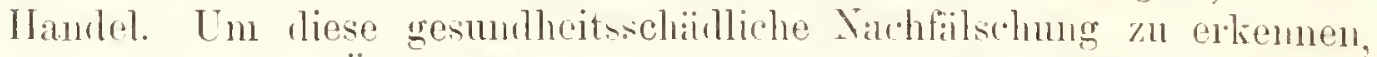
erhit\%t man das öl mit salzäinre, wohureh ihm diss Kupter entyogen

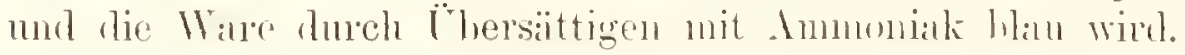

Gebrauch 1). A. Olivenöl und Oliven dienen 1. als Nahrungsmittel, indem die noch nirht gan\% reifon Frichte in siidlichen Ländern teils als Tishohst (als verdannug-stiinkences Mittel), teils eingenarht mit Salz, Fssig. Gewiiren u. s. uns in den Handel gehratht werten. Sie hilden in den G̈llindern eine Hamptnahoung des Volkes und einen wichtigen Handelsantikel. Die als reif gesanmelten nur eingemarhten Oliven heifsen in (iriechenland schware (Miven nud sind heim Volke, hesmulers an Fastagen. die

1) Meist mach Iaennis. Synopsis. 
belichtesten. Die feinen Solten des Bammöls dienen bei nus als Speiseöl, hauptsäichlich zu Salat (Salatiil), in siidlichen lä̈ndern aber wird baumial statt Fett, Butter nud Schmaly allen Speisen zugesetzt und biklet deshalb ein wichtiges Nillumgsmittel, ist jedoch, wie alle lette, schwer verdiulich. 2. Als Heilmittel bei Menscheu und Tieren dicnt a. Olivenöl, welches in der. Iteilkunde fist alle ïhrigen fetten Öle entbehrlich macht, als ein einluïlendes, geschmeidigendes Heilmittel, rorziiglich gegen hartuäckige Verstopfinngen, Rinhen, Wnımkrankheiten, gegen Vergiftmmgen durch Ätgifte, gegen Wespen- und Bienenstiche, bei Verbrennungen, zur Vorbengung und Heilung der Pest. sowie zur Basis vieler Salben, Eimeibungen, P'flastern, Klystieren u. s. w. 3. Zu technischen Zwecken gebrancht man das schlechtere oler Fabriköl, nnd zwar als Brennöl anf Iampen und zmm Einölen in Woll- nnd Lederfabriken, in Gerbereien, Färbereien etc. Zum Einölen ron Thren un anderen feinen Maschinen nimmt man das feinste $0 ̈ 1$, von dem rorher auch noch der Talgstoff (Stearin) abgesondert wird. Die schlechteste Sorte wird mit der Asche rerbrannter Meerstrandspflanzen zn Seife gebrancht, namentlich znr renetianischen und französischen Seife (Ölseife). Bammöl schüitzt Metalle regen Rost und dient mit Schmirgel zmm Abseifen des Stahls etc. 4. Zu religiösen $\mathrm{Z}$ wecken dient das Olivenöl noch jetzt als Chrisma (Salbing) den Katholiken bei der letzten Ölung (siehe Gesclichte).

B. Das Olivenholz ist mimsehmlich und gleicht dem Weidenholze, ist aber schön (auf griunlich-gelbem Grunde dunkel) geadert und dauerhaft and nimmt gute Politmo an, wird deshalb vielfach zu mancherlei Drechslerarbeiten benutzt.

Handelsstatistische Notizen. Frankrcich Ölente heträgt durchschnittlich 260000 Meterzentner auf 129000 Hektaren; aus anderen Ptlanzen gewimnt es iiber 800000 Meterzentner (j) und deckt damit seinen eigenen Bedarf nicht. Italien baut auf 2,5 Prozent von produktiven Lande 1600000 Hektoliter Olivenöl im Werte von 200 Mill. Franks nuel führt daron fïr 70 Millionen Franks aus. Spanien hat bei Malaga 700 Ölmühlen und modnziert 105850 Meterzentner öl, verbraucht den gröfsten Teil selbst. Kaudia führt 10 Meter'zentner' Olivenöl aus. Marseille soll 300000 Meterzentuer (O)seiten prodnzieren. Wenig bekannt ist, dafs das meiste Provenceröl nicht aus der Provence, sondern aus Apulien kommt, und terner, daf's vorziugliches Speiseöl nur in wenigen Gegenden wïchst. Apulien ist eine solche Gegend, mnd zwar besonders der Bezirk ron Barletta his Mola, suidlich von Bari. Ein grofser Teil des Bariöles geht nach Nizza, wo es als Provenceröl verkanft wird. In Griechenland belainft sich die Zahl der Ölbämme anf Millionen mud bildet daselbst einen Hauptreichtum des Landes. Es werden etwa 122000 Tomen Oliven geerntet. Beriihmt sind die Olivenwiilder am attischen Kephissos, sowie die von 
Megar:a und Amphissa. Algier besitzt etwa 4 Mill. Ölbäume. Tunis verschifft durchschnittlich 3500 Tonnen öl in Jahre. Syrien erzengt etwa 7 Mill. Kilogramm.

Geschichte. Der Ölbaum ist für lıeidnische und christliche Altertumsliunde seh" wichtig, die :̈ltesten schriftlichen Üherliefermugen erwïhnen ihn ('Taube Noali's) und er wurde im grauesten Altritun kultiviert mul geschït»t. Die Olive wall den Isracliten im Gelobten Iande verheifsen und bildete nebst Feige und Wein den Reichtum des Landes. Die Kultur des Olivenbaumes wurde besonders ron Ditrid und Salomo gefördert. Die Juden bedienten sich des Öls an Speisen und Backwerk, verwendeten es zu den speiseopfern, sprengten es als Opferöl, salbten dimnit Haupt- und Bartharr, sowie andere Teile des Körpers, besonders bei Gastmählern, brannten es in Lampen und gebrauchten es vorziiglich äufserlich als Arznei (der harmherzige Simariter). Die /weige des Baumes benutzten sie zn den Laubhïtten und das Hol\% des guten wie des wilden Baumes verarbeiteten sie. In Attika will man 2000 Jahre alte Öllö̈ume haben. Nan nimmt an, dafs die acht grofsen $5,14 \mathrm{~m}$ im Umfang haltenden und $19 \mathrm{~m}$ hohen, vereiuzelten (ilbïume am Irufse des Ölberges bei Jerusalem in dem sogenannten kleinen ölgarten, der beriihmt ist als Leidensort unseres Heilandes, noch aus Christi Zeiten herrïhren. Titus liefs bei der Zerstörung Jerusalems, wie Josephus Flavius berichtet, alle Waldungen um die Stadt niederhauen, aber die Ölbüume schlagen bekanntlich aus der 'Wurzel immer wieder aus. Wie hätte sonst anch Palästina, welches Jahrtausende durch Araber, Türken, Mammeluken und Ägypter verwiistet wurde, noch eine grolse Fïlle rou ölbärmen behaupten können? Die homerischen Griechen bauten nach Hehn den Olivenbaum nicht, oder doch uur sehr wenig an und fïhrten das Öl als Schmuckmittel für die Edlen und Reichen ein. Es trat allmählich an die Stelle des Tierfettes und diente zum Abreiben des Körpers und erst viel später zur Beleuchtung und Nahıung. Bei den späteren Griechen galt Athen als der U'rsitz der Olivenzucht. Solon erliefs gesetzliche Bestimmungen über Feigen- und Olivenbau und später bemiihte sich Pisistratus für die Aupflanzung dieses nützlichen Banmes. Niemand durfte auf' seinem Boden jührlich meh" als zwei Öbäume ausroden und die Früchte sollten nur von keuschen Jünglingen und Jungfranen gesammelt werden, Der (ilbaum war der Ninerva (Athene) geweilut (Suidas: "Weil das Öl \%ur Leuchte diente und der OHbaum dis Feuer nihhrte") und galt als Symbol des Friedens und der Fremdschaft. Der amgehlich ron der Göttin auf der Akropolis sellsst gepflanzte (ilhaum blieb fortwährend Gegenstand der heiligen Verehrung. Von diesem lanme stammten die der Göttin geweihten, unintistbaren ölbiume in der Akademie. Lin Kranz vou đ̈lzweigen war der I'reis für die olympischen Sieger, ein Ölzweig wir Auszeichnng liir einen 1 m den Stat verdienten Biirger. Das Vain- 
reiben des Körper's mit (̈) wurle allgemeine Sitte. P'linins sagt dariiher: „/Awei Fliiscigkeiten gieht es, die dem menschlichen Kürper angenehm sind. innerlich der Wein. änfserlich das (̈), das (i) etwas Notwendiges." Hemokritos rou Alderia. der beriihnte l'hilosoph, der ïber 100 . Tahre alt worde, erwiderte aul die Frage, wie man gesund bleiben mul seine Tage verlinnrern kïnne, mit der diätetischen Regel: ..Imnerlich Hong. äufserlich (i)" (Itehn). Durch die Seife, diese norlische Erfindung, ist die Sitte, den Leil) mit öl zu salben. verdrängt worden. Auch dis Hol\% des Olivenhanmes wie des Oleasters hemutzten die Alten. So ist die Kenle des Cyklopen ans diesem Material gefertigt. Die griechischen Kolonisten verbreiteten die Kultur des öbrumes his in die westlichen Mittehneerlïnder. Sach P'linius ist zur Zeit des T'aryninins Priscus noch kein (i)baum in Italien rorlamlen gewesen, aber im ersten fahrhundert vor Christi war die Halhinsel das an (ilbäunen reichste Land. 249 Jahre ror Christus kosteten 22 Pfund (̈) 10 Asse, 74 vor Christus 10 Pfund 1 As. Nach Marseille (Massilia) soll der (Olbaum durch die Phönizier 680 r. Chr. gekommen sein, so dafs also die Gallier den Ölbium friiher hatten als die Iiömer. Im siebenten Jahrhundert wird das Banmöl vou Bordeaux schon erwähnt. In England gedeihen Olive und Weinstock nicht. Auf der Insel Sardinien kam die Kultur des Ölbaumes erst in nenerer Zeit duch einen Erlafs des Königs ron Sardinien mehr in Aufschwmg, in welchem dem, der eine gewisse Anzahl dieser Bïume kultivierte, die Erhebung in den Adelsstand rersprochen wurde 1). Das Olivenöl diente auch in europäischen Staaten als heiliges Salböl. un Könige zu salben. Die alten Deutschen salbten ihre im Freien anfgestellten Götzenbilder mit (i) (Ö)göitzen). Anch gol's man Baumöl auf die geweihten Altaire als Opfer der Götter. Kortex brachte den Ölbam nach Mexiko, Antonio Ribera 1560 nach Peru.

Im üstlichen Asien wïchst der wohlriechende Ölbaum (Olca fruyus ${ }^{2}$ ) Thl.), dessen Bliitter dort in den Thee gemischit werden. Die Frïchte des amerikanischen Ölbaumes (Ola amcricuna L.) in Carolina, lilorila, werden als Speise gegessen; sein sehr hartes Holz führt den Namen Devil-wood (Teufelsholz). Ota maniculuta") R. Br. in (Gneensland liefert hartes, zïhes Holz zum Bröicken- und Häuserban. Ein noch härteres Holz, dass sogenamnte schwarze Eisenhol\% (blitck ironwood) giebt Oleu undulute Tuc\%. in Natal.

1) Coronedi-Berti, Volkshotanik. - 2) Duftend. - 3) Mit einer Rispe. 


\section{Tafel 13.}

\section{Figur I. Echter Safran $\left.{ }^{1}\right)\left(\right.$ Crucus $\left.^{2}\right)$ satirus $\left.{ }^{3}\right)$ L.).}

Der echte Saffran gehört wie die annerikinische Agave (S. 59) und die echte Ananas (\$.55) zur Ordnung der Schwertlilien, und zwar zur Fimilie der Schwertelgewïchse (Iridene).

Die Familie der Schwertelgewächse (Irideae). Ausdanermle Kräuter mit meist knullenfürmigem Wurzelstock, seltener nit Zwiebehn und einjälnigen Blitenschätten. Ihre ror dem Aufbliihen in Scheiden eingeschlossenen Bliiten hahen sechsteilige, blumenkronartig gefürbte und regelmälsig oler nuregelmälsig gehildete Perigone. Es finden sich nur drei Stanbblitter, welche am Grunde der Perigonziptel oler auf' dem Fruchtlinoten eingefïgt sind (Fig. I) nnd nach anfsen gekehrte Antheren haben (Fir. I5). Der Fruchtknoten (Fig. I3) birgt in drei Fïhern (Fig. I 4) zithleiche, zweizeilig angendhete Simnenknospen, trägt einen Griftel nit drei oft blumenblattartigen, grofsen Narben mod wächst zu einer fachspaltig antspringenden hapsel heran.

In 30 Gattungen, 600 in den warmen und gemülsigten Zonen, hauptsächlich am Kílp der guten Hoftnung einheimischen Arten.

Die Gattung safran (Crocus L.). Zwiebelgewiichse mit linealen, in der Mitte meist mit gelhen oder weifsen Streifen gezeichneten Bliittern und ummitelbar ans der dichten netzfaserigen Zwiebelknolle hervorkommenden, langröhrigen, trichtertörmigen, terminilen Einzelbliiten.

Echter Safran (Crocus sutius l.. Fig. I). Fin stengel- nul schattloses Zwiebelgewächs mit zwiebelstindigen Blumen.

Knollzwiebel unterirdisch, niedergedriickt-kugelig, an beiclen Enden vertieft. Heischig, stïrereich, mit einer diinnen, xiemlich fest anhäingemlen, feinfaserigen, nufshannen \%wiebelschale bedeckt, aber durch die Üherreste der abgestorbenen vorjährigen Scheiden geschoptt,

1) Com arabischen Sahafaran, bei den Arabern Arafrau. - ") xóoos ron xpox», Faten (in bezug auf dic Narben). - 3) Angebaut. 
Jingshermu unter der Scheide geringelt, miten mit einfuchen W ur zeln. Ohen ans der verticften Mitte entwickeh sich nuter der Schale eitue oder mehrere ein- his zweiblitige, an ihrer basis knollige Knospen, dic spiiter norh weiter auswachsen; aus dem limfinge

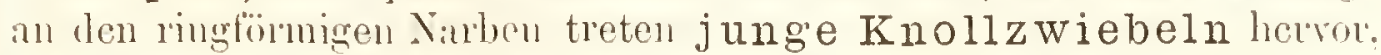
die im ersten Talne nu Blätter, keinc Zwiebch treibcn. Zwiebelscheiden fuinf- bis scchshäutig, gestreift, schief alggestntzt, ans der Basis der nencu endständigen Kunspe hervortretcnd und die Blitter nebst Bliten an der Basis umhiullend. Wurzelblätter aus der endstindigen knospe. mit der Blïte zugleich, schmallinienförmig, stumpf. am Rande umgerollt, dunkelgriin, mit einer nuch unten levrortretenden, dort weifsen Mittclippe. Blüten ein his zwei, zwichchstïndig, : lus der Vitte der endstiindigen Knospe, kurzgesticlt, ron doppelten. häntigen. durchscheinenden Bliitenscheiden nmhiillt. Al1gemeine Blütenscheide kur, einblïttcrig, röhrig, bcide Bliiten einschliefsend. Besondere Blütenscheide zweiblïtterig, fast ron der Länge der Perigonröhre, die innere schmaler. Blütenstiel kurz, undeutlich dreikantig, unterirdisch, $1 \mathrm{~s}$ bis $25 \mathrm{~mm}$ lang. Fruchtknoten (Fï. I, 3 n. 4) unterstïndig, länghlich, fast stielrund, drcitächerig (Fig. 3 a und $4 a$ ). Samenknospen mittenstïndig (Fig. $3 \mathrm{~b}$ und $4 \mathrm{~b}$ ), zweireihig. Perigon oberstïndig, blumenartig, rerwachsen-blätterig. trichterfürmig, rcgehmäfsig; $R$ öhre 5 bis $10 \mathrm{~cm}$ lang, untcn ungefïrbt, oben blafsviolett oder lila, am Schlunde bärtig, Saum scchsteilig. Staubblätter drei, anficcht, Staubfäden (Fig. I. 5) der Länge nach mit der Perigomöhre rerwachscn, an Schlunde frei. im freien Teile kürzer als die Staubheutel, 7 bis $9 \mathrm{~mm}$ lang, ungefïrbt; staubbeutel 12 bis $14 \mathrm{~mm}$ lang, linienförmis, an der Basis pfeilförmig, dort angeheftet, gelb, zweifïcherig. Fruchtblätter drei, den Scheitel des Fruchtknotens, sowie Griffel und Narben hildend. Griffel von der Länge der Staubfäden, 7 his $9 \mathrm{~mm}$ lang, fadenförmig, unten ungefüirbt, oben gelb. N a $\mathrm{r}^{\mathrm{b}} \mathrm{b} \mathrm{n}$ (Fig. I, 1 und 2) drei, fast den Rand des Pcrigons erreichend, erst aufrecht, dam herablü̈ngend, $3 \mathrm{~cm}$ lang und oben $2 \mathrm{~mm}$ breit, röhrenförmig cingerollt, nach oben allmählich erwcitert, am Rande umegclmälsig gekerbt, dunkelonangcrot, gegen die Basis gelb (nach Berg).

Frucht und Samen milekannt.

Blüht im September und Oktoher.

Vaterland: Persien und Klcinasien. Verbreitungsbezirk: Thal ron Kaschmir. Indicn, China, Japan, Vorder-Asien, Anatolien (Distrikt Safranboly), Oricut, Mazedonien, Neapel und Sizilien, nordöstliches Afrika, Gâtinais bci Orleans und Umgcgend ron Orange und Charpenticr, Arragonien, Nieder-Österveich, Bayern, Wallis, Pennsylvanien.

Kultur. Der Krokus verlangt einen gutcn Boden, der sich leicht pulvern lälst und doch anch cinige Bündigkeit besitzen mufs. 
Von Janmar bis 7n1 Legezeit in Mitte Juli ist das Land schon dreimal gehackt und gekliint worlen. Man legt die Zwiebeln in lirihen ant Fingerlinge rom einander mul $18 \mathrm{~cm}$ tief, und liifst bis zur Ernte kein Lnkrant aufkommen. Mit Encle September, Anfang Oktoher konmen die Bliiten, mul zwal so hastig, dal's sie in einer Nacht völlig anfgreschlusen sind, sich am Morgen in der Somne entfalten und das ginze Feld in einen stark duftenden violetten Teppich rerwandeh. aut welehem nicht das mindeste Grïn sich zeigt. Regen ist in dieser Zeit schädlich. In ersten Jahre wird wenig geentet; lie Haupternte erfolgt in zweiten Jihlre. Nich der ersten Ernte bearbeitet man den Boden nur obertlächlich. Die zuerst gelegten Zwichehn sind, nachdem sie ein par junge gebildet, abgestorben. Die jungen Zwiebehn treiben reicher Blïten, lassen aber im nïichsten Jahre wieder 1n:ıch. mul werden nach der dritten Ernte anderswohin verptlanzt. Achtzehn Jahre miissen vergehen, ehe man das alte Kulturfeld wieder nit Zwiebehn besetzen darf. Der Saftumbancr hat in der Regel drei Folder mit Safran besetzt, ein ein-, zwei- und dreijilhriges. Die Ernte dinert zwei his vier Wochen. Die Bliiten werden des Morgens geptliickt wie sie anfgebrochen sind und miissen noch am nömlichen T'age anfgearbeitet werden. Die dreiteilige rote Xarbe wird ron dem langen gelben fatenförmigen Pistill abgelüst, so dafs ein Teil des gelhen Fadens. daran sitzen hleibt. Die Arbeit geschieht möglichst im Freien wegen des starken Geruchs, der den Leuten lïinfig Kopfschmerzen vernusacht. Anch der geïbteste Arbeiter kann tïglich nicht mehr als ein Kilogramm Karben zupfen. Nach Marquarts Berechnnng erfordert ein I'fmud Safram gegen 60000 Bliiten. Das Trocknen geschicht mmittelbar nach dem P'fliicken, so, dafs minn den safinan anf Haatriehen ansgebreitet 1'2 Stunde der Wïrme eines Kohlenfeners anssetzt. - In Siid-Frankreich richtet der Safrantod, eine Wurzel-Schmarotzerpflanze (Rhizoctonice crocormm) oft grofse Verwiistungen an.

Gehalt. Die Zellen der Safrannarben sind reich an Polychroit. einem roten, im gelösten Znstande gelben Farbstoff mul fiihren auliserdem noch Fettropptehen. Der Siffan hat cinen strrken, etwas betänbenden $\left.{ }^{1}\right)$ Geruch nud bitteren, sewiir\%aften Geschnack, firibt den Speichel rotgelb, Wasser, Alkohol, tette und itherische Öle goldgell, bleicht an lichte ans nud rerliert an der Luft den Geruch. Der firmende Bestandteil des Safrans wmole als Crocin") (Safranin, l'olychroit) bezeichnet. Es wird durch konzentrierte Sidwefelsïne crst blin, dimm riolett, durch salpetersämre griun. Lis ist rot, formlos.

1) Auch in den chinesischen Gelbschoten (Gardenia-Arten) enthalten. 1)!. Wittstein erzält in seinem oben gemannten Thehenhuche, dal's ein ilamelungshener, ler in eincm Wuren-Magazin die Sachtwate und als Kopthissen

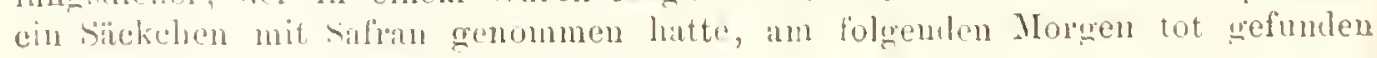
wurle. - ") Klenoke. Wittstein, l. ‘. 
in Wasser mul Alkohol leicht, in $̈$ ther schwer löslich und aufseroritentlich stark fitrhent.

Gebrauch. Wer Sillian wirl an stïrksten num Wiir\%en rerschiedener speisen, dann aber zum Färben (moschïdlich) ron likïren, von Teigwaren (Satran malcht die kuchen geh), landesibhlich anch ron Butter und hïse. sogut Wiirsten gohnulucht. Als Fïrbestoff wirl der satrin in ler lärherei weren seines hohen Preises und wegen seiner geringen 11altbarkeit nur sehr wenig (nach Zusitz ron Sïuren zmm Blan -. Lilil - und (iriinfïrben der Seide) angewendet. Nls Heilmittel wirkt der safran in kleinen Gaben belehend, gelinde erregend, schnerz- und kiramptistillend. in gröfseren aber betiubent und stark

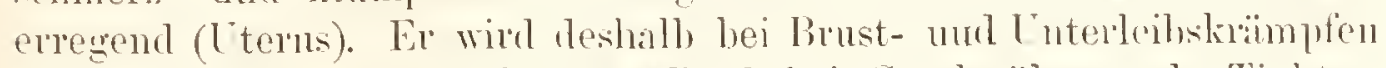
und äufserlich als zerteilendes Nittel bei Geschwiilsten als T'inktur, Zuckersatt und I'Haster gohraucht und auch vielen Heilmitteln \%.1gesetz.t.

W a renkunde ${ }^{1}$ ). Der getrocknete Safran lildet ein (iewirr ron dumkelpurpuroten. bramoten oder rotbramen, fettglinzenden, gegen die Basis gelblichen Fürlen. Die Fïden sind zïhe und hiegsam. Gute Handelsware darf nicht dunkelbraun. nicht zu feucht sein, einen etwas heifsemlen, starken, aromatischen Geruch, einen bitteren, warmen. halsamartigen Geschmack besitzen und möglichst wenigg gelbe Spitzen haben, die indes selten ganz fehlen. Fühlen sich die Fïden ïlig an. so ist das ein Zeichen, dafs sie in (̈) cingetaucht wurden, um ihr' Gewicht zu erhöhen. Die Nürnberger '/wischenhändler lassen ron besonderen "Safranklaubern" oder ..Elegierern" die gelben Fasern heranslesen und rerkaufen diesen Safrim dann als "elegierten", den unansgesuchten als "naturellen." Handelssorten 1. der österreichische Safrau. Teuerste (it Pfund 240 Mark) und beste Sorte. Die Narben sind grofs und schön rot, trocken, ohne gelbe Fïden, ron sehr starkem. eigeutimlich aromatischem. betïubendem Geruch. Fird nicht ausgeführt. Woil er den eigenen Bedarf nicht deckt; wird angebaut in Cnter-Österreich zwischen Mölk und St. Pöilten. und hei Meifsen am Nanhardtsherge und auf den simonismirkte in Krems rerhandelt. 2. Der ungarische Safran, dem vorigen ähnlich mod aus demselben Grunte nicht ausgefiihnt. 3. Der französische Safran mit dem Gritinais-silfran (Departement des Loiret) als beste Qualitiit. Die läiden sind ling, breit, dick. schön dunkehrot und gliinzend, whe gelbe dirunter. trocken und geschmeidig. Etwas schmäler. und heller ist der Ariguon-Safran (Departoment Vaucluse). Eine geringe Sorte baut man in Languedoc nun Angoulème, er besteht aus diinnen, langen, zarten, oben zart roten. muten gollblichen his weifslichen Fïden. Nach Deutschland und Österreich kommt hauptsiichlich der Gâtinais-Safran. 4. Spanischer Safran, fast im ganzen Lande

1) Klencke, Wittstein, l. c. 
getaut, besonders aher in Nencastilien und Iragonien; die beste śorte gewinnt man in der Mancha mod ant Malloreá Geringer als der französische. Wird nit baumöl und Zuckersaft gretrïnkt. 万. Italienischer Safran. Der beste ist dor unter dem Tamen AyuilaSafran anf den Markt kommende neapolitanische. Er steht in Giite dem framöisclien Safran kam nach. Dic calahresische Waro (Cosenzar mol Garigliano) hat kleine Narben und ist nicht gan\% rein; die sirilianische Ware wïre gnt, wenn man sie nicht nit Salfor nunl andren Bliten rermengte. 6. 'T'ürkischer. levantischel oder' macedonischer Saflan (auch aus Kleinasien und den Insehn des ïgeischen Meeres) gelangt über 'Triest, Semlin und Ofen naeh Österreieh. Fr hat breite, dicke Narben und selur schwachen Gerneh. Die Einsanmler benetzen, um der Ware ein schönes Insehen zu gehen, die Finger mit Sesamöl, wodurch die Narben ölig werten. Er ist aueh in der Regel rerfïlscht und es ist ihm oft schon ein Teil seines Farbestoffes und (i)es entzogen. 7. Safran vom Sichwarzen Meere (russischer Kaukasus, Paku), gehört zu den vorzïgliehsten Sorten. Man benetzt ihn durt mit Wasser, prefst ihn in liinne, etwa $231 / 2 \mathrm{~cm}$ im Durchnesser haltende Kuehen, die nan in der Mitte zusammenbricht und troeknet. Die beste Sorte benutzt man dort zum Seirlefärben. - In Persien, Kaschmir u. s. w. wird auch rorziighlicher Safian grelaut. Verfälschungen des Sifrans kummen ror mit Saflor (Carthămus tinctorı̌s I.), Ringelblumen (Calcndulu officinulis), mit den Staubfiden des Saframs und des Frühlingssafrans (Crocus vermus L.). Um diese Verfälschungen zu erkennen. weiche man die Ware zuror in Wasser auf. Echtel Safran hat eine dreispaltige Sarbe, Saflor aber eine röhrenförmige, die Rirugelblume plat te Sarbenblätchen. Hat man Safran mit den Staubfïden derselben Pflanze vermischt, so ist dieser Petrug leicht an den gelhen Fïden, die an ihren Enden Pollentaschen tritgen, und an den ausgestrenten Blütenstaube zu erkennen; die Stauhfürlen des Friihlingssafrins hatben eine runde Form. Bein Aufweiehen in Wisser sieht man zugleieh. ob der Safian nit gefübten Mineralien, Kreide. Gius ete, die man inm oft mittels Honig oder Syrup anhängt, beschwert worden ist, denn diese lösen sich los und sinken zn Borlen. Die Narben anderer Crocus-Arten, \%. I). des Crocus verme, liese sind droimal kinzer mul oben breiter, tutentömig, geruchlos und von heller Farbe; - des Crocus tutcus ron citronengelber Fabe und geringer Liinge. des Crocus susianus von geringer Lïnge ete, zuletrt die unter der Renemmug Feminelle in den Inandel kommenden Griffel des Crocus sativus, die mit den Alugange der Nirben remittelst Butter und warmen Wasser's aufgefiuht sind. - Wie Merck mitteilt, ist nenerdings anch ein ehenisehes Produkt unter dor Boreiehnung Safransurrogat (i Pfund 52 Mirk) zum Verkiuf gestellt worken. Es ist rles ein jerlenfalls nit Salpetersïure bereitetes Produkt aus 


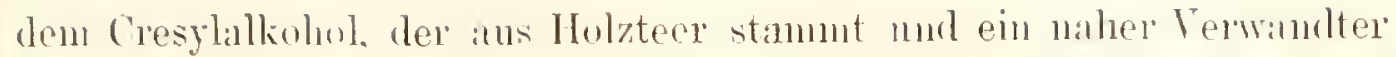
des hreosot (Kirrbolsinure) ist. Es erscheint als gelhrotes l'ulver, das

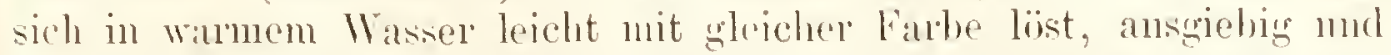
enerwisch (besonder's die Hant) fairbt, aher widerwiitig, stark nurl hrennend schneckt.

Handelsstatistische Notizen. England importiert jïhlich mugetähr 9500 Pfund Safran, woron es iilser 5000 Pfund wieder ansfiht. Ther Homburg geht gewöhnlich etwas iiher 1250 Pfund Sifran ins Dentsche Leich. Die gröfseren deutschen Handelshänser stehen mit Frankreich nud Sprnien in direkter Verbindung. In Nieder-Österreich scheint die Produktion des Safrans in Niedergang begriften zin sein.

Geschichte. Saltian liente schon den alten Juden als Gewiirz, Heil- nud Färbemittel. Die griechischen Mythen lassen ilıre (iötter und Helden mit safrangelben Kileidern, Schleiern, Schuhen ete. geschniickt sein. So tragen Bacelı s und die Teihnehmer an seinen Frendenfesten Safrankleider, der nengeborene Herakles ist in krokusgelbe Windeln gewickelt (Pindar) und der Pallas Athene sticken attische Jungfinuen das hunthurchwirkte Krokusgewand. Der Krokus ron Cyrene, der rom cilicischen herge Corycus und der cyrenäische galten den Alten als die rorziuglichste Ware. Nach Plinins ist der Silfran ron Sizilien besser. als der in Italien gebaute. In Rom besprengte man die Theater des Wohlgeruchs wegen mit Safranwasser, zur Kaiserzeit Hiefsen die Statuen in Theater ron hrokussaft und Heliogabalus badete sich in Teichen, deren Wasser mit Safran wollriechend gemacht worden war und liefs seine Gäste bei Mählern at Polster ron Krokusnarben niedersitzen. Safran war ein LniversalHeilmittel und durfte in keiner Arznei fehlen. Die eigentliche Satranknltur wurde indes erst ron den Arabern nach Spanien gebracht, wie auch der Name Safran (S. 82, Note 1) arabischen Lisprungs ist. Heute schïtzt man das Aroma der Blüten nicht mehr so hoch, wie friiher.

Es werden $30 \mathrm{Krokus-Arten,} \mathrm{bei} \mathrm{uns} \mathrm{hesonders} \mathrm{Crocus} \mathrm{icrmus,}$ Frühlings-Safran, als Topf- nur Gartenzierpflanzen wegen ihrer Farbenpracht als : Friihlingsblumen kultiviert. 


\section{Figur II. Gemeiner Kappern ${ }^{1}$ )strauch

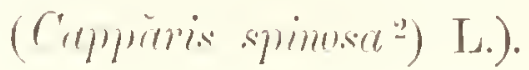

Der gemeine kapperustranch gehört \%ur Kilasse der \%wejsunen-

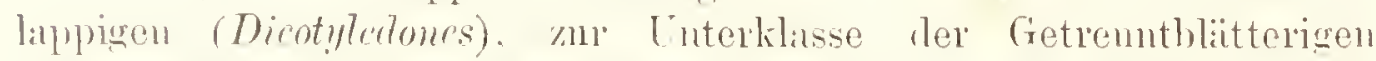
(ETeutheropestatur oder Potypetutae), zur lieihe der Budenbliitigen (Thutumifloruc), zur' Ordunng der Mohnptlanzen (Rhocudes) und zur Fomilie der Kapperngeräche ('uphariteue).

Ther lie Unterklasse der Getrenntblätterigen und die Reihe der Bodenblütigen siehe J. Ahteilung S. 24.

I) Ordnung der Mohnpflanzen (Rhoeales) s) wird charakterisiert dnrch die bihhung des Fruchtknotens. Dieser wird von zwei orler mehr Fruchthliittern gehildet, deren Rïnder mit einander rerwachen sind und die Samen tragen, nnd seine Xarben sind nicht die rerlüngerten Mittelrippen der Fruchthliitter, sondern deren verlïngerte liänder.

Ther tie Fanilie der hrenzhlimler siehe moere .. hepräisentanten einheimischer Pflanzenfannilien" II. Nhteilung.

Die Familie der Kapperngewächse (Capuridcur). Lirïnter oder strïincher. I'nterscheilen sich ron den Krenzhliunlern durch die vier mächtigen, oft zahlreichen St:mblblïtter und den einf:̈icherigen. gestielten orler auf einer miterständigen Schcihe (I)iscus) sitzenden Fruchtknoten. Die Frucht ist eine Becre oder Kapsel. Die nierenfïmigen Samen enthalten kein Eiweifs. Diese PHanzen sind in den tropischen und subtropischen Zonnen rorzugsweise Amerikils und Afrikas zu Hause. Sie enthalten scharfe Stoffe.

Gemeiner Kappernstrauch (Cupuris spinosu $L_{\text {. }}$ ).

Der Stranch ist rierlich, dornig, rankend, his $1 \mathrm{~m} \mathrm{hoch}$, wiichst wild anf steinigem Borlen. an F'eken und anf llanerus. wird kultiviert und auch als lanulstranch angehaut.

Blätter ahwochehul, rundlich, fint her\%fömmig, ganzrandig, an

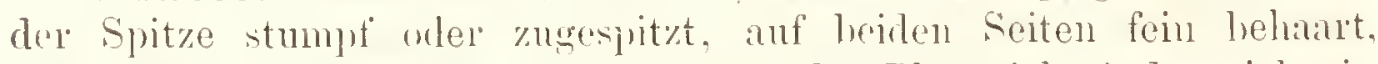
sonst glitt, ku1\% gestielt. An der Barsis des Bhattstiels tinden sich ein oler zwri hakenförmig zurïckgekriimmte in Dornen (spinae, daher spinosa) nngewandelte Nebenhliitter. Bei cinigen Spielanten fehlen diese Dormen.

Blüten hlattwinkelstïnlig, mit langem. anfrechtem, walzenrmulem Stiel; Kelch vierbliitterigg, steif. Kelchbliitter koukir, fast

1) Capprtris sehon von Plinins und Dioscorides so gentunt. - ") Dornig. 3) Von iquic. Granatapfel, dessen Blumenfarbe mit der der Mohnptlanzen ïhnlichlieit hat. 
machenförnig, mgloichfömig. mregehmissig; Blumenblätter grölser als die lielchblitter, weils, rundlich, mugleichmifsig, ‘um Tril mit gekerhten käindern, die heiden an der Basis mit einem Nagel rersehen, die zwei nnteren haben am verdickten Grunde eine sponförmige Verlängerung. hinter welcher sich eine griune zart behante Vertieling befindot, welche der Vertiefung der muteren Kelchblittere entspricht. in die sie sich engesenkt. Anfserdem sind diese biaitter an ihrem inmeren limde rerwachsen. Staubblätter 60 his 80. auf- und alwiirts gerichtet, purpurrot; Staubbeutel grofs; der Fruchtknoten besityt noch einen hesonderen Stiel. welcher der Staulfulcnlïnge gleichkommt und lem Mooskapselstiele entspricht. eiförming lïnchlich.

Frucht (Fig. II, 2 und 4), eine fleischige, einföcherige Schote, mit zalulreichen in einem breiartigen Zellgewebe olme bestimmte Anordhnng gelagerten nierenförmigon simen (Fig. II, 3).

Heimat und Verbreitungsbezirk: Nord-Afrika und siid-Enropa, besonder's Siid-Frankreich und Spanien, Balenten, It:lien. Sizilien und in den Ebenen um Athen auch auf diirrem, sandigen Boden der Felder.

Kultur. Nan baut den Stranch auf steinigen und somigen Feldern, die fast nichts weiter zu tragen vermögen. Durch die Kultur sind eine Nenge ron Spielarten entstanden. Sobald die Ḱnospen des Kiappernstranches die Grörse eines Pfefferkornes oder eincr Erbse lahen, werden sie ron Weibern und Kindern des Lambolkes so albgezupft, dafs sie noch einen Teil des Stieles tragen, vier bis fünf stmulen lang im Schatten getrocknet, damit sie welken, in Fässer mit gesalzenem Lssig geschïttet und an die Saleur's rerkinft, die die Mare nach der Gröfse sontieren und in starken Essig oder in trockenes Sal\% legen.

Gehalt. Die Blïtenknospen des Kappernstrauches, die Kappern (Gemmac coppurides), enthalten einen Hiichtigen, scharfen Stoff' (Rutin), der in Verbindnug mit Essig oder Salz angenehm pikinnt schmeckt und angenehm anf die Geschmacks- und Verdaumugsorgane wirkt.

Gebrauch. Han gebrancht die Kapper'n als Gewiirz an rerschiedene speisen, Sancen mu Salate, im Sïden mehr als hei mns. In Griechenland mud Frankreich werden anch die liüchte eingemacht und wie Essiggurken gegessen. Die Franzosen hringen sie unter dem Namen Cornichons de Cumier in den liandel.

In Griechenland werden die jungen mud frischen Zweige und Blätter nach Landerer mit heifsem Wasser abgebriht und in Essigg eingemacht und gleich den Kapperu gegessen. Auch fürbt man damit halthar branngrin.

Warenkunde. Capres en races nemt man die Ware (urofse und kleine unter einander), wie sie der Lamblmann an die Salenrs verkauft. Die besten und teuersten sind die kleinsten, die Nonucreilles 
hrilsen. Etwas grölser sind the Sur-fines oter Cunneines, die gewöhnlich noch die Sticle ("Kiappern mit langen Sohwänzen“) hahen. Ine grölsten sind die hilligsten, sie heilsen Capres rommenes und sind fiinf- bis sechsnal shwerer als die Nonpurcilles. Die feinen Sorten heilsen auch in Dentschland Kilpuziner- odel Kinpotkappern. (inte kappern miissen cinen etwas scharfen und littorlichen Geschmack hahen. dunkelolivengrïn gefiirl,t, klein, hart, rund unt noch vollkommen seschlosen sein; alte und reldorbene sind schwïrzlich, weich und geschmacklos. Find die Kappern rom anffallend hochgrimer Farbe, so sind sie gewöhlunlich nit Kupfer gefülldt. Man kamn das leicht erkrmnen, wenn min eine Messerklinge in die Kapperntliissigkcit legt, da dieselhc hei Vurhandensein von Kunfer dasselbe metallisch anf sich niederschlägt. Nls Surrogate werden auch verkautt die Ḱnospen der Kapuzinerkiesse (Tropurolum majus L.), Capres de Gront oder dentsche Kijpleru, die Kinospen des Fesenstranches (Spartium scopurinm L.). auch die des Holhnuders (Sambucus nigra L.), die der Sumpfdotterblume (Caltha puhustris L.). die des Scharbockskrautes (Ficariu ranunculoides Roth.) etc. Dic fleisehigen schotenförmigcu, $5 \mathrm{~cm}$ langen Friichte des Kappernstranches werden auch in Essig eingelegt und als Cornictions de Caprier in den Handel gebracht.

Geschichte. Dies Gewiir\% war schon den alten Griechen und Römern bekimnt. Eine der beriihntesten Hetïren Griechenlands. die schöne Phryne aus Thespia in Böotien, kam als Kalpennhändlerin nach Athen. - Griffith liailt den Kappernstranch für den Ysop der Bibel.

Es gielst zalılreiche Spielarten. 


\section{T a fel 14 .}

\section{Echter Brotfruchtbaum ${ }^{\prime}$ )}

(Artecapus: incisa $\left.{ }^{3}\right)$ L. fil.).

Der echte Irotfruchthaum gehört zur L'nterklasse der perigonbliitigen Dikotyledonen (Apetulue, Monorlamydece), zur Ordnung der Nescelgewïhse (Urticince oder Scabridtae, siehe Ramieptlanze S. 50) und zwar zur Familie der Brotfruchtgewächse (Atoccipecte ${ }^{2}$ ).

Die Familie der Brotfruchtgewächse (Avtrarpece). Sie unterscheiden sich ron den Maulheergewächsen (siehe bei "(iemeiner Feigenbum“. S. 97) durch die gerade Form des fiemes und den Nangel des simeneiweilses.

Die Gattung Brotfruchtbaum (Artocurpus L.). Bäume nit meist fiederspaltigen und buchtig eingeschnittenen Blättern und zweihäusigen Blïten. von denen die mämnlichen Kätzchen hilden, während die weiblichen gedlüingt auf einem fleischigen Fruchthrden stehen, welcher zu einer kugeligen, höckerigen Frucht auswächst.

Der echte Brotfruchtbaum ${ }^{+}$) (Artoearms incisa L. fil.) wird 13 bis $17 \mathrm{~m}$ hoch and 33 bis $50 \mathrm{~cm}$ im Durchmesser dick. Bildet besonder's auf den Lnsehn Polynesiens mit seiner schönen, grolsen Krone iiberall Gruppen $\mathrm{mm}$ die Hiitten. Blätter $33 \mathrm{~cm}$ his $1 \mathrm{~m}$ lang, oft $50 \mathrm{~cm}$ breit, lerlerartign, wechselstindig, eiförmig, der obere Teil eingeschnitten („incisa"), fiederspaltig geteilt in drei his nem spitze, mehr oder weniger tiefe Lappen. An den Schöfslingen sind die Blätter oft ganzrandig, an den Sprossen und stïkeren Zweigen oft nur zwei- bis dreilappig. Oben dunkelgrün, ron gelhlichen Nerven durchzogen, fast ganz glatt, unten riulh, hleicher gefirbt und nit hervortretenden lippen. abfillend; Blattstiel kur\% mul dick. Nebenblatter grofs, wollig, welkend und hinfillig. Die Blätter durchlaufen beim Welken die ganze Farbenreihe zwischen dunklem Griin mnd

1) Aufser den oben angeführten Werken (iuilding in Curtis' Botanical magazin. - 2) "dotos. Brot, und \%onos. Frucht, Brotfrucht. - 3) Betrillt die eingeschnittenen (incīous) Bliitter. - ${ }^{4}$ ) Siche das Bild des Baumes auf s. 92, aus Glolus, Bd. 50. 
hremendhellem Rot. Dits eine Ende ist oft noch sammetgrin. withrend die Mitte goldgell, lenchtet und das andere Ende wie P'urpur

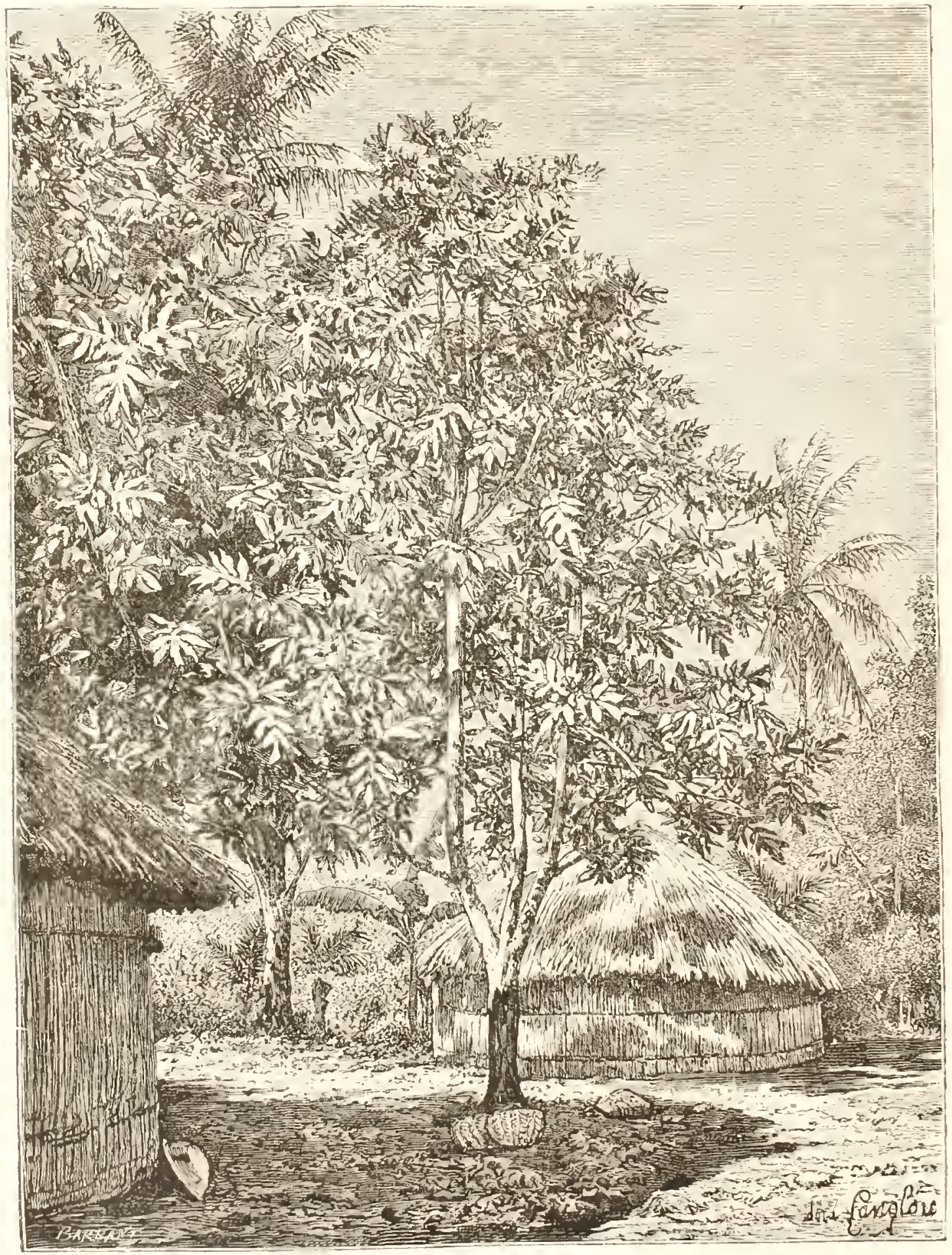

num Scharlach strahlt. Blüten entspringen cinzoln ans den oberen \%weighliittern; der obere Blumenstiel trïggt die mämulichen, die niedrigeren die weiblichen Blinten, beide anfangs in ein mud derselben Hiille 
eingrschlossen. Die männlichen Blüten stehen dicht grenäingt rings an einen kreisunden, schuppigen bellälter, so dilfs sic ein cylinlrisches oder kenlenfömiges 30 his $40 \mathrm{~cm}$ linges, gelbliches Kätzchen hilden. Blütenhülle (Figr. 3) einblïtterigg, cylindlisch, der motere Teil \% wei Klappen hildend; Staubblatt eins (Fig. 3), Staubfaden breit. so lang wie die Blitenhïlle, weifslich; Staubbeutel rondlich. жeilappig, zweilaicherig. Die weiblichen Blüten sind zn cinem kngeligru, stacheligen liopf mit einem runden, schuppigen Behïlter. rereinigt; $B l u m$ en hüllen einzhn, Heischig, sechsseitig, anfsen an den Kinten, wo sic scharfe primidale, wollige spitzen hilden, mit eniander verwachsen (Figr. 1). Nur der nutere 'Teil jerler liliitenhïlle ist hohl nud inwendign, wo das Pistill ist. wollig. Fruchtknoten (Fig. 2) eitormis, ein- bis zweifaicherigr; Griffel (Fig. 2) seitenstiindig, mit dem festen, oberen 'Teile der Bliitenlü̈lle (Figr. 2) verwachsen, wird wieder sichthar oberhalh des Punktes, wo er eine oder zwei ptrienrfürmige Sarben bilket.

Frucht eine grolse zusammengesetzte, eifömige, lingel-oder melonenförmige, Heischige Beere, grgen $42 \mathrm{~cm}$ lang. $24 \mathrm{~cm}$ im Durchmesser dick und $: 3$ his 4 P'tund schwer. Ein grolser Teil der Bhïtenhiillen hleibt unfruchthar, erleidet keine Verïnderumg nurl wirrl nur Heischiger und grö̊ser"; die linchtharen lüsen sich von den ührigen im unteren 'Teil mm die fleischigen Kanten und bilden einen losen. becherartigen, faserigen Behälter (Fig. 4) fiur die in ihnen eingeschlossene Nuls, die oben auf der Oberfläclıe der Frucht durch einc sechshöckerige Erhölnng angedeutet ist. Huilse oder Samenkapsel eiförmig, auf der einen Seite höckerig, faserig, netzaderiğ, noch mit rlem verwelkten Griffel verselıen.

Same orler Nufs (Fig. 4) anfrechtstehend, unregelmälsig, eiförmig, bramn, aderig. Embryo (Fig. 5 oben) grols, gelblich, Keimblaittehen (Figr. 5) nnglcich.

Vaterland: Siidseeinseln (lahiti) und Ostindien (Sumatra, Jara, Amboina, Nolnkken), aber nirgends meln wild. Verbreitungsbezirk: In den Lïndern zwischen den Wendekreisen, besonders auf St. Mamrice, in Westindien und Siid-Amerika (ron Guiana bis nach Neu-Grautula).

Kultur. Der kultivierte Brotfuchtbaum lililet in seinen Friichten keinen keimfähigen Samen aus. Fleischige Fruichte scheinen dureh Fehlschlagen des Samens mehr Nahrumg zu erhalten nnd dadureh gröser zu werden fwie hei Ananas, Citronatcitrone, Banane, Dattel, Erdbeere, Feige, Korinthentrabbe etc.). Der lirotionchtbaum wird lurch Schölslinge kïnstlich vermeht. En gedeilnt in geeigneten Klima in jedem Porlen, selhst in solchem, der zu keiner anderen Kultur benutzt wrorlen kann. Der liamu bleiht 60 bis 70 Jahre lang tragbils. Die Ernte währt nem Monate, näinlich rom November his zum Juli, und ist so aufserortentlich reich, dals die früuchte von zwei his drei 


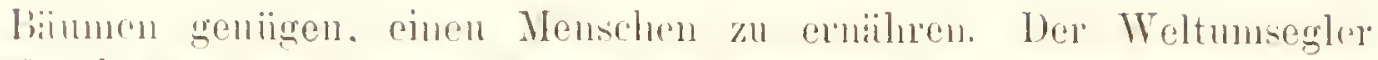
Conk sagt ron diesen liaume: .. Hat jemand in semem Leben zehn Brothïume geptlinkt. so hat ar seine ['flicht regen sein eigenes und gegen sein nadhfolgendes dieschlecht ehen so vollstïndig mol reichlich erfïllt, als ein Einwohner moeres ranhen Ilimmelstrichs. del sein leben hindureh wïhreml der Kïilte des Winters geptliigt, in der Sommerhitze geerntet mul nicht nur seine jetzige Haushliltung mit Brot versorgt, sondern anch semen Kindern noch etwas an batarem Gelde kiimmerlich erspart hit." Nach Seemann soll indes die Brotfrucht nu1 auf einigen Siirlsee-Inseln als Xiln'ung genossen werlen.

Gehalt. Der ganze Bam ist von einem sehr zäluen, farlenziehenden Milchsaft durchdrungen. Die Friichte des Brotfinchtbanmes enthilten eine grofse Menge ron Stïrkemehl. Diese Stiirke (Brotfruchtstiinke, fúcule du fimit de tarlwe is proin) wird gegenwärtig num rersuchsweise auf Martinique. in Guiana, Brasilien und anf Rémion dargestellt.

Gebrauch der einzelnen Pflanzenteile. Die Früchte werden teils in hallneifem. teils in ganzreifen Znstande algenommen. Das mehlige Fleisch, roh nicht efshar, wird gerïstet. z.n Brot rerbacken mul anf mancherlei Art hereitet genossen. a. Gebranch der halbreifen Frïchte. Beim lacken in heifser Asche. auf heifsen Steinen, seltener in Öfen, wird die Rinule schwar\% nul schrumptt ein. Die änfsere Rinde wird abgeschaht und es bleil,t dann eine innere zarte, diimne Kiruste. Das Innere der gebratenen Frucht ist weifs und weich wie Brotlirme, mufs indes gleich gegessen werden, da es nach 24 Stunden musig und fad wird. Nur in Scheiben geschnitten und getrocknet hïlt sich die Frucht zwei Jalne, kann dam den Schiffszwieback ersetzen und wird anch ron den Spaniern als solcher benutzt. Die Schiffsmannschaften ziehen diese Nalırung dem Brote ror. Auf den Siidsee-Inseln benutzt man die Brotfrucht anch zu einem sehr schmickhaften Mus, indem man sie nur menig röstet, dam von der Schale befreit, das Fruchtfleisch in kaltes Wasser lningt und darauf zu Brei quirlt. Eine selı sclmachlafte Mahlzeit lereitet man ferner aus der geöffneten Brotfrucht, inden man iln die Rinde und das Kelnhaus nimmt nud sie in einem Mörser tiichtig stanpft. Nun giefst man danut die ans dem saftigen Ken einer reifen hokosmufs rerriebene dicke Nilch. die man durch kleine, ans feinen kokosfasern gewelite Bentelchen prefst. b. Gebrauch der röllig reifen Früclite. Ist die Mehrzahl der Brotfriichte reif geworden, so tindet die Hilupternte statt. Die reifen Friichte sind goldgelb, weich, inwenlig breiig, widerlich siifs schmeckend und riechend. Dieser rohe Bree ist eine muresunde Speise und wird nicht, oder doch num mit gröbster Vorsicht gegessen. Den geenteten Fribliten nimmt man Rinde und Kerngehïuse mul stumy ft sie in hïlzernen Gefifsen zu einer teigigen Masse, die man in kleineren Posten sorglïltigg in blitter nul 
Bast hiillt unl jalnelang in Kiellern anfhewahrt. Diese so anfhewahrte Brotmasse (Muhe genannt) soll dureh lïngeres Lagern an Giite gewimnen. Die Insulaner backen darans nach Bedatf, nachdem sie den Teig haben gïren lassen, Kunchen ron hernsteinartiger farbe und etwas herbem, aber nicht unangenehmem Geschmack, der feinem Weizenlnot, wler (uach Anson) gebratenen Kartoffeh ähnlich sein soll. Mit dem saft der Apfelsine gretrïinkt, soll das Brot siifs wie Äpelpastete Sschmecken. Auch kann man den Kuchen wie Pndding bereiten. Von dieser aufbewahten Brotmasse nälnen sich die Insulaner fast ausschlicfslich im August, September und Oktoher, wïhrend welcher ' Ceit der Brotbaum keine Friichte trägt. Der Bast junger' Zwreige wird auf den Siidsee-Inseln zur Bekleidung, der anderer Arten (Artoc. hirsute Lam., Artoc. hirsute Willd. nnel Artoc. lacoocha Iioxh.) in Indien zu Flechtwerken und zur Papierbereitung henutzt. Yon den Brotfuchtbïumen wird ferner ein Dammarharz (Dammar selo) gewonnen. Der Dammar wird in der Firnifsbereitnng nud nnter anderen auch zur Darstellnng eines klaren Firnisses (Dammarlack) und zur Einschliefsung mikroskopischer Präparate benutzt. Von Artoc. integrifolic wird auch ein geringes Kautschuk gewomnen. Die Rinde ron demselben Baume dient in Indien zum Gerben und Färben. Der Milchsaft des echten Brotfruchthaumes wird mit Kokosmilch rersetat zn Togelleim und mit Zucker, Eiweifs und Sägemehl rermengt zu hitt rerwendet. Das gelbe Holz henutzt man zum Hänserban, zu Booten und Hansgeräten. Die Blätter verwendet man wie starkes Papier zum Einwickelı von Gegenständen und Aufbewahren ron Lebensmitteln; die halb rerwelkten, bunten werden ron den Eingeborenen an der Mittelrippe aufgeschlitat nnd als Kopfbedeckung benutzt, sonst dienen sie anch als Servietten, 'Tischtiicher' und Teller. Die ahgefallenen männlichen $\mathrm{Kätzchen} \mathrm{benutzt} \mathrm{man}$ als Zunder und Lunte. Der echte Brotfruchtbaum dient in Amerika wegen seiner schönen Belaubung mehr zu einem Alleen- als zu einem Fruchtbraume.

Geschichte. Der erste Bericht ron dem Brotfrnchtbaume rührt ron Dampier, der ihu massenweis auf den Diebes-Inseln fand, aus dem Jahre 1697 her. Genauere Nachrichten über diesen Baum erhielten wir durch die Reiseberichte Georg Forsters, der mit seinem Vater den Kapitän Cook anf dessen zweiter Reise um die Welt (1772 bis 1775) begleitete. Georg III. wollte anf Wunsch der englischen Kolonisten in Amerika den Baum in Westindien einfiihnen. In seinem Auftrage gelang es dem Kapitiin Bligh (sprich Blei) 774 I'flanzen einzuschiffen, allein die Expedition wurde dnrch eine Menterei der Mannschaft vereitelt. Erst die zweite Expedition gelanng. Von 1150 frischen Brotbanmptlanzen iberstand ein grofser T'eil die Reise, 550 wnrden in St. Vincent (Jannar 1793) gelandet, die ïbrigen kamen nach Jamaika (aufser fünf für den kew-Garten bei London). 


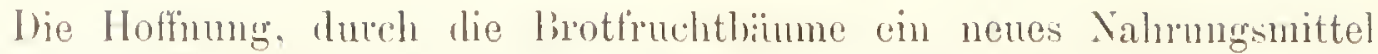
fïr die Sklaven in Amerikal zu erhalten, verwirklichte sich nur unrollstïndig, dem sie zogen die besser sehmeckende Banane, die roh zu geniefsen ist, sich chenso leicht anptlanzen lïlst und eher Friichte trägt. vor. Anch dem Siidsee-Insulaner ist es nicht angenehm, dals er alie Brotfrucht erst noch zuhereiten muls, ehe ar sie essen kamn. .. Dilher träumt er sich auch in seinem I'aratiese eine Brotfrucht, die keiner Zubereitung bedarf und frisch rom Banme weggegessen werden kium (Forster)." Bei der Geburt eines Kindes pttanzt er einen Brotfruchtbanun, der fiir das Kind allein bestimmt wird.

Andere Arten: 1. Indischer Brot-odel Jackbaum (Artoearpus integrifoliu ') J. fil.), von den Englïndern .Jackbaum genannt. Er trïigt in den dicken Ästen und am Stamm biswcilen his zur Erde herahlängende, 10 his 25 Pfind schwere Fritichte. Jaka genannt, die aber nur im Notfalle genossen werden. Auf Ceylon findet dieser Bamm Verwendung als Schattenspender in Kaffee- und Kakioptlanzungen, auch wohl als Windbrecher. 2. Weich haariger Brotfruchtbaum (Aitoectur pubescens"2) Willd.) in Ostindien. Hat liartes Holz und efshare linichte.

Verwandte: Der amerikinische Vilch- oder Kullbaum, der giftige Upashamm, der Sackhaum Ostiudiens, der Imeisen-, Kanonenoder' Trompetenbaum, die Platinen, die Maulbeer- und die Feigenbiilume.

1) Ganzblätterig. - 2) Weichhaarig. 


\section{Tafel 15.}

\section{Gemeiner Feigenbaum (Ficus $\left.{ }^{1}\right)$ carica $\left.{ }^{2}\right) \mathrm{J}_{\text {J.) }}$.}

Der gemeine Feigenbalum gehört wie der Brotfruchtbaum zur Ordnung der Nesselgewächse (Urtieince, siehe S. 50), und zwar zur Familie der Maulbeer"ewächse (Mloreae) ").

Die Familie der Maulbeer'ewächse. Milchsaft enthaltende Ptlanzen mit alwwechselnden Blättern und hinfülligen, hïutigen, bei den Feigen die Blattknospen umliillenden Nebenblättern. Bliiten cin- bis zweilïusig. Die Staubfadenbliiten bilden Älnen orler Trauben und besitzen kein oder ein drei- oder vierteiliges Perigon. Die Stempelblïten stchen in Kützchen (Maulbeeren) oder auf cinen gemeinsamen Blitenborten (Feigen) und haben keine. oder eine vierblïtterige oder fünfspaltige Bliitenluïlle. Die Frucht ist eigentuimlich, becrenartig. Im Eiweifs sitzt ein gebogener Keim.

Die Gattung Feig'enbaum (Ficus L.). Bäume oder Sträucher mit zerstreut stelıenden, meist breiten, ganzen oder gelappten Blïtern, die ror der Entwickelung in oft verwachsenen, spüiter abfallenden Nehenblïttern eingerollt liegen. Ans den Blattachschn wachsen die allgemeinen Bliitensticle als keulen- oder verkehrt eiförmige, jungen Frïchten ähnliche, holıle Bliitenhoden hervor, die fleischig werden und die Blüten lirugartig mmliillen. Die Blüten sind drei- bis sechsblätterig. entweder nur weiblich oder im oberen Teile auch männlich. Dic am Scheitel durch Deckblïtter vorschlossenen Bliitenboden (Bliitenstiele) rerwandeln sich in die fleischige Scheinfrucht, in welcher die kleinen, ei- oder kugelınden oder kantigen Nülschen eingebettet liegen.

Clber 300, der tropischen \%one anghörende Arten, von denen 66 in Afrika, 80 in Amerika, aber nur eine Art in Europa einhemiscll ist. Viele Spielarten sind in Laufe der Jahrtansende entstanden, deren Frïchte von nahezn schwar\% bis nahezn weifs, mit Abstufingen in liot und Gelb, sefiirbt sind.

1) Aus dem griechischrn yixos, fucus, 'T'ang, vder aus rivon, Feige oder

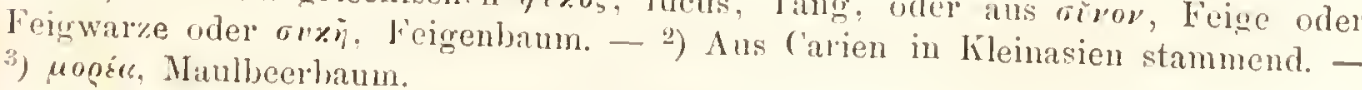

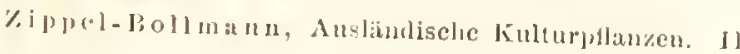


Gemeiner Feigenbaum (Fïcus coricu I.). Stamm im willen Zustande oft strunchartig, kultiviert hammatigr, bis 10 n hoch und 40 bis 50 'nu in Durchmesser dick. Krone riemlich grofs und stark belaubt. An den jüngeren Kreigen sieht man die Narluen der abgefallenen Biatter. Bast, Blätter mnl Friuchte mit Milchgefälsen versehen. Holz leicht und porös, mit schwammigem Malk wie das des IIolunders.

B1ätter zerstrent stehend, kiirzer orler lïnger gestielt, steif, stumpl; in der liegel herzfornuig, gekerbt odev geschweift gezälnt, auf der obcren Seite schart, anf der muteren meist filzigr, abfallend, versclieden gestaltet, die untersten länfigr mugeteilt, handnervig geadert; Nebenblätter zwei, zu einer das folgende Blatt einschliefsenden 'Tute zusammengerollt, nur an dem olsersten lilatt vollanden. bei dem Anwachsen der nmschlossenen Endknospe ringsumschnitten al)geworten und so an jeden Kinoten eine ringförmige Narbe zuriicklassend.

Feige meist birnförmig, achsel- oder seitenstïndig, grewöhnlich einzelı, an derselhen Pthanze ron verschiedener Beschaffenheit, mol zwar mit drei Formen, als friihzeitige, sommerzeitige nnd spätzeitige rorkommend. Die frühzeitigen Feigen (Grossi oder Orni) entstehen gegren Ende des Winter's an dem oberen Teile der rorjäln'igen Äste dicht iiber den Narben der albgefallenen Blätter und enthalten bei der wilden Pflunze zahlreiche männliche, bei der kultivierten ausschliefslich weibliche Blüten. Alle ïbrigen Feigen entspringen ans den Blattwinkeln der diesjährigen Zweige; rou diesen heifsen die unteren, vor dem Fall der Blätter reifenden sommerzeitige (Fortini), die obersten, welche nach dom Blattfill den Winter lindurch bleiben, spätzeitige (Cratiri) Feigen. Die sommerzeitigen des wilden wie des kultivienten Feigenbaumes enthalten nu० selır wenige männliche bliiten, oder die des letzteren oft gar keine, bringen aber demnoch kemfäihige simnen hervor, wihlend die frïhzeitigen des kultivierten Bammes stets unfruchtlatr bleiben. Die spätzeitigen erzeugen gar keine oder nur unvolstiandige männliche Blïten Der Feigenbanm treilst seine Blïten in der Fruchtknospe rersteckt. Die Frucht ist streng 'genommen gar keine Frucht, sondern nur ein Bliitenboden oder F'tuchtstaind, der aus Stengelmasse besteht. Sie schlicfst olne sich in Stielchen zu teilen, somdern zu einer binnfömigen Gestalt fortwïchst, die auf der Oberseite zallueich entstelıenden wirklichen bliiten wie in einen Bentel ein und es bleibt in der Mittelachse nul ein feiner Kanal (Fig. 1) mach vorn offen, dessen Mïndung an der zahnen l'rucht durch einige Schiippehen verdeckt ist.

Del gemeinschaftliche Blütenboden ( "lig. 2 f') ist festHeischig, mit vielen kumen Iiirchen und sehr zallheichen gedrüngt stehenden bliitchen hesctzt. Wr hefinct sich einzeln wler zu zweien seitliel an cinem axillaren Ianbkü̈spchen mul ist an Gounde von

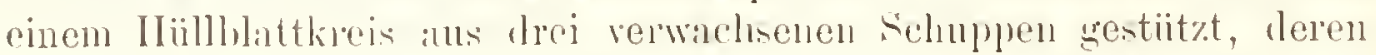


eine (puer zum Trighlatt gestollt ist und das Deckblatt des Bliitenboulens: rorstellt, wïlnent die beiden anderen als Vorblätter des Bhiitenstandes sclhst hetrachtet werden können. Zuerst entstehen die in Grumde der I'rne hefindlichen lBliten (weibliche), dimm die iibrigon in allgemeinen rentrifugal nit fortwiihrenden Auftreten nener Anlagen zwischen den :ilteren. Die männlichen Bliiten finden sich nach der Miïndung der Ume hin.

Blüten mach der Nitte gewendet, gestielt, farblos, blafsrot oder schwach griunlich, in der Frucht des knltivierten bammes gewöhnlich nn1 weilsliche, mïnnliche nur gegen die Niundung rorkommend, oft giın\% fehlend. Männliche Blüten der knltivierten Feige gewöhnlich lïnger gestielt als die weibliche, Bliitenliiille meist fiunfteilig, Zipfel ungekehrt linzettförmig, spitz; Staubblätter (Fig. 6) ein bis fuinf; Staubfäden verbreitert, mit heiden Rïndern nach innen umgeschlagen mol dadurch rinnenförmig; Staubbeutel fast kreisrund, am Grunde angeheftet, länglich oft bogenförmigg gegen einander gekriummt, einem rundlichen, mit dem Rande gleichfalls nach innen mungeschligenen Mittelb:unde (Konnektiv) anfgewachsen; Stempel ganz fehlend, zuweilen etwas entwickelt, aber unfruchtbar. Weibliche Blüten del kultivierten Feige (Fig. 1 und 2). Blütenhülle meist fünfblätterig; stempel manchmal zwei-, meist einf̈̈̈cherig, Fruchtknoten eiförmig (Fig. 2 fr), Samenknospe an der Seitenwand entspringend (Fig. 3 sk), Griffel zweispaltig. zweinarbig (Fig, 2 g).

Fruchtfeige, Scheintrucht, eigentlich der Heischig gewordene sehr vertiefte Fruchtboden, birnförmiger Schlauch, an dessen imnerer Wand die Samen wie die Kerne einer Steinfrucht sitzen, rom kultivierten Baume birnförmig, anfsen von grünlicher, purpurroter, brauner o:ler fist schwarzer Farbe, manchmal bereift, innen gallertartig fleischig, Fleisch durchscheinend, groldgell, rötlich oder purpurrot. Steinflucht mit einem weichen Fruchtfleisch, das sich leicht von der zerbrechlichen, gelhen Steinschale trenut. anfserdem von der fleischigg gewordenen Bliitenhiiille umgeben. Der Bau einer halb-oder ganzreifen Feige diirfte manchem Leser nuverständlich sein. Es findet lier cine Verschiebung des Scheitelpunktes statt. Wïhrend hei anderen Pflanzen der Scheitel- orler Vegetationspunkt konisch erhaben ist, komnt er hier an die Basis einer tiefen Höhlung zu liegen, deren Wand dadurch entsteht, dafs ältere, eigentlich unter den Scheitel liegende Ciewehemassen sich vordrängen und aufwärts wachsend den Scheitel sellst ïberwölben. Die Feige ist, wie Fig. 4 und 5 zeigen, ein metamorphosierter \%weig, dessen Scheitel bei 4 noch beinale eben, später durch einen biattertragenden Ringwulst iiberwallt. hei 5 urnenförmig rertieft ist; der Scheitelpunkt dieses Sprosses liegt hier am tiefsten Grunde der IḦ̈hlung, deren Innenseite eigentlich nur die Verlängerung der Aussenseite 
der Feige ist mul dementsprechend sehr zahlreiche liliilutriint.

Same cifinming, seln kilein.

Vateriand: Semitisches Vorderisien, Syrien und l'alistina; Verbreitungsbezir k: Gebiet des Mittelmecres, in zahlreichen Varietiiten, in Mittol-Enropa nm bei rweckmälsiger Belecknng; an rielen ()ren Luropas rerwildert.

Kultur. Der leigenhaum rolangt nasse Winter mit nu 20 C. Kiilte und trockne Sommer mit bis $\% 5^{0} \mathrm{C}$. Wäme in der Sonne (Distrikt Aidin in Kleinasien), eine gegen Nord- und Ostwinde geschützte Lage mud samdigen Ilumushorlen mit Kilkuntergrund. olygleich er auch in geringeren Erdreich fortkommt. Nan pflanzt ihn am besten durch Stecklinge fort, durch Simen nur dann, wemn nene Spielarten gewonnen werlen sollen. Ist die junge PHanze $3 \mathrm{~m}$ hoch geworden, so spitzt man sie cin, un ihn Wachstum in die Breite zn reranlassen. Die Wurelschöslinge und die Wasserschossen sind zu entferuen, dis tote Holz mufs ausgesägt werilen, denn nur die jungen Zweige hringen Fridchte hervor. Tim diese nach Möglichkeit zu remehren, hineift man die spritzen der jungen Triebe ab, wenn sie etwa $12 \mathrm{~cm}$ lang sind. damit sie in nächsten Jahre reichlich tragen. In der Regel brancht eine Auslichtung ron ersehöpftem Holz nicht ror dem 20. Jilne stattzufinden. Der Feigenbaum wird mehrese hundert Jahre alt. Wirtt ein Baum seine Frichte ror der Reife ab, so muls eine Wruzelbeschneidung stattfinden. Wiichst ein Zweig zu ïppig, so dröickt man seine spitze gegen das Ende hin mit dem Finger so zusimmen, dals die weiche, suftige Sulsstanz dem Drucke nachgiebt, wodurch del Zweig aufhört, sich mehr zu verlängern und infolge dessen der Saft zuriickgeht und unn da rembiancht wird, wo es notwendig ist. Dadurch und durch das biegen der Zweige in Bogen. die Spitze nach ahwairts, werden diese 'Teile sohr fruchthar. In Frülıjah miissen die Iäume gediingt werklen.

In Griechenland wendet man, um die Frichte schneller zur lieife zu hringen. Hie sugenamite Gall wespenbefonchtung (Coprificatio. 1. i. (icisfoigc) an In die mucifen Frichte des wilden, friiher tragenden Feigenhaumes. welcher in Orient Geisfeige (Cumificus) heifst, legt die leigen-(rallwespe (Cymips pscnes) ilno Eicr. Man schmeidet dium ron diesem wilden Feigenbanme entwerles ganze zweige mit Feigen ah und hängt sic anf die kultivierten Bäume, odel nan durchhoh't die Foigen dessolhen mit linsenhahmen und befostigt an jedem

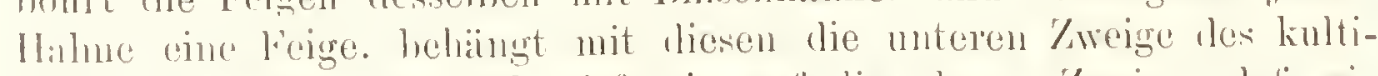

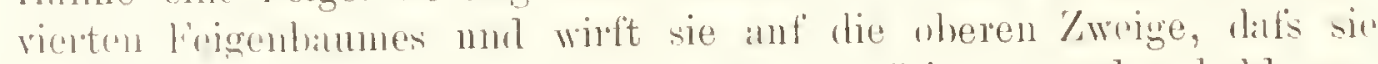

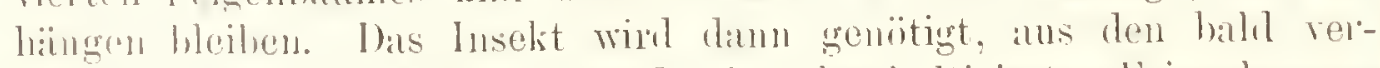
welkonlen wilden feigen in die frichte des knltivierten leigenlanmes

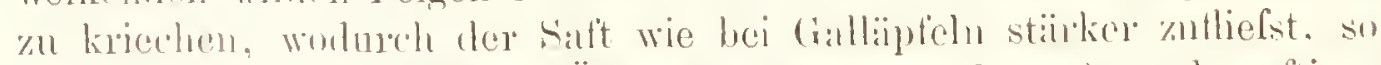

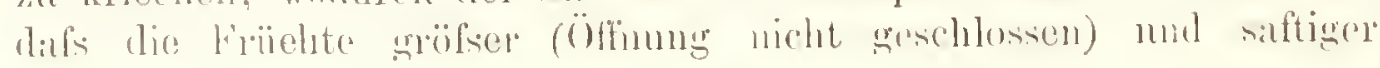


werden mul der Erutcertrag bodentend sich rermehr, aher die Samen fehlschlagen. Śchonl l'lutaleh, 'Theophrast mul l'linius kannten diese Kaprification. Doch ist sie naeh der Proisschitt eines neapolitanischen Botanikers nntzlos und beruht $\mathrm{nur}$ a uf einem eingewurelten Vorurteile, wie lenn dieselbe anch in vielen Iaindern (Amerika), wo man gleichfalls Foigen kultiviert, ganz nnhekannt ist mul die Orientalen hei Mangel an wilden Feigen auch die durch Iilattlainse an Pflanzen entstandenen Taschen, natuentlich ron Ulmbïnmen, zur Kaprification heuntzen sollen. lı Spanien, Italien und Sïd-Frankreieh, wo man die Kaprifikation nicht liennt, befördert man das friihere lieifon der Friiehte dadmreh, dafs man sie mit Dornen oder Stichehr, oder auch mit Strohhalmen oder Federn, welehe mit Olivenöl hestriehen sind, anstieht. Die in Dentschland gereiften Feigen schmeeken fad-süfslieh und sind riemlich mertlos. In Siid-Europa giebt ein völlig ausgewaehsener Feigenhaum durehschnittlich $100 \mathrm{~kg}$ frische Feigen, die im getroekneten Zustamle etwa $30 \mathrm{~kg}$ schwer wiegen. Die frühzeitigen und Sommerfeigen erregen, friseh genossen, Erbrechen und Durehfall und eignen sieh anch nicht gnt zum Trocknen. Die Haupternte ist die der Herbstfeigen, die im August und Septemher reifen. Naeh der Ernte gieht man den Feigen ein Laugenbad, breitet sie dam anf somnig und luftig gelegene Plätze aus, so dafs sie einander nieht berühren und wendet sie alle zwei Tage. Naeh dem Dörren dureh Sonnenwärme folgt das wiehtige Bad in heifsem Wasser, $11 m$ die Insekteneier zu töten und die Hïute der Feigen geschmeidiger zu machen. In Gegrenden, wo nieht auf dauernde sonnige Witterung zn rechnen ist, verwendet man hesser eine milde, kïnstliche Wärme zum Dörren der Feigen. Will man kandierte Feigen bereiten, so bringt man sie naeh dem Bade in cinen heifs gehaltenen Sirup. Nmn kömnen sie versandt werden.

Gehalt der Feigen, der Blätter und des Holzes. (ietroeknete Feigen enthalten 17,5 Wasser, 6,1 Eiweifsstoffe, 57,5 7ucker, :.10 Stäke, 5,4 Pektose und Pektin, 0,9 fettes Öl, 7,:3 Rohstoffe und 2,3 Asehe. Die nureifen Früchte, die Blätter mul das leiehte, sehwammige Hol\% enthalten einen ziemlich scharfen mud hitteren Milchsaft.

Gebrauch de r Feigen. In den siudlichen Läindern sind die Feigen ein Hauptnahumgsmittel fïr Nensehen nnd Tiere und werden frisch mud gedïrrt als gesundes Obst gegessen. Im Morgenlande bereitet man ans den geschälten, eingenachten nnreifen lieigen ein beliebtes Znekerwerk. Werden die frischen mreifen Feigen geschält, so mufs man Handsehmhe anziehen, weil der frisehe Milchsatt der Feige leicht Gesehwine nnd Entziindung der Hant vermsaeht. In spanion verwentet man die anserlesensten feigen znr Bereitung von Kïse, lem nin geschälte Mandelı, Hasehüisse, Pinien, Pistacion, foine Kräuter und Gewiirze zusetzt. Die leigen kommen anch in Büchsen präserviert in den Inudel, anch fiihnt sich Feigenmus als 
Ilamblesurtikel eiu. Getruckuct nut bram geröstet liefern sie den leigenkalfee. Bei uns dienen die Feigen hamptsächlich zn menticinischen Vepwendungen, als bimstmittel und zul Erweichnug rou Geschwiren, hesmulers am Zahntleisch, ferner als Nischwerk und als Beitrisg zillm Dessert.

Warenkunde. Durch die langgijilnige Kultur des Figenbatumes ist eine urofse Henge Varictiten hervorgehracht worden. Es werden lesonders folgende Spielarteu angelaut: San P'edro (in Sizilen Fienli San Piefo), ene woifse Spielart, die in Italien und Dahnatien geziichtet wird und nur eine Lirnte erzengt. Die aufserordentlich grofise Frucht ist sehr' schmackhaft, ist 'Tafelfrucht und kann nicht gediorrt werden. Die hranue Türkische ist die klmilhïrteste aller spielarten. Die Frucht ist grofs, linglich, birnfömig, mit dunkelbraumer Hant, die mit dicken, Binem stauhe bedeckt ist. Dis Fleisch ist rot und schmeckt selur fein. Fignet sich nicht zmm Dörren. Die hraune oler schwarze Ischia mit rundlicher, eifömiger Frucht rou mittlever Gröfse. Die Haut ist dunkelviolett, das Fleisch purpurrot, süfs und saftig. Die Frucht kam nicht gut gedörrt werden. Die Spielart ist sehr traghar und klimahart. Die weifse Ischia ist noch klimahärter als die vorige. Die kleine, getblichgriue frucht schmeckt aromatisch und eignet sich zum Dörren. Der Bitum trögt frihzeitig. Igo Brelia ist die an höchsten geschïtzte Tiafelfeige Spaniens. Sie ist weifs und dimuschillig, erster (iröfse mud erster Güite, eignet sich nicht zum Dörren. Angelika. Frucht klein, ciförmig, mit blasser, griunlichgeller Haut, the mit lichten Filecken punktiert ist. Dis weifse Fleisch ist ziemlich suifs. Es empriehlt sich nicht, die lincht zu diirren. Der klimalarte, reich tragende Baum lriugt meist zwei Frnten in Jahre hervor. Nerii mit kleiner, rundlicher, eifömiger Frncht. Haut hafs griunlichgell, Fleisch rot, sehr guter. kräftiger Geschmack. Sollte nicht gerlinert werdeu. lílimaharter Ottalo eignet sich vorziighich zun Dörren. Die Frueht ist weils und wird in Sizilien am hö̈chsten geschïitzt. Vortrefflich zum Dörren eignet sich die weilse Genuafeige. Die Frucht ist grols, rundlich, fahlgelb, mit diinner Hant mol von feinem Geschnack. Der Banm ist nicht klimahart, schwachwiichsig und vertrïgt fenchteren Boden. Die weifse Snyruafeige lïfst sich hesonders gut dïrren. Die sehr grofse, weifslichgelle, diunhliautige Frucht ist siifs nud ron fenem (ieschmack. Der baun gielnt des Jahres zwei Finten. Die hesten Marken der Smyrnafeigen sind Elemi nud Erbell. Sie sind in ihrer ursprünglichen form helissen, die hesten sind in runde Schadhteln ('Trommelu) eingepackt, die unit Lorbechbiitter'n ansgelegt siul. Surten vou seringer (iiite

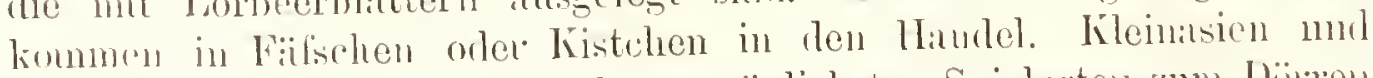
henachlonte Inseh. Fiir eine der vorziighichsten Spicharten zum Dörren gilt die weifse Adriatische. Sie wird in Dahmatien, Italiou num

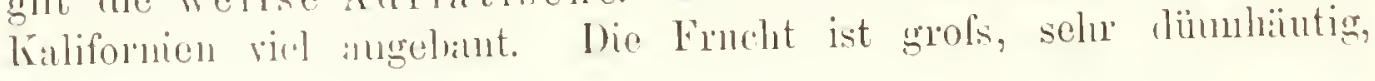


weifslichgehl, sehr Heischig. hat siifsen, sehr angenehmen Geschmack. Der sehr kleine Same liegt nieht wie bei vielen anderen siphelarten in cinem Hohlraum. Eignet sich auch zur 'Tatelfrncht. ber liamm trägt gut, aber nur einmal in Jihne, wïchst schnell empor nol entwickelt eine sehr schöne lauhkrone.

Besonders im Sommer halten sich die Feigen nicht lange, sondern gehen bald in Giarung ïber und sind damn an ihrem sänerlichen Geschmack erkemitlich. Man bewahre sie deshall, an möglichst kiihlen Orten auf, lasse sie in fester Verpackung und schiitye sie vor den Zutritt der Luft. An ihrer Oberfäche setzt sich ein weifslicher Staub, der von ausgetretenem Traubenzucker herriilnt, an; oft indes ist dieser Stanb auch Schimmel. In manchen Gegenden Italiens ïberstrent man die Feigen mit Kastanienmehl, wodnreh ihnen Fenchtigkeit und leider anch Zucker entzogen wird.

Handelsstatistik. Der Verbrauch von Feigen ist besonders in den Erzeugungsländern ein sehr grofser. Die Ausfuhr der Smyrnafeige beträigt jährlich durchschnittlich 240000 Meter-Zentner im Werte ron 10300000 Mark; der Wert der Feigenausfulır aus Griechenland schwankt zwischen 5 Mill. und 2 Mill. Mark, der aus Portugal zwischen 1500000 Mark und 1800000 Mark, und der Wert der im Jahre aus der Tiirkei ansgeführten Feigen beträgt 8500000 Mark. In Osteu Australiens und in Kalifornien wird der Feigenbaum in so ausgedehnter Weise angebaut, dafs von dort bald Ausfuhren zu erwarten sind.

Geschichte des Feigenbaums. Der Feigenbaum gehört wie der Ölbaum zn den :̈ltesten aller Fruchtbäume, Heimat und Verbreitung desfelben sind von beiden ziemlich dieselben, wenigstens in Bezug auf die letztere in der Alten Welt. Die Feigen waren nebst Korn, Oliven und Weintrauben die wertvollsten Schätze des gelobten Landes. Archilogos erwihnt (700 vor Christi) die Feigen als Erzengnis der Insel Paros. Später fand man die besten Feigen in Sikyon und Attika. Die alten Griechen betrieben einen bedeutenden Handel mit Feigen und in Attika wurde bei schlechter Ernte und hei Tenerung die Ausfuhr derselben verboten und das Verbot von besonderen Wiichtern (Sycophanten) iberwacht. Die Stadt Athen hatte eine Feige in ihrem Wappen und Feigen sollen den Bewohnern dieser Stadt die Inaptnahrung gewesen sein, bevor sie den Getreideban hetrieben. Nit der griechischen Kolonisation kam die Feige nach Italien. Iommlus und Remus wurden nach der Sage unter einem Feigenbaum ron einer Wöltin gesïugt. Die alten Röomer brachten an 1. Januar den Gröttern nehen Datteln und Honig Feigen als Opfer und den Freunden als Geschenk. Auffiallig ist die Thatsache, dal's von Planchon ${ }^{1}$ ) in dem quarternären Tuffstein von Montpellier und von dem Marquis de Silportat ${ }^{1}$ )

1) Planchou, litude sur les tufs de Montpellier; De Saporta, Ia flore des tuf's quarternaires en Provence. 
in jencm der Aygaladen mahe bei Nontpellier, sowie in den quarternären 'Terrain ron la Celle in der Nähe von Paris Blätter und selbst Friichte des wildwachsenden Ficus Curica gofunden wurden.

Andere Arten sind: 1. der Maulbeer-Feigenbaum (Fious sycomoms [..). Afrika. Dis Holz diente den alten Äsyptern zu Mumiensïrnen; 2. der Gift-Feigenbaum (Ficus toxicuria L.). Java und Sumatrat; 3. der indische Feigenbaum (Fious indice Roxb.). Ostindien; 4. der Gummibaum (Ficus elasticu). Ostindien, besonders Assam, enthiilt Kantschuk, wird hei ms in Tïpfen gezogen; 5. der heilige Feigenbaum (Ficus religiosa L.). Ostindien. 


\section{Tafel 16.}

\section{Banane ${ }^{1}$ ) oder Bananenpisang ${ }^{2}$ ) \\ (Mhusus sapientum ${ }^{4}$ ) L.).}

Die gemeine Banane gehört zur Klasse der Einsamenlappigen (Monocotyledones), zur Ordnung der Gewiirzschilfe (Scitamineae, I. N1)teilung. S. S8) und zur Familie der Bananen oder Pisange ${ }^{2}$ ) (Mnsaceue).

Die Familie der Bananen oder Pisange (MInsaccue). Diese Tropenbewohner sind die gröfsten Krrautptlanzen der Welt. Sie besitzen ausdanernde unterirdische Wurzelstöcke und saftige, krantartige Stengel, welche durch die einander umschliefsenden Blattscheiden oft einen bedeutenden Durchmesser erlangen. Die Blätter sind wechselständig, gestielt, am Grunde scheidenförmig, mit grofser, in der Jugend der Länge nach zusammengerollter, einfacher, ganzer Fläche und starker Mittelrippe, ron welcher parallel gebogene Seitennerven ausgehen. Die Bliten stelıen in den Achseln grofser, blumenkronartiger Deckblätter. Das Perigon ist sechsblätterig, blumenkronartigr, ein oder zwei Zipfel desfellen sind lippenartig gestaltet. Von den sechs am Grunde der Perigonblätter befestigten Staubblättern schlïgt gewölnnlich das hintere f'ehl, nud manchmal sind einige antherenlos. Die Friichte sind dreifächerige weiche Beeren.

In vier Gattungen gegen 40 Arten.

Die Gattung Banane, P'isang, Paradiesfeige (Musa L.). Sehr' grofse, ipplig entwickelte, baumartige Stauden mit einem ron den Scheiden der ahgestorbenen Bliitter umgehenen Schaft. Zwischen den mächltigen Blätter'n treten lange Bliitenkolben hervor, die unten fruchtbare, weiter nach oben unfruchtbare 'witterblïten und zu oberst müunliche Blïten tragen.

1) Aus dem Sanskrit-Worte l'hala oder Pala, Frucht, entstanden und hezeichnet die wichtigste Frneht Indiens. - 2) Von ten Malaien so genannt. 3) Linne benante die rattung nach $\Lambda$ ntonius II usa, Leibaryt des Kaisers Augustus und Bruder des lisuphophus. - 1) Die indischen Weisen (sapientes) lebten von den Früchten. 
Banane oder Bananenpisang (Musa sapicntum L.).

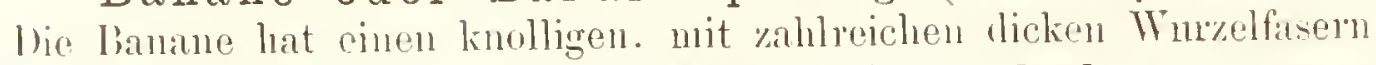
losetrten W urzelstock und cimen? his $6 n$ hohen, nur ans langen, fest monominder gerollten Blattscheiden gebildeten. kirautartigen, innen mit wïsserigem Salt angefiillten Schaft, der 33 his $60 \mathrm{~cm}$ im Durchmesser dick und anfsen mit glinzenden, pmpurrotgestreiften, ziihen Iniuten, dem Überreste der zusammengetrockneten Blattstielhäute alter, ahgestorbener liaitter, bekleidet ist.

Blätter (grölsten aller Blaittor) in grofser Krone, anf dem (ripfel zu sieben his zeln, 3 bis $3,75 m$ lang, 60 his $90 \mathrm{~cm}$ hreit, am Gruncle ungleich herzformigr, aufrecht oder bogentörmig gewölht, an heiden Seiten abgerundet, vorn mit einem Stachelspitzchen, ganzlandig, dunkelgrin, unterseits hlisser und mit ricker, stark rorspringender Mittelripe und eininder schr genäherten, parallelen Seitennerven versehen, zarthäntig, mit lockeren aneinander gereihten Gewebszellen, welche infolge des schnellen Wachstums der Breite der Blïtter nach zerspringen. Der Blattstiel ist knry und dick, seine Räinder sind wie rlie der Blätter oft rötlich gefaribt.

Blütenkolben herabhängend, his $1,5 \mathrm{~m}$ lang, zn muterst mit 12 bis 16 Ringen ron je 15 his 20 fruchtharen Bliten, von denen jede mit einem grolsen, roten, hinen oder violetten Deckblatte umgeben ist, oberwirts aber mit unfruchtbaren, mit ihren Deckliaittern abfallenden Bliiten besetat und trägt an Ende noch eine eiformig-kegelige, blaue, eine unentwickelte Bliite einschliefsende Knospe. Also \%u unterst fruchtbare, dam unfinchthare Zwitter- und zu oberst männliche Blïten. Blüten polyganisch; Blütenhülle. Von den sechs Perigonbliittern sind fïnf zu cinem Hüllblatte verwachsen, es ist also in Wirklichkeit nur ein sehr grofses (Fig. 2a) und ein kleines (Fig. 2 b) rorhanden. Das gröfsere äufsere Hüllblatt ist gell, nnd rot, es umfilst die Stanhblatter (Fig. 1); das $\mathrm{kleinere}$ innere $\mathrm{Hüllblatt}$ ist km\% und steht jenen gregeniibel. Staubblätter sechs, woron oft ein orler fiüt verkiimmert sind, selur rerschicden entwickelt; bald die Stanbhlätter findig nit pfeilformigen Staubbentehn ( $\mathrm{Fig} .1$ st), bald zungenförnig mit plötzlich infgeset\%ter spitze nul kumer, herzörmiger Inthere. Fruchtknoten (Fig. 2 unten, 11. Fig. 3) dreifächerig. unterstindig; Griffel (Fig. 2 g) dick, bleibt nach dem Verblïhen auf der Frucht zuriick (Trommelklöpuel); $\mathrm{N}$ arbe (Fig. 1 nut 2) trichterig, kenlig. In den mänulichen bliiten sind alle sechs Stanbliaiter rollkonnen ansgebildet, in den nufruchtbaren Zwitterblïten ist cin Stanhlubut ohne Staublentel, in den fruchtharen $\mathrm{Z}$ witterblïten sind fünf Stambliatter antherenlos. Deckbläter fillen ab.

Früchte (Fig. 4 nnt 5) cutwickeln sich in zwei Monaten ans den woilhlichen Bliiten (Fig. 2), sitmen in Gruppen ron 12 his 16 stiick um den Frumbtoulhen, zu 150) bis 180 Stiick an einer 'Tranbe (hei 
einigen Abuten his 300 stiuck), werten 20 his 30 en ling und 5 his scm in Durehmesser dick nnd ungetäh ein Pfund selwwer. Sie sind walzig, sechskintig (Fig. 4 nud b), gurkenibhlich, unten sichelantig gekriimmt, von verschichener lathe, gewöinlich griinlich-gelb. Div his einen \%entuer schwere Finchttranle hengt die P'flanze etwas nach oillel Seite.

D) Samenbildung (Fig. 4, die dunklen Punkte denten dic fehlgreschlagenen Samen an) ist durel die Kultm zu Giunsten des Fruchtfleisihes unterdrückt worlen. Pei der wildwachsenden Stammptian\%e sind die Simnen gerlüickt kugelig, schlagen hei den kultivierten Arten fehl.

Mit der vollstïndigen Entwickelung der Bliite hat das Wachstum der linnane sein Ende erreicht, mit der Reife der Fïichte stirht der Schaft ab, entwickelt aber nene Nebensprossen. Die I.ehensdauer beträgt je nach Boden, Klima mul Eigenschaft der Spielart 9 Monate bis 3 Jahre, meist und unter günstigen Verlü̈lnissen 12 bis 14 Monate. Wïhrend lieser Zeit entwickelt sich die Pflanze zu der vielbewunderten, stattlichen Gestalt - eme Entwickelung, die selbst nuter den tropischen Gewichsen ohne Gleichen ist.

Der gameine Pisang, Aramsapfel ${ }^{1}$ ) oder Paradiesfeige ${ }^{1}$ ) (Musu paradisiucr L.) ${ }^{1}$ ), unterscheidet sich von der gemeinen Banane nu durch schlankeren Wuchs, den grüunen Schaft und durch die schmaleren Blïtter mit längerem und weniger dicken Blattstiel und den lïngeren, gurkenähulichen Früchten (Fig. 5), die aber weniger schmackhatt als die der Bamanen sind.

Vaterland: Siid-Asiatische Insclı. Verbreitungsbezirk: Heilse Zone (Kosmopolit) bis $30^{\circ}$ (tropisches Sammland), in lieifsen Anerikit rerwildert, verlangt $26^{\circ} \mathrm{C}$. Würme und steigt unter dem Äquator bis $1600 \mathrm{~m}$ hoch linauf. Gerleilht ausgezeichnet in KentralAmerikit und den Kiistenregionen Mexikos. An der Ost- und Westkiiste Afrikas wird sie nur in beschränktem Umfange kultiviert.

Kultur. In Amerika kennt man gegenwärtig 44, im siidlichen Asien und auf den Insehn muzihlige Spielarten der beiden Hauptarten. Diese Pflanzen repräsentieren die schönste Pflanzenform, sie sincl das Hinuptmotir jeder 'Tropenlandschatt, der Schmuck feuchter Gegenden und iberall um dic Hütten angepflanst. Sie erveichen ihre iippigste Vegetation an der Meereskiiste, wo sie aus der Feuclitigkeit ilıen Salzgelalt einsungen kömuen, denn Sal\% (Chlor-Natrimm) ist in iluem Safte enthalten. Ihre Kultur ist sehr einfach mol macht wenig Miihe. Sie werden, da die Samen zu Gunsten des Fruchttleisches rerkïmmern oder fehlschlagen (sogrm das Kernhaus fehlt), durch Wumelschöflinge vermehrt (siehe "Geschichte"), die num 2 m weit anseinander, an liehsten in fenchten, humusreichen, tiefgriundigen, noch nicht sehn

1) Aus dem Paradiese stammend. Siehe "Geschichte". 
henut\%ten, am Rande von sumptigen Wassern gelegenen Rioden pflanzt.

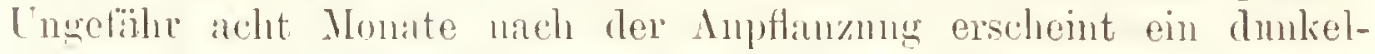
violetter Knoten an dem I'unkte, wo sich die olsersten biitter trennen; balk tritt er frei ans seiner Ungehnng hervor, an cinem langen stiele hïngend, der sich bengt unter dem Gewichte der inzwischen entwickelten Blïtenhiille, welche die Form eines zugespitzten Eies hat.

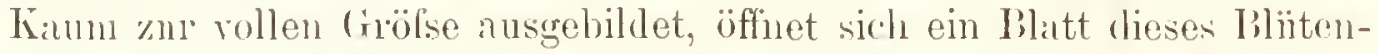
kolhens und rollt his zur Basis zuriick, intem es eine lieihe ron fünf his sechs Bliiten dem Blicke freilegt. Die andern IBä̈ter der Biliitenhiille entfalten sich eins nach dem andern in derselben Weise; schliefslich sind 20 bis 30 Bliitenhïndelchen aufgedeckt, die alle an dem einen stiele hïngen. Wenn die Bliitter der Bliitenhiille verwelken und al,fallen, legimen die Fruchtknoten zu schwellen, und von dal his zu ihrer Reife rergehen drei bis vier Monate. Die Wumeln der Banane sind kurz, weshall, die Pflanzen leicht rom Stume zu Boden gestreckt werden. Hat die Banane eine Höhe ron einigen Metern erreicht, so billen sich aus ilnem Wurzelstocke neue Schöflinge, von denen man indes nu zwei stehen lälst, wïhrend die übrigen beseitigt werden, damit nicht aus der geordneten Pllanzung ein undurchdringlicher Wald cntstehe. Das Unkraut wird zwei- bis dreimal jährlich entfernt. Nach der Blïtezeit wendet sich das Wachstum der I'flanze auf die grolse Anzahl von Friichten (zwischen 20 bis $40 \mathrm{~kg}$ ). Da Mutter- und TochterpHanze nicht zu gleicher Zeit bliihen, lommt es, dafs man, die trockenste Zeit im Jahre ausgenommen, fast immer Bliiten und Frïchte auf dem Bananenfelde findet. In der fruchtlosen, trockenen Zeit freilich sind die Tropenmenschen gar oft der Hungersnot ansgesetzt, da sich die Banimenfriichte nicht aufbewahren lassen, weil sie leicht in Gïirung iil)ergehen. Die Hanpternte (Mutterpthanzen) findet rom Jamnir bis Man statt. Man erntet die Friichte ror der völligen lieife, wenn sie noch gelbgriun (Fig. 5) sind, dis sie sonst leicht in Gärung geraten und anch ron verschiedenen Vïgehn (Mrusophague, Pisangfiesser), ron Eichhörnchen, Fledermäusen und einigen Insekten geerntet werden kïmnten. Man schliigt die PHanze nieder, zerschneidet sie in Stiicke mul dïngt damit den stehen gebliebenen Wurzelstuck mit den nenen Tochterpflanzen. Die im uneifen \%ustande algenommene Fruchttrauhe wird unterm Dache oder in der Küiche anfgehängt zur vollstïndigen Reife gebracht. Dilbei fïirbt sich die ïnlsere Fruchtschale bei dem gemeinen I'ising pupnurot bis schwar, bei der Bamine heller gelh. wohei das Fruchtheisch nehr und mehr erweicht und sich die stairke desfelhen first gant\% in Kucker verwandeit. Mann kemnt his jet\%t kene

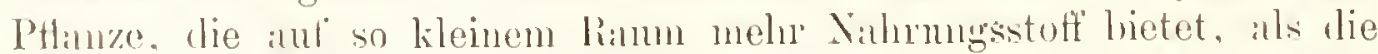
baname. Die Banane giebt anf gleidher Grundhïche dreieinlalbmal mehr Nahrmugsituff als die Kirtuftel mul 15mal mehr als aler Wei\%en.

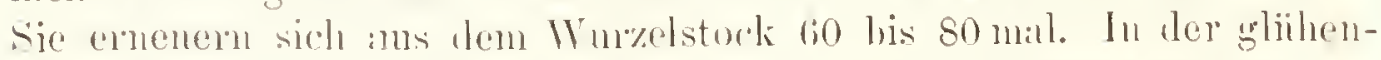
den sumnenhitze mud bei der grölsten Trockenheit beschiatten sie sich 
selbst morl hewirken durch die hedentende näichthiche Wöimeans-

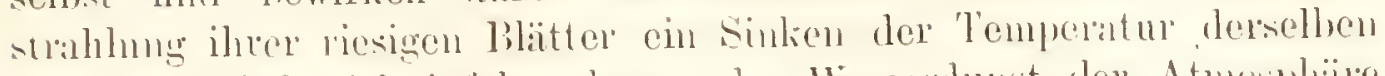

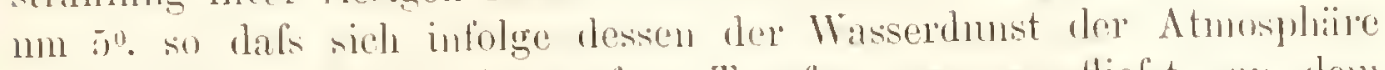
ant ihnen verdichtet, in wolsen 'J'ropfen zusammentliefst, an dent Schafte niedersickert mul die brole rings nm die Wrmel anfenchtet, als oh sie begossen sei. Thter dem Äpuator danert die Lehensperionde piner banane ron der Bildung des Schaftes an bis zur l'ruchatreife kiam linger als nem Monate. I)ieser Keitram nimmt in demselben Verhiiltuisse zu, je weiter rom Aquator entfernt die Kinltur dieser PHanze getrieben wird. Doch erfïhrt die Ibananenkultur durch die hohen Bodenanspriiche eine starke lieschü̈nkmg. Keine andere Nutzptlanze elschüptt den Boden in gleichen Malse wie die Banane.

Gehalt der Früchte. Die Irüchte beirler Arten entlalten nicht so viel Nilnumgsstoff, als das Getreidemehl, aber mehr als die Kintoffel und viele Gemiise. Ist die Frucht noch nicht voillig reif, so enthiilt sie rorwiogend Stälie, ist sie reif, Kucker mud finumi (aufserdem Pflanzensïure. Gallussïure, Eiweifsstoff, T'ektinsïn'e unl anorominsche Stoffe). Reife geschiilte bananen enthalten 73.9 Proz. Wasser, 4.8 Proz. Eiweilsstoffe (Weizen 19 Proz.), 19,7 l'roz. Zucker und Pektose, 0.6 I'roz. fettes Öl, 0,2 Proz. Rohtaser, 0,8 Proz. Asche. Die Bananen säueru ilnes grofsen /hnckergehaltes mud ihres geringen Mineraliengehaltes wegen leicht im Magen und rufen dalurch Stiirungen in der Terdaum hervor, die leicht zu Fieberkiankheiten ansarten. Nordländer, die sich noch nicht rolstindig akklinatisient haben. sollten diese Frucht m sehr mälsig genicfsen. Schncll getrocknetes Bananemmehl hat einen Gcruch, der an firsches Heu elimmert, es schmeckt angenehm und ist leicht verdanlich. - Der Saft I) der Blätter und des sichaftes entlïilt 'Tamnin, Gallussïme, Essigsäiure, Chlor-Natrium, Kali, Alumin- und Kíallisalze.

Gebrauch der einzelnen Pflanzenteile. Fast alle Teile der Ptlanze werilen verwemlet.

1. Die Friflite. Die Bananen dienen in ten Tropenländern vielen Millionen Mouschen als Nahn'ung. Die als unreit abgenommene Frucht (Terton) wird, nachilem sie gekocht orler gerüstet worden, nm wallu genossen. Sie schmeckt hart und herl, soll aber der Gesundheit zuträglicher sein, als die reife. Die Friichte im ersten Grad der Reife (Pintim) werden auch gekocht und geröstet, gebacken oder rebraten. Nur die völlig roifen Fuichte werden roh gegessen und sind siifs, mild nud wohlschmeckend, füllen aber und blähen. Sie werden anch ant rerschierlene Art (gerlürrt und eingenachit) zubereitet. Am häufigsten indes gewinnt man ein grobes Mehl, cine Art Gries, darans. Fine Ablochung der Friichte mit Wassu' liefert den lacuten dont eine tiig-

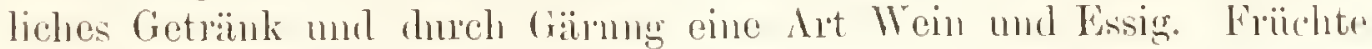

1) Bunsingault. 
und Salt dienen anch als Ileihnittel. Dals die Friichte leicht in (iiirung ïhergohen, ist hereits crwähnt worden.

2. D) ie Kunspe am Ende des Bliitenkolbens nud die jungen Schossen werden wie hei Palmen (siehe S. 8) der Pahnkohl als Gemïse gegessen. Im Siiden Chinas werden die Bliiten zmr Bereitung eines gesehiityten Salats rerwendet.

3. Die saftigen Blattscheiden mod der noch nicht erhärtete Wryelstock werden ron dor Äthiopiem gergessen.

4. I)ie Blïtter werden, 1 m das spröde, leicht rerreifshare IBlattgewebe n tïten, einige Male langsan durch die Glut eines gelinden Feners hin- und hergezogen, wodurch sie weich num geschmeidig wie Papier nud wasserdicht werden und nun ein rorzigliches Packmaterial (die Tahake ron Manila versendet man darin) geben. Ferner dienen die Blätter zum Decken der Wolmungen, zи Sonnenschinmen, zu

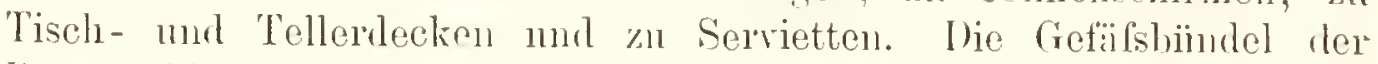
Bananenblätter besitzen nur geringe Festigkeit und Haltbarkeit, so dafis sic zur Herstellung von Seilen, Timen mud dergleichen gar nicht tanglich sind.

5. Die Blattscheiden enthalten branchlane Fasern, die schon seit den ältesten Zeiten zu Matten, Stricken mnd anderem l'lechtrerk, sowie zu Geweben und zu Zunder rerwendet werden.

6. Aus dem Schafte (nicht ans den Blättern nud Blattstielen) fast sïmtlicher Pisang-oder Bananenaten wird eine Faser ahgreschieden, die unter dem Namen Manilahanf in den Handel kommt und in griofster Menge anf den Philippinen, und zwar vorziiglich ans dem Schatte des Gewehepisangs (Musa trutilis Nees.), gewonnen wird. In Indien wird Manilahanf in sehr ansgedeluntem Mafsstabe ans Musu textitis, aber anch ans Musu supuentum (Vorderindien), in Gruiana, ferner anf den Antillen, in Nenkaledonien nul auf Rínnion und in Angolat ans MLusa paraulisiaru und in Yensiidwales ans der ror kurzer" Zeit ans Dbessinien eingefuihrten Mresa Ensate gewonnen. Diese Faser fïhrt im Handel anch dic Nomnen Plantuin fibre, Batunentascr, Sïun hemp. Abaca, White rope. I'm die Bananenschiifte anf die Faser ru verarbeiten. entfernt man die Bliitter, ehe die Bliite eintritt nud liilst die schuifte drei Tage anf dem Felde stehen. Die Abscheidung der

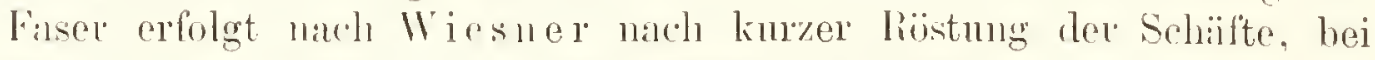
weleher das Oberhant- mol Grundgewehe der letzteren zo Grunde geht. Ine in räulnis befindlichen schäfte werden durch Eisenkïmme lindurcligezogen, wolurch es gelingt, die wohl erhaltenen, im Nittel etwa I lis $2 \mathrm{~m}$ langen l'aseru rein zu gewimen. Die äufseren l'artien der

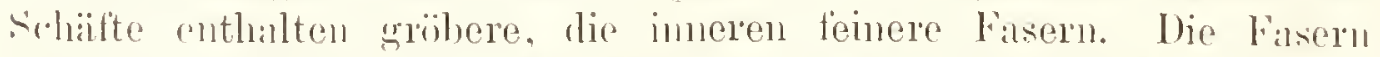
hestehen volwiegend aus Bastzellen von 2 bis 8 mm läinge und 0,012 his $0.042 \mathrm{~mm}$ IVicke. - Der Manilahand findet rine ansgedelunte Ver-

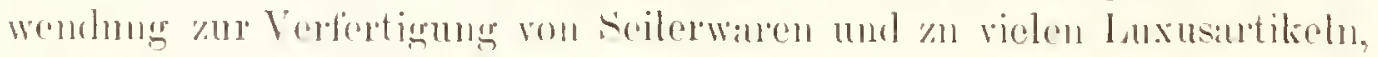

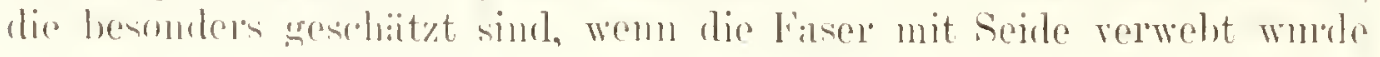


(Manila-Tatschentioher, Manila-Glockenziige ctc.). Seiner Maltharkeit im Wasser mul semer Leichtigkeit wegen dient ex zur Vorfortigung ron Sclniftstanen, ist aber schwerel zu verablueiten, als Hanf. In Frankreich hat nan anch ans Musafasern (wie aus der Faser der Agave mexicame, siche diese) feine Papiere gemacht; in Sïd-China kmmmon

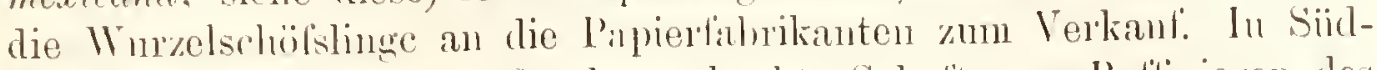
Asien wind der in kleine Stiicke zerhackte Schaft zum Ralfinieren des Zuckers hemutzt. Der Saft des Schattes wird ron den Malaien als Beize \%un Fixicren griuer Farhen gehnancht. Bammwoll- nnd Ideinenzeng kïnnen in ganz frischem Safte gelhgran gefïrlut werden; wenn cr einige \%eit der Luft ausgesetat ist, nimmt er eine schmntrigrote Farbe an, die ebenfalls zum lärben rerwendet werden kann. Del Saft dient als Arzuei gegen Dnrchtall (Tamin) und Blntmigen. Die Bananen sind auch als Zierpflanzen in mseren Treibhäisern beliebt und besonders wird dort die chinesische Zwergpalme (Musa Cacendishii) häufig gezogen.

Handelsstatistik. Fiir den Welthandel ist die Bananenfrucht noch mwichtig, da sie sich nicht lange genug aufbewahnen läst. New-York füht jählich weit über 1 Mill. Bananenbïndel ein. Iuch San Franzisko kauft grofse Mengen dieser Frucht. Trinidad führt 5 bis 6 Mill. Bananenfrïchte jälnlich ein. In der I'räsidentschaft Madras sind 17000 Acres mit Bananen beptlanzt. Im Süden Chinas, auf den Philippinen und auf den Malaiischen Inseln wird ein bedentender Localhandel mit Bananen getriebcn. Annähernd richtige Angaben iiber Produktion nud Konsumtion der Musafaser lassen sich nicht beschaffen. Die Insel Manila soll jährlich über 620000 Kentner Manilahanf ausfiiluren; auch Albay, der siidlichste Teil der Insel Lnzon, damn dic Insehn Zebu und Negros liefern grofse Quantitäten Musafasern. Ungrefähu 280000 \%entıer gehen nach den Vereinigten Staaten, hesonden's nach Sew-York, etwa 120000 \%entuer nach England nnd gegen 50000 \%entner werden in Nanila selbst zu Schiffstanen (1 bis $15 \mathrm{~cm}$ Umfang und gegen $200 \mathrm{~m}$ ling) verarbeitet. Der Manilahiuf ist sehr billig und wird ron den Schiffern meist nur als Ballast verladen.

Geschichte. "Wie die mehlreichen Cerealien oder Getreidearten des Nordens," sagt Humboldt, ,so begleiten l'isangstänme den Mens'hen in allen Kontinenten unter" den Wendekreisen seit der frïhesten Kindheit sciner Kultur', soweit Tradition und Geschichte reichen." Die Frïchte der Bamanen 1) nud Palmen sind jedenfalls die Nahrung der ersten Menschen gewesen. Darin, dafs der Mensch spïter von Gewïchsen, welche inl'sertich muscheinbar sint (Wurzeln, Getreide), scine Nahnung nahm, zeigt sich eine höhere Entwickelung seiner geistigen lähigkeiten. Nach der Siıg liefs Gott, als a dic

1) Der krantige s'chaft der linanen biegt sich bei dor Reife der sehwrom Fruehttraube nach einer seito. so dafs nie linte soln erleichtert wird. 
ersten Menschen schuf, anch die Bananen ans dem landen hervorsprosisn, also ohne Sinnen cutstehen, den sire anch jetat nuch nicht tragen. Man namnte die Banane oder den P'isang P'aradiesfeige oder Adamsapfel, weil man ('Thunherg) ihn fïr den Bamm der Erkenntuis des Guten null bïsen hielt, an dessen Frnelit (schneckt feigenartig) Adam und Lia in Paradiese, das man anf Cerlon in den den ..Adramsl'ick" nungebenden Wäldern sncht, gesïndigt haben sollen. Anch sollen die Bbiitter der Banane den ersten Menschen das erste Material zu Kileidungstiicken gegeben laben. Als Alexander der Grofse Indien heimsuchte. fand er dort die Banane angebant. Obgleich die In'aninen und indirchen Weisen ron den Friichten derselhen lehten. hielt sie doch Alexander fïr mogesund mol rerbot semen Soldaten, sie zu essen. Plinius nemut die Banane Poli. Finige halten auch die Frucht, welche dem Moses anf seinem Zuge ans Ägrpten nach dem gelobten Lande ans dem Thale Esknl gebracht wurde und so schwer war, dafs zwo Mïnner daran zu tragen hatten. für eine Paradiesfeige, die indes in den Pibeliibersetzungen fïr eine Weintranbe ausgegeben wirl. Die Banlanen verbreiteten sich ron südöstlichen Asien ans nach allen wïimeren 'T'eilen desfelben, nach Afrikit ('Tunis, Algier), nach der spanischen Küiste bei Milaga und Algarbien (Portugal) und dureh Neger nach dem tropischen Amerikit. Nach Humboldt kultirierten die Amerikiner schon ror der Eintdeckmng Amerikas Bantuen. Eine Verbindmug zwischen Mexiko mol China scheint schon lange ror Kolnnbus' Zeiten bestanden zu haben. - Die grölste Musil, vielleicht die grö̈ste aller Kírutpflanzen, ist die schon erwähnte linzeht oder Anzeht (Musa Ensète) der Abessinier. Eine einzelne Pflanze bringt 19000 Bhiiten hervor. Eine fünljührige l'flanze in Palmhillse \%n Kiew hatte schon ïloce $10 \mathrm{~m}$ Höhe, unten an Schafte $2 \mathrm{~m}$ L'mfing und nit Einschlulus des Blattstiels $6,66 \mathrm{~m}$ lange nud $1 \mathrm{~m}$ breite Blätter. I lie IBlätter dieser Musa-Art wurden schon von den alten Ägyptern als treftliches Viehfutter verwendet, dem man hat Hieroglyphen gefunden, auf denen Nilpferde dargestellt sind, die Rananempflanzen zerstören. Durch Einschnitte in den mächtigen Schaft llielst ein köstlicher Salt atn. der von den Abessiniern, wem er mit Milch nud etwas Butter vermischt wird, fïr sehr wohlschmeckend nund nahrhaft gehalten wird. Die Früchte dieser Banine sind nicht genielshar, aber ihre Schölshinge bilden ein kistliches Gemüse, und dats Innere des Schaltes wird gekordit und ist das einzige regetahilische Nihnrungsmittel einiger afrikanischer Völker'schalten.

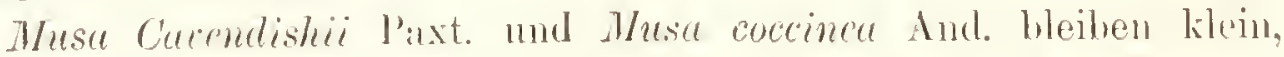
werden in unseren Winmhäusern lonttivert und dienen als Zimmerptlan\%en. 
denartig geteilt. Rispen battgegenstïndig. Bliiten in Biischeh oder

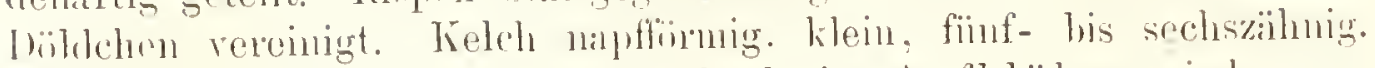
Bhmenhlätter fiinf his sechs, gleich, heim dufbliihen sich vom Cirunde an trennend. Oben zusinmenhängend, und als eine oben gewilbte, unten fiinflippige Klappe (Fig. 3) ahgeworfen. Staubfinlen fiei, in der Kinuspe eingeschlagen, Staubbentel anf dem hiicken angeheltet. Fruchthoten ron einer Hachen, fuintilrisigen scheile unterstiitat, deren l) riisen mit den Staubblittern wechsehn (Fin. 4). eifömign, zwafficherig (Fig. 5).

Der Weinstock (Vitis vinifere l..) ist ein iber $30 \mathrm{~m} \mathrm{hoch}$ klimmender Strauch, der sich mit seinen Wickelranken festhailt und 800 his 1000 Jalne alt werden kimn.

Wurzel ästig, stirk, tiefgehenl.

Stamm stranchartig, holzig, mit aufstrebenden Ästen. zuweilen sehr dick, rund, an den kinuten verdickt. Rinde des stammes und der älteren Äste nit einer graubrïunlichen, sich abblïtternden, fiserig zerrissenen, ans diumen Schichten bestehenden lingelborke. Die Weinrinde ernenert sich juintich, die abgestmbene ungieht aber die regetierende. Die Rinde mufs alssterben, weil sich in ihrem immersten Parenchyn ein ling ron Korkzellen bildet 1). Aus dem Kimbiun entwickelt sich dam eine neue linde. Holz zïhe, hiegsim, porïs, nit dentlichen Jahrestingen und breiten Markstrahlen, bei juingeren Ästen grïn; Mrarks schlammig, weifs, spöiter braun. Äste oft sehr lang, hin- und hergebogen, stielrund, an den Kmoten verdickt, gestreift, blïulichgriun, an der: Sonnenseite meist bräunlichrot, etwas bchaart, heblïttert, meist rankend.

Blätter an den rankenlusen Sämlingen, den Wurzel- mul Stockprussen zerstrent, an den ans libattwinkeln hervorgegangenen Trieben abwechselnd. zweizeilig, linggrestielt, rundlichlerzüming, buchtig, fint-, seltener dreilappig. moleich und grob gesïgt, oft relspaltig, fünt-, seltener dreinervig, unterhalb weinhlanrig, wollig oder filzig. im Alter meist kahl; lilatt stiel fast stielund. gestreift, :mo Cirunde verdickt, hehant oder kihl; Nehenbläter eiförnnir. allfallend.

Wuchs und Ranken. Der Weinstock macht \%weierlei Triebe, Linngtriebe oder Lotten mol Kurztriebe oler Geizen. Fine (nicht bliihende) Lotte trïgt nach zwei grumdstindigen Niederhlättern his 40 Laubhliitter. aweizeilig wecheht und nit je ciner Geize in den Achseh. Die untersten drei his lünf Lanhhliatter sind nuch ohne lianken; ron da an tritt Rankenbildung ein,

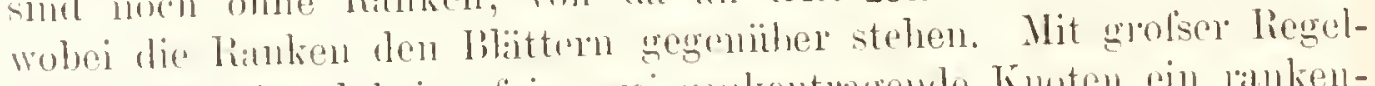
mälfigknit folgt dabei anf je anci rankentragende knoten ein ranken-

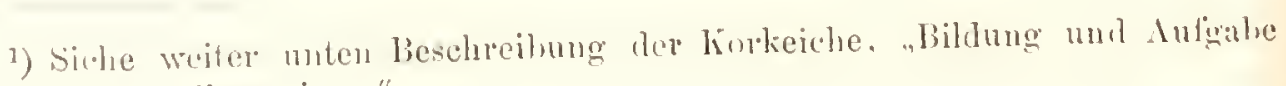
des liorkes in allwemeinen." 
loser. so dals die Ranken, wo iher zwei munittelhar anfeinander folgen. nach entgergengesetzten Seiten der Lotte hinfillen, anf die nämliche aber, wo sie dnreh einen rankenlosen Kuoten getrenut sind. An bliihenden Lotten stehen an Stelle der unteren Rianken Iiliiten-

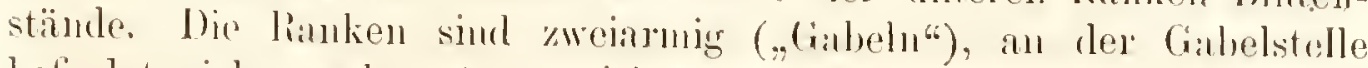
befindet sich, mach miten gerichtet, ein schnppenfiomiges Bbittchen, das Deckhiatt des muteren, etwas lïngeren Rankenarmes. Daraus geht hervor, dal's die Ramken Zweige sincl.

Blütenrispen (Fig. 1), blattgecrenstiindirg, ans den : unteren Kunoten der rankentragenden İste entspringend nud durch Pmlildung ler Ituputachse der lianke entstanden, sehr ïstigr, anfrecht. hej der Fuchtreife hängèd; Bl ütenstielch en büschelartig gehänft, einhliitig; Drckblïttchen klein, cinzeln.

Blüten klein. gethlichrriu, wohlriechend. Kelch sehr klein (Fig. 2, 3 mul 4), finst scheibenförmig, wie lieseda riechend. Blumenblätter (Fig. 3) füif, mugreliehrt eilinglich, oft weichlıarig, grïnlicl, an der Spitze verwachsen, nich unten frei, abgestntzt, durch die sich rerlïngernden und auseininder strebenden Staubbiitter l,ein Aufllibluen alggerissen mnd als Miitze alggeworfen; staubblätter fünf (Fïg. 4), vor den Blumenbliitteru stehend, in der Knospe eingelogen, nach dem Abfillen der Bhmenhlätter aufgericlıtet; Staubfäden diinn. Ifriemlich; Staubbeutel eiformig, oben und muten ansgerandet, zweifïcherig, der Iäinge nacls aufspringend; Stempel (Fïg. 4 und 5) oberstïndig, durch Verwachsen von zwei Fruchthlüttern entstanden, am Grunde von einer kleinen Scheibe unterstiit\%t, an Riande mit fiunf, ror den Kelchzïhnen stehenden Drüsen 1) (Fïg. 4) rerselen; Fruchtknoten eifümig, unten rollstindig, oben unvollständig zweifacherig (Fig. 5); Scheidewand durch das Verwachsen von zwei randstaindigen, nur an Grunde leiderseits eine Samenknospe tragenden Sin entrïgerm entstanden; Griffel (Fig. 4 gr) kur\% sïnlenfö̈mig; Narbe (Fig. 411 und Fig. 5) niedergertriickt, in der Nitte etwas vertieft.

Frucht eine Beere, kugelıund oder länglich, von rerschiedener Gröfse, rom Grimen durch Gelblichweifs, Rot und Schwarzot, ins dunkle Veilchenl,iun iibergehend, hereift, ein- bis viersinnig, mmeilen simenlos (Korinthen).

Same (Fig. 6 und 7) birnfirmigr, mit einer Rinne, srüulich, glänzend; Keimgroblo (Hitum) etwas iiber der äufsersten Basis anf der Batuchthäche; Samennaht an der Keingrube heginnend, nach der

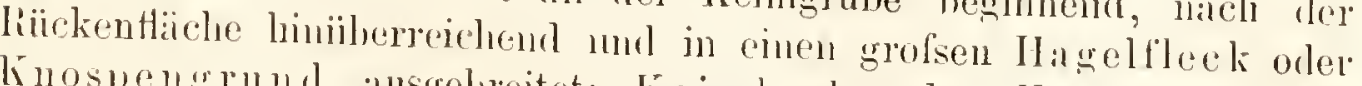
knospengruma ansgebreitet; Keimborls oder Keimmund am ̈̈nfsersten Gunde; Samenlant doppelt, ïnfsere häutig, innere steinschalenartig; Eiweifs (Fig. T) harthleischig.

3) Infruchtharen Staubbittern. 
Blüht Juni und Iuli.

Die grofse weilse Cibebentraube ist langheerig und griinlich-gelb, die kleine hlane Korinthentranbe ist kleinbeerig nud samenlos.

Man kennt an 1400 Spielarten des ellen Weinstockes, die durch Kunltur, ̈̈rtliche Verhältnisse, verschiedene Behandlunıssweise entstanden sind und sich durch ihre Blïtter, durch Grölse, Form und Farbe der Friichte. durch Geschmack n. s. w. unterscheiden. Einige nehmen an, dafs roul den drei Urarten des Weinstockes: von Vitis vinifora, dem gemeinen Weinstocke, Vitis vulpina, der Fuchstraube, und Vitis labrusca, dem wilden Weinstocke, alle Traubensorten durch natiirliche und kïnstliche Befruchtung und Samensat entstanden sind. Nach liabo mol Metzger unterscheiden wir folgende Hauptsorten deutscher Reben:

A. Rundbeerige (Beeren rund, 5 bis $12 \mathrm{~mm}$ im Durchmesser).

a. Grofsbeerige (durchschnittlich 10 bis $12 \mathrm{~mm}$ ): 1. Trollinger (eine Traube oft 3 bis 4 I'fund schwer); 2. Alicant; 3. Spanier.

b. Mittelgrofsbeerige (s bis $10 \mathrm{~mm})$ : 4. Gutedel; 5. Tokayer; 6. Elben oder Alben (die :ilteste und verbreitetste Rebensorte); 7. Muskateller; 8. (iänsfuifsler; 9. Sylvaner.

c. Kleinbeerige (5 bis $s \mathrm{~mm})$ : 10 . Korinthe; 11. Burgunder; 12. Rielsling (die edelste deutsche, die meisten und besten Rheinweine liefernde Riebe, rom Rheingau aus immer weiter verbreitet).

B. Langbeerige (Lïngsdurchmesser 7 bis $17 \mathrm{~mm}$ ).

a. Grofsbeerige (10 bis $17 \mathrm{~mm}$ lang und 7 bis $12 \mathrm{~mm}$ dick): 13. Damascener; 14. Orleans.

b. Nittelgrolsbeerige (s bis $12 \mathrm{~mm}$ lang und 5 bis $7 \mathrm{~mm}$ dick): 15 . Veltliner (aus dem lombardischen Alpthale Veltlin stammend); 16. Irïngling.

c. Kleinbeerige (6 bis $10 \mathrm{~mm}$ lang und 5 bis $7 \mathrm{~mm}$ dick): 17. Kleinedel; 18. Klärner (ron Cläven oder Chiavenna in Ober-Italien); 19. 'Traminer (Tramin, ein Dorf Tirols unweit Botzen).

Folgende Sorten diurften fiir den Weinhan die wichtigsten sein: Blanfrïnkische. blane (Limberger), K. 1) fiir Rotwein. wie Portugieser, mul mit dieser gemischt gebant, hesonders in Nieder-(Osterreich. Blusard, blaner oder friiler blauer (Poulsard), T. "), Frankreich; Burgunder, haner (Klevner, blaner oder schwarmer). beste Rotwein-

1) Keltertaulse. - 2) Tateltriube. 
traube fiir Hache Itiggellagen hei laugen Schnitt mul kriiltigem Boden; Burynder, friiher biner (frïher Klevner, Angnsttranle, Jakobitranbe, laturengitraube), friilheste blane K. 1) und 'T. ${ }^{2}$ ) fiir l'anlere (regendeu. Dentschland und Österreich; Burgunder, weifser (weifser Kiferner, echter oder früher weifser Burgunder), sehr edle Weifsweintraube, selbst iu gringen Borleuverhïltnissen mud höheren Lageu noch gedeiheni, hesonders zur Champagnerfulbrikation, Deutschliund, Österreich; Din alszener, früher wrilser (Malagatranbe), T'; Danaszener, weilser Muskat (Muskit-Alexandriner), K. und T., verlangt langen Schnitt, sehr gute Lage und hohe Erziehnugsart; Elbling, weilser (Weifsalbe, weil'ser Sylvaner), äulserst traglare K. fiir leichte 'Tischweine. in Deutschland sehr verbreitet, besonders für Masseuprodultion; Feigentraube, weifse (Sylvaner, weilse Muskat), T.; Gutedel, friiher weifser (Diamant-, Perltraube), T.; Gutedel, geschlitztblätteriger grïner (Petersilientraube, spanische Traube), I.; Gutedel, hall, geschlitzthlïttriger grüner (grofse Petersilientraube, grofise spanische Traube), '1.; Gutedel, königssroter (königlicher Gutedel), T.; Gutedel, roter, K. und 'T.; Gutedel, Muskat, weifser, 'T.; Gutedel, weifser' Fratch- (gelher oder weifser Guterlel), K. und 'T.; Imperialrebe, feigenblätterige weifse T.; Kadarka, blaue $K$, in sehr warmen Lagen, Lngarn; Kïlner, blaner, K. und 'T., Steiermark; Malrasier, friilher weifser, 'T.; Mosler (Shipon, Zapfner, Furmint), K., Steiermark; Miillerrebe, haue (Meunier), K., Deutschland, Frankireich; Muskateller, gelber oder grüner, K. und T. für warme steile Lagen und kräftigen Boden; Muskateller, roter und schwarblauer, blaner, T.; Orleans, grimer oder gelber, T. und K., Deutschland; Orangentraube, gelbe, 'T; Ortlieber, blauer, K., Steiermark; Ortlieber, gelber (Kniperle), Elsafs, sehr traghare, gute K. fïr höhere Lagen und langen Schnitt; Portugieser, hlauer (Porto), Dentschland und Österreich, eine fast in allen Verhältnissen ertragreiche T. nnd K. für Rotwein; Portugrieser, roter (Kralovina), Steiermark, K., sehr reich tragend für höhere Lagen; Riesling, roter, K., Deutschland; Riesling, weilser (Rheinrieshing, Kleinriesling, Pfefferl), edelste und bouquetreichste K. fiir trockene, warme Lagen, verlangt Spätlese; liuläuder, graurot (graver und roter Klerner), für guten Boden, flache Hïgellagen und langen Schnitt empfehlenswerte friih reifende K., auch zur Champagnerfabrikation; Rotgipfler, weifser (Reifler), reich tragende, edle K., auch fïr höhere Lagen; St. Laurent, blaue, friihzeitige, reichtragende K. fuir mittlere Lagen zur Rotweinbereitung; Seidentraube, gelbe oder grïne (Friilhleipziger, frïher Kienzheimer), T.; Steinscliiller, roter (Rusitza), K., Ungarn, giebt in guten Lagen vielen, aber leichten, Wein; Sylvaner, griiner (Muska, Schönfeilner), selbst fïr ärmere Bodenarten und geringere löhere Lagen noch eine gute, reichtiagende

1) Koltertraube. - 2) Tafeltrabe. 
K. 1 , verlangt langen Schnitt mud gilt in rauheren Lagen anch als frihe 'T." ); 'Traminer, roter, in gutem Borlen mittlerer Lare nul bei langen Schnitt eine sehr edle K.; Trollinger', blauer oder sehwarzer (Fleischtrambe, Frankenthaler', Schwarzwelscher), 'T'. nud K. nit bis $2 \mathrm{~kg}$ schweren Tranhen, Dentschland; Vanilletraube (geschlitzthlätterige Basilikumtraule), 'T.; Veltliner, früher roter (rote Babotraube, frïher roter Milvisier), K. and T. Nierler-Österreich; Welscher, frïher h) lumer, 'T. mul K., Steiermark; Welschriesling, weifser, fïr gnte geschïtzte Gehirgslagen sehr tragbare und zur Erzengung guter Tischweine geeignete K.; Zierfahuller" roter (roter Reitler, Gumpoldskirchner spätrot), sehr ertragreiche, edle k. fïr warme Lagen und kurzen Schnitt $\left.{ }^{3}\right)$.

Vaterland. Die Heimat des Weinstockes ist nicht mit Sicherlıeit bekannt; walnrscheinlich stammt er ans den laindern siiıllich vom Sichwarzen und Kaspischen Meere; Verbreitungsbezirk: Die wirmen Lämuler der gemälsigten Zone, gedeilıt iiberall da, wo Mandeln nnd Ptirsich im Freien anshalten, eine Region, deren mittlere Sommerwärme $20^{\circ}$ und deren mittlere Wintertemperatur +5 bis $0^{0}$ beträgt. Anf der nördlichen Italblingel läuft die Grenze des Weinbanes ron der Mindung der Loire $\left(47,5^{\circ}\right)$ zum Rlein $\left(51^{\circ}\right)$ und in Schlesien (Grincherg) bis 520 nördlicher Breite, fïllt dann rasch nach Siiden mnd in Bessarabien ant 46\%. In Norwegen reift die Tranbe an den Ifern des Sognefjords noch muter 610. Die Äquatorialgrenze läuft ziemlich parallel mit dem 30. Grarl, sinkt jedoch in Seeklima bis zum 10. Crarl. In England wird die Tranbe nicht reif. Die oberste Grenze des Weinbaues ist sehr verschierlen und reicht an Himalaya sogar his $: 3200 \mathrm{~m}$. Wo die mittlere Mhlrestemperatur $21^{\circ} \mathrm{C}$. iibersteigt, gedeilit der Weinstock nicht mehr, da beginnt dis Reich der Palmen (Ersatz fiir den Wein).

Kultur. Die Bodenart hat auf die Qnalität der Tranben resp. des Weines grofsen Einthl's. Die Weinrebe kommt fast in allen Erdarten fort, am besten sclü̈gt ilır ein warmer, trockener, lockerer und kräiftiger Boden zu, gut ein steinigter, oder mit Kialk. Quarz, Thonschiefer und grobem Sand rermischter Boden, an schlechtesten ein schwerer, feuchter, mit nassem Untergrmul versehener Lehmhoden. Sehr gut geleiht der Weinstock auf rerwitterten Gesteinen und in vnlkanischen Erolen. In mittleren Frankreich gerät er am besten auf Shaieferschichten und Kralkfelsen, die leicht verwittern, im nördlichen lrankicich wird der grohe Samd, mit Kalkerde vermischt, vorge\%ogen. Jer 'Thonschiofer, 'Thonmergel, Gips, Kalk nund Kreide schligen dem Weinstuck an hesten zu. es wachsen anl diesen Bodenirten die besten spanischen (die Weine zn Prienre in Katalonien), französischen (Chann-

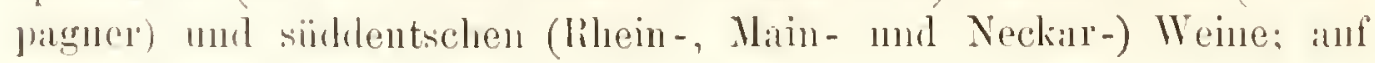

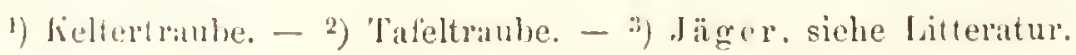


Laviborlen an Vesur wïlchst rer beriihmte Lacrimae Christi, anf l'orphyrgebirgen in Ungam gedeiht der bekannte Tokayer. Schwerer Thomboden orengt unter gleichen sonstigen Verhältnissen einen schweren, stark gefirinten, bonnuetreichen, haltharen Wein mit Wohlseschmack; - Sandboden einen leichteren, dimnen, minder bonquetreichen, fïr Lagern weniger geeigneten, schwiicher gefindten Wein; kalkreicher Boden legginstigt die Siilse des Weins, weniger das Bonrnet. Ein trocliener, steiniger Alluvialschuttboden (Liebfranenberg bei Worms) erzengt einen süfsen, starken, lagerhaften Wein mit cigentiimlicher Gïre, aher olne viel Bouquet. In Rhein-Bayern hat man durch Öherfahren des Weinhergbolens mit Basaltschutt aus bonquetlosen Tranbensorten bonquetreiche Weine erhalten.

In der Vitte eines Berges wächst in der Regel der loste Wein, indem der motere Teil den Nachteilen der Ebene ansgesetzt und der ohere meist zu trocken ist mond dort eine kïltere Luft herrscht; anf der Ebene wïchst zwar mehr Wcin, allein derselbe ist geringer. Jeder Weinherg mul's gegen ranhe und kalte Winde geschiitzt sein. Die heste Lage ist daher die mittägige, weil hier die Somnenstrahlen an lïngsten rerweilen. Die gegen Morgen sind den kalten Wiuden un Frösten ansgesetzt, dagegen haben die Weinberge, die gegen Abend liegen, mehr Schnt\%; am schlechtesten gerleihen die Weinherge gegen Mitternacht. Er gedeiht nur hei wiederholter krïftiger Düngung.

Die Weinrebe wird meist im grolsen, in Weingärten (Weinbergen), welche gewöhnlich an Bergabhängen terrassenmälsig angelegt sind, angebant, doch trifft man sie öfters als Spaliere an Gebäuden, sie client ferner zn Decke von Lanben und Lanbgängen, und wird auch als Zierde in Töpten grezogen. Die Weinrehe wird rermehrt und fortgepflanzt 1. durch Samen, als die natiirlichste Art der Fortpflanzung, 2. durch Schnittlinge oder Stecklinge, 3. durch Absenker oder Einleger. 4. durch Ableger, 5. durch Augen mul 6. durch Pfropfen. Zur Beförderung des Fruchtansatzes biegt und bindet mam die Rinten und nähert die Trauben möglichst der Erde, um deren wärmerïickstralılende Kraft auszunutzen. Triebe, welche weder früchte versprechen, noch zum kïnftigen Schnitt zu gebrauchen sind, werden gleich in der ersten Zeit des Austreibens ausgebrochen. Dimit Luft, Licht und Wiirme ungehindert in das Innere des Stockes dringen kömnen, wird das Ansbiatten, Austliigeln, Verhanen und (Gipfeln angewandt. Durch das Riugehn (Ablösen eines Rindenringes) sncht man den Saft einzehen Tranhen znzntiilnen. $11 m$ sie grölser und schöner zu machen. Der Imolen im Weinherg wird dreimal im Jahre gelockert, gehackt mul rom Unkiant hefreit. Mehn als dreifsig Jahre kamn der Weinber. nicht stehen und in der fiegel hat man nur noch zwanzigjillurige Nut\%ng, worauf wieder frisch gerodet wird und der boden einige Jahre der landwirtschaftichen Bementmy iberlassen bleibt. - Strenge Winter sind dem Weine weniger nachteilig als knrze und kalte Sommer. 


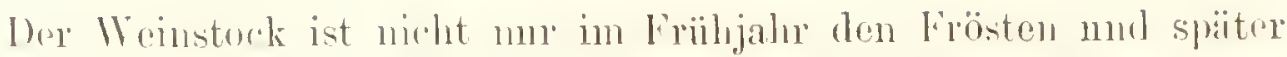

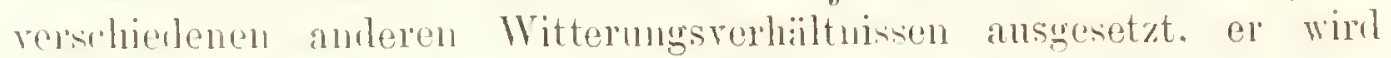
anch ron zahlreichen Insekten, dem Springwumwickler und dem II'nwurm, don lichenstecher, mehreren Enlen. der Rehenshlibllaus, der Leblins, den Mirikïfern, Bienen, Wespen, Hornissen, Ameisen, Sehnecken, Staren, Krantsrögehn, Weindrossehn, Elstern, Rebhiihnerı, Sperlingen, Fïchsen, Dathsen, Mardern, Wiesehn mad dem Hochwild, dam mehreren P'ilzen (an geführlichsten das Ö̈lium Tucheri) nud verwchiedenen Kr:mkheiten heimgesucht. Der furchtharste. wenn anch der körperlich kleinste Feind ist indes die Rellaus oder Wurzellaus des Weinstocken (Phylloxera vastatrix Planch., Fig. 8 his i0), ein Insekt aus der Ordunng der Mallhfliggler und der Familie der Hattlinse. Das Insekt ist $0,8 \mathrm{~mm}$ lang und $0,5 \mathrm{~mm}$ breit, nur punktgrofs, mandelförmig, nach der Iläutung gollgelb. spiiter griulich und dunkler, sitzt in grofsen Massen zusammengedrïingt an der Wurzel des Weinstockes und kommt in einer anderen Form anch an den Blittern deslelben vor. Der Körper ist durch Querfurchen in deutliche Alschnitte geteilt. Der Kopf ist etwis nach unten geschoben unl trägt zwei zusammengesetzte Augen, zwei dreigliedrige Fiihler und einen zuriickschlagharen Sangriissel. I'ngefliigelte Rebläuse iiberwintern in Spalten und Rissen ron Rehwuzelı, hïnten sich im Friilijalhr, gehen an die Faselwurzehn. in welche sie ihre Saugriissel eimbohren, und legen. sobrild sie ansgewachen sind. 30 bis 40 gelhe, später dunkler werdende Eier. Aus ihnen schlï]fen in wenig Tagen die Jungen oder Ammen (Fig. S u. 9), saugen sich an den Fascrwumeln des Weinstockes fest und legen nach etwal hrei Wochen auch Eier. Auf diese Weise entstehen sechs bis acht Genelationen. Ilie Ammen verwindehn sich endlich in Nymphen und diese in das rollkonmen getliigelte Insekt (Fig. 10). Fi kium sich demnach ein Insekt his Emle Sommer's anf 30 Mill. Individuen remehren. Tuter der letrten Generation finden sich getliigelte Rebliuse. Diese legen etwa vier Eier an die verschiedensten oberirdischen Stellen des Weinstockes, besonders gern in die Grabehn der Blattrippen, und sterben. Ans den gröfseren diever Eier schliipfen ungetliigelte Weibchen, aus den seltencr vorkommenden kleineren gefligelte Miinnchen. I) hese nngefligetten Weihchen sind $0.35 \mathrm{~mm}$ lang. $0.15 \mathrm{~mm}$ hreit, hellgelb, nit verkimmertom Sangriissel. Sie legrn ein hesunders grolses Winterei an Ende der Gïnge, welche am älteren Holze durch die Loslösung der alten von der jungen Rinde entstehen. Aus diesen Ki erwïchst dann wieder die fruchthare Stanmmutter einer ganzen Generationsreihe. Die Entwickehnusgeschichte ist noch keineswegs vollstaindig anfgekliirt. An anerikanisehen lieben tritt die lichlans an der lintersite der Weinblitter auf. wo sie Gallen erzeugt, die sich an der Ober-eite öfthen und cins bis drei thigellose Insekten nelst einer Brut von Eiern und Inugen enthalten. Wuden Weinstieke von der Rehans heingesncht, so werden in zweiten linhe ihre Blitter 
frïher gell, pollen sich an den liaindern ein und fallen alb. Sie

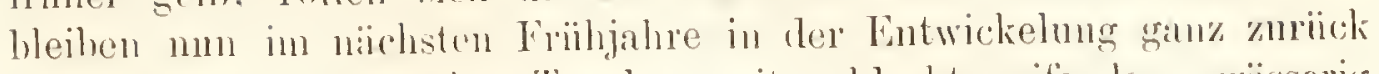
und reitigen mur wonige 'Tramhen mit schlecht reifenden, wïsserig schmeckenden Reeren. Dic junge, dem lii entkrochene Phylloxera setzt sich an den zillten Timwurzehn des Wrinstockes fest, bohrt mit ilıem Riissel dureh dis Zellengewebe (Fig. 9) und senkt damn ilure vier Saugröhren ein, mu den Saft zu sangen. Nun bleihen die Tierchen nuheweglich sitzen, dicht aneinundergedrängt, gleich einem Schuppenpanzer. Die verwumbeten Stellen der Wurzehn likden Wiilste oder Verdickmgen (Fig. 11) ron hellerer larloc, gehen nach und nach in Fänlnis iiber und bewirken das endliche Absterben des Stockes. 1)as Inselit remreitet sich entweder dnreh die Phade der Risse nud Spalten im festen Erdreich (im rimenden Sindboden bleibt es nnschädlich), oder es wandelt an der Erdoberflïche ron Stock zu Stock, endlich als gefliigcltes Insekt, sei es mittels eigener oder der Kraft des Windes. Alle bis jetzt gegen die Reblanskiankheit des Weinstockes angewandten Nittel haben sich als unzureichend erwiesen. Vernichtung der befallenen Rebstöcke, Desinfektion des Bodens oder Bebanen desfelhen auf eine Reilue ron Jahren mit anderen Gewächsen bieten die einzige Möglichkeit, sich an einer bestimmten Stelle der Reblaus zn entledigen. Da die imerikanischen liebsorten schmell aulserordentlich reiches Wurzelwerk treiben und so der Reblaus besser widerstehen, empfiehlt es sich, solche "Jacquez" anzupflanzen und die europäischen Sorten durch Pfropfen anf amerikanische Wurzelunterlage zu erlaalten. In Amerika wurde das Insekt 1854 ron Asa Fitch entdeckt. 1863 fand man es in 'Treiblüusern bei London und kurze Zeit diuranf an einigen Punkten Englands und Irlands. 1863 wnrde man im siidlichen Frankreich auf die Reblauskrankheit des Weinstockes und 1868 auf die Reblans selbst (Planchon) anfmerksam. Binnen zehn Jahren hatte sich das Tier iiber 1 Million Hektare, die gesegnetsten Weindistrikte Frankreichs, verbreitet und 30 Nillionen Franken Schaden angerichtet. Die französische Regier'nng setzte 1869 einen Preis von 20000, im Jahre 1874 einen von 300000 Franken aus fïr ein erfolgreiches Mittel zur Vertilgung der Reblans, doch kein Mittel half. 1870 trat die Rehlaus anch in Portugal an Douro (Portwein), 1872 in Österreich, 1874 in der Schweiz, 1875 in Deutschland bei Bom und 1870 bei Erfiut, 1882, 188:; mul 1s84 an der Ahr, bei Meilsen (Weinböhla) und in Krimmitschan (Wahlen) ${ }^{1}$ ) anf. Die gesetzgebenden Faktoren der weinbanenden Lïnder Emropas hahen gesetzliche Bestimmmugen, die Einfuihrung infizierter Rehen, sowie die Desinfizierung der von der Rehlanskrankheit befallenen Weinherge betreffend, geschaffen. Jetzt wirl eine neue Krankhoit des Weinstockes, der Meltau, aus den

1) An einem im Jahre 1871 aus Jrankreich bezogenen Weinstocke. 
Departements Gaurd, Basses-Pyrénćes, Vaucluse und im Arrondissement ron $\mathrm{Aix}$ gemeldet.

Bestandteile der Beeren siehe unten.

Benutzung der Trauben: $\Lambda$. frisch als wohlschmeckendes und gesundes Berenobst (Efstranben); B. getrocknet als Rosinen (Zibeben orler Cibeben, italienisch zibibbo, die besten un grölsten liosinen, französisch raisin, lateinisch racemus, Tranbe, getrocknete Weintranbe) und Korinthen und C. zur bereitung von Weinen.

B. Bereitung der Rosinen und Korinthen. Das Trocknen der Rosinen ist mannigfaltiger. als das der Korinthen. I lie Rosinen kommen ron verschiedenen Rebsorten; am meisten dienen dazu solche mit grofsen länglichen Beeren. Die gewöhnliche Behanklung behufs des Trocknens ist die, dafs man die Trauben bei voller Reife schneidet nud mehrere Tage der Sonne anssetzt; mufs man hei ungiinstiger Witterung zur' 'Trocknung durch Ofenwärme schreiten, so fiillt die Ware im Ansehen minder gut ans. Eine besonder's geschätrte Sorte wird erhalten, wenn man deu Stiel der Traube, bevor die röllige lieife ringetreten ist, hal') durchschneidet mo sie num so lange :mm Stocke lïlst, bis die Trocknumg vollendet ist. d. h. die Wasserteile verfliichtigt und der Zuckersaft konzentriert ist. In Frankreich und Spanien tancht man die reif geschnittenen Trauben, ehe man sie an die Some legt, in eine Briihe von Wasser und ans Weinranken oder Kïmmen gebrannter Asche; die Lange bewirkt. dals der Saft zum Teil durch die Schale nach aufsen dringt und, indem er nun äufsertich :uftrocknet, der Frncht ein glinzenderes Ansehen giebt. Damit die Beeren Cilanz erhalten, nicht zu sehr austrocknen und schrmmptig werden, taucht man sie in Kleinasien in walmes Wasser. auf welches etwas Bannöl gegeben ist. I) versandreifen Trauben werden entweder ganz, gelassen und als Traubenrosinen in Schachteln oder Kisten in den Hindel gehracht, oder man sondert die Beeren ron den Kïmmen ab. Die Versendung geschieht nur bei guter Ware in Schachteln orler kleinen Kisten, bei gewöhnlicher in Fïssern, seltener in Mitten oder grolsen Täipfen.

Die Korinthen (kine Rosinen), in Griechenland Staphiden genannt, wuchsen ursprünglich nur um Korinth, das ihnen den Natuen gal), und entstammen einer dureh die Kultur ihrer kerne verlustig sehenden Traubensorte (Vitis vinifera var. apyrence L.) mit kleinen dnnkelblanen Trauluen. Gegrenwïrtig hesitgt ganz Griechentand eine seiner wichtigsten Erwerhsquellen in ihnen, doch zieht man die ron P'atrats mul Vostizzal vor, olschon sie anch im Golfe ron Argos mud Nauplia elenso herrlich gedeiluen. Die Korinthen ron den liparischen Inseln sind geringwertiger als die grinchischen. Der Wert der horinthen hängt ron ihrem Trockmen alh. Naw Landerer liilst jeder staphidenbaner den zolnten Tril sines Landes zur Trockentenue manentlich da ïhrig. wo der. Borlen abschïissiger ist, num den etwa 
fallenden Ringen rascher abzuleiten. Ein thonhaltiger, nit Ochsen-oder Ziggenmist durchkneteter, festgeschliagener Borlen ('T'enne) bildet die poröse Unterlage, welche sich iiberdies terrassenförmigg erheht nurl natiirlich die Fenchtigkeit in hohem Gande an sich zichen muls. Alle zehn his zwölf Stmnden mit Sehanfeln mugewendet, trocknet hier die Ansbente eines Jallres bei grutem Wetter in S lis 10, hei feuchtem in 15 lis 20 Tagen. Die Stiele mud Schmutzteile werden durch Lesen und Sieben entfernt. Grolse Rosinen werden ron Kileinasien, Italien, Frankreich und Spanien, Koriuthen oder kleine liosinen fast nur von Griechenland gelicfert.

Gebrauch der Rosinen. Die Rosinen, grofse wie kleine, werden lanutsä̈hlich zu Backwerk und Kïchenzwecken (Korinthenbriihe sprichwörtlich) 1. s. w., sowie medicinisch als Unterstiitzmugsmittel hei Brustleiden (Brustthee), zu 'T'abakssaucen, zur Nachbesserung schlechter Weine. wohl auch yur Herstellung vollkommen kïnstlicher weinartiger Getränke benutyt. Ist die Weinernte in Griechenland iiherreichlich, so bereitet man aus den frischen Korinthen einen recht. krïiftigen Korinthenwein.

Handelssorte der Rosinen. I. Grofse Rosinen. I) besten Sorten kommen als Traubenrosinen, die ibrigen abgebeert in den Handel. 1. Smyrnaer (d. h. kleinasiatische Rosinen. Ausfuluplatz Smyrna). Grols und rotgelb. a. Sultaniarosinen, klcin, soldgelb, sehr zarthïutig, stein - nnd stiellos, gut gelesen, tener. h. Primaware: Elemé (Auslese), gute stiellose, grofse Beeren. c. Geringe Sorte von den Inseh Kos und Samos. Schwarz, klein, hartschalig nnd grofskernig. d. Die Rosinen der Insel ḱreta, sehr gering, zu Sorbets, Branntwein etc. 2. Damascener Rosinen, selu' lang, wie kleine Pflanmen, brïmnlich-gelb, durchscheinend, sehr suifs und gewöhnlich ansgekernt. Ausgezeichnete Ware in Truben. 3. Italienische Rosinen. Beste Sorte Calabreser Rosinen (heim Stältchen Belverlere). Aulserdem Mittel-Italien und die liparischen Insehn. 4. Französische Rosinen ("Provencer Rosinen'"), meist in ganzen Tranben. von sehr guter Qualität, die besten die ron Roquevaire (Marseille) und die von Lunel und Frontignim (nur Muskatellertrambe). 5. Spanische Rosinen ("Malagarosinen") aus den Weinprovinzen Malaga, Valencia, Alicante. Beste Sorte MalagaMuskateller. Entweder mit halbdurchschnittenem Stiel am Stocke getrocknet (Königs- oder Sonnenrosinen), orler in Asche und Öl getanclit (Lexia. klehen zusammen).

II. Kleine Rosinen oder Korinthen. Grichenland und seine Inschn, Rumelien, Morea (Patras, Vostizza), Zante, Kephalonia, Theaki (Ithaka). Geringere Sorten von den liparischen Insehn.

Handelsstatistik. Von Malaga mol Valencia werden jülutich etwa 3 Millionen Kisten Rosinen') mit einen Nettogewichte ron

1) Muskateller rosinen. 
$3: 350000 \mathrm{~kg}$ anngefiihrt. England ist dre gröbste lionsument von grofsen (italienischen nud framzïsischen) und noch mehr von kleinen Liovinen, da clort Mehlspeisen mit dieser Frucht versiilst eine allgemein belielito Kost bilden. Sein eigener Berlanf an Koninthen betrïgt jälırlich weit iiber 1 Million, an grofsen liosinen an 400000 Zentner. d)utschlind konsmmiert an Korinthen wie an grolien liosinen (spa-

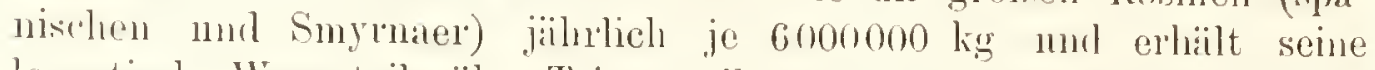
levatusche Ware teils iiler Triest, teils iiber Hamburg (auch spanische Beziige), das in nenerer Zeit etwa die Hiallte des gesanten Imports vertitt.

C. Gewinnung des Weines. Der Weinstock er\%eugt in seinen Beeren nicht Wein, sondern nur Most. Werden die Beeren: ron den Kïmmen abgesondert und allein gekeltert, so giebt dies den Beerenwein, nnd wenn nur die besten Beeren der Tranlse vorweggenommen werden, den Ansbruch. Der in Bïtten oder Krufen nit durchlöchertem Borlen gekelterte Most kommt, nachrlem man ihn in offenen Gefïlsen der Jerührmng mit der Luft atussetzte und Ilefenkeine ((ryptococcus fermentum) hineingelangten, in Gäirung; or wird 1 un trübe. Diese Ilefenpilze steigen von kleinen Gaslliaschen getragen geschiiftig in die Höhe, setzen an der Oberflïche das Gas ab, sinken damn unter, um mit einer neuen Ladung emporzusteigen (Gärung). Die (rïrung beschleunigt man durch kiinstliche \%ufuhr von Luft (Mostpeitsche, Lüftnngsipparate). Dnrch diese (stiirmische) Gärmng wird der Zucker in Alkohol (Weingeist) und Kohlensäure zerlegt nnd bildet sich der Wohlgeruch des Weines. Darnııch klïrt sich die Flüssiskeit und wird nach Alsscheidnng der Itefe in grolse Füisser gebracht, wo cine Nachgïrung (stille Gïrmug) stattfindet, wailnend welcher sich der rohe Weinstein und die IIefe nehr absetzen, der Knncker fist ganz verschwindet und sich die sogenamnte Blume bildet. Der Wein lommt nnn in kleinere (bei Weilswein geschwefelte) Fïisser zom Zwecke der Lagergä̈lung. Un liotwein ans blauen und roten 'Tranlen z.n erhalten, liifst matn den Most, welcher wie der ans weifsen Beeren farlolos ist, nit den Iliilsen zusammen gären. In diesen steckt der im Maste mulösliche Farbstoff; in dem Matse, wie sich durch die Gärnng Weingeist erzeugt, löst dieser denselben wieder atul". Dieser Farbstoff liat anch die Natur des Gerbstoffes, dilher die Rotweine mehr zusammenziehend schmecken und wirken. Schann-oder ('hampagner-Weine ${ }^{\text {) }}$ orler moussierende Weine entstehen da-

1) Korkstropsel nnd Champagnerwein ("l'fropfentreiber, Teufelswein“) sollen rou Dom l'erignon, 1670 bis 1715 l'ater-liellermeister der Abtei von HantVilliers, erfunden worden sein.

l)ie l'aluikation des Champagners. In der sonnigen, kreilehaltigen Chumpagne sind es namentlieh die l'rïfekturen Chalons-sur-Marne, Hipernay, leims, Saint-Ménébonld nud Vitry-sur-Nlarne, sämtlicl im llepartement der Marne, welche die besten Woine zur tirzengung des Monssenx lieferu, jedoch werden in 
durch, dafs man den junggen Wein nach der ersten Giarung in starke lilaschen falst mol sic wihrend der Nachgärung versehlossen hailt. Ls spmmt sich num die entwickelte lohlensïme in freien linmme

Frankreich aufser in der Champagne auch noeh an vielen anderen Orten Schaumweine erzeugt, die aber den Namen "Champagner" nieht führen dürfen. Der Mousseux ist niemals das Erzeugnis einer bestimmten Lage oder Tranbensorte, sondern immer ein Gemisch ans dem Moste (vin ln'ut) blaner und weilser 'Trauben, wobei gewöhnlieh vier Fünltel der ersteren anf cin Fünftel der leţteren kommen. Die Gewinnung des Mostes geschieht in derselben Weise, wie bei allen Weinen, nur achtet man sehr genau darauf, dal's die 'Trauben den richtigen Reifegrad erlangt haben, und liest die reifen und gesunden Beeren mit peinliehster Grewissenhaftigkeit aus den fanlen und umreifen ans. Frïher trat man die Trauben mit den Fül'sen, heute werden zum Keltern nur eiserne Spindel- und líniehebelpressen benutzt. Neist finden dabei seehs Pressungen statt, von denen die drei ersten den Most für den besten Champagner liefern, wïhrend der Ertrag der vierten zum späteren Nachfïllen dient. Die fünfte Ausquetschung giebt das Mlaterial für eine geringe Champagnersorte, und die seclıste mufs noch einen leichten 'Tischwein liefern. Der Most wird in Fässer gefüllt, in denen er ein sehr sor'ysam ïberwaelıtes Gärungsstadium durchzumaehen hat, dann werden die Füsser geschlossen und bleiben bis zum Januar liegen, worauf erst die eigentliche Champaguerbereitung beginnt. Die dafür bestimmten Kellereien ziehen sieh in den Kreidehügeln von Chalons, Epernay, Reims u. s. w. meilenweit hin. Oft findet man drei unterirdische Kellerstockwerke unter-oder übereinander, mit versehiedenen 'Temperaturgraden, wie sie der Wein gerade in den verschiedenen Stalien seiner Fntwickelung zum Champagner braucht. Verbunden sind diese Stockwerke dnreh Treppen, Fahrstïhle, Aufzüge, sehiefe Ebenen u. s. w. und neuerdings durelıweg nit elektrisehem Lichte beleuehtet. Die Kellereien der grolsen Fabriken gehören zu den Sehenswürdigkeiten der genannten Städte. Namentlieh Reims ist reieh an grofsartigen Kellereien; die der dortigen Firma Pommery und Greno bestehen aus 130 kolossalen Sehachten, die mit so ausgedehnten Galerien in Verbindung stehen, dafs man stundenlang gehen kann, ohne dieselbe Stelle zweimal zu betreten. Die erste Hauptarbeit in diesen liellereien besteht in dem Verstechen oder Versehneiden (eoupage), der Vermischung versehiedener Lagen und Rebensorten, wovon die Gïte und der Geist des Champagners wesentlich abhängt und worauf hauptsäehlieh die zarten Nüancen der versehiedenen Marken von Veuve Cliquot, Jaerjuesson \& Fils, Moët \& Chandon, I. Röderer, Ileidsieck, Mumm \& Cie., Deutz \& Geldermann u. s. w. beruhen. Jeder Fabrikant bewahrt daher auch die Theorie und Praxis dieser Mischung: streng als Gesehäftsgeheimnis. Fs folgt das Kiären nittels Hausenblase, die aler stets durch eine hinreiehende Quantität Wein verdünnt wird, bevor man sie in die Wüisser schïttet. Ist der Wein ganz klar, so fïllt man ihn auf frische fässer und zieht ihn in April oder Mai mit einem kleinen Zuckerznsatz auf Flaschen (tirage). Da die Gärung des Weines im Fasse noeh nicht beendet war und der Hauptsaelıe nach erst jetzt vor sich geht, so mïssen die Flasehen vorher sorgfältig anf ihre Stärke geprifft werden. Trotzdem zersprongt der gärende Wein 8 his $16 \mathrm{l}^{\prime} \mathrm{r}$ z. der horizontal gelagerten l'laschen, deren liork $n$ ur dureh ein schmales Bleehband festgehalten wird, während in schlechten Kellereien sogar sclıon Verluste bis zu 5o l'roz. vorgekommen sind. Wer Wein aus den zerplatzten lilasehen fliel'st in wasserdiehte schiel'c linnen (ähnlich dem Kúngllauf einer Kegelbahu), un sich in einem grol'sen Fasse zn vereingen. Man macht darans einen ansgezeielneten Weinessig oder benutzt ihn zum Anffïlleu icl. greringeren Champagnersorten. Nach einer bestimmten Zeit werden die l'lasehen, 
der Fische hetrichtlich an mod wird deshall, in Weine in so reichlichem Mallie alogesondert, dal's sie beim öffinen der F'lasche stürmisch entweicht. Siilse (siidliche, Weine werden erzengt, indem man die Giarung schuell muterhricht und norh Zucker zusetzt, Sekt oler starke suil'se Weine ans first trocknen Beeren (Kanariensekt, Xeressekt), Ausbruch ans halbgetrockneten, anserlescnen, nit frischem Moste begrssenen und gekelterten Trauben. Schwere Weine sind reich an Alkohol (französische Weine enthalten 9 his 1s, l'roz. Alkohol, l'ortwein 18 his 21, liheinwein 9 bis 12, (irineberger 6). Un die abgesetzten Verunreinigungen aus dem Weine zu entfornen, klärt und schönt man den Weifswein mit Hansenblase, den Rotwein dnrch Blut, Milch. Gelatine, Thonerde mud dureh rorsichtiges Filtrieren bei Luftabschlul's. Nan macht den Wein halthar, indem man ihn his auf 60 bis $70^{\circ} \mathrm{C}$. erwirmt, wodurch lieime und Fermente zerstört werden, ohne dafs der Wein leidet.

Wïluend der Nachgärung des Weines setzt sich eine krystallinische Rinde, der rohe Weinstein (Tarturus crudus) ab, der gereinigt in Form kleiner, weifser, durchsichtiger Krystalle in den Handel gehracht wird. Bei dieser lieinigung bildet sich auf der OherHäche der Lauge ein aus zarten pulverfömigen hirstallen hestehendes Hïutchen, der Weinsteinrahm (Cremor tartari). Aus den nach dem P'ressen der Trauben zurïckgebliebenen Trestern erhält man durch Gärung und machherige Destillation den Franzbranntwein (Spiritus rini Gullici).

Bestandteile der Beeren, des Mostes und des Weines. Die Weintrauben enthalten je nach Art, Borlen, Lage und Witterung nach 12 Analysen im Mittel etwa:

deren luladt - wenu uötig - nachgefüllt worden ist, iш pultartigen Ciestellen vou ziomlieh steiler Neigung mit dem Kupfe nach unten anfgestellt, und jeden 'Tag zwemal dnreh einen ron Gestell zu Gestell gehenden Arheiter resehüttelt, wobei sieh Hefe und alle Unreinigkeiten anf den I'fropfen ablagern. Zehn bis zwölf Monate nach dem Keltern beginnt nun die eigentliehe Chanpagnerarbeit. mit dem Eutkorken (dégorgement), wobei ein Arbeiter jede Flaselu mit einer greselickten Handbewegun uach dem I'fropfen zu schwenkt und diesen dann raseh wegschlägt, indem er den lials der l'lasche seitwïrts in ein f'als hält. Dabei schleudert di' ungestün entweieheude liohlensäure alle angesammelten l'mrinigkiten mit fort. Der Arbeiter schlielst die Flasche rasch mit einem gewöhnlichen Kork und reicht sie einen zweiten. der die "dosage" hincinzufüllen hat, d. h. einen hiıueur, der je nach Menge und stärke dem Champagner seine siifsigkeit, Sehwere und lärbung giebt und den "Vin lu"nt" erst in Chanpagner verwandelt. Die "/isammensetzung dieser" "Duse" wird elenfalls vou jede! Firma als ein streng zu hiitendes (icheinnis betrachtet; in allgemeinen soll es sieh dabei wn eine Zuckerantlïsung mit Kusatz ron ('ognae und altem Wein handeln. Wer nächste Arbeiter treiht hielant mittels der stïpselmaschine 'inen neu'n, dicken liork, der vorher

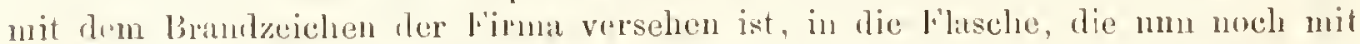

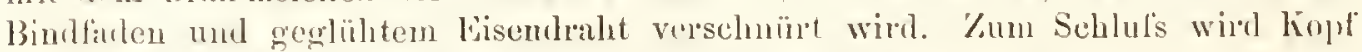

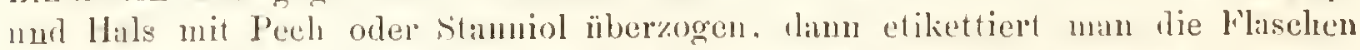

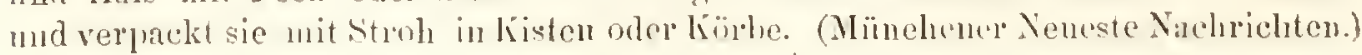


Wisser 78,17, stickstoftsulstan\% 0,59, 'Tranbenzueker 14,36, freio

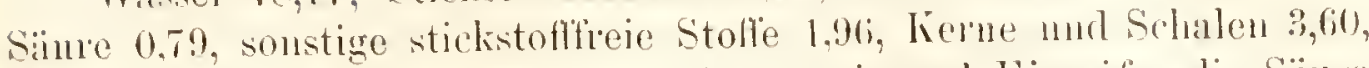
Asele 0,50. Dic Stickstoffsulustan\% ist rorwiegend liweifs, die Säne

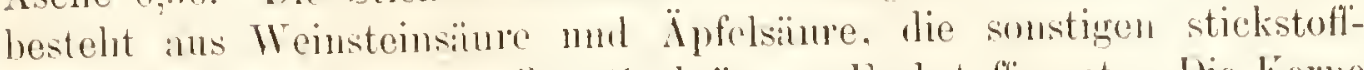
freien Stofte ans I'ektinstuffen, (ierbö̈uren, Farbstoften etc. Die kerno und Schlialen enthilten rontegend Gerbsime. Der Most enthilt in Mittel (naeh 23 Anilysion):

Spezif. Gewicht 1,1024, Wisser 74,49. Stickstoffsulstin\% 0,28, Zucker 1!). 1, siine 0.64. sonstige stiekstofflreic stufle 4,48, Asche 0,40.

Der Gehalt des Weines schwinkt in don rerschedenen Arten, lämlem und Jahrüngen. Sinch Rösler hetrïgt die mittlere oder numale Zusammensetzung des Weines:

Wasser 57.0. Alkohol 10.0, Zncker 0.20, Extraktisstoffe 0,58, Weinsïme 0,60, Weinstein 0,65. Glycerin 0,60, Bernsteinsiume 0,12, Alhmun 0,10, Gerbsïure 0.15, Essigsïne 0,0T, Asche 0,25. Dis spezifisehe Gewieht des Weines schwankt awischen 0,992 mol $0,998$. Zucker ist in den deutschen Tranben grering, in den siudländischen (Rosinen) mehr, im Liqueurwein (Ungarwein) bis z.1 1/4 des Gewiehtes enthalten. Dis bei der Giirung sich bildende Bonquet (.Bhmme“) bestelit aus dem sogenamten Önanthäther (Capryl- mol Caprinsänreither) und anderen mubekannten Bouquetithern in nicht hestimmbarer Menge.

Die Asche des Weines besteht zu fast $2 / 3$ ans Kali mud $1 / 3$ ans Phosphorsïmre. Der Gesamt-Extrakt normal znsammengesetaten Weines beträgrt etwa 2 Prozent.

Wirkung des Weines. Der Wein ist der menthehrliehe Genosse hei jeden fröhliehen Feste, das edelste nnd für die Mlenschen angenehmste Getränk, ist mïfsig und unverfälscht genossen dem juugen Mensehen nieht schädlich und vorziiglieh alten Lenten („Milch des Alter"s") sehr zuträglich. In heifsen Lündern wird ler Wein noch jetyt wie bei den alten Römern nnd Griechen mit Wasser gemischt als tägliehes Geträuk benntzt. Für die nicht an Weintrinken gewöhnten Menschen ist guter, alter Wein wahre Ar\%nei, welche die Nerven anregt, die Verdanmmg rermeht und den Magren stïrkt, das Gemiit erheitert („der Wein erfreut des Mensehen Her'z"). die intellektuchen Fïhigkeiten erlöht mud leichtere und raschere Muskelbewegmig hervorruft. In den Weinläntern sind the Menschen im allgemeinen lieiterer, geistreicher und geselliger, sie haben mehr Offenheit und Zurorkommenheit in ilıem Betragen. In Streite hausen sie leicht anf, aber sie trageu selten nach, wem sie geïrgert wurden, und ihre Riehe ist nieht tiickiseh. "Der" Wein", sehreiht Mantegazat, .,ist vermöge semes Gelaltes an Trauhenzucker, Dextrin und Sal\%en ein direktes Niilnmittel. wïhrend er indlirekt die Ermähnung fürlert dadnech. dals er den Stoffinmsit\% vertanersimnt. Obgleich die im Lahon-

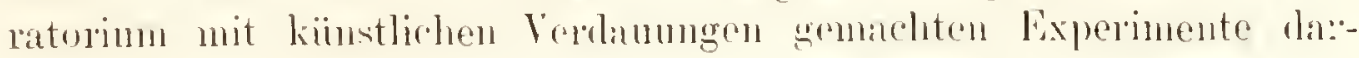


thun, dal's die Auflösmng der Speisen mittels des Magensaftes langsimmer von Stitten gelit, wenn demselben Wein beigemischt wird, so heweist doch die gewöhnliche Erfahmung, dats viele Weine, mol namentlich die gnten, die Verdanmg förlern." Fïr die der Gesmudheit dienlichsten Weine hïlt Mantegazza die hitterlich schmeckenden, doch stellt er die Ansmittehung der fïr den Einzehen förderlichsten Weinant der Selbstbeobachtung anheim.

Über die Wirkung des Weines schreibt Professor Dr. Harnack in Halle in der Festschrift der Universitit: "Das Ligenartige in den Wirkmigen des Alkohols, was ilu so unersetzlich als Genufsmittel erscheinen lïfst, liegt nicht in dem Nacheinander, sondern in dem Nebeneinander gewisser erregender und lïhmender Wirkungen, deren Ansgangspmlit in zentralen Terrensystem zn snchen ist. Thei steigender Intensitït der Wirkung iilerwiegen immer mehr die lähmenden Effelite, nm in den höchsten Grarlen schliefslich allein zn herrschen. Aber schon bei den ersten Graden der Gesamtwirkung machen sich gewisse erregende nnd lïhmende Wirkmngen gleichzeitig geltend, d. h. der Alkohol vermag namentlich gewisse Gehimthïtigkeiten anzuregen und zin beleben und dadnrch angenehme Vorstellungen zu erwecken, während er zugleich andere Teile des Gehirns lähmt, dadurch lïstige oder quälende körperliche und seelische Empfindungen rorïbergehend heseitigt mnd so den Mensehen in gewissem sinne von sich selbst und von störenden Einfliissen der Anfsenwelt roriibergehend befreit. . . . . Firr die richtige Beobachtung dieser Kombination ron erregenden und lïhmenden Wirkungen in den niederen nnd mittleren Graden der Alkoholwirkungen finden sich in den alttestamentlichen Schriften zahlreiche, mingemein bezeichnende Beispiele." Der zu häufige Genu「s junger Weine und anch alter Rheinweine rerursacht Steinkrankheit, zu hänfiger Genuls selbst der besten Weine kann Podagra, Kupferausschıg im Gesichte, Nervenschwïche, ja den Sïuferwahnsinn zur Folge haben.

Weinsorten. Plinins: „So viel Weinberge, so viel Weinsorten." Nach den Er\%eugungsslindern.

I. Deutschland: 1. Rheinweine (Johannisberger, Riidesheimer, Hochheimer, Assmimnshïuser, Geisenheimer; Narkobrumer; Liebfrauenmilch). 2. Mosel-, Sarr-, Alr-, Pfuilzer- mel Neckarweine (anch Würtemberger Weine). 3. Fankenweine. "Frankenwein - Krankenwein" 1) (Leisten- mnd Stein- oder Heiligegeistwein bei Wiir\%lurm, Schalksberger, Schlof Salecker bei Itammelhnrg). 4, Geringe Landu weine. Nammburger, Grimeberger, Meifsner, Güttinger ete. II. Frankreich, das erste Weinland der Welt. 1. Bordeanxweine (Chîtean Margot, Chitean Larose, Chatean Latitte etc.). 2. Burgunderweine (Wein des Rhone mul der P'rovence, Anjouweine, P'ny-

1) Neckarwein - Schleckerwein, liheinwein - fein Wein. A. Ki ufunann. 


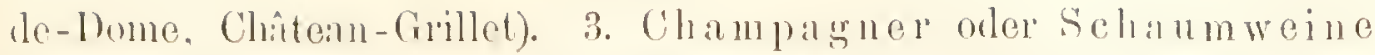
(licims, Fyerniy, (hâtons sur Minne cte.). III. Spanien und Portugal. For\%ïglicliste Sorten: Malagar. Sherry oder Xeres. 'l'into, Alikinte ete. Rosinenbanm mur in Sïlden. Portwein (Madeim, siche unter Afrika). IV. Schweiz. In den kantonen Waalt nud Ziirich, ann Genfer- nud Nenfehuteler-Sce (Licote mul Lavenx), in liaselland das schweizerbhnt, ferner der Veltliner etc. V. Italien. Dem Anbin des Weinstockes ist in nenerer Keit grölsere Sorglint zugewendet

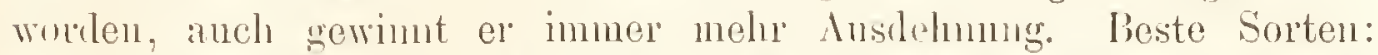
1. P'iemont und Toskana: Asti, Brolio, Montepulciano, Ponnino, Barolo, Bantero, Grignolino etc. 2. Venetien: Negrara, Refosco, Valpolicella etc. 3. Neapel: Capri, Vino greco, Lacrimae Christi. 4. Sirilien: Marsila, Malvisier, Moscato ete. VI. ÖsterreichUngarn. 1. Jïhnen: Mehuicker. 2. Nieder-österreich: Grinzinger; Kloster-Neuburger, Bisimlerger etc. 3. Tirol: 'Traminer, Botzner, Meraner, von 'Trient etc. 4. Illyrien, Istrien, Dalmatien: Malvasier ron Calmota, Klein-Tokilyer ron Capo d'Istria, Mareschino ron Sebenico. 5. Ungarn: Tokayer (60 Sorten), bester Liquenrwein im Distrikte

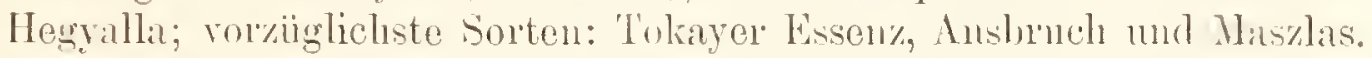
VII. Griechenland. 1. Hie Siebeninscl-Weine, ron denen die ron Cephalonia die wertrollsten sind. 2. Die Weine des I'elopomes, die hesten von Patras nud Kurinth. 3. Die Weine des Ïgriischen Neeres, die besten ron šmtorin und Eubö̈. 4. Die Weine Attikas. Yon den tïrkischen Weinen ist dre Cyperwein der beste. Rosinennund Forinthenhan. VIII. Rufsland. Weinbau in Bessarabien, Cherson, h́rim und Jokatharinoslaw. IX. Asien. Weinban dnrch Molnammed nit Gewalt zerstïrt. In Persien bei Ispahan mul Schiras vorziiglicher Wein. Anch Kabul, Tibet nud Kaschmir. Vornehme Inolnammedaner trinken Wein muter 132 Namen, und Champagner, da er ja nicht den Nimen Wein hat. Anf die Tafel der alten persischen Könige kam der Wein ans Chislybon (Aleppo). X. Afrika. Weinlan schon bei den alten Ïgyptern (nnreotischer Wein). Jetyt Azoren, Kanarische Inseh, Maldein, Kap wein (Konstantiawein). XI. A merika, hesonders die Südwestkiiste. nenerdings Kalifornien. Ohio, der „amerikatuische Iihein".

Warenkunde, Verfälschung und Verunreinigung des Weines. Nach Klenckel) soll guter Wein holl, blank, nicht zn blals, von angenehmen Genche mul Geschmicke, von liingerer Nachwirkung anf der Zmuge, nielit saner', nicht zu schnell

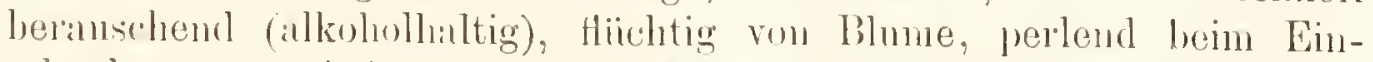
schenken, ron kener erschlaffenden onler Kopfschmer\% erregenden

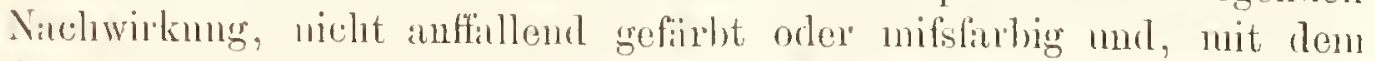
Arïumeter gentessen, nie schwerer ats Wasser sein. Iä̈nger anlail-

1) Klencke, Lexikon der Verfitschungen.

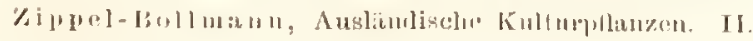


tendes bremen an Gammen lïfst anf \%usat\% von Weinsteinsïnre schliefsen. I anggewordener Wein erscheint schleinig nud Hiefst wie (i); ist dor Wein henhe oder ranh nud gieht or wenig Geist nud Weingernch zu erkennen, so liifst er 'l'resterwein vermuten. Kein Lehensund henufsmittel wird so sehr verfälscht als der Wein. Wir kïmuen nus hier nicht in chemische Analysen verlieren und missen anf lie hotreffenden Fachschuften verweisen. Was das Weinprüfen in allgeneinen anlangt, gehen wir die ron Kilencke') aufgestellten Regelı. 1. .Man muls gut bei Geschnnck und Geruch sein, kurz rorher werler geraucht, noch Siifses oder Herbes gegessen oder getrunken hablen. 2. Rei Proifing nehrerer Weine nach einamler muls man jedesmill etwas trockenes Brot vor der nenen Probe kïnen, um den Geschmack des vorhergegangenen zn tilgen. 3. Man mufs muterscheiden. ob rer geprinfte Wein oben oder unten ans dem Fasse anfgehoben ist; ohen ist er schwïcher und nilder, unten herber mol strenger, in der Mitte am besten. 4. Der Wein mufs beim Kosten nicht za kalt und nicht lanwarm sein und man mufs stets frische, reine Glaiser gebranchen. wenn man verschiedene Sorten prüt. 5. Man mufs beriicksichtigen, of man in der \%eit prifit, wo die Reben treiben (Mär\%. April), orler hliihen mud zeitigen (Angust), da damn leicht anch in Weine Bewegungen (chemische Umsetmugen) rorgehen, die den Geschmack etwa: inrlern und voriihergehend ranher machen kömuen; desgleichen bei Gewitten'n. 6. Man füllt ein helles Glas, sieht von der seite daraut, o) rler Wein völlig durchsichtig ist oder Wölkchen, Flöckchen etc. zeigt, ob er glänzt, ob er beim Einschenken in lingen Strable nicht furlig wird, ob er Perlen wirft oder schäumt mol in welcher Art. 7. Man hiilt das Glas schnell muter die Nase, ob die platzenden Perlen angenehm frisch das Gefühl reizen oder der Geruch liehlich oder unangenehm sei; riefst etwas Wein in die Hohlhand, reiht und hält die Nase linein. 8. Man bringt den Wein $11 m$ anf die Zunge, lälst ihn einige \%eit darauf. bewegt sie, drickt mit der Spit\%e, die das teinste Gefïhl hat. gregen den Gammen, dals der fliichtige Dmot hinten in die Nasenöffinung viehen kamn, mul pröit sowohl diese Eindriicke wie die Dinner, welche mach dem Hinmuterschlucken der Germch mul Geschmack erhalten." — Verdorlene, ungesehligene orler groninge Weine werden gewöhulich gefärbt. Der echte blane Farbstoff der Schalen giebt. mit Weingeist ansgezogen, eine rote 'Tinktur. lileizncker faibht dieselbe griin. Fs folgen hier einige der anl meisten benutsten Prifungsnethoderi.

1) Kilencke, Lexikon der'Verfülsehuugen. 
lieaktionen durch 'Thonerde nud kohlensanres Ammonimm nud libeizncker; nach dacob.

\begin{tabular}{|c|c|c|c|}
\hline & Woinf:urben & $\begin{array}{c}\text { Thoneric und } \\
\text { kohlensatures } \\
\text { Ammonizm }\end{array}$ & Blcizucker \\
\hline $\begin{array}{l}\text { Natïrlicher } \\
\text { gefärbt mit }\end{array}$ & $\begin{array}{l}\text { Wein ....... } \\
\text { Canplechehol\%. . . }\end{array}$ & 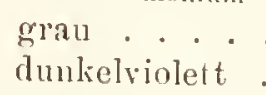 & $\begin{array}{l}\text {. blau (grïn-) grau } \\
\text {. . schwachdunkelblau }\end{array}$ \\
\hline 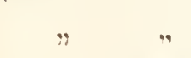 & Fernambuk. . . . & karminrot. . & - weinrot \\
\hline$"$ & lilatsuhrosen. & schiefergrau & . . sclumutrigurau \\
\hline$"$ & Simblucus clotus. . & hellviolett. . & - . blaugrau oder schïn grün \\
\hline$"$ & 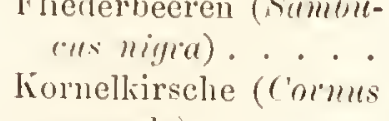 & blaugrau & - . schmutziggrïn ${ }^{1}$ ) \\
\hline$"$ & $\begin{array}{ccccc}\operatorname{mascul}(1) & \cdot & \cdot & \cdot & \cdot \\
\text { Lackimus } & \cdot & \cdot & \cdot & \cdot\end{array}$ & hellgriün & $\begin{array}{l}\text {. selmmutziggrü } \\
\text {. blaugriun. }\end{array}$ \\
\hline
\end{tabular}

Reaktionen durch $\ddot{A}$ trkali nach Chevallier²).

Wein gefïrbt mit Attichleeren ...... violett

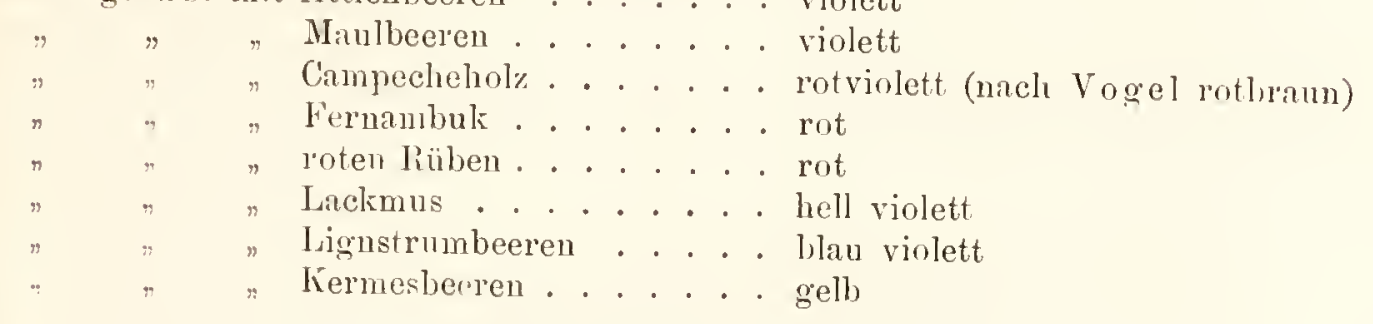

Echter liotwein ........ gelbbrann

Brasilienholz. . . . . . . . rotbrann

Ileidelbeeren . . . . . . . grün

Fliederbeeren ......... griün

Rote liüben . . . . . . . gell (durch Sïnren wieder rot werdend).

Rebennolz oder Weintrestern liefern durch Verhenen das Rehensehwar"z oder Frankfurter Schwar\%, einen feinen, zul Buchdruckerschwiirze vorziiglichen Farbstoff.

Handelsstatistische Notizen. Die Erreugung wie der Verbrauch des Weines sind im steigen begriften, es lassen sich daher Durchschnittsherechmmgen nicht gnt anfstellen. Zun Vergleich mögen folgente beiden Tabellen dienen.

An Wein sind wïlnend des Juhres 1890 im Dentschen Reiche $2974593 \mathrm{hl}$, im folgenden . Jahre dagegen nur $748462 \mathrm{hl}$ gewomnen worden. Wem man berlenkt, dals im Durchschnitt der yehn Jalure 1881/90 22,2 hl anf' den Hektar geerntet wurden, wïhrend dieses Dur'hschnittsquantum im minginstigen Jahre 1891 nnl 6,3 hl betrng bei einer Gesamterntefliche von 11!) 294 hat, so kann man hierans dentlich genug

1) lieagiert nur, wemn der Fliederbeerensaft frisch ist. - 2) Alte Weine reagicren auders, wie junge. 
die Verhuste ler Weiuproduzenten im letzteren Jahre ermessen. - Rei der Weiner\%ugung Ientschlauds steht das Königreich Bayern (nit

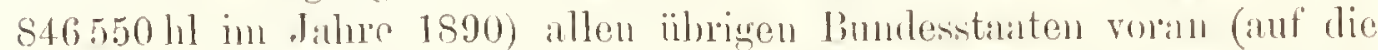
Plal\% kimen hier allein 6(33353 hll); an zweiter Stelle forlgte ElsilsLothriugen (mit 772684hl), dam das Grofsher\%ogtum llessen (nit 350474 hl. wohei anf the Provinz Rhemhessen allein 339384 hl entfielen); demuïchst folste dis Königreich Preufsen (mit 348772 hl, wovon in der Provinz Rheinland 256103 hl gewomnen wurlen). Hinter Preufsen folgten Baden (mit 331 634) und Wiirtemhers (mit 320117 hl); alle iibrigen deutschen Bundesstaaten sind an der Weinporduktion entweder mit sehr geringen Zilhlen (Sachsen mit 3168 hl im . Tahre 1890) oder iiherhaupt nicht beteiligt. - Um mun die Weiner\%engung Deutschlands mit derjenigen der iibrigen enropäischen lünder zn vergleiehen, dizu bietet uns ein ror küzem seitens des italienischen Ministerims für Landwirtschaft veröfentlichtes interessintes Werk wertvolle Angalleu. Es wird hier auf Grund von Ermittehngen, wetche in den Zeitranm von 1856 bis 1891 fallen, die gesamte mit Rehen bestockte Fläche in Europa auf 9189561 ha und der Ertrag derselben auf 117331000 hl gesehiitzt, und zwal betrug die Produktion nach IIektoliter'n in

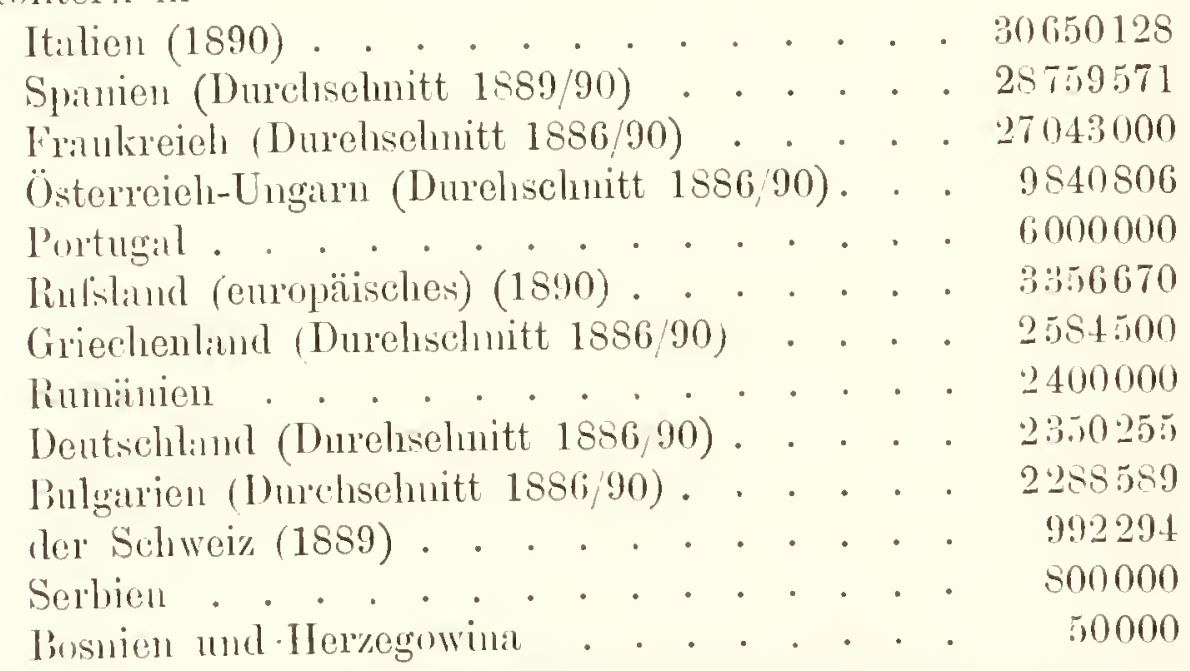

Wir sehen, dals Italiens Weirryeugung derjenigen aller iibrigen Länder weit voransteht. Die Folgen der Verwiistung dureh die Reblans haben herheigefüht, dals Frankreich in dieser Beriehung nenerdings ron sprunien ibertliigelt und in die dritte Stelle gedr:ingt worden ist. Wie folgende l'abelle reight, hat sich das wieder geiindert.

Die Weinproduktion der. Welt in den Jahren 1893 11. 1894 betrug nach dem Bulletin de statistique, l'ebruar 1895:

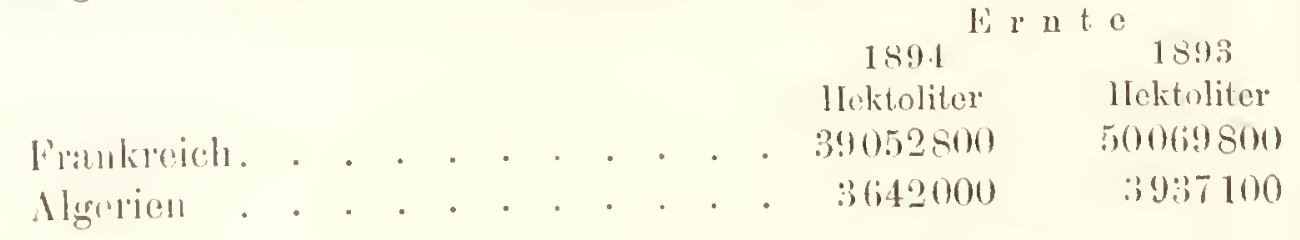




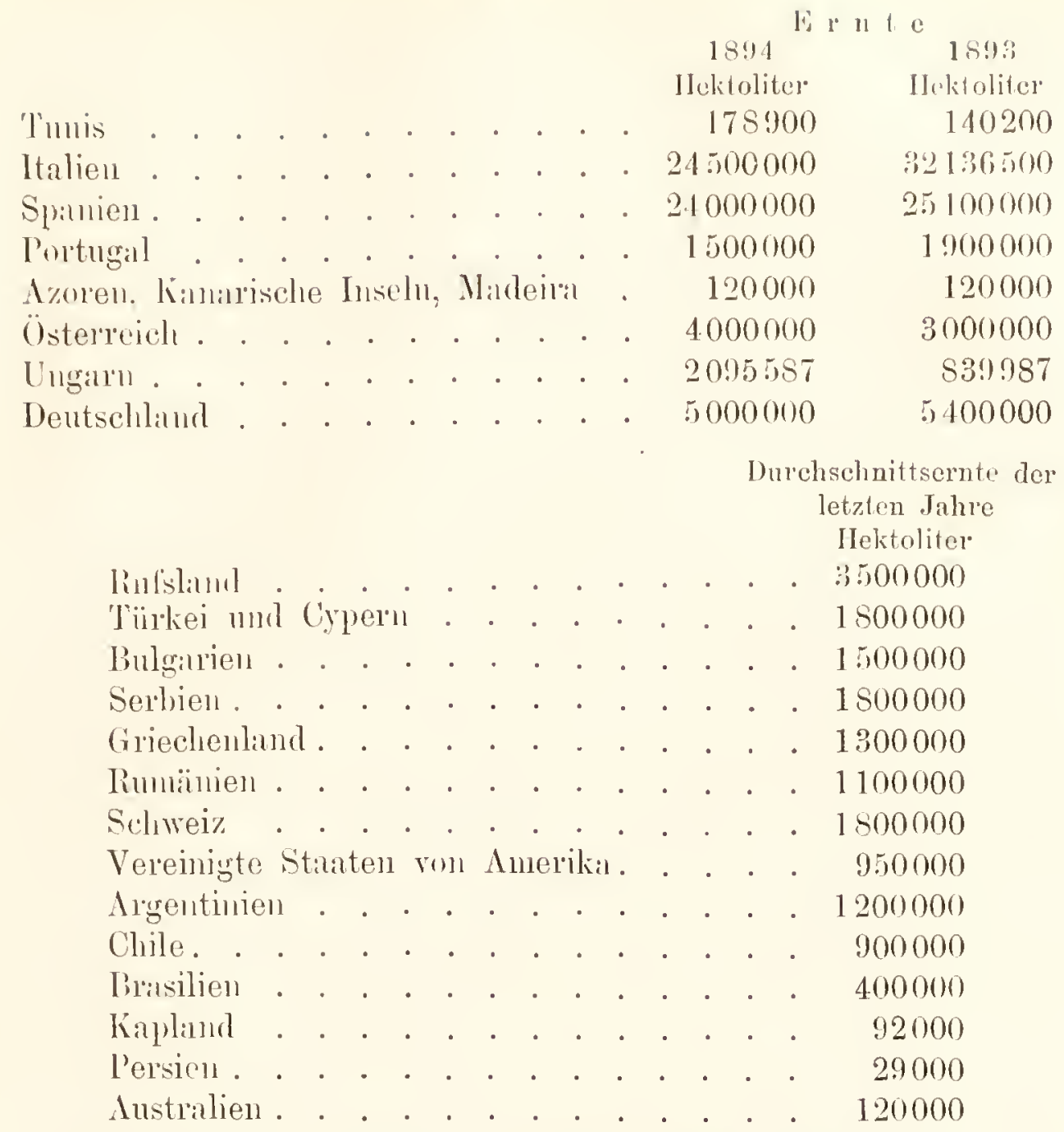

Die Weinsteuer brachte in Frankreich im Jahne 1894 einen

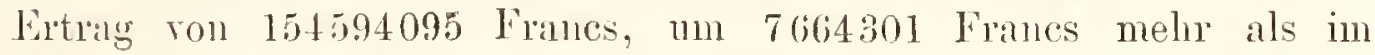
Jahre 1893. Der Weinverbrauch beträgt in Frankreich 86 Liter pro Kopf (199 Liter sogar an der Seine und 290 Liter in Heranlt), er ist fast $1 \mathrm{~m} 5$ Mill. Hektoliter gegen die frïheren Jahre gewachsen und betrïgt jetıt 321/2 Mill. Hektoliter. $7 u$ dem liange von Weltweinen heben sich Portwein, Champagner und Madeira. Danach rangieren Bordeaux und Burgunder, dinach Sherry und Rheinweine.

Geschichte des Weinstockes. Die ältesten Nachrichten rersetzten die Heimat des Weinstockes an den Fufs des Ararat, allein die Traulsen werden hier wegen der Höhe des Gehirges nicht reif (siehe oben "Vaterland"). Die Julen (Noah) banten schon ror" Abrahams Zeit den Weinstock an. Bei den P'ropheten dieses Volkes erscheint der Weinstock und Weinberg als Mittelpunkt von P'alahehn, Allegorien mul Fabehn. Anch wirl das ganze Volk oft mit einem Weinstock oder Weinberg verglichen und in diesem Simne war an der Vorhalle des Herodianischen 'T'mpels ein grofser goldener Weinstock 


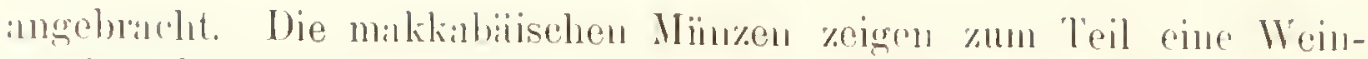

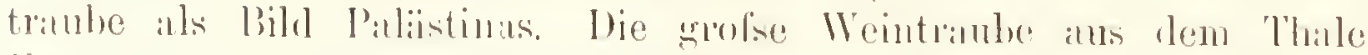
liscol (siche Gemoner l'isang, (ieschichte). Von Syrien dehnte sich die Kultur des Weinstockes allüilhlich ïber die witmen Jänder der gemïl'sigten Zonr ans. Die Semiten haben es zuerst verstanden. den Fruchtsaft der Weinbeere aul der Gïirmussstufe fostmulalten, wo er cin aufregendes mul betiinbendes Getrïuk alugieht. Bei den Homerischen Griechen ist der Wein schon im allgemeinen Gehranch, Jungfratuen mul Kinder trinken ihm. Yon Nysa an der thracischen Kiiste kommen tïglich weinbeladene Schiffe zum Lager der Griechen vor Trojir. Wie heute noch setsten die Griechen iln'em Weine der IIaltbarkeit habluer Itanz zu und bewalurten ihn anf in grofsen, irdenen, ansgepichten oder verkalkten Weinfiissern') (Diogenes in solchem Fasse) und Ziegenschläncheu. Sie tranken den Wein meist nit Wisser gemischt und erst spaiter nahm dic Unmïlsigreit im Weintrinken iiberhand. Sie kannten auch schon den Glühwein und parfïmierten (». B. Myrhen-) Wein. Das Verzeichnis des $\Lambda$ thenäus von berïhnten Weintrinkern nent den einen .Trichter" nud einen zweiten .Fals"“. Alexander der Grof'se hatte bei einem "Preistrinken" in Indien den ersten Preis auf 4500 Mark (ein Talent) festgesetzt. Das Ergebnis des Wettstreites war, dafs 35 anf der Stelle starben und dafs P'romaches, der Sieger, der 13,1 Liter "Wein vertilgt hatte, nur noch rior" Tiage lebte. Die Griechen betrachteten den Mein als Guschenk des Bacclus oder Dionysos. ditler die Dionysos-lieligion und die Bateclnnsfeste. Yon den Griechen kam der Weinstock zu den Römern. die ihn sorgfailtig anbauten und ptlegten, ihn in Schläuchen und Krï̈gen (amphora) aufbewahrten, in Gewölben abkiihlten und dann in Weinniederlagen (apotheca) im obersten Stockwerk lagerten. Wiihrend der Republik durfte sich der Mann ron der Frau scheiden lassen, wem diese Wein trank, ja Eguatius Metellus tötete seine Frau deshalb und wirde dafuir weder gestraft noch getadelt. Alter Wein war gesucht, Plinius will 200 Jahre alten Wein gesehen und Caligula soll 160 jührigen Wein auf' siner Tafel gehabt haben. Als Cäsal das Volk in 22000 Zimmern speiste, liefs er in jerlem Zimmer жrei Fals Wein ans seinen kellern anflegen. Durch die lïmer erhielt dits westliche wir das mittlere Europar den Weinstock. Yielfich wird angenonmen, dals in Deutschland, an der Mosel und am Rhein (2so Jalure nach Christi) und in Ungarn Katiser Probus die ersten Weinherge anlegen liels. Doch soll der ilteste Weinbau :) in Dentschlinul. soweit nachweishar, nicht schon in der rönischen \%eit, sondern erst in dem \%eitram der anstrasischen liegierung der merowingischen Kö̈nige zu suchen sein. Die älteste noch diıriiber aufbewalnte Urkunde ans

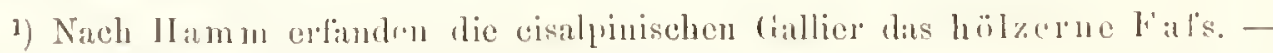

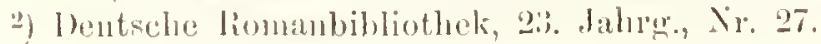




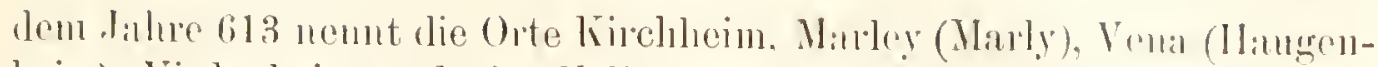

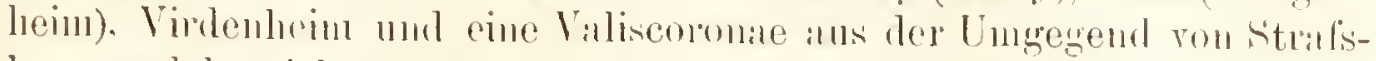
burg, welche sich zuerst mit dem Wemban lesedniftigten. Von hier ans breitete sich der Weinban namentlich in lihein- und Domangebiet

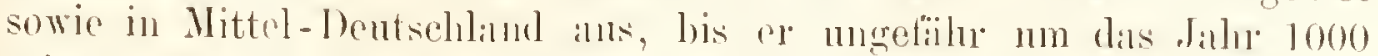
scine grölste Anslneitung in Dentschlinnd crlangre. Das älteste Bild iiber die Art der Rebkultur in friihester Keit in Deutschlann ist eine liandzeichunug anf einer Handschrift des zwölften Jahrhunderts ans Österreich. Lis zeigt die Kultur der Rehe anf Pfïhlen, wie sie unch in einem Teile Österreichs, sowie :m Rhein und im Elsals iilhich ist, und als bei den Griechen gebriuchlich, sich anf dem Srlith des Achilles darstellt, sowie in der Odyssee beschrieben ist. Dills, wie im Altertum, anch zun Zeit des iiltesten dentschen Weinbunes ror dem Keltern die Trauben nit Fiilsen getreten wuden, zeigt ein Verbot Karls des Grofsen gegen diese Sitte in seinen Kapitularien. Die alten Dentschen wandten sich rom Biere all dem Weine zu, so dal's Karl der Grolse, der die Weinkultur zwar förderte, vergehens der 'Trmuksucht zu stenern suchte. Die Apostel der Dentschen halfen die Weinkultur verbreiten. Benediktiner Mönche bebanten den Johnunisberw mit Weinstöcken; der heilige Lienno reranlasste 1073 den Anbau des Weines bei Meifsen, Otto ron Bamberg 1128 in Pommern. In jener Keit war der Klosterwein ror\%iiglich, da die Klöster mehr anf die Ciüte, als auf die Menge des Weines sahen. Auch in Nord-Dentschland, sogar in 'Tilsit und Memel, wurde der Wein kultiviert; aber der Winter von 1437 rernichtete alle Weinberge an der Weichsel. 1421 kim der Wcinbau durch Europïer (Prinz Heinrich der Seefahrer) nach Madeira, nach Teneriffa (durch Alonzo de Lugo), nach dem Kap (168. durch franzïsische Hugenotten), später nach Amerika.

Der Weinstock kann selı alt werden. Plinius erwiilnt selı dicke Weinstöcke. Tozetti fülut in seinen "Reisen in Toskana" einen Weinstock in den Wäldern der Lmgehnug ron Montelamboli an, dessen Stamm zwei Männer nicht umspannen konnten. Im botanischen Garten zu Pisa wird der Stumpf eines durch Sturm entwurzelten Weinstorkes ron 1,6 11 im I mfinge aufluewahnt. Die 'Thliirfliigel der Kathedrale von Ravenna sind ans Weinlolz gearbeitet. 


\section{Tafel 18.}

\section{Fig. 1. Gemeiner Walnu (s baum ${ }^{1}$ ) (.Juylans ${ }^{2}$ ) regia:) I.).}

Auch der gemeine Walnulshan gehört zur den perigonlhiitigen Dikotyledonen (siehe 1. Abteihung S. 67), mul zwal zur Ordumg der Kïtzchentrïiger (Amentucece) und zur Familie der Walnufsge wächse (Jugl(undear) $)^{2}$ ).

Dic Ordnung der Kätzchenträger (Amcntaceré) $\left.{ }^{4}\right)$. Bänme und Strä̈ncher mit eingeschlechtigen Bliiten. Inir St:mbhattbliiten stehen immer, die Stempelhliiten selten in Kïzchen. Die Blïtenhïlle fehlt entweder ganz, oder ist selu unvollkommen intsgehildet, oder es stehen an ihrer Stelle kleine walrenförmige Schiiluchen oder Hare.

Über die Familie der Weiden-, der Hainbnchent. der Birken- und der Gagelgewächse siehe unsere "Repräisentanten einheimischer Phinzenfammilien", II. Ahteihng.

Die Familie der Walnufsgewächse (Juthtundruc). Baimue mit wechselstindigen. muparig gefiederten. nebenhlattlosen

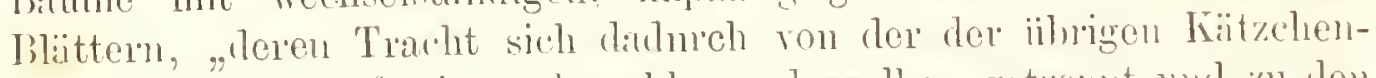
träger entfont. dals sio anch wohl ron denselben getremit und zut den Therebinthinem (hei den l'olypetalen) gestellt werden". Bliiten ainlänsig. Die Stambhatthliiten sind rom einem Derkblatte gentiitrt.

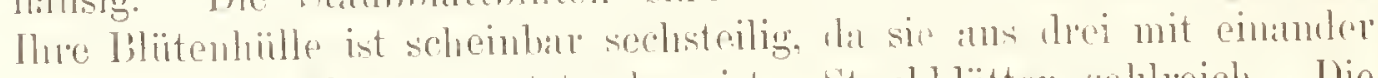

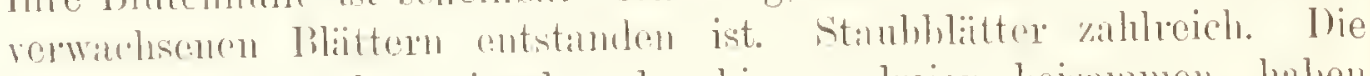

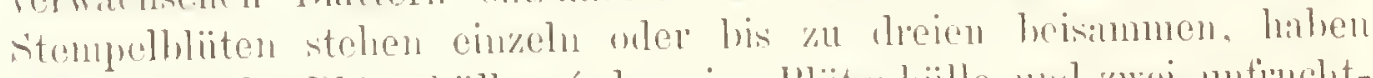

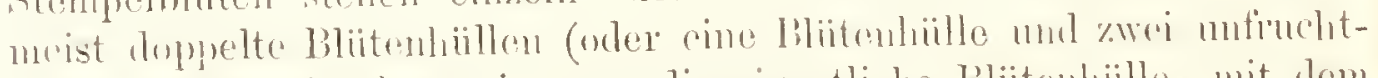

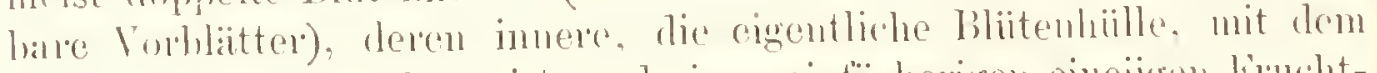

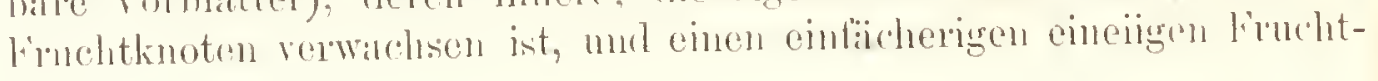

1) Wahuls odre witsche (auslimblische, fiam\%ösche, italienische) Nuls. -

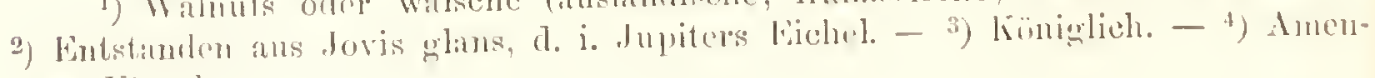
tım, Käitych!n. 
knoten mit zwei Ninben. Die Samenknospe stelit anliresht in Gronde

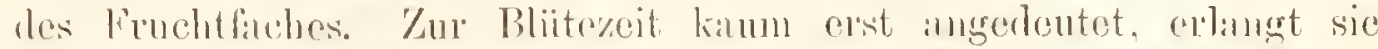
ihre rollkommene Entwickelung erst n:leh der liestïubung. '/nur Bliitezeit sind Scheidewinde norle nicht walnmuehmen. Die frucht ist eine Stcinlreore, deren inlsere Schale zrei- lis dreiklappig rerreifst mud ablfillt, wiluend die Nuls geschlossen bleibt. In Inneren der Nufs finden sich iiherall Scheidewandlitdungen ror, die indes nieminls vollstimulig sind und sich stets in oberen 'Teil der frucht mehr mer weniger rusch in die Aulisenwand zuniickiehon; der Same, der gleichsam cinen Ausgnffs ler Fnchthlöhle rorstellt, wird durch dieselhen nehr order weniger gefureht orer gelippt. Ganz regelmälsig sind zwei von den Verwachsungshinien der F'uehthlätter ansgehende vorhanden, die somit unter den Begriff der echten Scheidewände fallen; diese vereinigen sich stets im unteren Teile der Frucht und hilden dureh dis Zns:mmmenstulsen eine Art Mittelsänlchen, anf dessen Gipfel der Same lefestigt ist. I) Same ist eiweifslos, fleisehig und ïlig mnd lesitzt uncegehülsig zusammengefaltete, rierlappige lieimbliitter. In den tertiören ma ynarternïren Perioden kommen viele Juglansarten anf unserer Ilemisphäre ror.

Die Gattung Walnufsbaum (Juglans L.). Das Nark er-

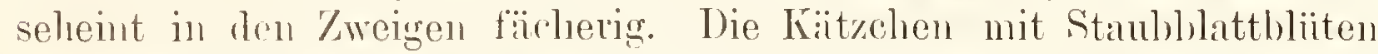
stehen an vorjihnrigen Zweigen, die Stempelbliiten erscheinen in arm-

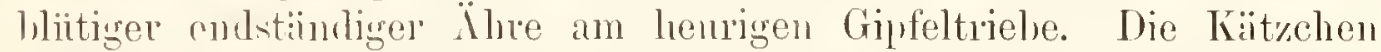
mit Stanlblatthlüten sind sehn reichl,liitig. Sie heginnen mit zwei gegenïlserstehenden Vorblätter'n, auf welehe sofort die Bliitenhiillb)iitter in spiraliger Ordnung folgen. Es werden bald vier, zuweilen fiinf l'erigonlliitter ausgobillet, öfter jedoch nur drei, oder nur zwei. Boi der Stempelbliite ist das Deckllatt l,is ïher die Mitte, die beiden

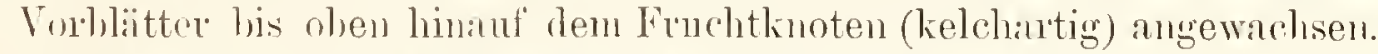
Deckblïttchen, wie Vorl) lättehen verkïmmern spliter.

Fossil kommen Bliitter und Holz dieser Gattung in weiter Verbreitnng in Tertiïrschieliten vor. Blïtter sind anch in den quatemären 'T'uffistrinen der Provence gefunden worden.

Der gemeine Walnu $\mathrm{s}$ sbaum (.Juglans reygia L..).

Der Balum wild 14 bis $27 \mathrm{~m}$ hoch mil 40 lis $100 \mathrm{~cm}$ in $\mathrm{Durchmesser}$ dick. Die jungen $\mathrm{Z} w$ eige sind olivengrün.

Blätter mgleich gefierlert, mit einem dicken, gestreifton unl etwas lehaarten Stiele; Fiederblättchen eiförmig, zugespit»t, am liande meist ungeziilnut oder an der Spit»e loicht gesïgr, kahl, kurzgestielt, his $11 \mathrm{~cm}$ lang und 5,5 cul lmeit, junges lamb rïtlich.

Blüten einhïusig. Staubblattblüten (Fig. al) in langen, lockeren, walzigen, gribuen, viohliitigen $\mathrm{K}: \mathrm{i}$ t\%ehen, mit zwei gegen-

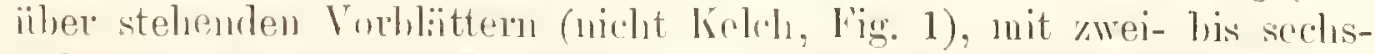

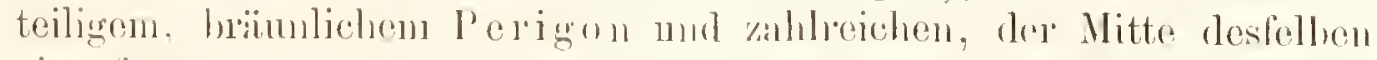
eingreliigten Staubblättern (Fì. 3) mit sch. ku\%en staubfäden 
mm hrïmlichen staubbeuteln. Stempelblüten (Fig. ら)

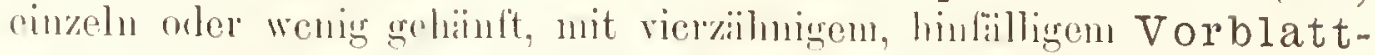

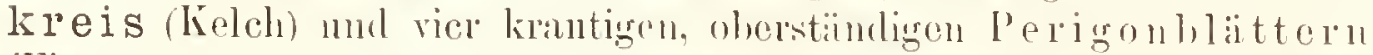
(Fig. 5hl und Fig. (; hl1, bl2), einem sehr kurzen Griffel (Fïg. 6) und zwci griingelhen, winzigen, riickwärts mngeloggenen Narben (Fïg. $5 n$ nnd Fig. 6n); Frnclitknoten (Fig. 5f) eiförmigr, driisig behaart. Samenknospen (Fig. 6s).

Steinfrucht (Fig. T) rundlich, etwas zangespitzt, 5,3 cm grofs, von einer dicken, erst griunen, zuletzt olivenbramen Schale $11 m$ schen, dic unregelmïlsig anfspringt mul cinc awciklappige, heinharte, lunzlige und gefurchte steinschale (Fig. 8) hat, die eincn gelappten, von einem gelblichen Häutchen umgebenen wulstigen, wohlıschmeckenden Samen orler Kern (Fig. 9 u, 10) umschliefst. \%wischen der äufscren und der Steinschale liegt ein gelbes, zierlich geschlitztes Gewebe (Fig. 8).

Die Nufs wird durch die Keimung des cingeschlosscnen Samens regclmälsig in zwei Hälften zersprengt.

Blüht im April und Mai.

Vaterland: Persien mol Hochland /entral-Asiens, Nordablï̈nge des Himalaja. Verbreitungsbezirk: Aufser jenem siidliches und mittleres Furopa, badensches Oberland, Schwciz (in den nördlichen Alpen bis $800 \mathrm{~m}$, in den siidlichen bis $1100 \mathrm{~m}$ linaufreichend), Piemont, Savoyen, gemälsigtes Ost-Europa bis Japan und Nord-Amerika, aufserdem Süd-Kalifornien und Clile. Er kommt wild wachsend auf den Gebirgen Griechenlands und denen des Banats vor. Der Watnufsbaum iilerschreitct (Schleswig) kaum die Nordgrenze der Weimebe nnd geht nach Siiden viel weniger weit vor.

Kultur. Der Walnufsbanm ist empfindlich für schroffen Witterungswechsel, zumal zur Zeit des saftanfstiegs im Frülijilnr. Wo aher das Kilima von diesem schroffen Wechsel frei ist, verträ̈gt der Bam einc beträichtliche Kälte. Wird ilm nur eine geniiggende Feuchtigkeit im Boden (kein Grundwasser) gegehen, dann loleibt ihm die Fenchtigkeit der Inft riemlich grleichgiiltig. Zum Anılan fïr nördliche Cregenden sind spaitblïhende Spielarten auszuwählen (\%. B. Scrotina, anch St. Johanniswahnufs genamnt, Proeparturius, forncr die spüte P'oeparturins). Fiur die halhtropische Zone grilt es, dals der Ansat\% und die erste Entwickelung der Frucht in das fouchte Friilijalır laillt. (Gant-oder Bijou-Walmufs, Parisienne eignet sich aufserden wic die Mésange und Bartlerc auch fiir warme Gegenden der gemïlsigten Zone, Claberte.) Zun Anbau fiir die wïmeren Gegenden der gemäfsigten \%one sind andser der Parrisienne mul der Mísange die 'Traubenwahnuls und dio Franquette zu enplehlen. Es kïmnen zwar alle Sprelarten als Wildlinge geziichtet werden, doch niissen solche, die zur Ausintung geneigt sind, reredelt werden. Wo num anf dic Veredelung der IBimme veraichtet, vermehrt man den Walnufsbaum 


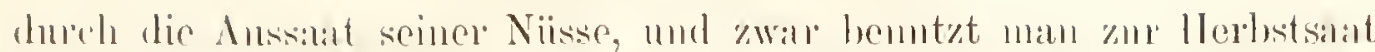

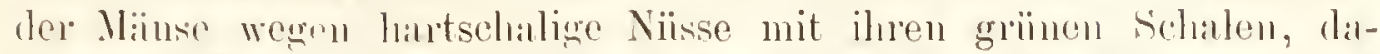
gegen in friblijahr woichschalige. Man kann anch die Niisse in Sand keimen lassen und sio dinn in die Bammsehulen verpflanzen. Der Bamm nimment mit dem geringsten boden vorlieh. Wie der Mahagonihanm (I. Ahteilung S. 165), so grobt anch der anf steinigen Anhöhen

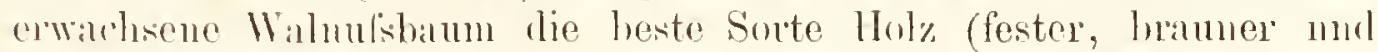
atcriger). wïluend der in lohmigem oder mergehigem Theflande sediehene zw:ar schneller und grö́ser wïchst, aher leichteres mud grofsporiges Hol\% liefert. Üherhaunt kommt der Bam in nördlich geleacnen Lïulcru (Deutschland) hesser aut Auhöhen und Bergen, als in der licfe fort, wo er leicht rom Frost leidet. In nördlichen Läindern ziindlet man hei starken Frösten Ranchfener von Lohe und Spänen unter den Bïunen an. In die Gïiten pflanst man ihn nicht, wegen sciner weiten Imwuzelung, wegen seines stark verbreiteten Schattens und wegen seiner schädlichen (?) Ansdiunstung. Gewöhnlich \& his 10 . Talne nach der Aussiant tritt die Tragharkeit des Baumes ein, die his zu scinem 40. his 50. Talne währt. Nan läfst die aligenommenen Niisse auf Stroh gelegt so lange nachreifen, bis sie gut ron den Schalen gehen. Dis Schwarzwerden der Hülsen schadet der Schale und dem Kierne, weshalh nan die Nüsse in wames Wasser weicht, nit einem stumpfen Besen durcharbeitet und dann trocknen liifst, wodnch sich die schwarmen Flecken meist verlieren. Wirft man die Niisse feucht anf Hanfen, so werden die Kerne schimmlig. Die Nüsse, die eingelegt werden sollen, nimmt man im Juli von dem Bamme, wemn sie noch so weich sind, dafs man sie mit einer Nadel durchstechen kann.

Gehalt der Nüsse, der Blätter und der Rinde. Der Kern der Nufs ist mit einer schmutzig-gelhen Hant umhiillt, welche einen hitteren Geschmack hat; ist dieselhe entfernt, so schmeckt der Kém suils. Der reife Kern cuthält 40 bis 70 Prozent fettes, geruchloses, hafs-gelhliches ÖI ( $\mathrm{NuCsöl),} \mathrm{das} \mathrm{von} \mathrm{sehr} \mathrm{mildem,} \mathrm{an-}$ genehmem Geschmacke ist, erst hei $-27^{\circ} \mathrm{C}$. erstarrt, ein spexifisches Gewicht rom 0,9260 hat, weiche Seife liefert, an der Inft leicht ranzig wird mul schnell austrocknet. Wregen dieses (O) gehaltes sind dic Nïsse schwer zu verdauen, beförder'n aber wie der Kaise die Verdaumng anderer Speisen. Aufserlem sind in dem Kern noch Wasser, Eiweifsstoffe, Stïrke nud Dextriu. Rohfaser und mineralische Bustundteile cnthalten. Alle grünen krautigen Teile des Bames zeigen hosonders hein \%erreiben einen starken aromatischen Geruch und schmecken hitter. schisf und herl. Rinde und Holz enthalten eine Latuge, weshalb der Bamm selten krank wird und wenig ron den Insckten \%u leiden hat. Die gröne Walnursschale fïrbt beim

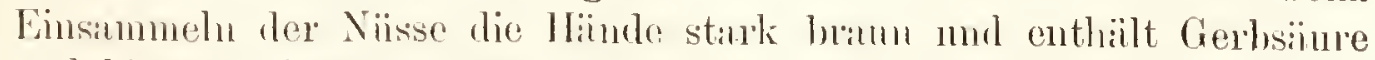
und hitteren Extraktirstofl. Der Saft des baumes cuthailt /aucker, 
dow ist cine Znckergewinumug $11 m$ dit möglich, wo wïhrend des

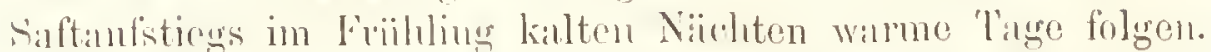

Das Holz des Nufsbaums. Farle des hreiten splintes

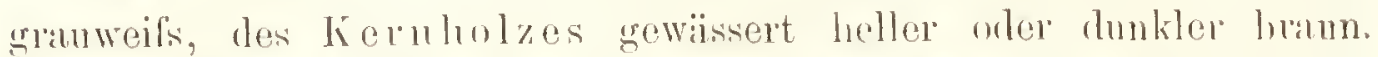
Poren einzeh. Markstrahlen kiam sichthar. Markröhen 3 his 6 mm hreit, Mink gefichnert, ist sehr fest. sehwer und fein gefïgt, leicht spaltbar, soln danerhaft im Trucknen, wirl von den Wiirnern (nur das Splintholy) nicht zerstiort, schwindet, reilst und verwirft sich wenig. ist schön hell- und dunkelgemasert, -geflammt mul-gefleclit, was hesomder's nach der politur prïichtig hervortritt. Wird immer leller (Mahagouiholz immer dunkler). Das Holz junger läane ist weifs, weich und nicht hrauchbar.

Nutzen des Baumes. Der Wahunsham gehört in Folge seiner schönen, grolsen krone zu den hosten, schattenspenderden Bïmmen nud wird leslahl, auf iffentlichen Plitzon, Nlleen etc. angeptlant. Fr ist der König unter den Obstbäumen und seime reifen $\mathrm{N}$ üsse sind ein helichtes Olst. Die mmeifen Niisse finden Verwondung zu P'ickols und Ketschup (gewiirzhafte, dickttiissige Briihe als Beigahe zu Fleischspeisen), auch werden sie nit Zucker cingemilcht gegessen und lieferu mit Zncker und Bramntwein den sogenanniten Nufsliqueur. Ian thut sie mit den Sulaten als Gewiir\% mud z.un Branufirben in das Pllanmenmus. Die reifen Kerne sind ein vollkommenes, aber schwer verdauliches Nahnungsmittel. Mit den mit Silber - und Gollblättchen helegten Niissen schmückt man den Weihnachtsbaum. Blïter siml offizinell (Skrotulose). Die zeryuetschten Blätter werden zu grewiirzhaften Brülıen für Gärhottiche 11 . s. w. rerwendet; zwischen Kleider gelegt, rerhindern sic dis Auftreten ron Motten. Die griinen Schrilen, die unreifen ganzen Frïchte und die Biatter werden in der Apotheke zu Abknchungen und Fxtrakten verwendet. Aus einer Abkochung der libitter, Rimde und rorziinglich der griuen Fruchtschalen (Leifol) mit Alamn bereitet man eine hranue Farbe zum Fïrben von Holzwaren und Wolle (Hite), und durch Zusatz. ron Orlean und Plauhol\% gewimen die Tischler die Nufsheize darans. Die innere harte Nufsschale wirl zu Tusche und Druckerschwärze verarbeitet. Man schiit/t Pferde vor Miicken mul Stechfliegen. wenn man sie nit einer Alkochmng der Bhïter wäscht. Das Nufsöl ist uffizinell, wird aufserden zur Verfïlschnng tenerer Öle. als Bremö̈l, zu Seifon, wie zur Bereitung sehwarzer I) ruckfirnisore beuntyt. Das Holz eignet sich vor'miiglich fiir 'Tischler, Instrumentenmacher num Biichsenschaifter. Die darrans gefertigten Mähel lï̈nen mit den Malkagonimiobohn in Fileganz nund Dancrhaltigke it wretteifern.

Warenkunde (siche ohen "(iehalt"). Es giebt iiber 50 Spielanton des Wilnulshalumes, dic wieder in longende Hanptarten eingeteilt

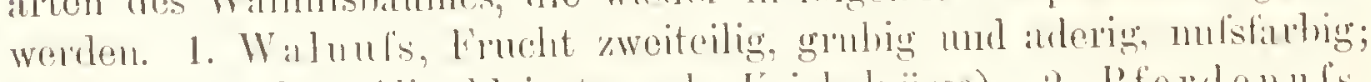
frnchthiille glatt (die kleinsten als Krichehuiisse). 2. Pferdenuls, 


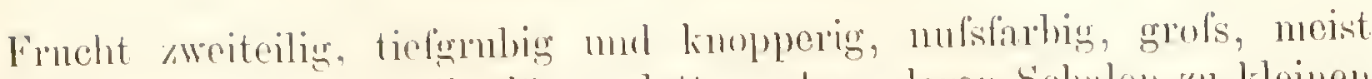

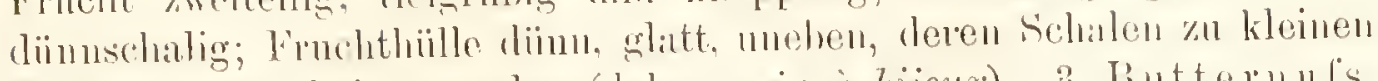

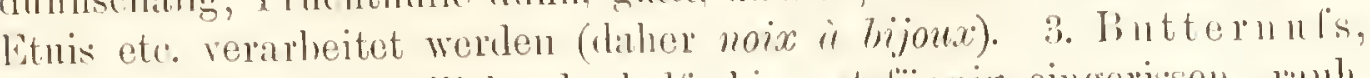

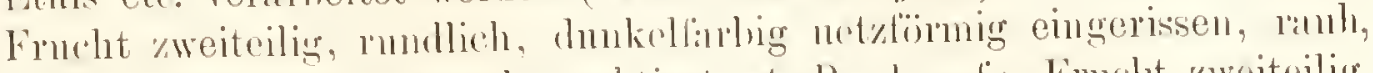
steinhart; Fruchthiille rauh punktient. 4. Pechnnls, lancht zweiteilig, lïnglich, dnukelfarlig, muzlich und tief gefureht, stemhart; Fruchthiille harrig und kleberig. 5. H ickorynufs, Frucht vierteilig, weifs. 6. Olivenunls, Frucht rerteilig, haun. 7. Die T'ranlenwalunles, mit hreiten Scheitel, wird in Frankreich und Kinliformien geziichtet. Die Riesemmls, \%ur ersten (iattung gohiorig, wird his 10,5 cm lang nud 7.9 c'm lorit.

Dats Hol\% des amerikanischen schwaryen Walnufshumes (Jugluns nigno) iilertrifft das des gemeinen Walunlshammes.

Der Kankasus und die persische Proviu\% Gilan führeu viel Ninfshaumhol\% ans.

Angaben über den Handel. Kaschmir und andere Thïler des II imalaja decken den heträchtlichen Bedarf Indions an Walniissen. Aus Persien, wo die Bevölkermug der Wahnusbaumkultur eine besmulere Aufmerksankeit znwendet, findet aus Mangel an billigen Verkelursmitteln eine Ansfinlu nicht statt. In Spanieu und Frankreich werden auf den Ahhängen der P'yrenien grolse Massen ron Wahiissen erzeugt. In Frankreich zeichnen sich anch noch die P'rovence und die Alpenablïuge aus. Die Walnufsernten betragen in Frankreich durchschuittlich im Jahre 1600000 Neterzentner im Werte von iiber 20 Mill. Mark. Marseille allein fülnt für 3 Nill. Nark Niisse in Jahre, das Departement Savoie für 350000 Mark Walnul'sbaumlol\% ans. Im Departement Lot sind 32000 ha mit Wahnufsbïmmen bepflanzt, im Departement Dordogne 4000 ha und in Departement Loire 5000 ha. Italien bringt an der Riviera und in Sizilien vorzingliche Walniisse hervor, Österreieh in siid-Tirol und Istrien. In Deutschland ist die Erzeugung von Walunissen nur an der Berystrafse und im Elsals ron einigem Beling. England baut in allen siidlichen Grafschaften Wahuïsse, anfserden besonders in Kent Haselnïsse. Die Eryengung von Walnufsöl in Frankreich soll den fünften Teil der Olivenölerzengung hetragen und in der Steigernng begriffen sein. Chile fiihrt jiilndich Walniisse im Werte von etwa $700000 \mathrm{M}$ : 1 k meist nach Nord-Amerika aus, aus Siid-Karrolina hetrïgt die Ausfulur an diesen. Frïchten iiber $550000 \mathrm{~kg}$ in Jahne. Wohl in keinem Lande werden su viele Nïsse zum Nachtische gegessen wie in Fugland. Es liihnt im Jahre (anfser 61055 Bushels IBirnen, 48000 Bushels Pilammen, 57048 Bushels Kistinien und 195.7 Bushels Tramben) 68363 Bushels Walnuisse ein.

Geschichte. In Indien ist der Walnufsham ron alters her angehaut worlen, moh kennt miun einen Simskritnamen Akschôdiı,

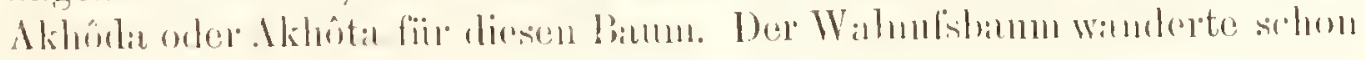


in Altertume aus seiner Heinat Persien naeh dem Westen. Fs ist indes nicht genau naehzuweisen, wann er naeh Italien gekommen ist. Sichr. ist. dafs die Frueht in der römisehen Kaiserzeit ron Kastanien und Mandehn unterschieden wurde, wihnend in frïherer Zeit die Namen dieser drei linchtarten olt verwechselt wurden. Schon die IBibel (Hohes Lierl: c; 10) erwïhnt Nufsgiirten und Nufshïume. Am Sce Genezareth wuchsen ehemals die Bäume wild. Nebst allen Eieheh tragenden Bäunen war der Nufsham dem Zeus heilig (Juglans-Joris glans, 1. h. Jupiters Eichel). Wïhrend der Nufsernte hegingen die laeedïmonischen Jungfranen ein lest (Karyar) zu Ehren der Artemis Karyatis. Auch galten Walniisse bei den alten Griechen als Symbol der Fruchtbarkeit mul Munterkeit. Cieero erzählt, dafs sieh der Tyrann Dionysius der Ältere von seinen Töehtem den Bart mit glühenden Nufsschalen habe ahbrennen lassen. Die Dentsehen schmiicken ihren Weihnachtsbanm mit Niissen. In der siidlichen Krim fand A. v. (irimm einen Nufsbaum in Thale Baider bei Balaklava, dessen jährlieher Ertraø anf 70000 bis 80000 Nüsse berechmet wurde. In der Grafschaft Norfolk in England steht ein Wahnufsbaum. dessen Stamm ann nnteren Teile $10 \mathrm{~m}$ Unfang hat und sieh bei $3 \mathrm{~m}$ Höhe in fünf Hanntiiste teilt, die $5,4,39,2.82,2,51$ und 2,51 m Dicke im Umfing liesitzen. Der Baum ist $28 \mathrm{~m}$ hoeh und hat einmal in einem Jahre 54000 Nüisse getragen.

Audere Arten: 1. Der schwarze Nufsbaum (Jugluns nigra L.) 1). Östliehes Nord-Amerika und Texas, wird ïber $45 \mathrm{~m}$ hoch, liefert vortreffliehes Holz (siehe oben) und geniefsbare Früchte. Wird bei uns, wie aneh der fulgende, als Zierhaum angeptlanzt. 2. Weifser, Butter-oder Ölnu fsbaum (J. cincrca? ${ }^{2}$ L.). Kiulada, östliche und mittlere Staaten Nord-Amerikas. Liefert vorziigliches Nutzholz. In Massachusetts verarbeitet man den Sift auf Zucker. Die Rinde wird als abfithrendes Mittel benutzt. 3. J. rupestris ${ }^{3}$ ) in Nevada. Arizona und Nen-Mexiko ist dem sehwarzen Nufshaum :ihnulich, liefert aber kein gleich wertrolles Holz. Dieser Art :̈lnulieh ist der Kalifornische $\left.\mathrm{Nufsbaum}(J \text {. culifornica })^{4}\right)$, wïchst zwergiger und hat eine liingere Frucht als die vorige. 5. Der Traubenwalnufsbaum (J. racemosa $)^{5}$. Die Niisse geben in der Grölse den edlen Wahuïssen nieht viel nach, sitzen zu 8 bis 15 . zuweilen his 20 in Bïschelı, welehe in Durehschnitt $18 \mathrm{~cm}$ lang und $8 \mathrm{~cm}$ dick sint.

1) Schwar\%. - - Aschgrau. - 3) Felsig (Standort). - t) In Kalifornien. 5) 'lraubig. 


\section{T a fel 19.}

\section{Maronen-Kastanie (Castenec $\left.{ }^{1}\right)$ vesca ${ }^{2}$ ) Gürt.).}

Anch die Maronen-Kastanie gehört zur Ordnung der Kätzchentrïger (Amentaceae, siehe S. 136), und zwar zur Familie der $\mathrm{Näpfchenfrüchtler} \mathrm{(Cuputiferae).}$

Die Familie der Näpfchenfrüchtler (Cupuliferce)?'). Holzgewïchse, meist Bäume nit ahwechsehnden, einfachen Blättern, hinf:̈̈lligen Nebenblättern und einhänsigen Bliiten. „Die Staubfadenhlïten stehen in Kïzchen beisanmen und besitzen keine, oder eine rier- bis fünfspaltige Bliitenhiille und fünf bis zehn, dieser Hülle orler den Deckblättern eingefïgte Staubblïtter mit ungeteilten Füilen." Die Stempelbliiten bilden endständige Küitzchen. oder stehen einzehn oder z.ı wenigen bïschelförmig gehäuft. Ein unbedeutendes, später nicht mehr wahmehmbares Perigon unsäumt den nuterständigen Fruchtknoten. Dieser hat zwei bis sechs Narben, bis sechs Fächer und in jerlem derselben eine bis zwei lï̈ngende Samenknospen, deren jede zwei Samennintel besitzt. Die Schliefsfrucht hat eine leder- oder holzartige Schale, ist in der Regel durch Felılschlagen einfïcherig nud einsamig und "an ihrem Grunde ron einer becherartigen Hïlle (cupula) 3) ungeben, oder ganz darin eingeschlossen (Buche). Dieses Fruchtnäpfechen geht hier aus einer unterstiindigen Scheibe und nicht ans einem blitt der Bliitenliülle liervor, wie dies bei den Carpineen der. Fall ist ")". Samen eiweifslos, mit grofsem Keimling und dicken fleischigen Samenlippen.

Die Gattung Kastanienbaum (Castancae Mill.). Bïune nnd Sträincher mit grol'sen, elliptischen, gesïgten Blättern. Die Blïtenstände erscheinen in den Plattachsehn heuriger Triebe. Die Bliiten sind zu Köpfchen gehäuft an besonderen fadenförnigen oder an gemeinsamen Stielen. Die zwei oder drei glatten, auf der einen Seite konvexen, auf der anderen flachen Friichte werden von einer mit stehenden Borsten besetzten Fruchthiille eingeschlossen.

1) Siehe „Geschichte". - 2) Von esca, Speise, mit der Verstärkungspartikel ve, also gut efsbar. - "3) eupula, Nälfchen-oder Becherhïlle - ferae, tragende Gewäclise. - ${ }^{4}$ ) 'T'homé. 
Die Maronen-Kastanie (c'ustuner vescu (iairt.) reichnet

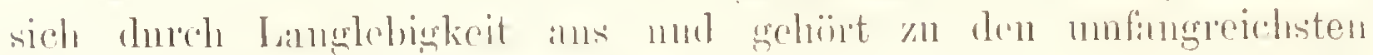
biimmen der Este. Der lianm wird 20 ) his $24 \mathrm{~m} \mathrm{hoch} \mathrm{und} \mathrm{t;0} \mathrm{his}$ $100 \mathrm{~cm}$ in Durchmessex dick, in Alter olt anch ruch stïliker.

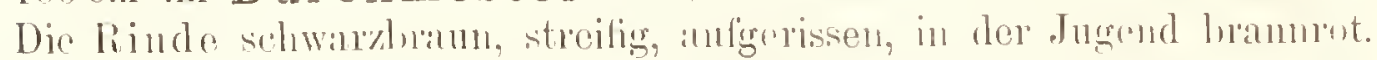
Äste stehen alwechselnd mul spitzwinkelig in die Höhe, Krone schëı, stumulf-kegelfirming.

Blättel wechsolstiundig, 14 his 20 cm ling und 5) his 7 cm hreit,

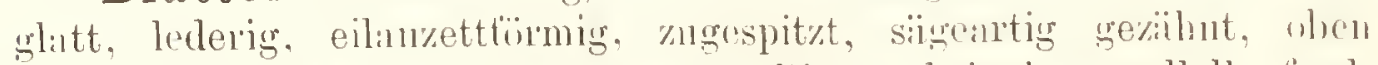

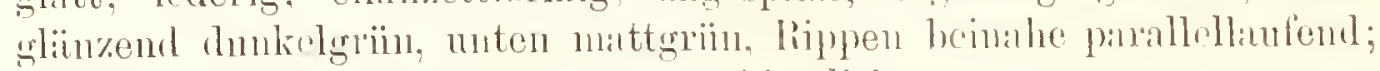
Nebenblätter hinfillig, schnalpfricmlich.

Kïtzchen mit Staubblattblüten (Fig. 1 a) in den liattwinkelu sitzend, 8 his $11 \mathrm{~cm}$ lang. locker. fatlentiormig, gelhlich, wilerlich riechend. Einzelne Bliitchen (Fig. 2) ungesticlt, greküunlt; Perigon glockig mit fiinf his sechs hall-eiformigen, spitzlichen Sinmlippen, an denen je zwei staubblätter mit zweificherigen, lïngsspaltig aufspringenden staubbeuteln sitzen. Die Stempelblüten (Fig. 1b und Fig. B) hestehen ans einem Krans. stacheliger, mit einander zan einer Inille rerwachsoner Blitter, auf deren Heischigem Grunde sich einige Bliiten hefinden. Diose hestehen ans eincr krmgförmigen, nit dem Fruchtknoten his an die sechs his acht Narbenschenkel rerwachsenen Hiille, wischen deren Zipfehn sich winz kleine verkiimmerte Staubblïtter zaigen. Die gegen einaluder dreikantig abgeplitteten Fruchtknoten hestchen gewöhnlich ans sechs Fruchtblïttern in zwei dreizilhligen Kreisen. Die Fïcher der Fruchtknoten sind zweieig, die Samenknospen läingend. In der Reilc wird meist nur eine ron allen ansgebildet.

Frucht, eine mit spitzen Dornen besetzte Becherhiille, die drei bis vier lederintige. germulet spitrige Niisse (Kiastanicn, Fig. 4, 5 u. (i) einschliefst und später vicrklappig ans cinander geht nnd den lnhalt ansfillen lälst.

Blüht im Nari, die Blätter lnechen sprïter aus.

Vaterland: Nittleres Asien, nach II ho n mittleres Kleinasien. Nan hat sie anch anf don Gehirgen ron kilough in Mgerien and an den Grenzen von Thuis getintulen. Verbreitungsbezirk: Aulser jenen in Portugal, Spanien, Siid-liankreich (l'rorence und Langnedoc), Italien (mugirtet in prachtoulden Lxemplaren den Kegel

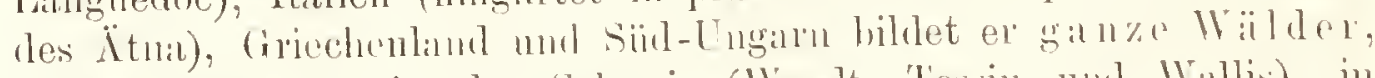
kommt anch vor in der Schwei\% (Wiardt. 'Tessin und Wallis), in

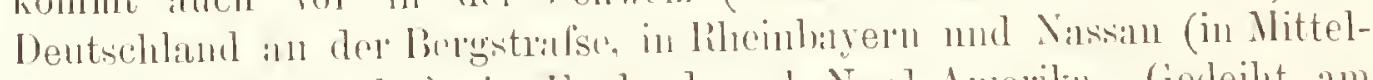
dentschland ortraghes), in Lingland und Nond-Amerikit. Ciedeiht am

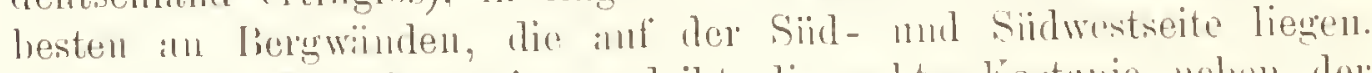
/un liesen der Vegetation gedeiht die echter Kastanie neben der Plitane in West-Asien. Die grolsen, vielgeteilten Wurchn (uhne eigent-

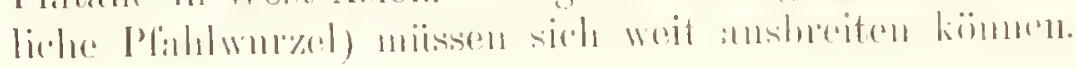


Die $\mathrm{Kultur}$ des Kastanienbanmes ist derjenigen des Wahmfsbanmes ïhnlich, die Verodelung der Wildlinge ist weniger schwierig. In wilden Zustande liefert der Bamm Firichte, die zwei oder drei kleine, durch Hänte getrenute Samn enthalten, aber geringen Wort hahen, da sich bei ihnen die Anshildung mehr auf das Hol\% und dats Wichistum wendet.

Gehalt der Früchte. Die Kinstunien oder Maroncn stohen in ihrem Nilhmugswerte dem Getreide nicht viel nach. Sie enthalten 1.71 Proz. Lett, 37,76 Proz. Stärkemehl. 23 Proz. Dextrin, 17,67 Proz. Zueker (im siidlichen Frankreich bis 23 Proz.), 7,45 Pro\%. Zellstoff, 9 Proz. Proteinkärper und 3,15 Pro\%. Asche. Die frischen Rerne enthalten 1,47 Pro\%. Asche, in weleher Kali, Phosphorsäure und Rohlensüure iiber 80 Pro\% betragen.

Das Kastanienholz hat viel Ähnlichkeit mit dem Eichenund dem Nulsbaumholz, nur gehen ihm die breiten Markstrihlen des letyteren ab. Altes Hol\% kimm im Aussehen un sehr schwer ron Eichenhol\% muterschieden werden. Fis ist ziemlich fein, gliinzend, nit hellbramem Kern und gellhich-weifsem Splint, dabei riemlich leicht, aber schön und diinnschupligg spaltend und rerspringt nicht. in der Jugend weifs, wird es im Alter rotbrïunlich, nach dem kern yn dunkler und meist geflammt. Es riecht stark nach Gerbstoff. Im Freien besitzt das Holz nur geringe Dauer, im bestinndig fenehten Ramm ist es dagegen sehı' danerhaft, noeh mehr in 'Troeknen. Der Splint wird bald von Insekten zerstört.

Nutzen. Fast alle T'eile des Bammes sind niitzlich zu verwenten.

1. Die Früchte, siilsen Nüsse (Schalenobst) oder Naronen anch italienische oder welsehe Kastanien genannt, sind in Sïd-Europar so sehr zur allgemeinen Volksnahrung geworden, dal's man in Frankreich die Trägheit der Korsen ihren Kastanien zugesehrieben und deshall, den Untergang dieser Bïume gewinscht hat. Besitzt eine korsische Familie nur zwei Dutzend Kastanienbämme, dazn eine Herde Ziegen. die das ganze Jahr hindureh frei weidet, so sind alle Bediirfnisse gedeekt. Ehenso ist es im rauhen italienischen Apemin. Die Kastanien dienen zerschnitten und geröstet zur Bereitmug eines chokohale:ihnlichen süfsen Getränkes, das dem Bohnenkaftee ähnlich riecht und sehmeckt und als gutes Ersatzmittel des Kaffees gelten kann. TTm die Maronen danerhafter $\%$ machen, trocknet man sie entweder auf Flechten drei 'lage an der Somne und schïtrt sie des Nachts vor Tau, oder man begiefst sie, un ihre Keinkraft zu zerstören, mit siedendem Wasser und trocknet sie wieder ah. Sie miissen sehr sorgfältig anfhewahrt werden, dic sie sehr leieht schimmehn und ihnen Insckten, Ratten und Mïuse nachstellen. Vor dem Verspeisen quelt man die Kastanien in Wasser auf, kocht sie mit Salzwasser und bereitet sie zu einem Mehlbrei zu. Nam bereitet anch aus Ninmenmehl mit Woizemmehl ver- 
mischt Backwerk, Brot, Brei, Klifse mit Milchsuppen, Strirke. Puder; man ifst die Maronen roh, gekoht, iiberznckert. Anch bilden sie als Zuspeise zu kohlantigen Goniisen und zu Füillsel gehratenen Federviehs einen nicht mulodeutenden Handelsartikel. Dic Frichte liefern unter der Presse einen zurkerhaltigen Saft, welcher leicht in Weingäirung iibergeht. Anch kann ein krimeliger /ucker darans gewomen wriden.

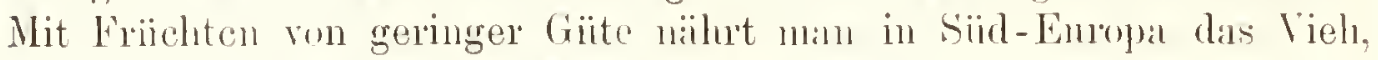
welches ein schnncklafter Fleisch daron erhält.

2. Dis Holz wird zu T'ischler- und Drechslerarbeiten, als Banholz, ‘nn Schiffban nnd \%n Weinfïssern benutyt. Der gröste Teil des Holzwerkes der alten Gebände Londons, sowie von P'aris und anderen Stïdten, besonder's des siidlichen Europas, besteht ans Kastanienhol\%. Dits branngemaserte Wurkelholz wird ron den Drechslern und Kunsttischlern zu den feinsten Arbeiten verwendet. Die jungen Zweige benutzt man in Frankreich zu Reifen für Weinfüsser. Junge Kastanienbämme sind zm. Verwendnng als Hopfen- nud Spalicrstangen sehr greschätzt. In Saroyen bereitet man ans Kastanienholz Ciallussinne in gröfserem Nafsstalie. I)as Kastanieuholz taugt nicht gut zum Verbremen und Verkohlen, da es springt, knistert und zn schnell wegbremt.

3. Die Rinde wird zum Gerben benutzt, ist aber nur lialb so viel wert als Fichenrinde, sie giebt fermer, zu Kohlen gebrant, eine schöne schwarze firbe.

4. Dic Blätter stopft man in Matratzen, die dimn bein Unwenden rauschen, weshalb man sie in Frankreich Sprech-oder Parlitmentshetten nennt. Endlich dient der Kastanienbaum

5. als Zierbaum.

Warenkunde. Der echte Kastanienbaum lat eine grofse Anzahl von spielarten. Die grolsen, kugeligen Frïchte, dic man vorzugsweise Ma ronen nemit, sind (die Marons de Lyon aus Lingueloc und der Provence) lie greschïtztesten. Die Zwiebelkastanien simd ron rundlicher, aufgetriebener Form. Die ghatten kleinen Niisse neunt nuan schlechtweg Kastanien. Die Friichte des nicht kultivierten Baumes sind viel kleiner und wenig schmakhaft.

Der Verbrauch der Minronen ist in den Produktionslindern ann hedoutendstin, denn sie bilden dort hesonders fiir die nntersten Volksklasson durch mehrere Monate himlurch das hauptsïchlichste, manchmal das ansschliefstiche Nahrungsmittel. Bei uns dienen sie melı als Delikitesse.

In Italien hetr:ingt die jühliche Durchschnittsernte 323 Mill. Kilosramm Friichte, sie wird anf einer Gesanttliche ron 200000 hal el\%engt. Die I'rovin\% L lnceal widnet $181 / 4$ Prow. ilures Bodens der Kastanienkultur. Von der Gesanternte werlen 4 Mill. Kilogramm im Worte ron 2 Mill. Inark anserefihnt. Frankreich er\%engt jïhlich rund 390 Mill. Kilo-

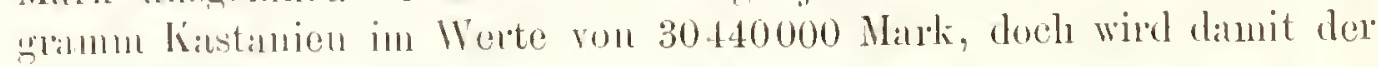


cigene Bedarf nicht vollstiindig gedeckt. In Departenent Sarthe wird die Jalnesernte mit $1200000 \mathrm{Mark}$ bewertot. In Departement Dordogne komnt der Linteüberschuls iu Werte ron 800000 Mark zur Versendung. In Corèe sind $60000 \mathrm{ha}$, in Korsikin der Iritte 'l'eil der Wälder mit Kistanienbänmen bepflanat. In weiteren 20 Departements wird die Kastanienbaumknltur in bedentender Ausdehung betrieben. Frankreich fïin't durchschnittlich S Mill, Kilogramm Kiastanien ans, empfïngt aher aus Italien Kastanien in Werte von 1500000 Mark nud aus der Tiirkei bezieht es 9 Mill. Kilogl:anm Kanstanien nud Kastanienmehl. Paris rechraucht jïhrlich 6 Mill. Kastanieu. England bezieht jïhrlich etwa $1432000 \mathrm{~kg}$ Kistanien.

Geschichte. In der römischen Kaiserzeit kannte man den echten Kastunienhanm, die Frichte werden znerst von Vergil (Ecl. 2, 52) Kastanien gen:unut. Man nimmt an, dafs der Name der Gattung mul der Friichte von der Stadt Kastana im alten 'Tessalien herriilıre, wo der Bann hïutig wild rorkan. Der grölste Kastanienbaum der Welt ist der an Ätna. Er lat über der Wurzel $60 \mathrm{~m}$ im Umfange. Nach anderen Berichten soll er ans mehreren, iiber der Wurzel verwachsenen Stämmen bestehen. Man nemnt ihn Custagno de cento cavallo. d. h. der Kinstanienbaum ron 100 Pferden, weil 100 Pferde nnter seiner Krone im Schatten stehen können. Der Sage nach soll der Baum schon vor 300 Jahren so grofs gewesen sein, dafs, als die Königin von Aragonien nach Neapel reiste und von da aus den Baum besuchte, hundert Rieiter in dessen Schatten Platz nehmen konnten. Nach der Zählung ron 1860 stehen anf den öffentlichen Plïtzen in Paris 148000 Kinstanien als Zierbäume. Ton ihnen war einer im Tuileriengarten unter dem Namen „Kastanienbaum des 20. Närz (Marronicr du 20 Murs)" beriihnt, weil es ein gliickrerheilsendes Zeichen fiir die Fanilie Bonaparte sein sollte, wenn der Banm jährlich am 20. Mïrz schon Blätter hatte. In England giebt es einige Kastanienbäume von ungeheurem Umfange.

Der Rolskastiuienbaum gelı̈̈rt nicht zu dieser Gattung.

Von den zahlreichen anbauwirdigen spielarten seien besonder's Marron de Lyon (Fig. 5) min Marron Combale (Fig. 6) hervorgehoben. Marron de Lyon gilt als die gröfste Spielint und als eine der vorzüglichsten. Die Frncht ist rumdlich, siil's mud aromatisch. Iarron Combale ist nicht ganz so grofs wie die vorige, steht ihr aber in Rezug auf Schmackhaftigkeit ebeubuirtig zur Seite. 


\section{Tafel 20.}

\section{Indigo pfla nze ${ }^{1}$ ) (Indigofera ${ }^{2}$ ) tinctoria $\left.{ }^{3}\right)$ L.).}

Die Indigopflanze gehört zur Unterklasse der getrenntblätterigen Dikotyledonen (Elentheropetalar, Polypetalae, siehe I. Abteilung S. 24). zur Reihe der Kelchbliitigen (C'alyciflorae, siehe 1. Alteilung S. 80), zur. Ordunng ler Hiilsenfrüchtigen (Leguminosae) ${ }^{t}$ ) und zur Familie der Schmetterlingsblütigen (Papitionaceup) i).

Die Ordnung der Hülsenfrüchtigen (Lerpminosuc). Blatter meist abwechsehnd, zusammengesetat und mit Nebenblättern versehen. Die Knospenlage des Kelches ist eine dachziegelförmige order klapplige. Der Kelch ist zweilippig, füntspaltig oder füntzähmig (selten vierteilig). Die Blüte hat meist so viele Blmnenblätter als Kelchippel; Staubblätter sind wenigstens doppelt so vicle da. Es ist ein einziges Fruchthlatt vorhanden, welches einen oberständigen, eintächerigen Fruchtknoten darstellt, der sich zu einer Kapsel (Hülse) oder Spaltfrucht (Gliederhiilse) umbildet. Die Samen sind entweder ohne Eiweifs oler hesitzen es nur sehr spärlich. Die Samen werden ron der Hiilse an der Seitenwand getragen.

Die Familie der Schmetterlingsblüter (Pupitionaccas). Bämme. Str:̈̈ucher, Iablsstr:̈̈ucher mol Kr:̈uter mit P'fihlwurzel; Blïtter wechselst:indig, zusimmengesetzt, fingerforming orlor gefiedert. Blattstiel mit zwei Nehenblättern, bisweilen anch die Teilblittchen mit einem kleinen Nehenblïttchen. Die Nebenbliittchon sind mitunter in Dornen mmgehildet, oft endigen die Blattstiele in Ranken. Bliiten in Köpfchen. Tranken, Dohlen, oder einzeh. Die Bliiten sind meist vollständig, unregelmit fsig und schmetterlingsförmig. Der Kelch ist fïnfzïhlig, sein mipalires (genetisch erstes) Blatt steht nach vorn; die boilen hinteren Kuldzïhne sind einuder mehr genähert, bisweilen miteinander verwrolssen. Die lïnf Bliitenblitter sind an Cromde des Kelches belestigt, ron ungleicher Bildung unl wechseh mit den Kelchahsehnitten. Diss wherste Blatt wird zur" "Fahne", die mittleren bihden sich $\%$ den

1) Litteratur wie olen. - 2) Indign tragend, siche Geschichte. - B) Von

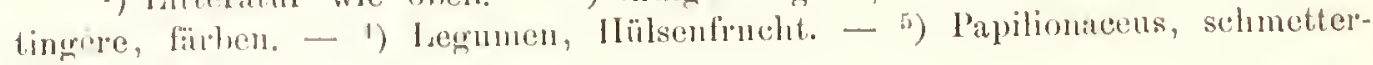
lingsfirmig. 
.Fliigeln" aus und die heiden miteren schliefsen sich zum "Schiffchen" musmmen und verwachsen dabei hänfig miteinander. Dic Fahne ist symmetrisch, die vier iibrigen Mliitenblätter sind jorles fiir sich asrmmetrisch ${ }^{1}$ ), doch die parrig gegeniiberstehenden spiegelbilllich sleich. Zuweilen sind anch alle Bhumenblitter miteinander rerwachsen. Anch Staubblitter und Griffel nehmen an der Unregelmïrsigkeit der Blïte teil, indem sie sich mehr oder weniger nach andwärts krïmmen, die Staubblïtter rückwïrts an Lünge ahnehmen (Fig. I h) und mitunter sich die vordere Griffelseite ron der linteren rerschieden anshildet. Die Füiden dor zehn Staubblätter sind entweder in eine Röhre verwachsen, welche den Fruchtknoten nmgiebt (einbriiderig), oder neun Stanbhïtter bilden eine offene Rimne, vor deren Spalte das zehnte Staubblatt liegt (also zweibriderig, Fig. 2). Der oberständige Fruchtknoten trïigt die Samenknospen an der Seitennaht (Riickennaht, Figr. 4). An der Spitze setzt sich der Frucintknoten in cincn einfachen Griffel fort (Fig. 4). Die Frucht ist eine einficherige, in zwci Kinppen anfspringende Kapsel oder Hiilse. Ist die Bauchnaht schr tief cingeschlagen, so wird die Frucht beinahe aweifächerig; bilden sich zwischen den einzehnen Samen neue Zeligewohsmassen, so wird sie mehrficherig; oft schnïrt sich dabei auch die Frucht an diesen Stellen ein und bildet eine Gliederhiilse; selten ist sie eine nicht aufspringende schliefsfrucht. Keime gebogen, Würzelchen auf die Spalte der Keimbliitter zurückgelegt.

In fast 400 Gattungeu ïber 3000 Arten. Durch ihren rielscitigen Nutzen in ökonomischer, arzneilicher und technologischer Bezichung ans sezeichnet, sowie durch Schönheit und Farbenpracht mancher Arten. Wegen des Gehaltes des Samens an Zucker, Satzmehl nnd an einer cigentimlichen, stickstoffhaitigen Substanz, Legumin, werlen viele Arten unter dem Namen ..Hiilsenfrüchte" als Nahungsmittel fuir Mensch und Tiere angebaut; einige Arten sind reich an Farbstoft (Indigo), andere an Gerbstoff.

Die Gattung Indigopflanze (Indigofera L.). Sträucher, Halbsträucher und Krïuter mit unparigg gefiederten, gefingerten oder einfachen Blättern, achselstïndigen, ein-, zwei- oder traubig vielbliitifen Bliitenstielen, roten oder weifsen Bliiten und stiehrunder oder vierseitiger, gerader oder sichelförmiger, rielsamiger Hülse.

Indigopflanze (Indigofera tinctoric L.).

Ein Halbstrauch, $60 \mathrm{~cm}$ his $1,55 \mathrm{~m} \mathrm{hoch}$ und $2 \mathrm{~cm}$ unten in Durchmesser dick.

Wurzelfasern mit kleinen, weifslichen, harten Kinollen.

Stamm aufrecht, einfach, holzig, verïstelt. Äste krautartig nit einem zarten Haariiber\%ug bekleidet, rund nud straff.

1) Lassen sich nicht durch eine Ebene in zwei spiegelbildlich gleiche Fiächen teilen. 
Blätter rerstrent stehend, unpaarig mefiedert, vier- bis sechsparig, Blättchen kurgestielt, diinn, nmgekehnt eiförmig, stumpl. nit einer Stachelspitze, mit wenigen Seidenhiraren besetrt, matt blangriin; Spindel seidenharrig; Nebenblätter linienpfriemlich, vergänglich.

Blütentrauben achselst:indig, sitzend, reich- und kleinhliitig, gewöhnlich kiiizer als die Blätter, seidenharig; Blüten (Fig. 1) klein, ron kleinen, pfriemlichen Deckbliittern unterstiitat, nn r die nnteren zu Friichten answachsend; geruchlos; Kelch klein, knr\% glockig, fünfspaltig, scidenhaarig, bleibend; Blume schmetterlingsförmig, sehr klein, aufsen seidenharig; Fahne umgekehrt eirund, zuriickgeschlagen, gewimpert, blafssgelblich oder griunlich; Flügel schief, mmgekehrt-länglich, kurz genagelt, rosenrot; Kiel zweiblätterig, Blätter oben verwachsen, cilänglich. gewölbt, schief genagelt, gewimpert, blalsgelblich oder grünlich, schnell abfallend; Staubblätter zweibriiderig $(9+1$, Fig. 2), rom Kiel umschlossen, beim Stäuben elastisch aus demselhen hervortretend, kahl, abwechsehnd mingleich lang, freie Enden der Stanbfäilen dreimal kiinzer als die Platte; Staubbeutel herzförmig, am Grmule angeheftet; stempel knur gestielt, etwas länger als die Staubblütter; Fruchtknoten (Fig. 4) linealisch, seidenharig, meist elfenig; Griffel aufwärts gekriimmt; Narbe klein, kopfförmig.

Hiilsenfruclıt (Fig. 5) hängend, etwas gekrïmmt, fiast stielrund, zwischen den Samen etwas eingezogen, Klappen dunkelkastanienlurann, innen querfächerig (Fig. 6), acht-bis zwölfsamig, Querwände diinn. same (Fig. 7) walzenrund, an beiden Enden rundlich abgestntzt, kastanienbraun mit weifslichem Nabel (nach Berg).

Vaterland: Ostindien. Verbreitungsbezirk: Zwischen den Wendekreisen ïber die ganze Erde, Ostindien, besonders nördliche Provinzen Bengalens, Java, Senegambien und Westindien, Mardagaskar, Ägypten 1), Japan. jetzt auch bei Neapel und besonders in Rufsland (Kreis Lenkorow am Kaukasus). In den Südstaaten der nordamerikanischen Union ist die Kultur der Pflanze wieder gesunken.

Kultur. Die Kultur dieser Pflanze kann in allen Gegenden mit einem heifsen und zugleich feuchten Sommer mit Nntzen rorgenommen werden, wenn der Borlen tiefgründig. fruchtbar und feucht (Kleeboden) ist und die Pflanze volles Licht haben kann. Der Anbin geschioht immer durch Aussaat. Nan bringt die Samen durch Drillmaschine in seichte Furchen, 2 bis $8 \mathrm{~cm}$ tief, $30 \mathrm{~cm}$ anseinander, Das Kulturfeld muss von Unkraut rein gehalten werden, denu Unliraut wiirde, nit verarbeitet, die Güite des Farbstoffes hedentend schïrligen. Nach zwoi bis drei Monaten. wenn die Pflanze anfïngt zu bliihen, wird sie morgens orler abends $10 \mathrm{~cm}$ ïber dem Boden abgeschnitten. In

1) Hier und in linfsland Indigofera macrophylla. 
der heifsen Zone kann man durch nene Schöfslinge his vier Fonten ron derselhon Pflanze halten, anf dem hesten Indigohoden, im Gangesdelt:1, verhindert dic Üherschwemmmng weitere Ernten. In Indien säet man alle zwei his drei, am Senegal alle vier bis fünf, die Araber in Ägypten alle sieben Jahre. In einigen Länlern nimmt nan der Pflanze, wenn sie $60 \mathrm{~cm}$ hoch ist, die Bliitonknospen und die letrten Stengeltriehe wer. wodnch sich der nach oben gerichtete Vegetationstriel, mehr seitlich wendet und die Blattentwickelnng befördert. Die Indigopflanze saugt den Boden sehr aus.

Ind igo, einer der wichtigsten blanen Farbstoffe, findet sich nicht fertig gebildet in der Natur, er ist in dem Pflanzensaft als farbloses Chromogen anfgelöst, das durch einfache Extraktion mit Wasser gewomnen werden kann und durch Einwirkung der Luft in Indigo iibergeht. Dieses Chromogen des Indigo findet sich in melneren Arten von Indigofera, auch in anderen Pflanzen (Isatis tinctoria, Wrightic tinctoria, Polygonum tinctorium, Gatepe tinctoria. Asclepias tingrns, Spritanthes tinctoria, Mercuriulis perennis etc.), doch enthalten sie nicht genug Fardstoff, un den Indigo vorteilhaft daraus darstellen zu können. Manche Milch scheidet an der Luft llanen Farbstoff ab, der nur ans der Nahrung der Kühe (Butomus umbellatus) ${ }^{1}$ ) hergeleitet werden kann.

Zur Indigogewinnung dienen hesonders Indigofera tinctoria, Indigofera Anit. Indignfera argentea und Indigofera disperma. Nan weicht die frischen Pflanzen in Wasser ein, um sie in Gäirung (unarfïhr 9 his 14 Stunden) zu bringen. Das Wasser färbt sich dam gelh, der Schlamm violett. Darauf läfst man das Wasser in ein niedriger aufgestelltes Schlagfafs abfliefsen. Hier wird die Fliissigkeit durch hölzerne Schaufeln zwei Stunden hindurch mit der atmosphärischen Luft in vielfache Beriihrung gebracht, damit sie den Sanerstoff der Luft anzieht, lis sich der Indigo als ein dichter, sehr feiner, blauer Niederschlag ausscheidet. Der sich als blaues Pulver zn Boden setzende Indigo wird nun durch baumwollene Tuicher geseihet, in Stiicke zerschnitten und getrocknet. $1200 \mathrm{~kg}$ Blätter sollen $36 \mathrm{~kg}$ Indligo geben.

Gehalt und Warenkunde. Indigo ist ein Gemenge von Indighlau, Indiglein, Indighraun, Indigrot mit Kalk- und Ammoniaksalzen, zuweilen noch mit fremden Beimengmugen; er ist von schöner, schwarzblauer Farhe und von erdigem, mattem Bruche, olue Geruch und Geschmack und wird weder ron Wasser, Alkolnol, fetten und ätherischen Ölen. noch von verdiimnten Sïuren aufgelöst. Er ist nicht giftig. Der blaue Farhstoff desfelhen, das Indigblau, mufs zum Fïrben erst in Indigokiipen anfgelöst werden. Die Giite des Indligns hängt von dem Gehalte an Indigblau ab, der 20 bis 80 Prozent betragen teilung.

1) Siehe unsere "Reprïsentanten einhcimischer Pflanenfamilien", M. Ah- 
kann und durel die sogenamiten Indigoprohen (anf chemischem Wege) woniner bestimnt werden muls. Die leirhtesten und am meiston kupferfarligen Sorten gelten als die besten. Vouzügliche Ware:

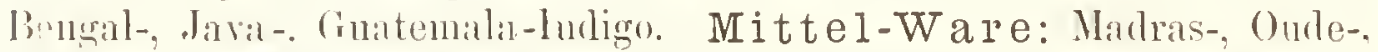
Manila-, Pondichery- (nicht ansgefïhrt), Caracas-, Domingo-. Rarhatos-, ägrytischer Intigo. Geringe Ware: Koromandel-, Brisil-, Lonisiana-, Karolina-. Kuragh-, Martinique-, Gradeloupe- mod GuianaIndigo.

Gebrauch. Mit Indigo fïpbt man alle Gewehe danerhaft hlau nnd grundiert andere Farhen damit. Die nit Indigo liergestellten Firben zeichnen sich dnrch Elegan\% und Dauerhaftigkrit aus. Vernittelst Eisenvitriol fürbt man damit englischbla u oder fayencehla u, vermittelst Operment (Auripigment, Ranschgelb, eine Verhindung des Arseniks mit Schwefel) schilder-orler kastenlulau. - Der Indigkinmin ist eine Verbindung des Indigs mit schwefelsanrem Kali. Noublan orler durch Indigo gefüirbte Stïrketïfelchen dienen zım Blanen der Wäsche (Waschblan). In der Medizin wird Indigo selten noch angewandt (gegen Epilepsie).

Handelsstatistische Notizen. In Indien verschalft der Indigoban 500000 Familien ihren Unterhalt. Die Gesamtprodulition des Indigos beträgt nach Scherzer etwa 150000 Zentner, woron die IIauptmasse auf Indien kommt. Ostindien führt jährlich etwa 81000 Zentner Indigo ans. Caracas versendet 20000 \%entner. Die jiilurliche Finfuhr dieses Farbstoffes in Europa hat einen Wert ron 180 Mill. Nark. In Hamburg gehen jährlich etwa 6000 Zentuer ein. Louton ist der Weltmarlt fiir diesen Artikol.

Geschichte. Der Indigo war schon den Alten hekannt. Rei den alt'n . Julen durfte keine Indigopflanze ausgerottet werden, wem sie nicht drei Jahre restanden histte. Noch im 14. Jillrhumiert blïhte die Kultur dieser Ptlanze bei Jericho. In Ostindien ist ihre Kultur nud die Benutzung dieses Farbstoffes am ältesten. Indigo (.. Indienm") wurle zur Zeit des Plinius und des Dioscorides (ans Fedrosien) nikn Enropa gebracht, und in Süd-Europa, wie Plinius herichtet. st:mnd dieser Fandsitnff nilch den Purpur im höchsten Ansehen. Arrian

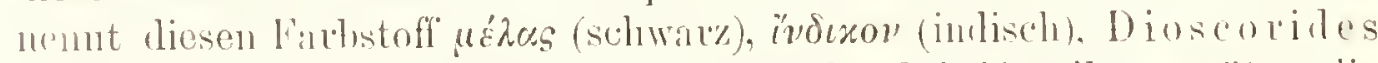

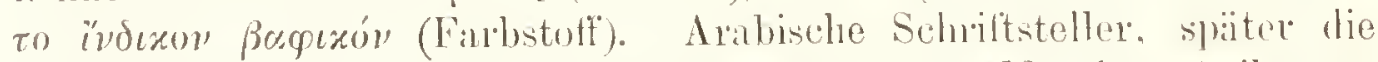

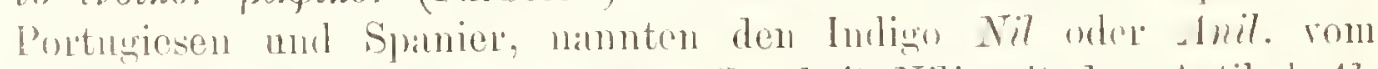
indischen Nila, I. h. Ban (aus dem Simskrit Nili, mit dem Artiket Al-

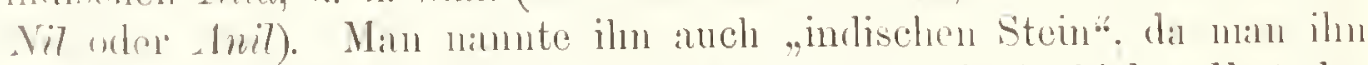
weren seiner Wiirfelgestalt in Europa fïr einen Stem hich. Erst der Venctimer II ank Polo in 13. Jihnthundert erkinnte ihn als einen p'lan\%enstoff. In Dentschland hielt man ihn noch 1705 fï̈ cin Mineralprohkt. Noch 1705 durfte nim einem Freiheitshriefe der Gewerke in don Bergrwerken des lïirstentuns Halherstalt nuter den Mineralien anch anf Indign gehant, werden. Rhe ede hachte die erste dentliche 


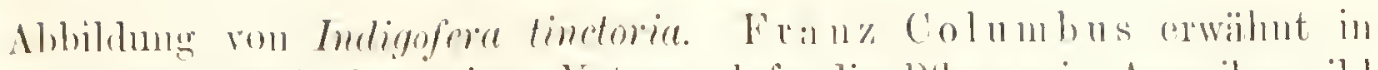
der Lebensgeschichte seines Vators, dalis die P'flanze in Amerika wild

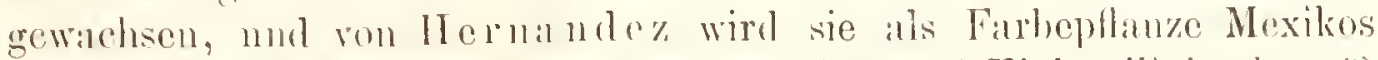
aufgeführt. 1)ie Mexikaner fairhten mit Indigo (.Xinhruilipitzahuac" ) iln' Han und malten damit. Dic Spanicr hereiteten ilne Tinte dinans. In Anfange des 17. Talullunderts wurle der Indigo in Dentschland durch die Inolländer ein begelnter Handelsartikel nud verdrüngte den Waid (Isatis tinctoria), der bis dahin der gewöhnliche Farbstoff für Blan war. Die hitteren Klagen der Waidbauern in Mittol-Europa (aufser Holland) veranlafsten das Verbot der Cinfuln des Indign, sogar hei Leihesstrafe (in Frankicich muter Heinrich IV. 1609, in Sachsen durch Georg I. 1650). Weil man konzentrierte Schwclelsïule zur Auflïsung des Indigo verwandte und mancher Färber diese nicht gelörig zu nentrulisicren verstand, so wurde das gefïrbte Gewebc verdorben, der Indirn kam als fressende nder Teufeisfarbe in Verruf nud wurde als schädliche, fressende, betriigliche Farbe obrigkeitlich scharf verboten. Dic Nïrnberger licfsen jeden Füirber schwörcu, dals er keineu Indigo gebranchc. und bedrohten ilnu im Übertretungsfalle mit Todesstrafe. Trotzdem breitete sich die Anwendung des Indigo immer weiter aus. Die röllige Frcigebung dicses Farbstoffes daticrt erst von 1737. Die Kunst, Wolle mit in Schwefclsänre aufgelöstem Indigo zu färben, wurde 1740 von Barth in Grofsenliain in Sachsen entdeckt. - 1826 entrieckte Unverdorben bei der trockenen Destillation des Indigo das Krystallin, das Fritsche in Petersburg durch Destillation eines Gemenges von Kalilange mit pulverisiertem Indigo erliclt, Anilin nannte und es 1840 znerst beschrieb. Min erzengt dnrch das Anilin schöne violette und rote Farhstoffe und gewimnt es jetzt meist direkt aus dem Steinkohlentheeröl. Die Wichtigkeit des Anilins datiert erst ron 1859 her. Parkins stellte 1859 ans dem Anilin das Anilinviolett (Violin) dar. Auch das Anilinrot (Rosin) wird in seinen versehiedenen Niiancen als Fuchsin, Fuchsiarin, Roseün, Aralin, Magenta- und Solferinrot dargestellt.

Bei uns als Zierpflanze hesonders Indigofera Dosua Hamm aus dem Himalaya, cin $1 \mathrm{~m}$ hoher Strauch mit gefiederten Blättern und hellrotcn Bliiten. 


\section{Tafel 21.}

\section{Kork-Eiche (Quercus $\left.{ }^{1}\right)$ sher $\left.{ }^{2}\right)$ L.).}

Anch die Kork-Eiche gehört zur Familie der Näpfchentrïchtler (Cupuliferue, siehe S. 143).

Die Gattung Eiche (Quercus L.). Hohe Päume nul Sträncher mit meist grofsen, ganz schmalen oder breiten und dinn oft buchtig gelappten oder fiederspaltigen, abfallenden oder meluere Jahre bleihenden (Korkeiche) Blättern. Die Blitter hahen cine eingetalzte und dabei wellig gefaltete Knospenlage. Die Blätter der rechten Zweigseite sind dahei entgegengesetzt gefaltet, wie die an der linken. Bliiten einhäusig. Die mümnlichen stehen in gröfserer Anzahı an fadenförmigen Stielen. Die weiblichen ${ }^{3}$ ) einzehn im Winkel eines schuppenförmigen Deckblattes. Dio letzteren sind umgeben von einer napffömigen, kleinschuppigen Cupula, haben ein oberstïndiges. meist drei + dreizähliges Perigon und einen dreifächerigen, dreibarbigen Fruchtknoten. Die Cupula ist zur Bliitezeit noch klein nud besitzt ron ilnen späteren Schiippchen erst wenige, gewöhnlich nur cinen oder zwei Kreise. Mit der Ausbildnug des Fruchtknotens nimmt sie gleichfalls $\%$; die nen auftretenden Schiippehen entstehon hierhei an den nach innen ahschïissigen, sich allmählich jedoch anfrichtenden oder gleichsam numstiilpenden Rande des Cupularbodens ron anfsen nach innen. I ie Cupula bildet später einen gerale abgestutzten. schuppigen Fruchtbecher, worin die einfächerige, einsamige, lerkerhïutige Nufs oder Fichel sitzt.

Yon den 280 Arten gehören Asien 148, Amerika 142 und Furopa 17 an. Afrika hesitzt keine eigentümlichen und Australien gall keine Eichen. Die Eichen werten im allgemeinen seln stark vom Ungezicfer aller Art heimgesucht.

1) Wiche. Vielleicht ans dem Celtischen, von yner, schön und encz, Banm, - oder vou dem griechischen жio\%ru. rauh sein - wegen der Rinde (le unis). -2) So nannten the Rämer die Korkeiche (viclleicht von subere, nïhren, siehe Geschichte), wihnend sic bei den Griechen yezros hiels. - ") Eichler. 
Die Kork-Eiche (Qurecus suber I.) \%eight in limfing umbl

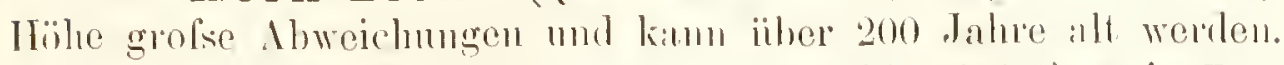

Bamm 10 bis 14 (16) moch h) und 50 bis 70 (90) cm im Durchmesser dick. Rinde ran mol mugleichmïlsig, an jüngeren \%weigrm

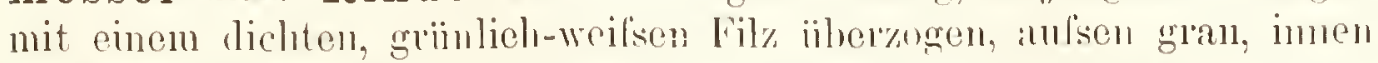
rostbram. Sic roplickt sich jührlich und fällt schliefslich ah, um dem neuen Nachwuchs Platz zu machen.

Blätte 1 ahweehselud, kurgesticlt, eilornigr, fast herzfömiglïnglich, am Runde meist nit kleinen, etwas ontternten, stachelspitzigen Zailunen hesetzt, selten grunzandig. Oherfliche gratt. Futerflache mit einem feinen weifslich-granen Filz bekleidet, dic gröfsten his 5 cm lang nud bis $3,5 \mathrm{~cm}$ breit, die meisten kleiner, im m e r griin.

Der Baum bringt im 12. bis 15. Jalue die ersten, aber erst später fruchthare Bliiten hervor. Blüten, männliche (Fig. 2 a und Fï. 3), zalulreich an den Euden der jungen Zwoige; dor gemeinsame Bilitenstiel fadenfömig, etwas filrig, 3 bis 6 cm lang. Einzelnes Blütchen (Fig. 3), Perigon aus einer durch mohrere kleine, verwachsene und am Rande mit Härchen besetzten Blättehen gebildet. mit sechs his acht Staubblatteru, dic aus diinuen, hatrformigen Staubfäden mit blafsgelhen, cirmullichen, zweifächerigen Staubbeuteln (Fig. 3) bestehon. Weibliche Blüten (Fig. 4) auf kurzen, dicken und filzigen Stielchen zn zwei bis drei augehiuft. Die äusere lundliche $H$ ïlle besteht aus feinen, dieht ansehlicfsenden, weichhaarigen Schuppen, welche den mit dreigespaltenen farlenförmigen, unten etwas umgebogenen hervoragenden Narben (Fig. 4 unten) verschenen Fruchtknoten nmgiebt.

Die Korkeiche erzeugt erst damn Friichte, wenn sie cine Rinde liefert, die zu Stopfen veruheitet werden kanu. Frucht²) cine fast $3,5 \mathrm{~cm}$ lange und 10 his $12 \mathrm{~mm}$ im Querdurchmesser starke. glatte brïnuliche Eichel. Die Bliitenhiille hildet sich in einen ans dicht iiber einander liegenden, graufilzigen Sehiippchen zusammengesetzten Fruchtbecher um.

In Marokko und Tumis wächst die Korkeiche wild.

Verbreitungsbezirk: Alle Nittehneeriander und die arlialtischen Kiisten, in gröster Menge 1200000 ha) in Algier (Provin\% Konstantine), auch zahlucich in Spanien (Viscaya und Oberesdre.. madura), im sïdöstlichen Frankreich, Dalmatien, Istrien, Ungarn, auf den Inseln des Mittelmeeres nud Griechenland und in nenester Zeit in den Siidstaaten der nordamerikanischen Tnion. Die Kork-Eiche geht in jenen Gebieten nirgends iiber den 45. Frad 11. Br. hinaus;

1) In Algier sind einigu Bämne gefunten worlen, di" $21 \mathrm{~m}$ hoeh und $97 \mathrm{~cm}$ im Jnrehmesser haben. - 2) Es giebt einige spiclart"n dieser liche. welche sehr süfse l'rüchte erzengen. So soll der Wohlgeschunck ler herühnnten Suhinken von Bayonne anf die Mästung der Schweine nit den Frïchten der Querws suluev zurückzuführen sein. 


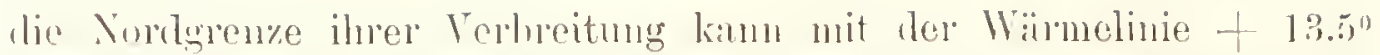
braidnet werdon. Der Banum steigt nirgends hoch ins Gehirge. In

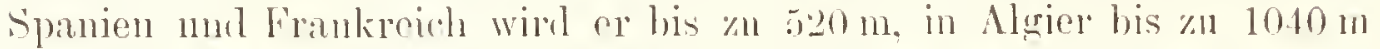
iiber dem Mecresspiegel angetroffen, nurl zwar, wenn in wilden Znstande, nur anf Granit- oler Schieforboden. Die nceanischen Kiisten Portugals mut Frankreichs liefern anch Kork ron Quereus occidentalis (siche unteli).

Kultur und Ernte. Die Kork-Fiche verlangt einen lebhaften Luftwechsel und eine Fïlle von Licht, doch mufs für Beschattmng des Bodens durch Schutzpilanzen (Pinus muritima) gesorgt sein. Die Fiche wird in derselben Weise angepflanzt wie nnsere Eichen. Dic Kultur der Korkeiche besteht darin, dafs sie im regelmäfsigen Retriehe entrintet wird, denn erst hierdurch wird der Banm angereizt zu dem wucherndon Wachstum der Korkzellen, welches im Verlauf ron sieben bis acht Jahren cine neue. wieder zum Abnchmen reife Rinde herbeifiilnt. In der P'rovinz Geroma emtet man den Tork alle 10 bis 12 Jahre, zin Herstellung von Champagnerstopfen alle 18 Jihre ab. Bänme, die nicht kïnstlich entrindet werden, haben nur eine harte, briichige Rimle, die sie in Nlter reitweilig von selbst abwerfen. Ein Bamm liefert in einer achtjïhrigen Kulturperiode ungefiih. $8 \mathrm{~kg}$, später gielt der voll erwachsene einschliefslich der Äste, die nicht so oft geschält werden, 100 bis $150 \mathrm{~kg}$ Kork. In Spanien nud Portngal schiilt man alle drei bis fïnf Jahre die Korkschichten a). In Algier hat eine Gesellschaft diese Korkwïlder in Pacht genommen und betreilst die Kultur derselhen und die Gewinnung des Korkes in regehmïlsiger Weise, nachdem die Regiorung den jührlich wiederkehrenden Wahlbrïnden Finhalt gethan hat. Die Araher suchten nämlich durch die Waldhrände ihre Weile zu rerbessern. indem das Berggras (Amudo tctuoides) unter den Korkeichen keine jungen Sprossen fuir ihr Weiderieh trieb.

Bildung und Aufgabe des Korkes im allgemeinen. Alle Rinden rom Holzgewïchsen (die Mistel ${ }^{1}$ ), viscum, ausgenonmen) enthalten als wesentlichen Bestandteil eine stirkere oder geringere Sohicht Konk. Ist der junge Holzstanm ilter als ein Jah geworilen, so lest er die Oberhant (Epidermis) ah mul es entsteht ein veriorkendes Fiilgrwehe (Parenchyngewehe, Perilerm, Kork) an ihrer Stolle, diss sich äufserlich durch einen bräunlichen Anthug kennzeichnct. Bei viclen Pflanzen (Siberpappel, Weide, Apfelbaum) geht diann diese Korkbildnng liänfig ron hranuen oder weilshichen Rindenwärzchen ans. Beiu Apfelbaum, Bimbann u. s. w., bein Oleander und den meisten Weiden entwickelt sich dor Konk ans den Zellen der Oberhatut. Sachdem die Oberhitut beseitigt ist, sterben die änfseren Kork\%ellen alb und bilden einen schiitzenden Überzug (Lederkork), der die Be-

1) Siehe unsere "licprïsentanten ete.", II. Abteilung. 
stimmung hat, die Verdunstung des in dem Stamme und den Ästen zirkulierenden Saftes (Biffision) \%u rerhindern. Line allseitig verkorkte \%clle muls sehr balı ahstorhen, da die Diffusion gestiort ist. Die Vermelumg der Korkzellen erfolgt sehr rasch. Fine Korkschicht schiityt die liartoffehn und Georginenknollen vor dem Austrocknen, bederlt alle älteren Wurkelteile, wirl durch ihr Auftreten die Ursache der herbstlichen Verfirbung und des Falles der Blätter und vernatht die Wunden, d. h. ersetzt die rerletate Oherhant. liisse anf Ohst veruarben durch eine Korkschicht, die 'Trockenfüule der Kartoffel ist ein durch Korkbildung gehenmter Finhlnisprocefs, indem einzelne kranke Gewebspartien durch kork isoliert und dadurch dem Gesamtorganismus muschïdlich gemacht werden. Selhst Blattwunden werden durch eine Korksehicht geheilt. Aus Holzzellen aber bildet sich niemals Kork. Entsteht der Kork in den tieferen Rindenschichten, so löst sich die alsterbende linde in Schuppen oder Streifen ab (Borke der Eiche, des Weinstockes, der Nadelhölzer etc.). Die stets glatte, weifsgef:irlute und sich fortwährend erneucrnde Membran der Birke (Birkenhunt geniannt) gehört ehenfalls zur Korkbildung.

Eigentliche Korkbäume. Die gleichmälsige F'ortentwickelung des Korkes wird bei den meisten liaimen und Sträuchern dnrch die Borkenlildung, einen hesonderen Abschuppungsprocefs, gestört, nur bei einigen Holggewïchsen dauert die Korkhildung (aus weiten Zellen) zeitlebens fort und dies sind die eigentlichen Korkbäume, zu denen hauptsïchlich gehören: Quereus suber L., Quercus occidentulis Gay, (hercus pseudo-suber Sinti (Ligurien), Acer cumpestre L., Ulmus suberosa ${ }^{1}$ ) Koch und Erythroxylon suberosum St. Hil. (Brasilien) etc. In Johore (Indien) dient die weiche elastische Rinde ron Pimus tomgifolic als Ersat\% für den Kork, wiilnrend in Westindien die Neger ans dem sehr schwammigen Holze des Alligatoraptels (Anona pulustris) Flaschenstopfen verfertigen.

Der Kork der Korkeiche und seine Gewinnung. Die junge Korkeiche wirft ihre Oberhant erst in zweiten und dritten Jalne ab und hat dann als Ersatz derselben eine diinne, ans platten, etwas spröden Zellen hestehende Korkschicht. Nach dem Imeren des Stammes zu bilden sich durch fortschreitende Teihngen nene Korkzollen, d. i. das Korkcambium (Mutterkork). Erst wenn die äulsere wertlose Korkschicht (männlicher Kork, le mäle) kiinstlich entfernt oder selhst alogesprungen ist, orzengt der Mutterkork branchbaren (weiblichen, fomrlle) Kork. Um möglichst grofse Korkplatten gewimnen zn können, wartet man mit der Fntkorkung der Bäimne. his sie einen Unfing voll 20 his $30 \mathrm{~cm}$ erreicht hahen. Nan greht an die Arbeit. wenn die Springe in der linde eine rosenrote lïirhung anzmohnen beginnen und die Zeit des starken Salttriebes vorbei ist, die Jahres-

1. biese linde wächst nicht dick grenug. 
zeit, wo liast und 110lzkïrper an festeston zusammenhalten und also dem Baume am wenigsten durch das $A$ bschiilen geschadet wird. Con die Biiume zn entkonken, macht ma:n 1,9 n ron rinander entfornte Líreisschnitte in die stämme der bïume, die man mit Iä̈ngsschnitten unter Benutzung ler hereits vorhandenen Risse verbindet. Die Korkplatten lassen sich nun mittels des IFackenstieles leicht lösen. Bei der Arbeit mul's dirauf gesehen werden, dafs der Mutterkork (Korkcambinm) woder durch śchnitte noch dureh liisse rerletzt wird. da ihn der Bam zu seiner Existenz nötig hat nud ans ihm die nenwathendo Linde sich bildet. Anch schadet es dem Mntterkork. wenn unmittellan anf die Entkorkung die Regenzeit folgt. Nach der Entkorkung lälst man den Baum gewöhnlich acht bis zelun Jahre rnhen, in welcher Zeit sich eine nene Korkschicht von 17 bis $26 \mathrm{~mm}$ Dicke bildet. Die erste Entkorkung erfähnt der Baum gewöhnlich erst in seinem 15. Jahre. Er wird 100 bis 150 Jahre lang benutzt. Ganz alte Bäune liefern ein sehr geringes Produkt.

Zubereitung der Korkplatten für den Handel. I'm die gewöhnlich 1.3 m langen Korkplatten (-schimken) zu trocknen. schichtet man sie in Hanfen and, die man mit Steinen beschwert. Durch das Trocknen verlieren sie nngefähr 15 Prozent an Gewicht. Nachdem man hieranf die oherste Schicht der beiden Hauptseiten der Lorkplitten durch Feilen oder Schaben entfernt hat, liifst man die Ware fünf bis sechs Minuten in grofsen Kesseln kochen, infolge dessen der Kork wieder an Gewicht verliert, an Auslehnung um ein Fünftel gewinnt und elastisch wird (weilser Kork). In Spanien zieht man die Korkschinken auch noch durch ein Flammenfeuer, un sie gegen den Wurmfrals zu schiitzen, wodurch sie aufsen eine schwärzliche, innen eine tiefgranlnaiunliche Farbe annelmen (schwarzer Kork).

Eigenschaften und Bestandteile des Korkes. I) Korkplatten sind bis zu $5 \mathrm{~cm}$ dick und es lassen sich an ilunen die Jahreslagen in Schichten ron 1 bis $5 \mathrm{~mm}$ Stïke erkennen. Der Kork ist elastisclı, für Fliissigkeiten und Gasse mulurchdringlich, wenig dicht. gegen änlsere Eintliisse wenig empfïnglich. Die Elasticitiit desfelhen berulat auf der Lufthaltigkeit seiner Zellen. Die Korksnlostanz hat rotwas Wachsartiges, Wiss sich den Eindringen der Nässe widersetzt. Korkstoff hricht das licht stark mul hat ein speritisches Gewicht rom 0,28. Wenn mim gepulverten Kork mit Alkohol iibergiclst, lleibt ein unlöslicher Rïickstand ron 70 l'roz. Nem derselbe nit silpetersïure behandelt wird, finden sich an wichtigeren Stoffen in je 100 Trilen: weifse Rohfiser 0,18; 11arz 14,72; Oxalsäure 16,00; Suberinsïuro (eine dem Kork eigentiinliche sïure) 14,2.

Verarbeitung und Gebrauch des Korkes. Anf den eben renannten Figenschalten des liorkes berult der vielfache

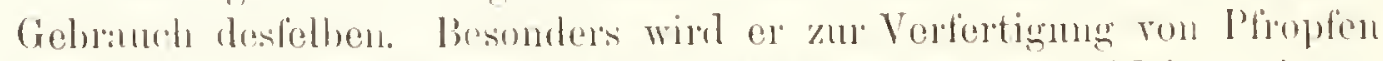
oder stöpseln verwentet. Niat Wiesner werden kleine, diinne 
Ptropfen parallel nur Oberfliache der Korkplatten, dicke, kur\% senkrecht hier\%n geschnitten; dicke l'forpen, deren liöhe mehr als $5 \mathrm{~cm}$ betragen soll, können ans gewöhnlichen konkplatten nicht meln senkrecht, sondern miissen parallel \%ur Oberfläche herausgeschnitten worden. Jlan kinn aus der hinge der dentlich sichtharen Jalnesschichten des korkes an jeden Pfropf erkennen, in welcher lichtung er ans dem Kork heransgeschnitten wurde. Die Pfropfen werden mit der Hand oder mit Maschinen geschnitten. Kork wird ferner zu Korksohlen, Lorkjacken, Einlage ron Hiiten, Schwimmern fiir Fischnetze, Üheræïgen für Niihlsteine (zmr Eisthïlsmng der Hirse). Schwimnkleidern, Rettungshooten, zur Ausfïttermug ron Insektenkasten, zu Modellen, zu Matratzen, zur Korkbildnerei (Phelloplastik) verwendet. Nach Varro sind die ans kork gefertigten Bienenstïclie die hesten, weil sie Winters die Kïilte mol Sommers die Hitze abhalten. Die Korkkohle (spanisches Schwartz) wird schon seit langer Zeit als Farbe henutzt. Korkabfaille werden in England zur Herstellung des Kamptulikon verwendet. In jüngster Zeit werden aus Kork Platten zur Überkleidung von Dampfmaschinen-Cylindern und Rohrleitmugen zum besseren Zusammenhalten der Hitze (Kork hat geringe Wärmeleitungsfilligkeit) gefertigt.

Die äufsere Korkschicht (mïnnlicher Kork) kommt nicht in den Handel und dient nur zum Bremnen mod etwa als Dachdecknngsmaterial. Das eigentliche Holz der Korkeiche wird wenig geschäitzt und steht weit hinter unserem Eichenholz zuriick.

W arenkunde. Kork aus warmen Gegenden ist besser als ein auf nör:llichen Standpunkten erzeugter, auch geben Bäune im Alter ron 50 bis 100 Jahren die beste Ware. Der beste, aber wenigste Kork wird ron den Büumen erhalten, die auf Bergen stehen; Bäume ron niederigen, feucliten Standorten liefern viel, aber geringen Kork. Der Kork entliält spröde Gewebe, die beim Trocknen und Quetschen desfellen zerstïnben und Hohlrämme zuriicklassen, deren Menge und Gröfse den geringen Wert der Ware andeuten. Der portugiesische Kork ist von dunkler, bräunlicher Ohertliiche; er ist weich und sammetartig. Der französische mol algerische Kork sind im allgemeinen reiner, weicher und elastischer als der spanische. Der spanische Kork ist meist schwar\% und dunkelhram, der französische sehr weils mul leicht, hat weniger harte Stellen und eine gelblich-l, rame Oberfläche. Der istrische und der sicilianische Kork sind die geringsten Sorten. Als Merkmale eines guten Korkes sind seine blasse Färbung, sein leichtes Gewicht, Elasticitït und schwammige, kleinporige Beschaffenheit zu betrachten.

Handelsstatistik. Die Er\%engung des Korkes ist nur da von Bedeutung, wo der Stant im Besit\% der hetreffenden Waldungen ist, da Privatpersonen nicht gern so lange anf eine Ernte warten. I)as Sanhaldschagebiet in der algerischen Provinz Konstantine ermengt weit iiher 100000 Tonnen ror\%iglichen Kork, wown Frankreich allein jähnlich 
25000 \%enture bexicht. Man nimme an, dafs die Produlition jährlich um 15 Prozent steigh. Sumien produziert jihlich 100000 'zentner Kork, woron Katalonion allein 33000 \%entner rohen und verarbeiteten Kork ansfiihrt. Dir spanische Regierung hat in den letzten Jahren die Korkinsfuhr ans Katatonien, Arrenas de Mar, Bancelona und Silragossi verboten, um die lricht zu bestreitende und ganz ergiebige Erzeugung von korkwaren in Lande selhst zu erhalten. In Deutschland wird die Korkschneiderei (Rohstoff' aus l'ortugal, Spanien, von Sardinien nud Sicilien) zwischen Delmenhorst und Syke, in hremischen, oldenburgischen und hannoverschen Dörfern und in Schwarzenherg und Buchhol\% in Sachsen betrieben. Im grö́lsten Umfinge wird die Korkschneiderei in England hetrieben, das für sich nnd seine ïherseeischen Versendungen tïglich mehr als 20 Millionen korke braucht und dieselben nur \%um kleinsten 'Teil schon fertig bezicht. Frankreich braucht für die Champagne allein jährlich 40 Millionen feinste P'fropten. Es produziert mehr, als es hedarf. In Nord-Amerika hestehen ïher 60 Korkwarenfabriken, die für 21/2 Nillionen Dollar jährlich Ware er\%eugen. Un blofs den Bedarf an Korken für NewYork befriedigen zu können, wïrde man allein 4000 Arbeiter bei Handarbeit brauchen.

Geschichte. Der Gebrauch des Korkes ist uralt, dem schon die alten Ägypter benutzten ihn zur Herstellung ron Sürgen. Zu des Plinius (Plinius XVI, 13) Zeiten wurden ron den römischen Frauen Korksohlen getragen, die der Trockenheit wegen unter die Schuhe (Pantoffelholz) geheftet waren. Theophrast nemb den Kork Phellus und sagt, man mïsse iln, um seinen Verderth zu verhiiten, alle drei Jahre von den Bäumen schälen. Erst im 17. Jalnhundert fand der lork die wichtige Verwendung zu Stopfen. Erst kimen die Korkstöpsel fertig goschnitten ans den Er\%engungslïnderı. Da die Versnche, die Korkeiche in fremde Länder zu verptlanzen, mifshngen, so hezieht man jetst aus den Erzengungsländern den Rohstoff und fertigt die Korkwaren in Inlande diuraus. In Deutschland haben sich hesonder's bremische Geschïftslente un die Einfïhrung der Korkindustrie verdient gemacht. 


\section{Tafel $\left.22^{1}\right)$.}

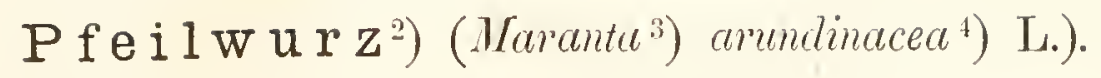

Wie die Banane gehört auch die Pfeilwurz zur Kklasse der Einsamentappigen (Monocotyledones), zur Ordnung der Gewiirzschilfe (Scituminere, siehe I. Abteilung S. S8), und zwar zur Familie der Bl umenrohre (Camaceac "i) oder Marantaceae).

Die Familie der Blumenrohre (Cannaceae). Die Blumenrohre sind den Ingwergewächsen (I. Abteilung S. SS bis 90) ganz :ihnlich mol ron ihnen nur durch die Bildung des einen frnchtbaren Staubblattes verschieden. Dieses ist nämlich eins der beiden seitlichen und trägt nur einen einfächerigen Staubbeutel, weil sich die eine Hiilfte des Staubblattes bhumenblattartig ausgebildet hat (Fig. 5 u. 6); auch findet sich bei ihnen niemals ein Samenmantel vor (Thomé).

Tropische ausclanernde Blattpflanzen, 'ausgezeichnet durch Schönheit der Bliiten und Stiikemehlgehalt des kriechenden oder verkiirzten Wurzelstockes und durch schöne Blätter. In sechs Gattungen gegen 125 Arten.

Die Gattung Pfeilw urz (Mtranta L.). Krantige Pflanzen mit Heischigem Wurzelstock nud endständigen Bliitenähren. Der Kielch ist ziemlich grofs. Die Blumenröhre ist am Grunde nach der einen Seite etwas bauchig, entweder verlingert und gebogen oder sehr kur\% und weit. Selır selten ist sie vom Grunde aus gleichmäfsig diinn, gerade und lang. Es sind zwei ̈̈ufsere Staminoiden (unfruchtbare Staub-

1) Litteratur: Siehe die ohen aufgefïhrten Lehrbïcher und Sammelwerke; anfserdem Körnicke, Monographiae Marantacenum Prodromus; Gris, Versehiedene Ablaudlungen, Marantaceen betreffend; Eichler, Blütendiagramme; Kleneke, Lexikon der Verfülsehungen; Wiesner, Rohstoffe des Pflanzenreiches. - 2) Ier frische Wurzelstock der I'flanze wird als Gegengift anf die Wunden gelegt, die durch die mit dem Milehsatte des Mansehinellebames vergifteten l'feile hervorgerufen wurden; dahlo der Name l'feilwur. - 3) Linné lanute die Gattung nach dem venetianischen Arate Barthol. Maranta (gestorben

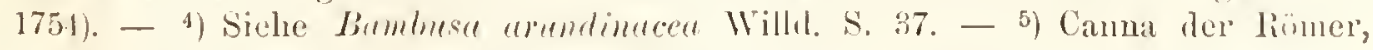
river, schilfatiges lohr, vom celtischen Can oder Cana, Rohr.

Zippel-Jollmann, Auslindische Kulturlinzen. 11. 
hiatter) vorhanden. Vom inneren Kireise hat das änfsere Staminoil eine stank herwortretende Schwiole. Die cine Seite des fruchtbaren Staubblattes träigt hlumenblattartige Anhïngsel, die andere die einfächerige Anthere (Fig. 5a. l, and $6 \mathrm{a}, \mathrm{c}$ ). Der Fruchtknoten ist einfäicherig nud hesitzt mur eine Samenknospe, anfserdem sind aus dem Samenträger noch drei Körperchen hervorgesprofst, deren Charaliter noch nicht festgestellt ist. Der untere IRand der Griffelmiindung ist ein wenig verlängert (Fig. 9). Frucht einsamig, häutig und häutig an der Spitze aufspringend. Der Same ist tönnchenförmig, oft dreikantig, an beiden Seiten abgestntzt, mit Höckern; Samenmantel verschieden ausgebildet oder ohne diesen und dafiir an der Keimgrube mit einer Scheibe versehen.

In den Tropen.

Pfeilw urz (MFaranta amminacca L., die Teilzeichnungen betreffen meist Muruntu bicolor). W u $r^{\circ} \mathrm{zelstock}$ wagerecht, weifs, verzweigt sich. seine oben mit einander verbundenen Glieder ("Fing er") sind ungefähr $32 \mathrm{~cm}$ lang, weifs und schuppig. Sie sind liurz ror dem Absterben mit einer grofsen Nenge Stïrke gefuillt. Stengel aufrecht, $10 \mathrm{~cm}$ bis $1 \frac{1 / 3}{\mathrm{~m}}$ hoch, krautartig, knotig gegliedert, meist rom Grunde an gabeliistig, schwachflaumig; Blätter spitz elliptisch, unten fufslang, oben kiirzer, von der stark hervortretenden Mittelıippe gehen höchst regelmäfsig gleichlaufende und dichtstehende Seitemippen aus; der Blattstiel reicht bis zum nïchstunteren Knoten und umfalst scheidenartig den Stengel. Blüte weils; Kelch und BI umenkrone je dreizählig, letztere röhrig (Fig. 1). In der Mitte der Blïte ') steht neben dem dicken einwiirts gekrimmten Griffel (Fig. 9) ein fruchtbares staubblatt (Fig. 5) und 6 ron beiden Pflanzen). Sein Faden ist nach der einen Seite in ein schmales blumenblattähnliches Anhängsel rerbreitert, das am Grunde des Staubbentels aufhört. Das Anhïngsel ist bei Muranta arundinucca viel gröfser und deckt von aufsen ein anderes Bliittchen, mit dem es am Grunde verwachsen ist. Dieses Blättchen (Fig. 5b) deckt kapuzenförmig den Griffel und hat an der dem fruchtbaren Staubblatte abgewendeten Seite ein Öhrchen (Fig. 5a unten). Aut eben derselben Seite folgt dam ein drittes gröfseres Blättchen (Fig. 4), welches gelappt ist und sich von allen durch seine dicke, schwielige Beschaffenheit auszeichnet und, da es halbkreistörmig gehogen ist. sich anf der anleren Seite an dis finchtbare Stauhliatt anschliefst. Anfserhall, dieser hrei Teile stehen zwei rerkehrt-eiförmige, mehr als die imneren blumenblattartigen bliittchen (Fig. 2 und 3), woron das eine etwas nrölser und an der spitze mehr ausgerandet ist, und von aufsen das fruchtbare Staubblatt mit dem an der einen Seite geöhrten liliittchen deckt. Es folgt also a ul die röhrige blumenkrone

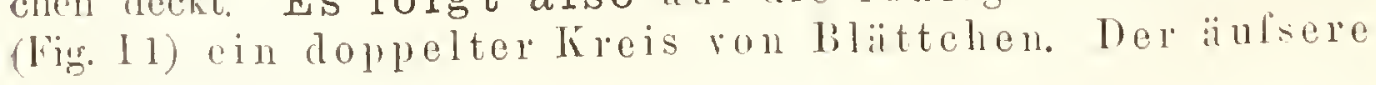

1) Thetriff hamptsichlich Manauta bicolor. 
Kreis besteht ans zwei Blïtchen, der innere aus drei, rou donen eins den fruchtbaren Stanbbentel triagt.

Frucht ron der Grölse emer Johannisbeere, dreiseitig, ellipsoïdisch. mit branem, glänzendem Samen.

Heimat: Tropisches Festlind Mmerikas. Verbreitungsbezirk: West-Indien, West- nnd Siid-Afrika, Ceylon, Ostindien, besomilers Bermudasinseln, Anstralien.

Kultur. Die Pfeilwurz wird in den genannten Lündern allgemein angebaut. Der Anban, ähnlich wie der mserer Kartoffel, kamn iiberall da erfolgen, wo zehn Monate des Jahres frostfrei sind und in den übrigen zwei Monaten nicht Fröste aultreten, wolche die Wurzelı der Pllanzen beschädigen. In die kältesten Monate nufs die Ernte fallen. Der Boden muls tiefgründig sein.

Bestandteile eines west-indischen Wurzelstockes der P'feilwmz: Stiirke 26 Proz., Rohfasern 6 Proz, Pflanzeneiweifs 11/2 Proz, Gummi, fliichtiges Öl und Asche 1 Proz., Wasser 65 $\frac{1}{2}$ Proz. Die Arrow-Rootstärke bildet ein sehr feines Mehl, giebt einen geruchlosen Kleister und ist leicht in kaltem Wasser löslich. Sie enthiilt 14,91 Proz. Wasser, 0,75 Proz. Stickstoff́substanz, 84,10 Proz. Stärke, 0,24 Proz. Asche. Lufttrockene Marantastärke hat ein spezifisches Gewicht ron 1,504, völlig getrocknete von 1,565 , bei einer 'Temperatur' ron 17 bis $18^{\circ} \mathrm{C}$.

Die Gewinnung der Arrow-Rootstärke geschieht durch Verreiben der Wurzelstöcke zu einem Brei und durch Trennen der Stärkemilch von den Pflanzenteilen durch feine Siebe. Darauf reinigt man sie durch öfteres Waschen mit Wasser. Nachdem sich das Satzmehl niedergeschlagen, wird es an der Sonne getrocknet.

Gebrauch. Da alle Stärkesorten sehr wenig Stickstoffsubstanz und Aschenbestandteile enthalten, sie also nicht das hinreichende Material für die Fleisch- und Knochenbildung bieten, sollte man sie nicht als Nahrungsmittel für Kinder verwenden. Wer ausschliefslich Stärke geniefsen wollte, miifste Hungers sterben. 'Trotzdem wird die Arrow-Rootstïrke als ein Kindernahrungsmittel nnd anch zu Speisen und Backwerken fïr Erwachsene verwendet. Sie dient auch zu arzneilichen Zwecken. Will man das Arrow-Root als Nahrungsmitel geben, so wird es mit Milch oder Fleischbriihe versetzt.

Warenkunde (siche Bestandteile). Das Arrow-Rootstiirkemehl soll nicht Wurzelfaserreste oder Überbleilssel der Wurzelhant enthalten, weil der harzige Stoff derselhen die Farbe des Mehles veräindert nund einen mangenehmen Geruch herbeifïhrt. Tadellose Wire ist nicht ganz so weils wie die Weizenstïllie und richt leicht die leuchtigkeit der Lult an. Reibt man das Mehl zwischen ien Fingern, so ist ein schwaches Kinnistern vernehmhar. Boi $66^{\circ} \mathrm{C}$. (1nillt sie in Wasser dentlich anf und beginnt also die Verkleisterung, die bei $70 "$ roll- 
kommen ist. Wird lis Arrow-Rootmehl mit zwölf Teilen seines Gewichtes mit konzentrierter Salzsïure behandelt, so verwandelt es sich zu einem mulnrelsichtigen Teige. Die stärkekörperchen sind ron waler, hirnfïrmiger, mulurchsichtiger Gestalt. Von einem l'mute (Hofe) gehen kmzentrische Ringe aus; in der Nïhe des Inofes befinden sich stern- und spindeltörmise Sprínge. Hanche Exemplare zeigen noch kleine Kïrperchen mit zapfenförmigen Answiichsen. Die Stärkekïrnchen sind denen der Kartoffelstärke ziemlich ähnlich, aher von greringerer Grösse und zarterem Ban. In kaltem Wasser werden sie mehrmals grö̈ser. der Hof nnd die konzentrischen Ringe verschwindenr die Hïlle zerreifst num eine gekörnte Mlasse tritt heraus. Anch zn den echten Marantastïrkemehlen gehören die von Murunta indica und Maranta nolitis gewomenen. Das ostindische Arrow-Root wird ans den Wurzelstöcken von Curcuma angustifolic Roxb. und ('urcumu lentiorhia Roxh. in Vorderindien (Malabar) gewonnen. Die Stärkeköruchen sind grofs, platt, scheibenfömig, oft mit einem kleinen Fortsatze rersehen, vou scharf ansgeprïgter Schichtung. Ihre Aufquellnng in heifsen Wasser findet hei $7^{\circ} \mathrm{C}$. statt. Das Tacca-A r $1^{\circ} \mathrm{OW}-\mathrm{R}$ oot

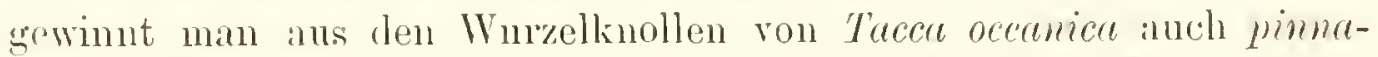
tifida (Siidsceinsehn, besonder's Tahiti) und ist ein weifses stäirkepulver, dessen Geruch an den des Schimmelpilzes erinnert, und dessen Förnchen etwas kloiner als die des Sagomphles und den letateren : ihnlich sind. Das Maniok-A r row-Root oder Tapioca stammt von den schweren Kinolleu des Maniok- oder Cassavestranches (Mfonihot utilissimu Pohl., siehe I. Abteilung S. 146). Das Portland-Arrow Root wird aus dem auch bei uns wildwachsenden mol besonders auf d.r. Insel Portland kultivierten Aroustal)e (Amu muculatum) gewonnen. Dourch die Kultur wird das Stärkemehl der Pllanze noch bedentend stïrker auscrehildet. Durch die dort angewandte Art nud Weise des Waschens und Trocknens des Satzmohles wird dieses ron allen scharfen bestandteilen gereinigt. Dis Stärkekürperchen dieser Ware sind (nnter dem Mikroskop gesehen) sehr klein, eckigrund, mit bald glatten, bild hallhkugelfoinnigen Oberllichen, einem Hof und fast immer mit kouzentrischen schulcnartigen Kingen. Nur selton findet man in der lïnuflichen Ware die oben charikterisiorte pchte Arrow-liootstirlie, sie ist viehnchr gewïhnlich verfälscht mit Kintoffelstärke (siehe „Repräsentanten cinheimischer P'flanzenfamilien", II. Abteihng), mit ArumArrow-Rot, der Tapinca, gemeinen Mehlen oder Sigo. Hier kimn man entwoder mit Hülfe des Mikrosknes mutorscheiden (siehe dic angergubenen Merkmile) orler min kocht verschiedene Sorten Arrow-liont uit (iner bestimmten Menge Wasser, giel'st dann letzteres wieler al

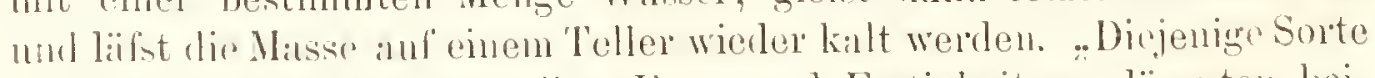
ist die heste, welche damn ihre Form und Festigkeit allu lïngsten beihehirilt. Wenn man die kilte Masse ron dem Gefilis rieht." Die feinste Ware kommt von den Bermudis-Luseh. Unverfälschtes Ma- 
ranta-A r low-Root ist rein. foin mud weifs. glänt wie l'erl-

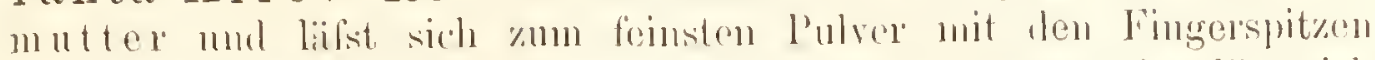
zerdriblich. In kaltem Wasser wird os leicht hroijg. liist sich in sienlemlen Wassor schnell ant. wird nicht eigentlich \%u Kleister

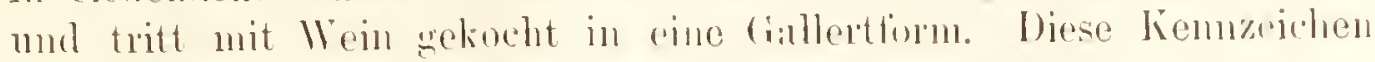

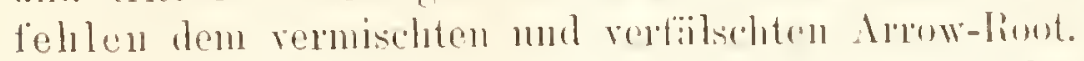

Handelsstatistische Notizen. In len alten liulturlindern der P'tan\%e ist ler Anban fortwithend gesmlken, nur anf St. Vincent nicht, das jiihnlich ctwa 1 Mill. Kilogramm Arow-Root

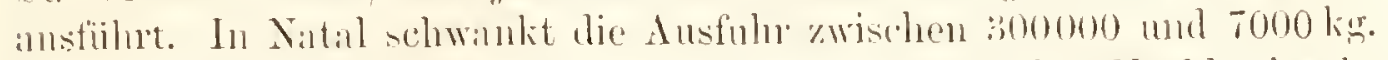
(weensland fiihnt $15000 \mathrm{~kg}$ aus. Tahiti fïhrt vom den Nachbarinsehn etwa $27000 \mathrm{k}$ : $111 \mathrm{~s}$.

Geschichte. Das Arrow-Root wurde in rer zweiten Hiilfte des rorigen Jahrhunderts bekimnt und land zu Anlang diescs Jahrhmulerts in Dentschlind Eingang. 


\section{T a f el 23.}

\section{A ngebaute ${ }^{1}$ ) Yam s ${ }^{2}$ ) w urzel \\ (Dioscorea ${ }^{3}$ sativa $^{4}$ L.).}

Die angebaute Yamswurzel gehört zur Klasse der Einsamenlappigen (Monoeotyledones), und zwar zur Ordnmg und Familie der Yamspflanzen (Dioscorcae) ${ }^{3}$ ).

Die Ordnung und Familie der Yamsplanzen (Dioscoreae) 3), in ler Tracht den Spargelgewiichsen (siehe unsere lieprïsentanten einheimischer Pflanzenfamilien II. Abteilung) ähnlich. Von den Kronbliitigen (Coronarice, siehe ehenda) durch das oberstiindige, krantartige, wenig blumenkronartige Perigon verschieden. Siidliche, windende oder klettende Pthanzen mit schwachem Stengel und knollenartig verkiirztem, meist stïrkemehlhaltigem Wurzelstocke. Die Blüten sind durch Fehlschlagen eingeschlechtig und zweilüusig. Die Blïtenhïlle besteht in beiderlei Bliiten aus sechs in zwei mit einander abwechsehnden Kreisen stehenden Blättern, die zu einer kurzen liöhre mit in sechs gleiche Zipfel geteiltem Samm rerwachsen sind. Das Perigon trïgt entweder die sechs ant' dem Grunde ihrer Zipfel eingefügten Staubblïtter, oder umschliefst einen dreificherigen, einhis vielsamigen Fruchtknoten. Die Frucht ist eine dreitliigelige hapsel oder eine Beere. Die Samen liegen in einem fleischigen Eiweifse.

In wenigen Gattungen gegen so Arten.

Die Gattung Yamswurzel (Dioseorra L.). Tropische, peremierende Schlingpflanzen mit knolligen Wurzelu, rankenden oder kletternden Stengeln, abwechselnden, meist herzförmigen, vielrippigen Blättern, kleinen Bliiten, die in C̈hren oder Trauben stehen und dreifïcherigen sechssamigen Kipsehn.

Angebaute Yamswurzel (Dioscorea sativa L.). Wurzelstock knollenirtig, grofs, ausiamermi; Stengel stielrund, glitt,

1) Litteratur; auf'ser den oben angefühten Werken Martius, Flori Brasiliens., fasc. 5; Pay er, Organog., 1. U81; Wiesner, hohprodukte des l'llinzen. reichs. - 2) Yam. Igname von yam, "essen", aus der Negersprache vou Guinea. 3) Nach Dioscorides, dem berïhmten griechischen Arzte benamnt. - ${ }^{4}$ ) Angrebant. 
kiahl; Blätter spiralstïndig, dïnnh:ïntig, kahl, gröbser als der Blattstiel, buchtig-herförmig, an der Spitze vorgezogen, sioben- bis nennnervig. Staubblatt-Blütentrauben (Fig. 4) verlïngert, gebüschelt-rispig, Griffel-Blütentrauben (lïg. 1) gehïuft, einfinch. Das einzig rorhandene, bei den Griffelhlïten gewöhnlich unfruchthare, bei den Staublattbliiten den neuen Wickelsprofs stiitzende Vorblatt lat seitliche oder schrïg nach riickwïrts verschobene Stellung, der unpaare Kelchteil faillt ihm gegeniiber. Die Griffelhliiten zeigen mitunter an Stelle der verkïmmerten Staubbliitter driisige Rudimente, die Staubblattbliten ein rerkiimmertes Pistill. Perigon (Fig. 2 und 5) sechsspaltig, mit glockenförmiger Röhre und lïnglich-eiförmigen, stumpfen, abstehenden Samenlappen. Die Staubfäden sind doppelt so lang als die Antheren und an dem Grunde der Röhre befestigt, die Antheren sind einwärts gekehrt. Fruchtknoten unterstïndig, dreifächerig (Fig. 3); Griffel steht auf dem Rïcken des Fruchtknotens. Fruchtkapsel (Fig. 1) lïnglich, mit verflachten, dïnnhäutigen Fïcherı.

Heimat: Indischer Archipel und Indien. Verbreitungsbezilk: Die Tropen.

Es seien hier noch die wichtigsten übrigen Arten erwälnnt: 1. Geflügelte Yamswurzel oder Igname (Dioscorea alata L.). Ostindien (Heimat), Siidseeinseln, Afrika und Süd-Amerika, Tropen. Stengel getliigelt-rierkantig, sich hoch emporwindend; Blätter pfeilherzförmig, trägt nicht selten in den Blattachseln zur Vermehrung dienende Ḱnöllchen; Wurzelknollen („Brotwurzeh"“) unregelmäisig 30 bis $45 \mathrm{~cm}$ lang, 12 bis $17 \mathrm{~cm}$ dick, oft noch gröfser und bis 30 Pfund schwer. Wegen der nahrhaften Wurzelknollen wie bei uns die Kartoffel angebaut. In Deutschland gelang die Kultur im Freien nicht. Die frischen Ḱnollen sind ungeniefsbar, betäubend und schädllich, werden aber durch Einweichen in Wasser, durch Kochen und Rösten geniefsbar. Das aus den Knollen gewonnene Mehl wird auch als Zusatz zu Brot und Mehlspeisen verwendet. Die Wurzelknollen dienen anch :iufserlich gegen bösartige Geschwiire als Iteilmittel. In unseren Treibhiiusern benutzt man die windende Pflanze als Bekleidung der Wände. 2. Bataten-Yams, chinesische Kartoffel, Brotw urzel, Tou-Schou der Chinesen (Dioscorea Batatas Decaisne) '). In China und Java allgemein angehaut. IIat keulenförmige, an Ende faustdicke, sich bis zul Spitze fingerdick verdünnende Wurzelknollen. Mos de Montigny, französischer Konsul zu Shanghai, fïhrte sie in SüdFrankreich und Algier mit gutem Erfolge ein. Ertrag nicht so grofs, wie friiher behauptet wurde. Decaisne beschrieh sie 1854 znerst genan. Erwiesen sich in Dentschlanr nicht als Ersatz der Kartoftehı. Gebranch der Wurzelknollen wie bei voriger.

3) Siehe bei Batate, Seite 169. 
Kultur und Gebrauch der angehanten Yamswurcel wie hei der gefliggelten Yamswur\%el, siche oben nuter 1. Die Yamswnzehn halten sich lange mul sind deshall, zur Verproviantiermag von Schiffen geeignet; man zersehneidet sie anch in scheiben mol trocknet sie.

Gehalt und Warenkunde. Die Kinollon sämtlicher Arten sind weniger schmalckhaft als die Bataten (siehe muten), enthalten aher viel Stïrkemehl. Dats Fleisch und dis Stirkemehl ron Kinollen der ..gefliigelten Yamswn"zel" ist weifs, das der iibrigen Arten gelb oder rot. Das Stäkemehl der letzteren lïlst sich durch Wasser nicht rntfïrhen. Kinnllen ron der , angebauten Yamswurzel" enthiclten 16,3 Stärkemehl, 2,2 Eiweifsstoffe, 0,5 fettes 0̈1, 0,9 Jinhfaser, 78,6 Wasser, 1,5 Asche. Fïr den Handel hat nur die weilse Stärlic ron der gefliigelten Yamswurzel eninge Bedentung. Sie ist mit Gewehshestandteilen durchsetzt, bildet ein etwas gelloliches Pnlver ron schwachem feruche mol mildem, milchïhnlichem Geschnacke. Sie kam dured! Waschen gereinigt werden. Sie set»t sich aus einfachen Stiirlickörnchen zusimmen. Thter dem Mikroskop zeigt jedes kom ein halbkugeliges und ein keilförmiges Ende.

Geschichte. Die wenigen bekinnten geschichtlichen Daten sind in den Noten und bei den einzeluen Arten bereits gegeben. 


\section{T a fel 24 .}

\section{Batate ${ }^{1}$ ), sülse Kartoffel (Batütas ${ }^{1}$ ) edulis ${ }^{2}$ ) Chois.).}

Die Batate gehört zur Unterklasse der verwachsenblätterigen Dikotyledonen (Sympetalue, Gamopetuluc orler Monopetalac), zur Ordnung der Röhrenblumigen (Tubiflor(ac), und zwar zur Familie der Windengewächse (Concolvulaceuc).

Die Familie der Windengewächse (Convolvulaceae) ${ }^{3}$ ). Krïiuter, Halbsträincher und Strä̈ucher mit meistens windendem Stengel und abwechsehnden, ganzrandigen, nebenblattlosen Blättern. Sie führen Milchsaft. Kelch fünfblïtterig oder fünfteilig, bleibend und oft fortwachsend. Blumenkirone hinfällig, oft schön gefürbt, regelmälsig, triclıterförmig, mit ganzen oder fünflappigem Sanme, in der Knospenlage gedreht; Staubblätter fünf in der Blumenkronröhre befestigt; Fruchtinoten ungeteilt, ron zwei bis vier Blättern gebildet, deren Bïnder mit einander verwachsen sind und nach dem Mittelpunkte rordringen, so dals er dadurch in ebenso viele Fächer geteilt wird. Sind diese Vorsprïnge nicht vollstïndig ausgebildet, so ist der Fruchtknoten einfïicherig. Jedes Fach entlüilt eine oder zwei aufrechte Samenknospen. Die Frucht ist eine klappig aufspringende Kapsel. Samen nit wenig Eiweils, gekrümmtem Keimling und gefalteten Samenlippen.

Ungefiilır 800 in den warmen und gemïlsigten Zonen verbreitete Arten.

Die Gattung Batate (Bututus Chois.). Kriechende oder windende Krä̈nter oder Strä̈ucher mit glockenförmigen Bliiten und vierficheriger Frucht.

Batate oder süfse Kartoffel (Bututas edulis Chois.). Wurzel einjähnig, faserig, kricchend, treibt an den Fasern melırere filustorofse, fleischige, meist walzen-oder spindelförmige, anch anders gestaltete, aulsen purpurrote, weifse oder gescheckte, inwendig aber weifse, weiche Knollen, die mehlartig und voll Milchsaft sind. Die

1) Das verunstaltete Potatoe d. i. Wrdäpfel. - 2) Irsbar. - 3) Vou convolvĕre, zusammenwickeln. convolvălus, Winde und auch Wickelraupe. 
Wurel treibt melrere Stengel, diese sind kricehend oder windend, 1,6 his 1,9 m lang, ästig; die Stengel treiben anch an ihren Gelenken Wm\%ehn. Blätter langgestielt, her\%örmig, viehrippig; Blüten (Fig. 1) trichterförmig, gegen $5 \mathrm{~cm}$ lang, inwendig purpurrötlich, aufsen rötlich gestrahlt, hisweilen anch gann weifs oder gann rot. Kelch fiinfblätterig, bleihend. Über dic Befruchtungswerkzeuge siehe uben das iiber die Familie Gesagte.

Heimat in tropischen Amerika. Verbreitungsbezirk alle 'Tropenlïnder', selbst in Europa bis gegen den 40. Grad anseptininzt.

Kultur. Die Bataten wachsen in jedem Boden, am besten anf mageren Feldern. Man macht Löcher $1 \mathrm{~m}$ weit aus einander und legt die Nutterwurzeh oder Triebe ron alten Pflanzen hincin. An den Mutterwurzeln bilden sich Schöfslinge, die rorsichtig alogelöst und damn geptlanzt werden miissen. Diese lïlst man wachsen, bis die hinteren Bliitter gelb werden, damn gr:äht man die eingedriickten Kince mit den Kunollen aus und läfst die übrigen Ranken stehen. So kann man einige Jahre auf demselben Felde Bataten graben; nachher aher werden 'die Bliitter kleiner und die Knollen hleiben aus. In Deutschland lïst sich die Batate nur im Mistbeet ziehen.

Gehalt. Die Bataten enthalten 1 bis 1,5 Prozent eiweifsartige Stoffe, 9 bis 16 Proz. Stiirke, 3,5 bis 10 Proz. Zucker, 0,5 Proz. Zellstoff, 0,2 bis 0,3 Proz. Fett, 3 Proz. Salze und 29 bis 67 Proz. Wasser. Sie sind sehr nahrhaft, leichter verdanlich als die Kartoffeln, sehr süfs und gesund.

Gebrauch. Sie werden fast wie die Kartoffeln zubereitet, gewöhnlich in Butter geröstet, jedoch auch roh nnd gekocht gegessen, auch als Sulit nud mit Zucker eingemacht. Aus den geriebenen Bataten gewinnt man ein Satzmehl, das man zu Brot biickt. Durch Gärmng bereitet man ein geistiges Getränk (Nobly in Westindien, Marmodia der l'ortugiesen) daraus. Die jungen Bliitter dienen als Gemuise. Die Bataten geben anch ein gutes Viehfutter. Eine besonder's gute Sorte führt den Nimen Cumotes.

Geschichte. Die Batate ist eine sehr alte Nihrungspflanze Siid- mud Mittel-Amerikis. Auf den Antillen trat man diese nuit\%liche Pflanze schon im Jahre 1526 in zahlreichen Abarten angebant. Die Patate wurde 1519 bekant, wo Pigafetta iiber ihre Kultur in Bratsilien herichtete; bald darturf wurde sie in spanien eingefïhrt, und ron dort und den Kanaren kam sie noch ror der Kintotiel nach Fumband. In den Sïd-Stiaten der nordimerikinischen Union bant man jülrlich iiber 42 Bushels.

Andere Arten: 1. Jalapen-Batate, Trichterwinde (Jiututus Jalupa ') Chois.). In Mittel- und Siid-Amerikil. Wumel fleischis,

1) So genanut nach der Stadt und Gegend Xalapa oder Yalapa in Mexiko. 
spindelförmig, sehr grofs, galt früher als die Stammpflanze der JalapenWurzel, besitzt anch purgierende Eigenschaften. Liefert wahrscheinlich die Radix Mechoncannue. 2. Rispenblütige Batate (Batätas paniculata ${ }^{1}$ ) Chois.). Finollen $60 \mathrm{~cm}$ lang, schwärzlich, inwendig weifs, milchend, als Nahrmngsmittel in West-Afrika, Neuholland, Ostindien, Guy:n1a, Brasilien etc. kultiviert.

1) Rispig.

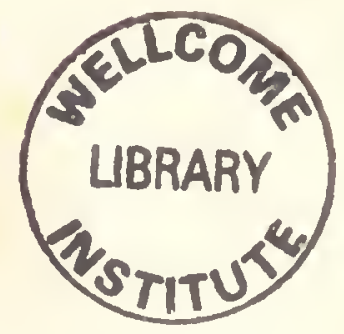






